UNIVERSIDADE DE SÃO PAULO

ESCOLA DE ENGENHARIA DE SÃO CARLOS

DEPARTAMENTO DE ENGENHARIA DE ESTRUTURAS

\title{
FLAMBAGEM POR DISTORÇÃO DA SEÇÃO TRANSVERSAL EM PERFIS DE AÇO FORMADOS A FRIO SUBMETIDOS À COMPRESSÃO CENTRADA E À FLEXÃO
}

GUSTAVO MONTEIRO DE BARROS CHODRAUI

Dissertação apresentada à Escola de Engenharia de São Carlos da Universidade de São Paulo, como parte dos requisitos para obtenção

do Título de Mestre em

Engenharia de Estruturas.

ORIENTADOR: Prof. Dr. Maximiliano Malite

São Carlos

2003 
Aos meus pais, Carlos Alberto Chodraui e Regina Helena Monteiro de Barros Chodraui. À minha irmã, Juliana. 


\section{AGRADECIMENTOS}

À minha família, mais uma vez, que é a base de tudo na minha vida.

Ao professor Maximiliano Malite, pela imensa orientação, amizade e incentivo desde o período da graduação.

Aos meus parentes e amigos, que sempre me incentivaram e apoiaram, em todos os momentos.

Aos professores Roberto Martins Gonçalves, José Jairo de Sales e Jorge Munaiar Neto, pela atenção e amizade.

Aos demais professores, funcionários e colegas do Departamento de Engenharia de Estruturas, por toda a ajuda ao longo da graduação e do Mestrado.

Ao engenheiro civil José Carlos D'Ambrósio da Silva, pela amizade e ensinamentos relacionados aos aspectos mais variados da engenharia.

À FAPESP - Fundação de Amparo à Pesquisa do Estado de São Paulo, pela concessão da bolsa de estudos.

À memória da Honey (minha cachorra - por mais estranho que pareça), pelos momentos inesquecíveis de alegria por ela proporcionados. 


\section{SUMÁRIO}

RESUMO

ABSTRACT

LISTA DE SÍMBOLOS iii

CAPÍTULO 1 - INTRODUÇÃO 01

CAPÍTULO 2 - REVISÃO BIBLIOGRÁFICA 04

2.1 Breve histórico $\quad 04$

2.2 Flambagem por distorção no contexto da estabilidade de barras de seção $\quad 07$ aberta e paredes delgadas

2.3 Modelos para a análise da flambagem por distorção 13

$\begin{array}{ll}2.3 .1 \text { Douty (1962) } & 16\end{array}$

2.3.2 Hancock $\quad 20$

2.3.2.1 Barras submetidas à compressão 21

2.3.2.2 Barras submetidas à flexão $\quad 29$

2.3.3 Moreyra \& Peköz 31

2.3.4 Expressão simplificada de ELLIFRITT et al. para perfis do tipo $U$ e $Z \quad 34$ enrijecido, submetidos à flexão

2.3.5 Expressão Ayrton-Perry 38

2.4 Perfis do tipo U e Z enrijecido com enrijecedor de borda adicional 42

2.5 Interação entre modos de flambagem $\quad \mathbf{4 5}$

2.6 Condições de extremidade das barras (empenamento) 46

$\begin{array}{ll}2.7 \text { Procedimentos normativos } & 47\end{array}$

$\begin{array}{ll}2.7 .1 \mathrm{AISI} & 47\end{array}$

2.7.2 EUROCODE $3-1.3 \quad 48$

2.7.3 MODELO AUSTRALIANO 49

2.7.3.1 Norma Australiana AS/NZS 4600:1996 $\mathbf{5 0}$

2.7.3.2 Norma Brasileira NBR 14762:2001 54

2.7.4 Método Direto de Resistência $\quad \mathbf{5 8}$

$\begin{array}{ll}\text { 2.7.4.1 Barras submetidas à compressão } & \mathbf{6 0}\end{array}$

2.7.4.1.1 Flambagem por flexão, torção ou flexo-torção $\quad 60$ 
2.7.4.1.2 Flambagem local

2.7.4.1.3 Flambagem por distorção $\quad 62$

2.7.4.2 Barras submetidas à flexão $\quad 63$

2.7.4.2.1 Flambagem lateral com torção $\quad 64$

2.7.4.2.2 Flambagem local $\quad 65$

2.7.4.2.3 Flambagem por distorção $\quad 66$

$\begin{array}{ll}\text { 2.7.5 GBT: Teoria de Viga Generalizada } & \mathbf{7 0}\end{array}$

CAPÍTULO 3 - ANÁLISE VIA MÉTODO DAS FAIXAS FINITAS

3.1 Breve noção sobre o método $\quad \mathbf{7 4}$

3.2 O programa computacional CUFSM $\quad 78$

3.3 Perfis adotados na análise $\quad \mathbf{8 4}$

3.4. Comparação: método das faixas finitas e procedimento da NBR 14762: $\quad 86$ 2001 - Perfis do tipo Ue

3.5. Comparação adicional: método das faixas finitas - Perfis do tipo Ue e perfis 105 do tipo Ze

CAPÍTULO 4 - ANÁLISE VIA MÉTODO DOS ELEMENTOS FINITOS 110

$\begin{array}{ll}4.1 \text { Breve noção sobre o método } & 110\end{array}$

4.2 O programa computacional ANSYS $5.7 \quad 110$

$\begin{array}{ll}\text { 4.3 Perfis adotados na análise } & 113\end{array}$

4.4 Comparação: método dos elementos finitos, procedimento da NBR 114

14762:2001 e método das faixas finitas

4.5 Análise da influência referente à porcentagem da configuração deformada 137 adotada para a imperfeição inicial

CAPÍTULO 5 - CONSIDERAÇÕES FINAIS E CONCLUSÕES 139

5.1 Sobre a revisão bibliográfica 139

$\begin{array}{ll}5.2 \text { Sobre a análise via faixas finitas } & 141\end{array}$

5.3 Sobre a análise via elementos finitos 142

$\begin{array}{ll}5.4 \text { Sobre o anexo } & 144\end{array}$

5.5 Sugestões para trabalhos futuros $\quad 145$

$\begin{array}{ll}\text { ANEXO } & 146\end{array}$

A.1 Exemplos de cálculo: força normal resistente e momento fletor resistente $\quad \mathbf{1 4 6}$ 
A.2 Comparação de resultados conforme diversos procedimentos: tensão convencional de flambagem elástica por distorção

REFERÊNCIAS 


\section{RESUMO}

CHODRAUI, G.M.B. Flambagem por distorção da seção transversal em perfis de aço formados a frio submetidos à compressão centrada e à flexão. São Carlos, 2003. Dissertação (Mestrado) - Escola de Engenharia de São Carlos, Universidade de São Paulo.

Os perfis de aço formados a frio apresentam, em geral, elevada relação largura/espessura, tornando-os suscetíveis à flambagem local, caracterizada por uma flambagem de chapa, mas que também pode ocasionar um outro modo de flambagem, denominado flambagem por distorção, desconsiderado no dimensionamento de perfis laminados, mas que pode resultar crítico principalmente nos perfis com enrijecedores de borda e constituídos por aço de elevada resistência mecânica. Tal fenômeno é caracterizado pela perda de estabilidade do conjunto formado pelo elemento comprimido e seu enrijecedor de borda, alterando a forma inicial da seção transversal. Portanto, as normas mais atuais têm apresentado procedimentos para avaliar a resistência de barras com base na flambagem por distorção, como o procedimento simplificado da norma australiana AS/NZS 4600:1996, proposto por HANCOCK e que foi também adotado pela recente norma brasileira NBR 14762:2001, o método direto de resistência, recentemente proposto para incorporação à especificação do AISI (American Iron and Steel Institute) e a GBT (Generalized Beam Theory).

Nesse trabalho é feita uma abordagem dos procedimentos propostos para a avaliação da flambagem por distorção em barras submetidas à compressão centrada e à flexão, comparando-se os resultados obtidos pelo procedimento da norma brasileira, pela análise elástica via método das faixas finitas - MFF e pela análise via método dos elementos finitos - MEF, admitindo barras sem e com imperfeições iniciais. É feita também uma abordagem com relação aos outros procedimentos internacionais para a avaliação do fenômeno.

Palavras-chave: Estruturas de aço, perfis formados a frio, flambagem por distorção, flambagem distorcional. 


\section{ABSTRACT}

\section{CHODRAUI, G.M.B. Distortional buckling of cold-formed steel members under} compression and bending. São Carlos, 2003. Dissertação (Mestrado) - Escola de Engenharia de São Carlos, Universidade de São Paulo.

Cold-formed steel members present, in many cases, an elevated width/thickness ratio (thin-walled members), which probably lead up to the local buckling, which is characterized by a plate buckling, and also may lead up to another buckling mode, called distortional buckling, not considered on the design of hot-rolled members, but which may result critical in cold-formed members, specially in the ones with edge stiffeners and made with high strength steel. Such phenomena is characterized by the instability of the group formed by the compression flange and its stiffener, changing the initial shape of the cross section. Nowadays, codes present procedures to evaluate member's resistance also due to distortional buckling, as the simplified method in the Australian code, AS/NZS 4600:1996, proposed by HANCOCK, which was adopted by the new Brazilian code, NBR 14762:2001, the Direct Strenght Method, recently proposed as an AISI (American Iron and Steel Institute) Draft, and the GBT (Generalilzed Beam Theory).

This work talks about procedures proposed to evaluate distortional buckling in members under compression and bending, comparing results obtained by the method showed in the brazilian code, by numerical Finite Strip Method elastic analisys - FSM, and by Finite Element Method analisys - FEM, on members with and without initial imperfections. It is also done an explanation related to other international procedures to evaluate the phenomena.

Keywords: Steel structures, cold formed members, distortional buckling. 


\section{LISTA DE SÍMBOLOS}

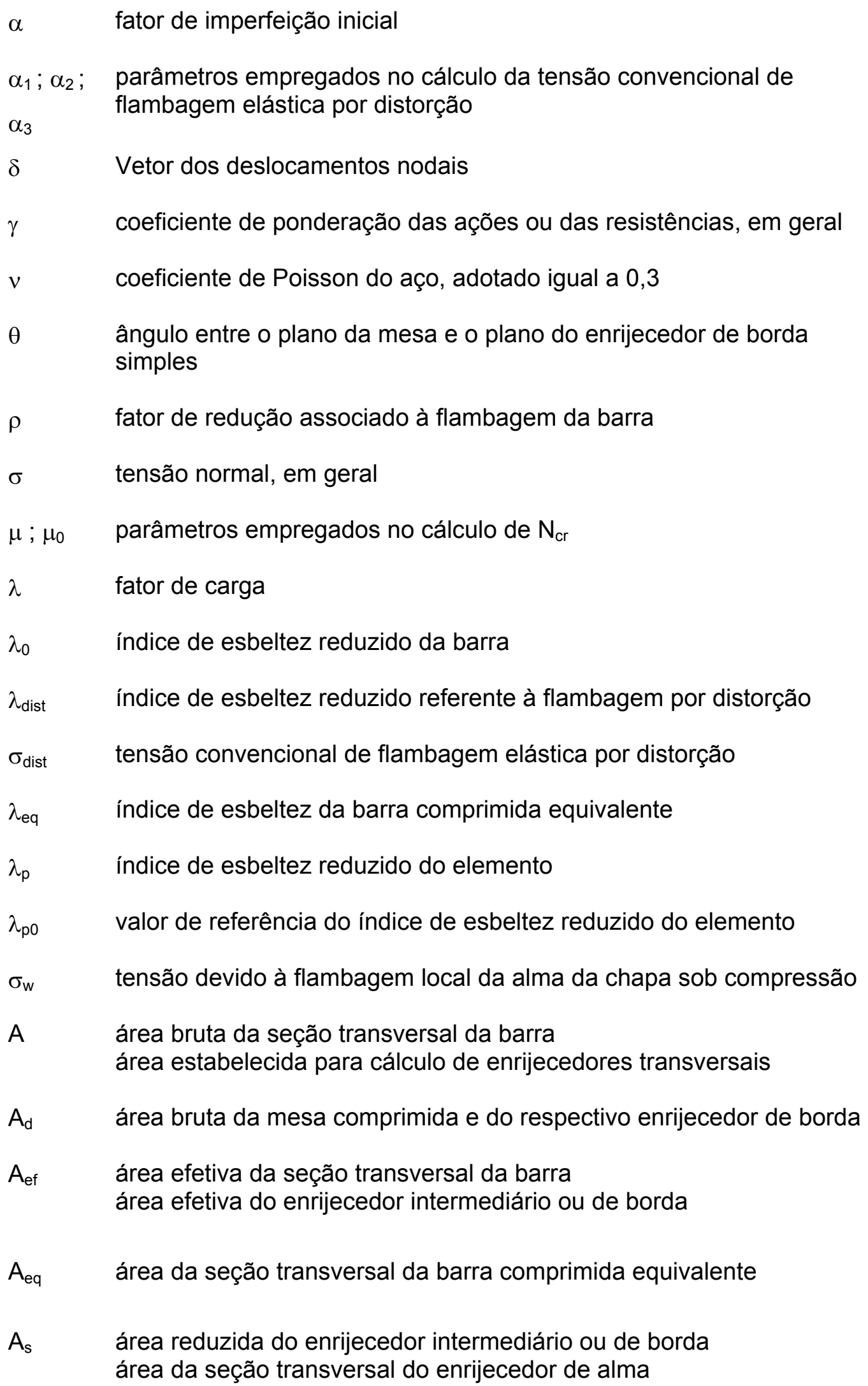


$\mathrm{A}_{\mathrm{st}} \quad$ área da seção do enrijecedor de borda ou intermediário excluindo qualquer parte de elementos adjacentes

b largura do elemento, é a dimensão plana do elemento sem incluir dobras

$b_{\text {ef }} \quad$ largura efetiva

$b_{f} \quad$ largura nominal da mesa ou do conjunto mesa - enrijecedores de borda

$b_{w} \quad$ largura nominal da alma

$\mathrm{C}_{\mathrm{w}} \quad$ constante de empenamento da seção

D largura nominal do enrijecedor de borda

rigidez da chapa à flexão por unidade de comprimento

$\mathrm{D}_{\mathrm{a}} \quad$ largura nominal do enrijecedor de borda adicional

$d_{c} \quad$ distância entre o eixo neutro e a fibra extrema comprimida da seção

$d_{\mathrm{ef}} \quad$ largura efetiva do enrijecedor de borda

$d_{s} \quad$ largura efetiva reduzida do enrijecedor de borda

$d_{t} \quad$ distância entre o eixo neutro e a fibra extrema tracionada da seção

E módulo de elasticidade do aço (205 $000 \mathrm{MPa})$

$f_{y} \quad$ resistência ao escoamento do aço

G módulo de elasticidade transversal do aço $(0,385 \mathrm{E}=78925 \mathrm{MPa})$ matriz de estabilidade da chapa

h largura da alma (altura da parte plana da alma)

$h_{x} ; h_{y} \quad$ coordenadas $x$ e $y$, respectivamente, do apoio da seção constituída pela mesa e enrijecedor de borda em relação ao seu centróide

${ }^{i j k} \mathrm{k}$ propriedades de segunda ordem da seção, as quais relacionam deformações da seção transversal com as distribuições de tensão

$\mathrm{I}_{\mathrm{t}} \quad$ momento de inércia à torção uniforme 
$\mathrm{I}_{\mathrm{x}} ; \mathrm{I}_{\mathrm{y}} \quad$ momentos de inércia da seção bruta em relação aos eixos principais $x \mathrm{e}$ $y$, respectivamente

$\mathrm{I}_{\mathrm{xy}} \quad$ produto de inércia da seção em relação ao sistema de coordenadas $\mathrm{xy}$

k coeficiente de flambagem local modo de deslocamento ortogonal

$\mathrm{k}_{\phi} \quad$ constante de rigidez à rotação empregada no cálculo da tensão convencional de flambagem elástica por distorção

$\mathrm{k}_{\mathrm{x}} \quad$ constante de rigidez à flexão do elemento sujeito à distorção

K matriz de rigidez da chapa

${ }^{k} B \quad$ rigidez transversal à flexão

${ }^{\mathrm{k}} \mathrm{C} \quad$ constante de empenamento generalizada

${ }^{k} \mathrm{D} \quad$ constante de torção generalizada

${ }^{k} \mathrm{q} \quad$ força uniformemente distribuída

${ }^{\mathrm{k}} \mathrm{V} \quad$ resultante generalizada de deformação

${ }^{k}$ W resultante generalizada de tensão

L distância entre pontos travados lateralmente da barra comprimento da barra comprimento sem contenção transversal do elemento sujeito à distorção

$\mathrm{L}_{0} \quad$ comprimento de referência empregado no cálculo da tensão convencional de flambagem elástica por distorção

$L_{d} \quad$ comprimento da meia onda longitudinal associada à tensão convencional de flambagem elástica por distorção

m distância entre o centro de torção e o plano médio da alma em perfil U

$\mathrm{M}_{\text {crd }} \quad$ valor do momento relativo à flambagem crítica elástica relativa à flambagem por distorção

$M_{\text {cre }} \quad$ valor do momento relativo à flambagem crítica elástica relativa à flambagem lateral com torção

$M_{\text {dist }} \quad$ momento fletor de flambagem por distorção

$M_{e} \quad$ momento fletor de flambagem elástica 
$\mathrm{M}_{\mathrm{g}} \quad$ Valor nominal do momento fletor resistente para a flambagem lateral com torção

$M_{n} \quad$ valor nominal do momento fletor resistente

$M_{R d} \quad$ momento fletor resistente de cálculo

$M_{y} \quad$ Momento fletor referente ao escoamento

$\mathrm{n} \quad$ número de meias ondas

número de modos de análise

N força crítica de flambagem

$\mathrm{N}_{c, \mathrm{Rd}}$ força normal de compressão resistente de cálculo

$N_{c r} \quad$ força normal crítica de flambagem elástica por distorção

$\mathrm{N}_{\text {crd }} \quad$ Valor da força relativa à flambagem crítica elástica por distorção

$\mathrm{N}_{\text {cre }} \quad$ valor mínimo da força relativa à flambagem crítica elástica entre a flexão, torção e flexo-torção

$\mathrm{N}_{\mathrm{crl}} \quad$ Valor da força relativa à flambagem crítica elástica local

$\mathrm{N}_{\text {dist }} \quad$ força normal de flambagem por distorção

valor nominal da força de compressão resistente para a flambagem por distorção

$\mathrm{N}_{\mathrm{e}} \quad$ força normal de flambagem elástica

força normal empregada no cálculo da tensão convencional de flambagem elástica por distorção

$\mathrm{N}_{\mathrm{et}} \quad$ força normal de flambagem elástica por torção

$\mathrm{N}_{\mathrm{ex}} ; \mathrm{N}_{\mathrm{ey}}$ forças normais de flambagem elástica por flexão em relação aos eixos $x$ e $y$, respectivamente

$N_{\text {ext }} \quad$ força normal de flambagem elástica por flexo-torção

$\mathrm{N}_{\mathrm{g}} \quad$ valor nominal da força de compressão resistente para a flambagem por flexão, torção e flexo-torção

$\mathrm{N}_{\mathrm{I}} \quad$ valor nominal da força de compressão resistente para a flambagem local

$\mathrm{N}_{\mathrm{n}} \quad$ valor nominal da força normal de compressão resistente 
$r_{0} \quad$ raio de giração polar da seção bruta em relação ao centro de torção

$r_{x} \quad$ raio de giração da seção bruta em relação ao eixo principal $x$

$r_{y} \quad$ raio de giração da seção bruta em relação ao eixo principal y

t espessura da chapa ou do elemento

$\mathrm{u} ; \mathrm{u}_{\mathrm{x}}$ deslocamento ao longo do eixo $\mathrm{x}$

$v ; u_{y} \quad$ deslocamento ao longo do eixo y

$w ; u_{z} \quad$ Deslocamento ao longo do eixo $z$

$W_{c} \quad$ módulo de resistência elástico da seção bruta em relação à fibra comprimida

$W_{c, \text { ef }} \quad$ módulo de resistência elástico da seção efetiva em relação à fibra comprimida, referente à flambagem lateral com torção

$W_{\text {ef }} \quad$ módulo de resistência elástico da seção efetiva referente ao início de escoamento da seção efetiva

$\mathrm{x}_{0} \quad$ coordenada do centro de torção, na direção do eixo $x$, em relação ao centróide

y $\quad$ coordenada do centro de torção, na direção do eixo $y$, em relação ao centróide distância entre o centróide da seção transversal da barra comprimida equivalente e o seu centro de torção

$y_{c} \quad$ distância entre o eixo neutro da seção bruta e o centróide da barra comprimida equivalente

yeq altura da seção transversal da barra comprimida equivalente

$\chi \quad$ fator de redução devido à flambagem

$\eta \quad$ parâmetro empregado no cálculo da tensão convencional de flambagem elástica por distorção 
Os perfis de aço formados a frio possuem, em geral, maior relação inércia/peso e maior esbeltez local (relação largura/espessura dos elementos) em relação aos clássicos perfis laminados. Por outro lado, propiciam igualmente a ocorrência de fenômenos localizados de instabilidade estrutural e de torção excessiva. A elevada relação largura/espessura torna mais acentuado o fenômeno da flambagem local, que é caracterizado por uma flambagem de chapa, podendo levar a outro modo de flambagem, denominado flambagem por distorção, desconsiderado no dimensionamento de perfis laminados, mas que pode resultar crítico nos perfis formados a frio, principalmente nos perfis com enrijecedores de borda e constituídos por aço de elevada resistência mecânica. Tal fenômeno é caracterizado pela perda de estabilidade do conjunto formado pelo elemento comprimido e seu enrijecedor de borda, alterando a forma inicial da seção transversal.

Os perfis de aço formados a frio têm sido amplamente empregados em vários segmentos da construção metálica, ganhando espaço até mesmo em setores antes dominados pelos perfis laminados, como por exemplo, em torres de transmissão. Os perfis formados a frio têm aplicação também em edifícios industriais, edifícios de múltiplos andares, silos, reservatórios, racks, sinalização e proteção rodoviária, indústria mecânica, etc. 
A carência de produtos de aço não-planos (perfis laminados) no mercado brasileiro conduziu as empresas a adotarem soluções alternativas a partir da utilização de produtos planos de aço (chapas), daí a intensificação do uso dos perfis soldados, em substituição aos laminados de médias e grandes dimensões, e os perfis formados a frio em substituição aos laminados de pequenas dimensões.

Nos últimos anos a construção metálica brasileira vem percebendo avanços significativos, permitindo sua inserção em segmentos da construção até então totalmente dominados por outros materiais e soluções. Nesse contexto, é fundamental que o crescimento do setor da construção metálica tenha uma base tecnológica sólida, fundamentada em pesquisas que permitam avaliar as particularidades da realidade brasileira e contribuir para o estabelecimento de soluções técnicas e econômicas viáveis.

Recentemente ocorreu a publicação da nova norma brasileira NBR 14762:2001 - Dimensionamento de estruturas de aço constituídas por perfis formados a frio, que apresenta, para o cálculo da flambagem por distorção, o "modelo australiano". Esse modelo, proposto por Hancock e incorporado à norma australiana AS/NZS 4600:1996 ${ }^{1}$, analisa a estabilidade de conjuntos formados por um elemento comprimido e seu respectivo enrijecedor de borda, vinculados elasticamente à outra parte do perfil. Embora também adotado pela nova norma brasileira em seu anexo $D$, há carência de pesquisas sobre o tema, enfatizando o comportamento de barras submetidas à compressão e à flexão constituídas por perfis usualmente empregados no Brasil, estabelecendo um melhor entendimento sobre o modelo, suas restrições e sua resposta para os perfis usuais.

Evidentemente surgiram dúvidas e o campo para as pesquisas nesse tema foi largamente ampliado. Dentre os assuntos relacionados, entende-se como prioritário um estudo sobre a flambagem por distorção, que constitui-se em um modo de flambagem que não é crítico nos perfis laminados e soldados, mas que pode ser dominante em perfis formados a frio e, portanto, não deve ser desprezado.

Portanto, apresenta-se neste trabalho um estudo criterioso sobre a flambagem por distorção da seção transversal em perfis de aço formados a frio, submetidos à compressão centrada e à flexão, verificando sua interação com os demais modos de flambagem, e analisando os modelos apresentados na literatura,

\footnotetext{
1 AUSTRALIAN/NEW ZEALAND STANDARD (1996) Cold-formed steel structures. AS/NZS 4600:1996.
} 
com o objetivo de comparar os resultados obtidos com base no procedimento de cálculo apresentado na nova norma brasileira (modelo australiano) e no Método Direto de Resistência, aos obtidos por análise numérica via método dos elementos finitos - MEF (programa computacional ANSYS 5.7) e via método das faixas finitas MFF (programa computacional CUFSM). 


\subsection{BREVE HISTÓRICO}

Segundo YU (1985), o emprego dos perfis formados a frio em construções teve início por volta de 1850 nos Estados Unidos e Grã-Bretanha, correspondendo, entretanto, a uma utilização restrita e ausente de informações técnicas específicas sobre o comportamento estrutural destes elementos.

Somente a partir de 1939 é que as pesquisas foram efetivamente iniciadas, por iniciativa e financiamento do American Iron and Steel Institute (AISI), tendo como responsável o Prof. George Winter, da Cornell University. Em 1946, os resultados destas pesquisas deram origem à primeira especificação para o projeto de elementos estruturais formados a frio, publicada pelo AISI. Desta forma, pode-se registrar que os norte-americanos foram os pioneiros nas pesquisas e no emprego criterioso destes elementos.

A partir de 1946, houve um grande impulso na utilização dos perfis formados a frio não somente na construção civil, mas também em outros setores que empregam estruturas metálicas. Várias edições da especificação AISI foram publicadas, sendo que a edição de 1986 foi a última a incorporar somente o tradicional método das tensões admissíveis. Em 1991 foi publicada a primeira edição em estados limites, e em 1996 a segunda, incorporando também o método das tensões admissíveis como alternativa. Recentemente foi publicada a norma norte-americana - North American Specification for the Design of Cold-Formed Steel 
Structural Members, 2001 Edition, e também a edição comentada - Commentary on the Specification (2001) - sendo ambas válidas no Estados Unidos, Canadá e México.

No Brasil, o emprego dos perfis formados a frio teve início praticamente no final da década de 60, quando algumas empresas adquiriram equipamentos específicos para a realização das operações de formação a frio, ou seja, prensas dobradeiras e mesas de roletes.

Em 1967 foi publicada a norma ABNT/NB-143 - Cálculo de estruturas de aço, constituídas por perfis leves, voltada ao projeto de estruturas em perfis formados a frio, cujo texto foi elaborado com base na edição de 1962 da especificação do AISI. Esta norma não foi adequadamente divulgada e foi pouco utilizada, não sofrendo revisões ao longo do tempo, consistindo, portanto em um documento técnico obsoleto e muito vago em alguns itens, como por exemplo, nas ligações. A obsolescência da NB-143, vinculada à antiga NB-14:1968 (tensões admissíveis), praticamente obrigava os projetistas a adotarem normas estrangeiras, como as do AISI (American Iron and Steel Institute), CSA (Canadian Standards Institute) e outras.

Em 1980 foi publicada a norma NBR 6355 - Perfis estruturais, de aço, formados a frio, a qual estabelece uma padronização de perfis formados a frio, apresentando nomenclatura, simbologia, dimensões e tolerâncias a serem respeitadas pelos perfis com propósito estrutural. Assim como a NB-143, essa norma foi pouco divulgada e utilizada, sendo desconhecida por muitos projetistas e até mesmo por fabricantes de perfis. Em dezembro de 2001 foram iniciados os trabalhos de revisão da NBR 6355:1980, com o propósito de padronizar perfis adequados ao nosso mercado, estabelecer tolerâncias de fabricação compatíveis com a indústria local e conferir compatibilidade com a nova norma de dimensionamento. Atualmente já existe um projeto de norma elaborado com relação à mesma.

A "inexistência" de uma norma brasileira para cálculo de estruturas em perfis formados a frio levou os projetistas a adotar uma norma estrangeira, muitas vezes gerando incompatibilidades principalmente quando é utilizada simultaneamente nos projetos à NBR 8800:1986 - Projeto e execução de estruturas de aço de edifícios, para os perfis laminados e soldados. Os coeficientes de ponderação das ações e os coeficientes de resistência diferem de norma para norma, portanto adotar as combinações de ações previstas na NBR-8800:1986 ou mesmo na NBR-8681:1984 
- Ações e segurança nas estruturas, e comparar os respectivos esforços solicitantes de cálculo aos esforços resistentes de cálculo estabelecidos por outra norma é, claramente, uma incompatibilidade.

Por outro lado, adotar a ABNT/NBR-8800:86 simultaneamente com normas em tensões admissíveis constitui-se numa incompatibilidade ainda maior, pois envolve dois métodos distintos para introdução da segurança.

A publicação de uma norma brasileira voltada ao projeto de estruturas em perfis formados a frio, cujos coeficientes de ponderação das ações e das resistências, além da nomenclatura e simbologia, fossem adequadamente calibrados e ajustados com outras normas brasileiras, proporcionando uniformidade de critérios e maior coerência nos projetos, foi a solução encontrada.

Em agosto de 1997 foi constituído pela ABCEM (Associação Brasileira da Construção Metálica) e com apoio da USIMINAS, um Grupo de Trabalho para a elaboração de um texto-base para norma brasileira, composto por docentes de várias universidades e representantes de empresas do setor. Houve, portanto, intensa pesquisa, buscando o necessário embasamento teórico que, aliado ao levantamento das particularidades da construção metálica brasileira, permitiram elaborar um texto para a nova norma, que traz procedimentos atualizados e compatíveis com a nossa realidade. Como um desfecho para tal trabalho, recentemente ocorreu a publicação da nova norma brasileira NBR 14762:2001 Dimensionamento de estruturas de aço constituídas por perfis formados a frio.

A crescente demanda pelo uso de perfis de aço formados a frio tem estimulado avanços especialmente em três segmentos:

- Fabricação de perfis: Desenvolvimentos tecnológicos que resultam em formas mais complexas e maior enrijecimento dos perfis, o que provoca uma maior automatização das máquinas que fazem a conformação dos mesmos (Figura 2.1);

- Matéria-prima: Busca pelo uso de aços com resistência mecânica mais elevada;

Pesquisa (projeto): Transição entre a modelagem simplificada dos elementos constituintes da seção transversal em separado, para procedimentos baseados na análise de toda a seção, como um só conjunto, o que permite avaliar a interação entre os elementos constituintes da mesma, além de proporcionar 
sofisticação no tratamento da flambagem local e por distorção, bem como na interação entre elas;

Diferentemente da situação que se apresenta aqui no Brasil, no exterior as pesquisas têm se desenvolvido com uma rapidez maior, em especial na Austrália e nos Estados Unidos, além de outros centros que apresentam notório desenvolvimento relativo ao estudo dos perfis de aço formados a frio.

Segundo DAVIES (2000), nos Estados Unidos aproximadamente 500 residências foram construídas sob o conceito de estruturas de aço leves em 1992. Tal número cresceu para 15.000 em 1993, 75.000 em 1994, sendo que se estima para o ano de 2002 um aumento ainda maior de residências, além de outras obras empregando-se perfis de aço formados a frio.
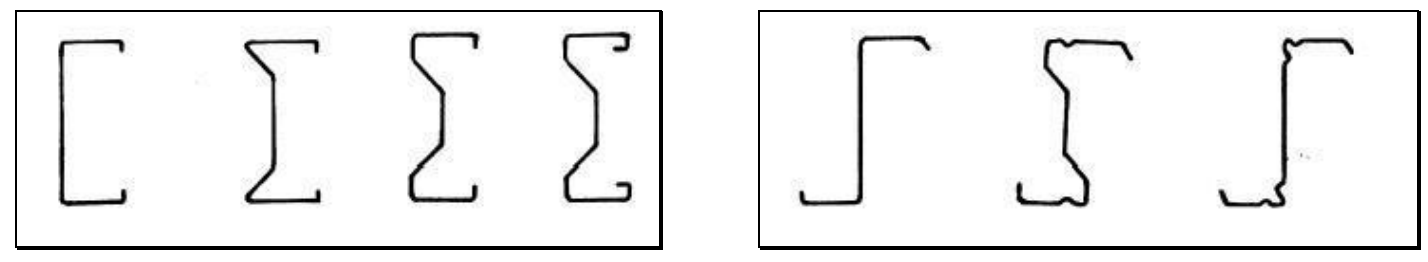

Figura 2.1 - "Evolução" na forma da seção visando maior enrijecimento

\subsection{FLAMBAGEM POR DISTORÇÃO NO CONTEXTO DA INSTABILIDADE DE BARRAS DE SEÇÃO ABERTA E PAREDES DELGADAS}

Os perfis formados a frio em geral são constituídos por seções abertas de paredes delgadas, empregando-se chapas finas de aço laminadas a frio ou a quente, resultando, portanto em elevadas relações largura/espessura dos elementos.

$\mathrm{Na}$ compressão e na flexão existem três modos de flambagem: local, distorcional, e global (para o modo global: flambagem por flexão, torção e flexotorção - para barras submetidas à compressão, e flambagem lateral com torção para barras submetidas à flexão). Por conseguinte, além dos clássicos fenômenos de flambagem global (da barra como um todo) ou local (flambagem de chapa), que 
afeta os elementos que compõem a seção transversal do perfil, há a possibilidade de ocorrência de outro modo de instabilidade, associado à distorção da seção transversal (Figura 2.2), que é especialmente característico dos perfis com enrijecedores de borda, sendo mais pronunciado no caso de aço de elevada resistência mecânica, como por exemplo, perfis do tipo $U$ e $Z$ enrijecido, perfis cartola e perfis "rack". Segundo DAVIES (2000) alguns perfis laminados relativamente esbeltos também podem estar propensos a apresentar o fenômeno da flambagem por distorção.

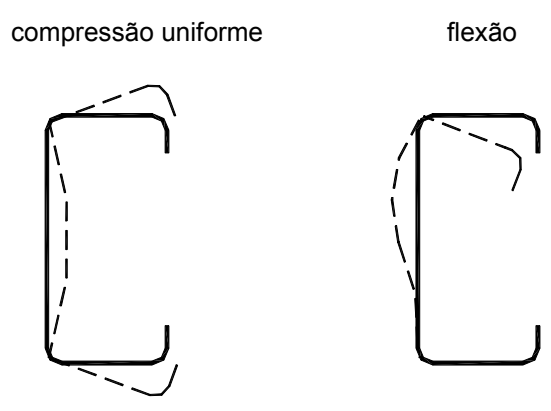

a) Seção tipo U enrijecido

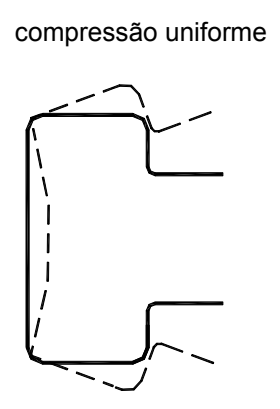

b) Seção tipo rack

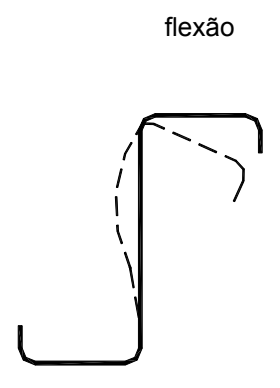

c) Seção tipo Z enrijecido

Figura 2.2 - Flambagem por distorção da seção transversal

[NBR 14762:2001]

TAKAHASHI (1978) parece ter sido um dos pioneiros a publicar um artigo descrevendo o fenômeno da flambagem por distorção.

Por definição, a flambagem por distorção, ou flambagem distorcional, caracteriza-se pela rotação e possível translação do conjunto formado pela mesa comprimida e seu enrijecedor de borda, alterando a forma inicial da seção (Figura 2.2), ao contrário da flambagem local, na qual por definição admite-se a conservação da posição original dos cantos dobrados da seção - os quais permanecem retos ao longo do perfil - assim como os ângulos formados entre os elementos vizinhos. A distorção da seção provoca o deslocamento do conjunto de chapas que formam a mesa da seção: dois elementos de chapa para as seções do tipo $U$ ou $Z$ enrijecido e três elementos de chapa para as seções de tipo rack (Figura 2.2). 
O modo distorcional (MD) é, na verdade, um modo torcional de um trecho da seção, desenvolvendo-se segundo meias ondas ao longo do comprimento do perfil (Figura 2.3).

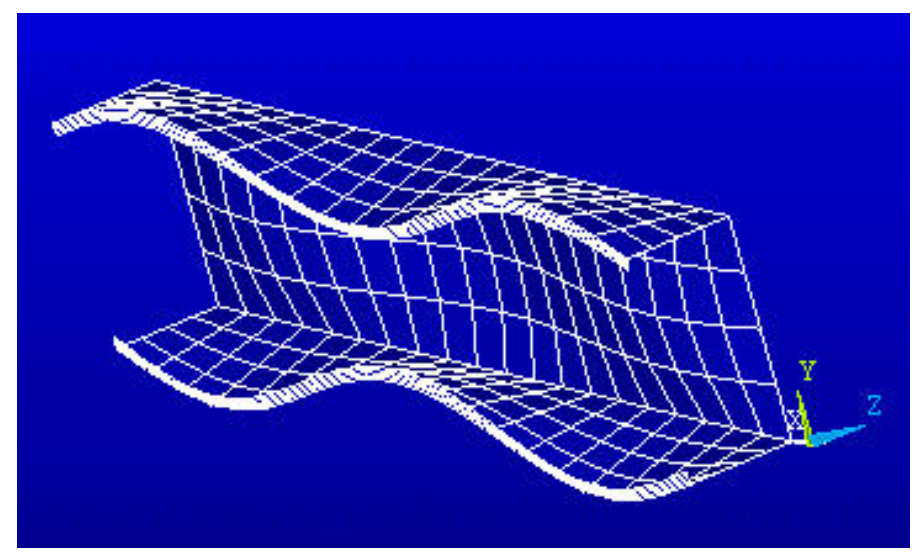

Figura 2.3 - Modo distorcional: configuração deformada de perfil do tipo U enrijecido submetido à compressão

Segundo ROGERS (1997), comprimentos de meia onda "pequenos" (o autor não quantifica a magnitude), relativos ao fenômeno da flambagem por distorção, englobam duas configurações deformadas (Figura 2.4). A primeira configuração consiste simplesmente na rotação do conjunto formado pelo enrijecedor de borda/mesa comprimida em relação à junção mesa/alma. A segunda configuração inicialmente também consiste na rotação do conjunto formado pelo enrijecedor de borda/mesa comprimida, em relação à junção mesa/alma, mas neste caso é seguido pelo deslocamento lateral da junção mesa/alma, o que ocorre próximo ao estado limite último.

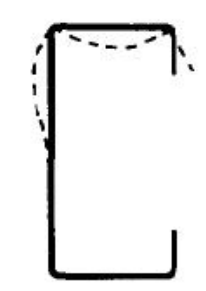

Flambagem local

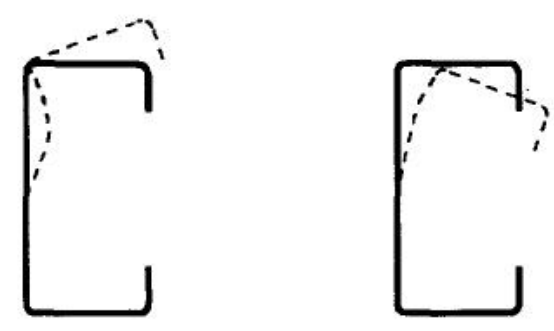

Flambagem por distorção

Figura 2.4 - Flambagem local e por distorção na flexão 
Para a análise de um tipo de perfil de seção arbitrária pode-se identificar os modos e as tensões de flambagem associadas, sendo o modo crítico detectado em função do comprimento da barra, a qual poderá estar submetida à compressão centrada, flexão simples ou flexão composta.

Perfis sem enrijecedores de borda em geral não apresentam o modo distorcional como crítico, sendo a flambagem local preponderante pelo fato do elemento (mesa comprimida) possuir apenas uma borda apoiada.

Segundo BATISTA (2000), as relações geométricas $b_{f 2} / b_{w}, D / b_{w}$ e $b_{f} / b_{w}$ têm influência sobre o modo distorcional, assim como a relação largura/espessura, $b_{w} / t$. As grandezas mencionadas são identificadas na Figura 2.5.

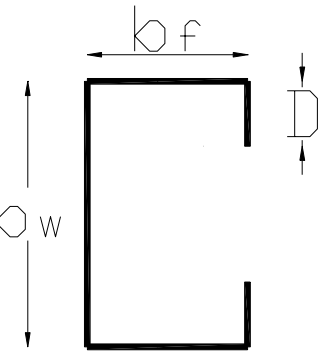

U enrijecido

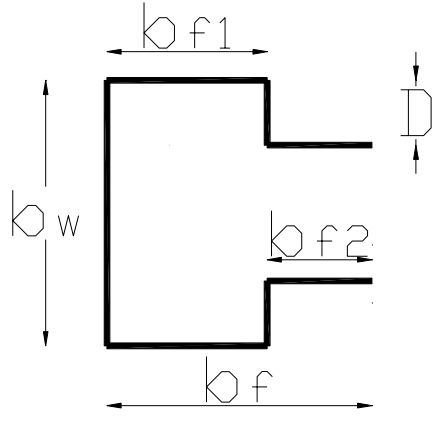

Rack

Figura 2.5 - Notação para perfis do tipo U enrijecido e rack

Portanto, as relações geométricas da seção transversal influenciam o modo crítico, como apresentado na Tabela 2.1. Quanto maior a dimensão da mesa da seção, entendida como $b_{f}=b_{f 1}+b_{f 2}$ (no caso do perfil $U$ enrijecido, $b_{f 2}=0$ ), maior será a possibilidade de se obter o modo distorcional (MD) como crítico. Por outro lado, quanto menor for a relação $b_{f} / b_{w}$, maior será a possibilidade do modo local $(\mathrm{ML})$ ser crítico. Para seções com relação $b_{w} / t$ muito elevadas, provavelmente 0 modo local será crítico. 
Tabela 2.1 - Influência das relações geométricas das seções do tipo U enrijecido e rack no modo crítico

\begin{tabular}{|c|c|c|}
\hline Quanto menor & Relação geométrica & Quanto maior \\
\hline$M L$ & $\mathrm{~b}_{\mathrm{f}} / \mathrm{b}_{\mathrm{w}}$ & $\mathrm{MD}$ \\
\hline$M D$ & $\mathrm{D} / \mathrm{b}_{\mathrm{w}}$ & $\mathrm{ML}$ \\
\hline $\mathrm{ML}$ & $\mathrm{b}_{\mathrm{f} 2} / \mathrm{b}_{\mathrm{w}}$ & $\mathrm{MD}$ \\
\hline$M D$ & $\mathrm{~b}_{\mathrm{w}} / \mathrm{t}$ & $\mathrm{ML}$ \\
\hline
\end{tabular}

De acordo com BATISTA (2000), comparações realizadas entre o procedimento simplificado para o cálculo de tensão convencional de flambagem elástica por distorção, apresentado na AS/NZS 4600:1996 e resultados de programas computacionais utilizando o método das faixas finitas indicaram que tal procedimento simplificado pode ser aplicado com razoável precisão se respeitadas as relações indicadas a seguir (Figura 2.6):

- $\quad 0,4 \leq b_{f} / b_{w} \leq 2,0$ (para perfis do tipo U enrijecido)

- $\quad 0,6 \leq b_{f} / b_{w} \leq 1,3$ (para perfis do tipo rack - ou do tipo $U$ enrijecido com enrijecedor de borda adicional)
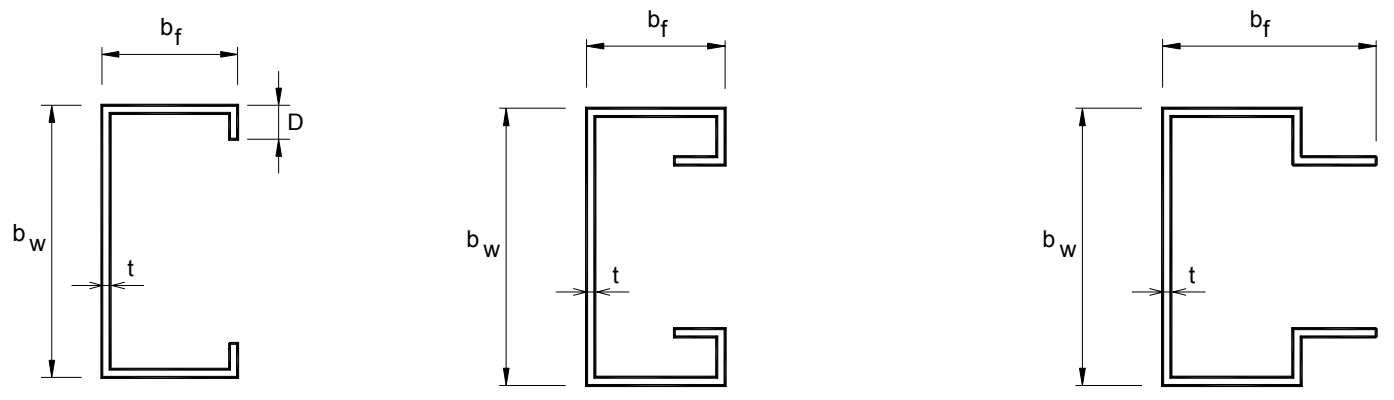

Fig. 2.6 - Perfis tipo $U$ enrijecido, $U$ enrijecido com enrijecedor de borda adicional e tipo rack [NBR 14762:2001]

Cabe salientar que as seções tipo rack são muito sensíveis ao modo distorcional. 
A capacidade de resistência pós-crítica está associada ao índice de esbeltez reduzido referente à flambagem por distorção $\lambda_{\text {dist }}$, sendo que com 0 aumento do valor de $\lambda_{\text {dist }}=\sqrt{f_{y} / \sigma_{\text {dist }}}$, aumenta-se a capacidade pós-crítica.

Segundo o EUROCODE 3 - Parte 1.3 algumas condições devem ser respeitadas quanto à geometria da seção transversal, com o intuito de se providenciar rigidez suficiente e evitar flambagem precoce do enrijecedor de borda (fenômeno similar à flambagem por distorção):

- $\quad 0,2 \leq \mathrm{D} / \mathrm{b}_{\mathrm{f}} \leq 0,6$

- $0,1 \leq D_{a} / b_{f} \leq 0,3$

Onde:

- $\quad b_{f}$ : largura nominal da mesa

- $\quad$ D: largura nominal do enrijecedor de borda

- $\quad D_{\mathrm{a}}$ : largura nominal do enrijecedor de borda adicional

As edições mais antigas das normas de dimensionamento de perfis formados a frio são omissas quanto ao modo distorcional. Entretanto, com o desenvolvimento de aços de elevada resistência mecânica os perfis têm resultado cada vez mais delgados, sendo que tal fenômeno pode ser crítico, tanto em barras submetidas à compressão como à flexão.

Além disso, é conhecido que as normas AISI (1996) e EUROCODE 3 - 1.3 (1996) não consideram aços de elevada resistência mecânica, mas é sabido que os problemas associados à estabilidade e ductilidade dos aços devem ser levados em consideração nos projetos.

Aços de elevada resistência mecânica têm geralmente tensões de escoamento acima de $550 \mathrm{MPa}$ e têm sido freqüentemente usados em perfis formados a frio na Austrália e Nova Zelândia. O modo distorcional nestes perfis pode ocorrer em seções de paredes finas sujeitas à compressão ou à flexão, em tensões significativamente menores que a tensão de escoamento.

Um método bastante utilizado atualmente para o cálculo da tensão convencional de flambagem elástica por distorção, $\sigma_{\text {dist }}$, é o método das faixas 
finitas, o qual permite uma discretização dos perfis com um grau de indeterminação e sistema de equações menor do que no caso do método dos elementos finitos.

Alguns dos procedimentos recentemente propostos e que têm sido importantes para o entendimento do fenômeno da flambagem por distorção são a Teoria de Viga Generalizada (GBT - Generalized Beam Theory) e o Método Direto de Resistência, os quais têm acrescentado contribuições significativas para o tema.

\subsection{MODELOS PARA A ANÁLISE DA FLAMBAGEM POR DISTORÇÃO}

\section{TEORIA DA ESTABILIDADE ELÁSTICA (TIMOSHENKO)}

Segundo a Teoria da Estabilidade Elástica, citada, entre outros, por TIMOSHENKO (1961), uma barra, por exemplo com seção transversal aberta na qual o centro de gravidade e o centro de torção não são coincidentes (caso dos perfis do tipo $U$ enrijecido), poderá sofrer flexão e torção ao ser submetida a uma força de compressão atuante no seu centro de gravidade.

Se esta barra estiver apoiada ao longo de seu comprimento por uma vinculação elástica idealizada (aplicação de $k_{x}, k_{y}$ e $k_{\phi}$.sendo respectivamente constante de rigidez relativa ao deslocamento em relação ao eixo $\mathrm{x}$ e $\mathrm{y}$, e em relação ao giro, conforme Figura 2.7.), e admitindo barra simplesmente apoiada, as três equações, relativas ao equilíbrio de forças nas direções $\mathrm{x}$ e $\mathrm{y}$, e equilíbrio dos momentos em torno do centro de torção, são descritas a seguir (Equações 2.9, 2.10 e 2.11), e determinam a força axial de flambagem $\mathrm{N}$. 


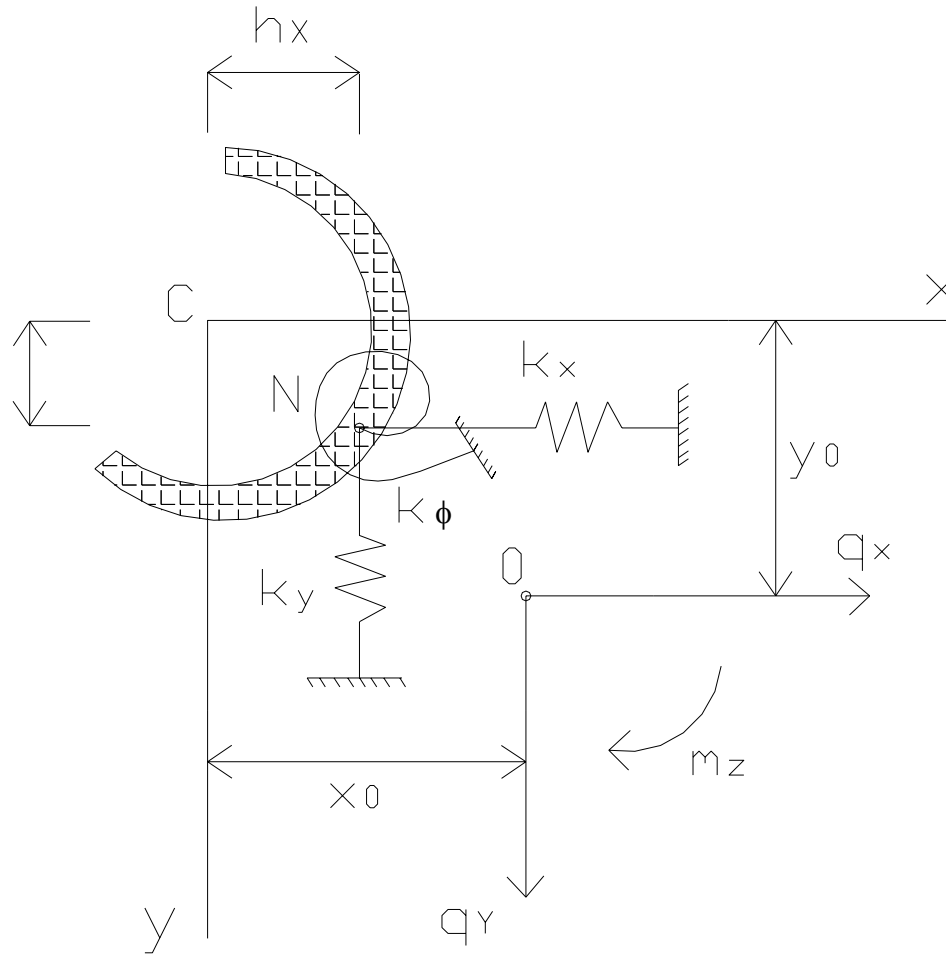

Fig. 2.7 - Teoria da Estabilidade Elástica: modelo teórico

$E I_{y} \frac{d^{4} u}{d z^{4}}+E I_{x y} \frac{d^{4} v}{d z^{4}}+N\left(\frac{d^{2} u}{d z^{2}}+y_{0} \frac{d^{2} \phi}{d z^{2}}\right)+k_{x}\left[u+\left(y_{0}-h_{y}\right) \phi\right]=0$

$E I_{x} \frac{d^{4} v}{d z^{4}}+E I_{x y} \frac{d^{4} u}{d z^{4}}+N\left(\frac{d^{2} v}{d z^{2}}-x_{0} \frac{d^{2} \phi}{d z^{2}}\right)+k_{y}\left[v-\left(x_{0}-h_{x}\right) \phi\right]=0$

$$
\begin{aligned}
& E C_{w} \frac{d^{4} \phi}{d z^{4}}-\left(G I_{t}-\frac{I_{0}}{A} N\right) \frac{d^{2} \phi}{d z^{2}}-N\left(x_{0} \frac{d^{2} v}{d z^{2}}-y_{0} \frac{d^{2} u}{d z^{2}}\right)+ \\
& +k_{x}\left[u+\left(y_{0}-h_{y}\right) \phi\right]\left(y_{0}-h_{y}\right)-k_{y}\left[v-\left(x_{0}-h_{x}\right) \phi\right]\left(x_{0}-h_{x}\right)+k_{\phi}=0
\end{aligned}
$$

Admitindo-se que as extremidades da barra são simplesmente apoiadas, isto é, estão sujeitas ao empenamento, e suscetíveis ao giro em torno dos eixos $\mathrm{x} e$ 
y, mas sem rotação em torno do eixo $z$, pode-se colocar a solução das equações 2.9 a 2.11 no formato a seguir:

$$
u=A_{1} \operatorname{sen} \frac{n \pi z}{l}
$$

$$
v=A_{2} \operatorname{sen} \frac{n \pi z}{l}
$$

$$
\phi=A_{3} \operatorname{sen} \frac{n \pi z}{l}
$$

Uma particularidade para o caso de seção transversal com um único eixo de simetria (caso dos perfis do tipo $U$ enrijecido, estudados no presente trabalho) é que, se o eixo $x$ for tomado como o eixo de simetria, tem-se $y_{0}=0$. Se for assumido que as reações elásticas forem distribuídas ao longo do centro de cisalhamento, então $h_{x}=x_{0}$ e $h_{y}=0$. Com isso, as equações $2.9,2.10$ e 2.11 se transformam nas $2.15,2.16$ e 2.17 :

$$
E I_{y} \frac{d^{4} u}{d z^{4}}+N \frac{d^{2} u}{d z^{2}}+k_{x} u=0
$$

$$
E I_{x} \frac{d^{4} v}{d z^{4}}+N \frac{d^{2} v}{d z^{2}}+k_{y} v-N x_{0} \frac{d^{2} \phi}{d z^{2}}=0
$$

$$
E C_{w} \frac{d^{4} \phi}{d z^{4}}-\left(G I_{t}-\frac{I_{0}}{A} N\right) \frac{d^{2} \phi}{d z^{2}}+k_{\phi} \phi-N x_{0} \frac{d^{2} v}{d z^{2}}=0
$$

$\mathrm{Na}$ primeira equação pode-se perceber que a flambagem no plano de simetria é desacoplada da torção e pode ser tratada separadamente. As últimas 
duas equações são simultâneas, portanto a flambagem na direção y é acoplada à torção.

Se a condição de extremidade da barra for como nas expressões 2.12, 2.13 e 2.14, das equações 2.16 e 2.17 pode-se obter a seguinte equação quadrática 2.18, que pode ser usada para o cálculo da força crítica de flambagem, $N$, sendo que para o caso particular, dois valores serão encontrados, sendo o crítico somente o menor:

$$
\begin{aligned}
& \left(E I_{x} \frac{n^{4} \pi^{4}}{l^{4}}-N \frac{n^{2} \pi^{2}}{l^{2}}+k_{y}\right)\left(E C_{w} \frac{n^{4} \pi^{4}}{l^{4}}+\left(G I_{t}-\frac{I_{0}}{A} N\right) \frac{n^{2} \pi^{24}}{l^{2}}\right)+k \phi+ \\
& -\left(N x_{0} \frac{n^{2} \pi^{2}}{l^{2}}\right)\left(N x_{0} \frac{n^{2} \pi^{2}}{l^{2}}\right)=0
\end{aligned}
$$

O modelo físico e de equações proveniente da teoria da estabilidade elástica será utilizado como uma das bases para o auxílio à análise do fenômeno da flambagem por distorção.

\subsubsection{DOUTY (1962)}

O modelo proposto por DOUTY em 1962 refere-se a seções do tipo cartola e seções do tipo $U$ enrijecido submetidas à flexão em relação ao eixo paralelo à alma com enrijecedores de borda comprimidos (Figura 2.8). Vale salientar que este modelo foi incorporado à norma americana, e, posteriormente à norma brasileira NBR 14762:2001.

Para as seções do tipo cartola (Figura 2.8a) e seções do tipo $U$ enrijecido submetidas à flexão em relação ao eixo paralelo à alma (Figura 2.8b), com os enrijecedores de borda comprimidos, a tensão convencional de flambagem elástica por distorção, $\sigma_{\text {dist, }}$ pode ser determinada com base no procedimento apresentado a seguir, e que consta na norma NBR 14762:2001. Entende-se que este trabalho não tem como intuito explicar o modelo físico deste modelo. Portanto, será apresentado um procedimento comentado somente. 
a) determinar a localização do eixo neutro da seção bruta, definindo $d_{c}$ e $d_{t}$ como as distâncias entre o eixo neutro e as fibras extremas comprimida e tracionada, respectivamente (Figura 2.8a).

b) definir uma "barra comprimida equivalente", com a seção transversal constituída pela parte do elemento sujeito à distorção compreendida entre a fibra extrema comprimida e a ordenada yeq (Figura 2.8c) dada por:

$y_{\text {eq }}=d\left(3 d_{c}-d_{t}\right) /\left(12 d_{c}\right)$

Onde d é a altura da seção

c) determinar $y_{0}$, que é a distância entre o centróide da seção transversal da barra comprimida equivalente e o seu centro de torção, na direção do eixo y (Figura 2.8c).

d) determinar a constante de rigidez $\mathrm{k}_{\mathrm{x}}$, em $\mathrm{kN} / \mathrm{cm}$, referente à flexão do elemento sujeito à distorção, isolando um segmento da barra com comprimento igual a $1 \mathrm{~cm}$ (Figura 2.8d).

$\mathrm{k}_{\mathrm{x}}=\mathrm{F}_{\mathrm{x}} / \mathrm{d}_{\mathrm{x}}$

Onde:

$F_{x}$ é a força transversal ao elemento, igual a $0,001 \mathrm{kN}$ e aplicada na posição do centróide da seção da barra comprimida equivalente;

$d_{x}$ é o deslocamento do centróide na direção de $F_{x}$, em centímetros, dado por:

$d_{x}=h^{2}\left(0,195 h+0,292 b_{f}\right) /\left(10^{6} t^{3}\right)$

h é a distância entre a fibra extrema tracionada da seção e o centróide da seção da barra comprimida equivalente, em centímetros.

$b_{f}$ é a largura nominal do elemento tracionado da seção, em centímetros. 
t é a espessura da seção, em centímetros.

e) determinar o parâmetro $\mu_{0}$ dado por:

$$
\mu_{0}=\mathrm{h} /\left(\mathrm{h}+3,4 \mathrm{y}_{0}\right)
$$

f) se a distorção é contida em duas ou mais seções:

$\mathrm{N}_{\mathrm{e}}=9,83 \mathrm{El} \mathrm{I}_{\mathrm{eq}} / \mathrm{L}^{2}$

$\mathrm{L}_{0}=3,7\left[\mathrm{l}_{\mathrm{eq}}(\mathrm{h} / \mathrm{t})^{3}\right]^{0,25}$

Onde:

$\mathrm{l}_{\text {eq }}$ é o momento de inércia da seção transversal da barra comprimida equivalente em relação ao eixo y (ver Figura 2.8c);

L é o comprimento sem contenção transversal do elemento sujeito à distorção.

$$
\begin{aligned}
& \text { - para }\left(k_{x} L^{2} / N_{e}\right) \leq 30: N_{c r}=\mu N_{e}\left[1+k_{x} L^{2} /\left(\pi^{2} N_{e}\right)\right] \\
& \text { - para }\left(k_{x} L^{2} / N_{e}\right)>30: N_{c r}=\mu N_{e}\left[0,6+0,635\left(k_{x} L^{2} / N_{e}\right)^{0,5}\right]
\end{aligned}
$$

A expressão 2.25 é representativa dos casos em que atuasse uma "mola fraca". Por outro lado, a expressão 2.26 é representativa dos casos em que atuasse uma "mola forte".

Em ambos os casos, $\mu=\mu_{0}$ se $L \geq L_{0}$ e $\mu=L \mu_{0} / L_{0}$ se $L<L_{0}$.

g) se a distorção é contida em menos de duas seções:

$\mathrm{N}_{\mathrm{cr}}=\mu_{0}\left(4 \mathrm{k}_{\mathrm{x}} \mathrm{El}_{\mathrm{eq}}\right)^{0,5}$

Até este ponto, foi realizada uma análise elástica da barra. A seguir será considerada uma análise não-elástica da mesma. 
h) determinar o índice de esbeltez da barra comprimida equivalente, dado por:

$$
\lambda_{\text {eq }}=0,0198 \mathrm{E} /\left(\mathrm{N}_{\mathrm{cr}} / \mathrm{A}_{\mathrm{eq}}\right)^{0,5}
$$

Onde $A_{\text {eq }}$ é a área da seção transversal da barra comprimida equivalente.

i) determinar a tensão convencional de flambagem elástica por distorção, dada por:

$$
\sigma_{\text {dist }}=\left(\pi^{2} E / \lambda_{\text {eq }}^{2}\right)\left(d_{d} / y_{c}\right)
$$

Onde $y_{c}$ é a distância entre o eixo neutro da seção bruta e o centróide da barra comprimida equivalente (figura $2.8 \mathrm{c}$ ).

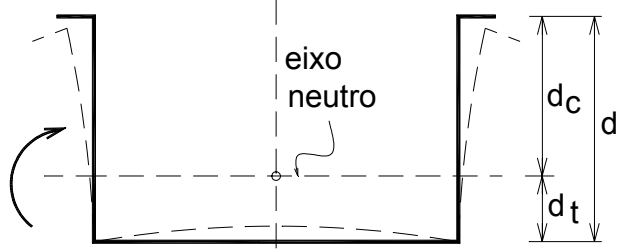

a) seção do tipo cartola

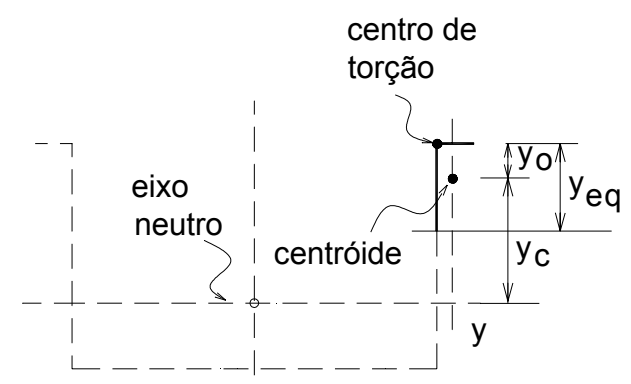

c) barra comprimida equivalente

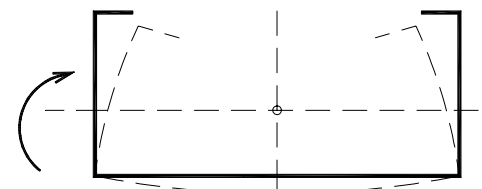

b) seção do tipo $U$ enrijecido

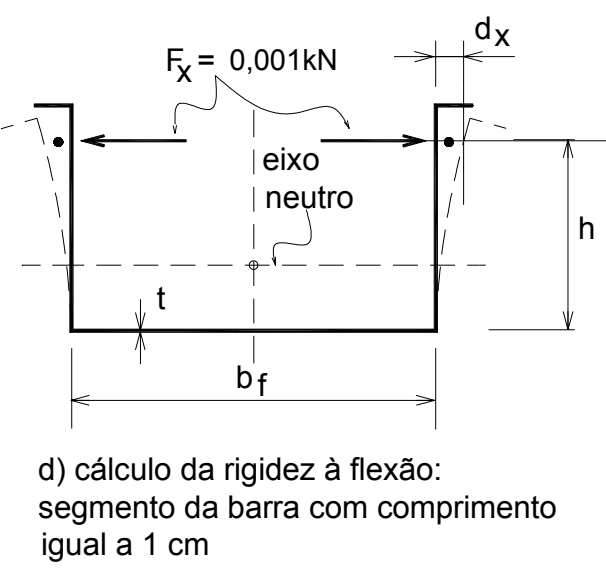

Figura 2.8 - Seções submetidas à flexão com enrijecedores de borda comprimidos [NBR 14762:2001] 


\subsubsection{HANCOCK}

Um modelo simplificado foi idealizado para se facilitar o cálculo da resistência de barras submetidas à compressão e à flexão, no que se refere à flambagem por distorção (LAU \& HANCOCK, 1987). Tal modelo simplificado é aplicável a barras com seções transversais abertas e paredes delgadas, e leva em conta somente o conjunto formado pela mesa comprimida e seu enrijecedor de borda, considerando os efeitos da conexão da alma ao conjunto mesa/enrijecedor por meio de molas com rigidez à flexão e à rotação, sendo representados por $k_{x} e$ $\mathrm{k}_{\phi}$, respectivamente (Figura 2.9).

Tais molas são contínuas ao longo do comprimento da barra para que representem de forma aproximada a conexão entre a alma e o conjunto formado pela mesa comprimida e seu enrijecedor de borda, e, portanto, a influência que a mesma exerce sobre o conjunto analisado, mesmo por que a alma propicia restrições à flexão e à rotação no ponto de conexão com a mesa. 


\section{MODELO DE HANCOCK}

\section{Mesa \\ Comprimida}
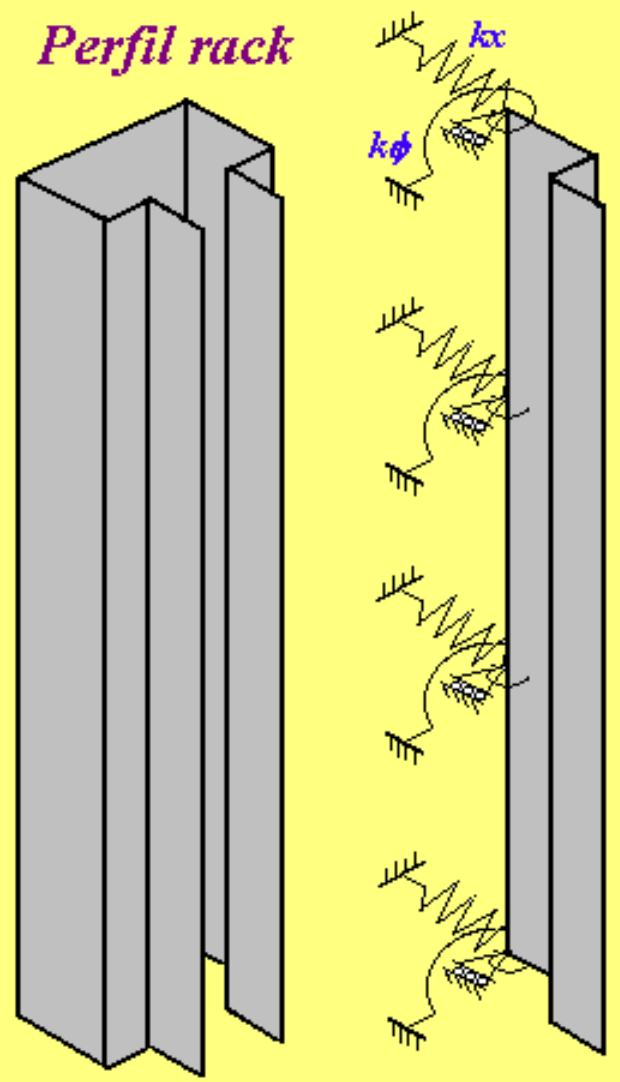

Figura 2.9 - Modelo simplificado: flambagem por distorção [SILVA, 2003]

\subsubsection{BARRAS SUBMETIDAS À COMPRESSÃO}

Segundo LAU \& HANCOCK (1987), algumas expressões analíticas são apresentadas para a abordagem da tensão associada à flambagem por distorção para perfis do tipo $U$ enrijecido com paredes delgadas, submetidos à compressão. Tais expressões se baseiam em um modelo aproximado do modo distorcional (Figura 2.9), devido ao fato de ser complicado formular uma expressão explícita para a análise do fenômeno da distorção para a seção transversal como 
um todo. Cabe salientar que este modelo aproximado leva em conta somente o conjunto formado pela mesa comprimida e seu enrijecedor de borda (Figuras $2.9 \mathrm{e}$ 2.10).

Expressões simplificadas são também apresentadas para permitir o cálculo "rápido" pelos projetistas da tensão acima referida, sendo que estas expressões simplificadas foram e têm sido comparadas com análises via faixas finitas, de modo a verificar sua validade e espectro de atuação.

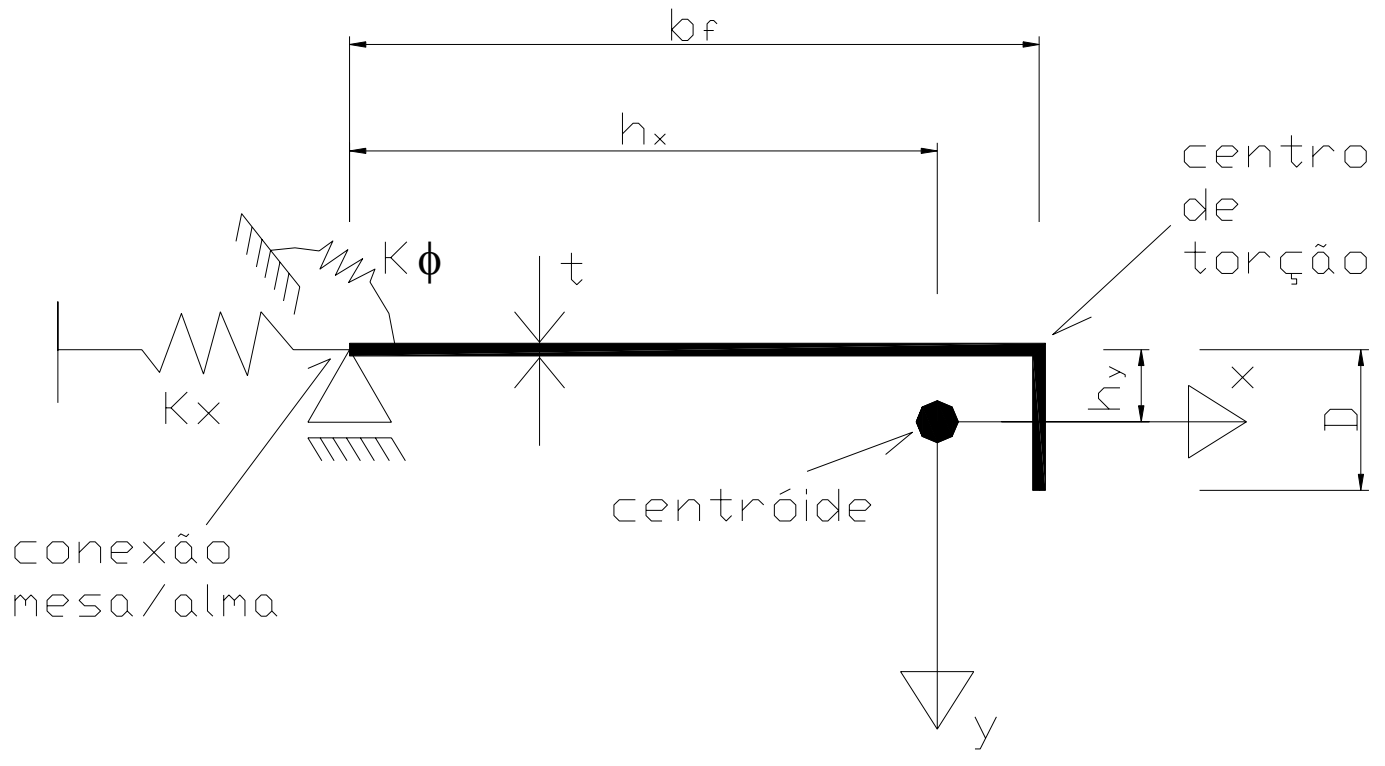

Figura 2.10 - Modelo simplificado: flambagem por distorção da seção transversal: conjunto mesa/enrijecedor

Pela Teoria da Estabilidade Elástica, já citada, após algumas simplificações, tem-se a equação 2.18 em outro formato, que pode ser utilizada para o cálculo da força crítica de flambagem por distorção, $N$, desde que se determine o valor de $\lambda$ (comprimento de meia onda, associado ao comprimento da barra dividido pelo número $\mathrm{n}$ de meias ondas ao longo da barra) que corresponde ao valor mínimo de $\mathrm{N}$ (Equação 2.30). 


$$
\begin{aligned}
& {\left[\frac{\pi^{2}}{\lambda^{2}} E I_{x y}\left(x_{0}-h_{x}\right)+\frac{\lambda^{2}}{\pi^{2}} k_{x}\left(y_{0}-h_{y}\right)-N y_{0}\right]^{2}+} \\
& -\left(\frac{\pi^{2}}{\lambda^{2}} E I_{y}+\frac{\lambda^{2}}{\pi^{2}} k_{x}-N\right)\left\{\frac{\pi^{2}}{\lambda^{2}}\left[E C_{w}+E I_{x}\left(x_{0}-h_{x}\right)^{2}\right]+G J+\right. \\
& \left.-\left(\frac{I_{0}}{A}-x_{0}^{2}+h_{x}^{2}\right) N+\frac{\lambda^{2}}{\pi^{2}}\left[k_{x}\left(y_{0}-h_{y}\right)^{2}+k_{\phi}\right]\right\}=0
\end{aligned}
$$

\section{CONSTANTE DE RIGIDEZ À ROTAÇÃO $\mathrm{K}_{\phi}$ :}

- A rigidez à rotação $k_{\phi}$ ao longo da extremidade longitudinal de uma chapa retangular submetida à tensões longitudinais de compressão e momentos distribuídos é representada pelas expressões 2.31 a 2.34. É assumido que a chapa é simplesmente apoiada nas extremidades, mesmo sabendo que na realidade a conexão entre a mesa e a alma pode sofrer deslocamento lateral. $\mathrm{O}$ valor de $k_{\phi}$ é assíntoto à constante $2 \mathrm{D} / \mathrm{b}$ para longos comprimentos de meia onda e valores pequenos de $\mathrm{k}$ :

$$
k_{\phi}=\frac{D\left(\alpha^{2}+\beta^{2}\right)}{b}\left(\alpha \tanh \left(\frac{\alpha}{2}\right)+\beta \tan \left(\frac{\beta}{2}\right)\right)^{-1}
$$

Onde:

$$
\begin{aligned}
& \alpha=\pi \sqrt{\left(\frac{b}{\lambda}\right) \sqrt{\left(\frac{b}{\lambda}+\sqrt{(k)}\right.}} \\
& \beta=\pi \sqrt{\left(\frac{b}{\lambda}\right) \sqrt{\left(-\frac{b}{\lambda}+\sqrt{(k)}\right.}} \\
& k=\frac{b^{2} t}{\pi^{2} D} \sigma
\end{aligned}
$$

O uso da expressão 2.31 para a determinação de $\mathrm{k}_{\phi}$ permitindo sua aplicação na expressão 2.30 não é prático pois envolve a força de compressão 
aplicada, e conseqüentemente um processo interativo para a determinação de $k_{\phi}$ se torna necessário.

BLEICH (1952) determinou a constante de rigidez à rotação entre elementos adjacentes de chapa em perfis do tipo U, I e Z para flambagem local, utilizando a expressão 2.40 multiplicada por um fator de redução no sentido de se levar em conta a força de compressão na alma. Este fator é a relação entre as tensões de flambagem local de elementos de chapa adjacentes. Portanto:

$$
k_{\phi}=\frac{2 D}{b_{w}}\left(1-\frac{\frac{F^{\prime}}{A}}{\sigma_{w}}\right)
$$

Onde:

$\sigma_{\mathrm{w}}$ : tensão devido à flambagem local da alma da chapa sob compressão;

$$
\sigma_{\mathrm{w}}=\frac{\pi^{2} \mathrm{D}}{\mathrm{tb}_{\mathrm{W}} 2}\left(\frac{\mathrm{b}_{\mathrm{W}}}{\lambda}+\frac{\lambda}{\mathrm{b}_{\mathrm{W}}}\right)^{2}
$$

F'/A: tensão crítica de flambagem da mesa, segundo a equação 2.30 , considerando $\mathrm{k}_{\mathrm{x}}=0$ e $\mathrm{k}_{\phi}=0$;

$\lambda$ : obtido da expressão 2.41 ;

O fator de redução $\left(1-\frac{\frac{F^{\prime}}{A}}{\sigma_{w}}\right)$ é determinado de modo que $\mathrm{k}_{\phi}$ se torna nulo se a alma e a mesa da seção sofrerem flambagem sob tensões similares, e $k_{\phi}$ se aproxima do valor $2 D / b_{w}$ se a tensão de flambagem da alma for bem maior que a da mesa. A expressão 2.35 será modificada para a 2.37 para se fazer o ajuste com o cálculo via faixas finitas, o qual inclui o efeito da força cortante e da distorção da mesa. A adição de $0,06 \lambda$ ao valor de $b_{w}$ na expressão 2.37 foi determinada por estudos paramétricos para seções com enrijecedores perpendiculares às mesas. 


$$
k_{\phi}=\frac{2 D}{\left(b_{w}+0,06 \lambda\right)}\left(1-\frac{\frac{F^{\prime}}{A}}{\sigma_{w}}\right)
$$

OBS.: Para seções com enrijecedores não perpendiculares às mesas, o termo $0,06 \lambda$ pode precisar de outros ajustes paramétricos.

\section{CONSTANTE DE RIGIDEZ À FLEXÃO $\mathrm{K}_{\mathrm{X}}$ :}

- $\quad$ Para seções com o enrijecedor de borda virado para dentro (Figura 2.11a), tem-se que a influência de $k_{x}$ é consideravelmente menor quando comparada às seções com os enrijecedores virados para fora (Figura 2.11b), devido à redução da estabilidade da alma. Conseqüentemente, para as seções com enrijecedores de borda virados para dentro geralmente adota-se um valor pequeno para $\mathrm{k}_{\mathrm{x}}$, sendo, portanto, ignorado nas análises a seguir.

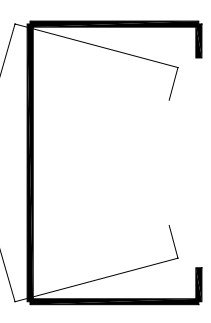

a)

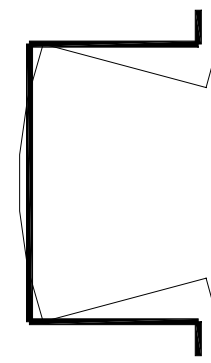

b)

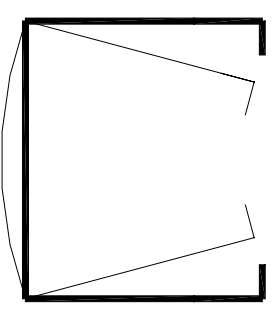

c)

Figura 2.11 - Modos de flambagem por distorção da seção transversal

- $\quad$ Será adotada nula, decorrente às fórmulas explícitas de projeto para perfis do tipo $U$ enrijecido, com enrijecedores de borda virados para dentro. 


\section{EXPRESSÕES SIMPLIFICADAS:}

Algumas simplificações referentes à equação 2.30 são apresentadas a seguir:

\section{- Comprimento de meia onda crítico:}

O procedimento interativo anteriormente apresentado para a determinação do valor crítico de $\lambda$ que corresponde à força crítica de flambagem por distorção, não é prático para o emprego em projetos.

A força crítica de flambagem por distorção é dada por:

$$
N_{c r}=\frac{\frac{\pi^{2}}{\lambda^{2}} E I_{w c}+G I_{t}+\frac{\lambda^{2}}{\pi^{2}} k \phi}{\frac{I_{x}+I_{y}}{A}+h_{x}{ }^{2}+h_{y}{ }^{2}}
$$

Onde:

$$
I_{w c}=C_{w}+I_{x}\left(x_{0}-h_{x}\right)^{2}+I_{y}\left(y_{0}-h_{y}\right)^{2}-2 I_{x y}\left(x_{0}-h_{x}\right)\left(y_{0}-h_{y}\right)
$$

Sendo $\mathrm{k}_{\phi}$ também função de $\lambda$ e de $\mathrm{N}$, para a obtenção da expressão explícita do valor crítico de $\lambda, \mathrm{k}_{\phi}$ passa a ser:

$$
k_{\phi}=\frac{2 D}{b_{w}}
$$

O valor crítico de $\lambda$ resulta:

$$
\lambda_{\text {crítico }}=\pi\left(\frac{E I_{w c}}{k_{\phi}}\right)^{0,25}=\pi\left(\frac{E I_{w c} b_{w}}{2 D}\right)^{0,25}
$$


Onde:

- D: rigidez da chapa à flexão por unidade de comprimento, $D=\frac{E t^{3}}{12\left(1-v^{2}\right)}$; - $\quad b_{\mathrm{w}}$ : largura nominal da alma;

Segundo LAU \& HANCOCK (1987), é constatado que um erro de $20 \%$ na determinação do valor crítico de $\lambda$ devido ao fenômeno da flambagem por distorção representa um erro máximo de $7 \%$ na tensão crítica de flambagem por distorção, sendo que este último erro é pequeno se o valor crítico de $\lambda$ é obtido usando-se a expressão 2.41 .

\section{FÓRMULAS PARA PROJETO:}

Substituindo-se $k_{x}=0$ na equação 2.30 e calculando-se $\lambda$. e $k_{\phi}$ pelas expressões 2.37 e 2.41, respectivamente, com o coeficiente de Poisson igual a 0,3, a força crítica relativa à flambagem elástica por distorção pode ser explicitamente escrita, com pequenas modificações, segundo formulário do Anexo $D$ da norma brasileira NBR 14762:2001, cujo conteúdo será apresentado mais adiante.

DAVIES \& JIANG (1996) fizeram uma calibração detalhada com base neste modelo proposto por LAU \& HANCOCK (1987), comparando-o com o modelo que considera a análise da seção como um todo, via GBT (Teoria de Viga Generalizada, será explicada mais adiante), e perceberam a sensibilidade do mesmo relativa à rigidez à rotação $\mathrm{k}_{\phi}$, propondo significativos avanços ao modelo.

Com relação às expressões para o cálculo de resistência propostas pelo modelo de LAU \& HANCOCK (1987), para perfis do tipo $U$ e $Z$ enrijecido submetidos à compressão, sujeitos à flambagem por distorção, as expressões serão apresentadas mais adiante.

Segundo VAZQUEZ (2002), dentre algumas das metodologias alternativas à da norma brasileira, pode-se citar a proposta por KWON \& HANCOCK (1992), que se apresenta como uma modificação da fórmula de Winter para permitir sua utilização no caso do modo distorcional de flambagem para perfis sob compressão centrada, como a seguir: 


$$
\frac{N_{\text {dist }}}{N_{y}}=\left(1-0,25\left(\frac{N_{c r d}}{N_{y}}\right)^{0,6}\right)^{\left(\frac{N_{c r d}}{N_{y}}\right)^{0,6}}
$$

Onde:

$$
\sqrt{\frac{N_{y}}{N_{c r d}}}>0,561, \text { senão } \frac{N_{\text {dist }}}{N y}=1
$$

$\mathrm{N}_{\text {dist: }}$ força normal resistente relativa a flambagem por distorção;

$N_{y}=A_{g} f_{y}$;

$\mathrm{N}_{\text {crd }}=$ valor da força relativa a flambagem crítica elástica por distorção

Existe também uma expressão proposta por CHAJES et al. (1966) para a flambagem por flexo-torção, posteriormente adaptada por LAU \& HANCOCK (1988) para determinar a resistência à flambagem por distorção, sendo que a mesma se baseia na parábola de Johnston. KWON \& HANCOCK (1992) propuseram uma extensão desta expressão inicial, para seções de paredes delgadas afetadas pelo modo distorcional, conforme apresentado a seguir:

$$
\begin{aligned}
& \frac{N_{\text {dist }}}{A}=f_{y}\left(1-\frac{A f_{y}}{4 N_{c r d}}\right) \quad \text { para } N_{c r d} \geq \frac{A f_{y}}{2} \quad \text { para } \frac{A f_{y}}{13} \leq N_{c r d} \leq \frac{A f_{y}}{2} \\
& \frac{N_{\text {dist }}}{A}=f_{y}\left(0,055\left(\sqrt{\frac{A f_{y}}{N_{c r d}}}-3,6\right)^{2}+0,237\right) \text { para }
\end{aligned}
$$

\section{LIMITAÇÕES:}

Segundo LAU \& HANCOCK (1987), se os enrijecedores forem muito curtos, proporcionalmente aos outros elementos constituintes da seção, o primeiro e segundo mínimos locais se tornam um único mínimo local, para um comprimento de meia onda curto, com a conexão mesa/alma continuando reta como em um modo 
local puro. Conseqüentemente, as expressões do anexo $D$ da norma brasileira NBR 14762:2001, itens D.2 e D.3 se tornam muito conservativas, pois a concepção das fórmulas de projeto admite que a conexão mesa/alma é passível de sofrer translação, e não somente rotação.

Para seções usuais, por outro lado, de acordo com as especificações do AISI (1980) para os requerimentos de comprimentos dos enrijecedores, tais expressões apresentam uma boa estimativa da tensão convencional de flambagem elástica por distorção, desde que:

$$
\mathrm{d}_{\min }=2,8 \mathrm{t}\left[\left(\frac{\mathrm{b}}{\mathrm{t}}\right)^{2}-\frac{27600}{\mathrm{f}_{\mathrm{y}}}\right]^{1 / 6} \geq 4,8 \mathrm{t}
$$

Onde:

- $\quad \mathrm{f}_{\mathrm{y}}$ : resistência ao escoamento do aço $(\mathrm{MPa})$

- $\quad$ b/t: relação largura/espessura da mesa

Segundo LAU \& HANCOCK (1987), com base em estudos paramétricos, constatou-se que para perfis do tipo $U$ enrijecido as tensões convencionais de flambagem elástica por distorção são próximas à obtidas via faixas finitas para o intervalo $0,5 \leq \frac{b_{f}}{b_{w}} \leq 2,5$.

Para seções que não atendem essa relação, tais expressões serão contra a segurança, pois a translação da conexão alma/mesa será significativa.

\subsubsection{BARRAS SUBMETIDAS À FLEXÃO}

Com relação aos perfis do tipo $U$ enrijecido, submetidos à flexão, HANCOCK (1997) diz que simplesmente o conjunto comprimido mesa/enrijecedor sofrerá rotação em torno da conexão alma/mesa, sendo que a formulação apresentada consta da norma australiana (Figura 2.4).

Se uma faixa unitária da alma do perfil tipo $U$ enrijecido, submetido à compressão uniforme, for tratada como uma viga simplesmente apoiada sob flexão, 
a rigidez à rotação da extremidade será $2 \mathrm{EI} / \mathrm{L}$, devido aos momentos aplicados nas extremidades serem iguais e opostos. Se, por outro lado, tal alma estiver submetida à flexão, e for tratada como uma viga com uma extremidade simplesmente apoiada e outra engastada, a rigidez à rotação da extremidade apoiada será 4EI/L, ou seja, o dobro (Figura 2.12).

Devido à alma estar submetida a um gradiente de tensões devido à flexão da mesma, sabe-se que o coeficiente de flambagem local da chapa, $k$, de um elemento de alma sob flexão no plano varia em função da relação entre os lados da chapa a/b, e em função de um fator numérico, $\alpha$ (em particular, temos para $\alpha=0$ o caso de compressão uniforme, para $\alpha=2$ o caso de flexão pura, para $\alpha<2$ combinação de flexão e compressão e para $\alpha>2$ combinação de flexão e tração).

Comparando-se o valor de $\lambda_{\text {crítico }}$ ao correspondente à compressão uniforme, pode-se transformar a expressão 2.41 na 2.46 , correspondente à flexão, conforme mostrado a seguir:

$\lambda_{\text {critico }}=\pi\left(\frac{E I_{w c} b_{w}}{4 D}\right)^{0,25}$

$k_{\phi}=\frac{4 D}{b_{w}}$

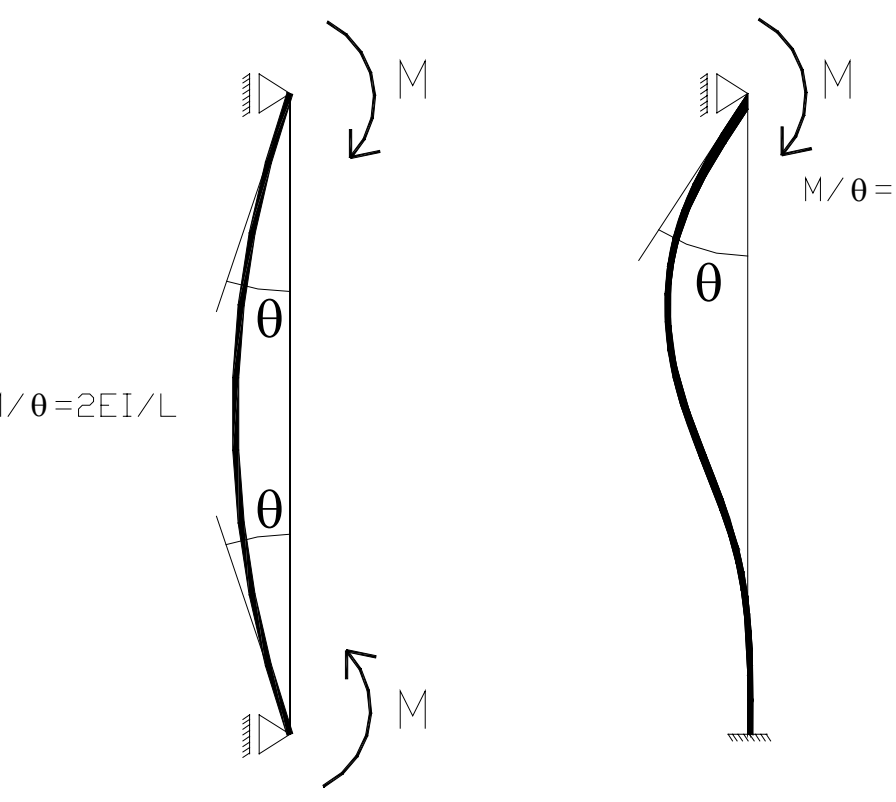

Figura 2.12 - Flexão: Flambagem por distorção 
As expressões para o cálculo de resistência propostas por Hancock, para perfis do tipo $U$ e $Z$ enrijecido submetidos à flexão, sujeitos à flambagem por distorção, serão apresentadas mais adiante.

Comparando-se os resultados relativos à flambagem por distorção entre o modelo proposto por Hancock e a GBT, com relação à análise de perfis do tipo $U$ enrijecido submetidos à flexão, percebe-se que resultados satisfatórios foram encontrados para almas "curtas", mas para almas mais "longas", as expressões oriundas do método de Hancock podem levar a resultados contrários à segurança devido à negligência da flambagem local da alma e ao fato de se assumir a extremidade inferior da alma (tracionada) fixa. No sentido de se melhorar os resultados propostos por tal método, autores sugeriram a introdução de um coeficiente de redução na expressão de $k_{\phi}$, além de se assumir a extremidade inferior da alma apoiada e não engastada. Tais expressões modificadas levaram a uma melhor estimativa do momento fletor crítico, comparando-se com tais resultados oriundos das expressões originais de Hancock. Tal fato novamente evidencia a sensibilidade dos métodos deste tipo com relação aos valores assumidos para $\mathrm{k}_{\phi}$, além da preferência por métodos que analisem a seção como um todo.

\subsubsection{MOREYRA \& PEKÖZ}

Moreyra \& Peköz (1993) apresentaram um método para analisar a flambagem por distorção em perfis formados a frio submetidos à flexão (para comprimentos de meia onda pequenos). Tal método consiste em se calcular uma tensão nominal de borda, desenvolvida a partir de um estudo paramétrico.

Após o cálculo da tensão inicial nominal de borda, o modelo de SHARP (1966) é utilizado para se determinar a largura efetiva do elemento de mesa. A especificação do AISI (1996) e o método relativo ao cálculo da alma efetiva de SOOI (1993) são usados para a determinação das larguras efetivas do enrijecedor de borda e alma, respectivamente. Algumas modificações ao método de MOREYRA \& PEKÖZ foram introduzidas. 
Inicialmente é calculada uma tensão nominal de borda, $\sigma$ :

$$
\sigma=\frac{f_{y}}{\left(\frac{b_{w}}{t}\right)^{2 / 3}\left(0,186+0,114 \frac{b_{f}}{b_{w}}\right)^{2}} \leq f_{y}
$$

Tem-se que $b_{f}$ e $b_{w}$ correspondem, respectivamente, às larguras nominais da mesa e da alma do perfil.

Dois modelos podem ser usados, com a variação de $k_{\phi}$.

$$
\begin{aligned}
& k_{\phi}=\frac{2 D_{w}}{b_{w}}\left(\frac{1}{1+\frac{2}{3} \frac{b}{b_{w}}}\right) \\
& k_{\phi}=\frac{4 D_{w}}{b_{w}}\left(\frac{1}{1+\frac{2}{3} \frac{b_{f}}{b_{w}}}\right)
\end{aligned}
$$$$
\text { Modelo } 1
$$

O método utilizado por SHARP baseia-se em uma barra uniformemente comprimida, sujeita à flambagem por distorção com comprimento de meia onda pequeno. Em contrapartida, o modelo de MOREYRA \& PEKÖZ foi desenvolvido para analisar seções submetidas à flexão.

O elemento de alma de seções submetidas à flexão encontra-se sob um gradiente de tensões, sendo que somente a mesa comprimida está sujeita à instabilidade. Portanto, o coeficiente $\mathrm{k}_{\phi}$ é multiplicado por dois (Figura 2.13). 


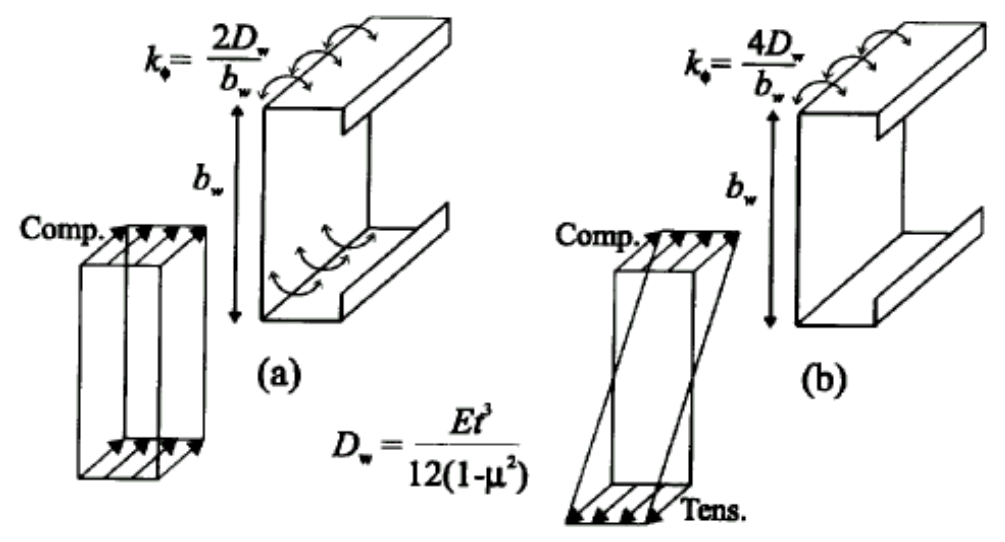

Figura 2.13 - Relações entre $k_{\phi}$

A esbeltez normalizada relativa à flambagem da mesa comprimida pode ser calculada como:

$$
\lambda=\frac{\lambda_{e}}{\pi} \sqrt{\frac{\sigma}{E}}
$$

Onde:

$$
\lambda_{e}=\pi \sqrt{\frac{I_{p}}{\frac{G I_{t}}{E}+2 \sqrt{\frac{{ }_{b} C_{w}}{E}}}} \geq 1,65 \frac{b_{f}}{t}
$$

Sabe-se que $\mathrm{G} / \mathrm{E}=0,375$ (para $v=0,3$ - aço), sendo que tais grandezas estão explícitas na expressão para serem válidas também para os perfis de alumínio.

Tem-se também que:

$$
\mathrm{C}_{\mathrm{w}}=\mathrm{b}_{\mathrm{f}}^{2}\left(\mathrm{I}_{\mathrm{yc}}-\frac{\mathrm{b}_{\mathrm{f}} \mathrm{t}^{3}}{12}\right) \geq 0
$$


Onde:

$\mathrm{I}_{\mathrm{yc}}$ : momento de inércia do conjunto formado pela mesa comprimida e pelo enrijecedor de borda em relação ao seu próprio centróide.

Com relação a SHARP (1966), citado anteriormente, apresenta-se uma expressão alternativa para o cálculo da tensão convencional de flambagem elástica por distorção para barras de paredes delgadas submetidas à compressão:

$$
\sigma_{c r}=\left(\frac{2 \sqrt{E I_{x} b_{f}{ }^{2} k_{\phi}}+\frac{E I_{t f}}{2(1+v)}}{\left(I_{x f}+I_{y f}\right)+A_{f}\left(h_{x}{ }^{2}+h_{y}{ }^{2}\right.}\right)
$$

Foi assumido que:

- $\boldsymbol{k}_{\boldsymbol{x}}=\infty$

$k_{\phi}=\frac{2 E t^{3}}{5,46\left(b_{w}+\frac{2}{3} b f\right)}$

OBS.: A expressão não permite a redução da rigidez devido à compressão na alma.

\subsubsection{EXPRESSÃO SIMPLIFICADA DE ELLIFRITT ET AL. PARA PERFIS DO TIPO U e Z ENRIJECIDO, SUBMETIDOS À FLEXÃO}

A solução analítica referente ao fenômeno da flambagem por distorção foi proposta por HANCOCK (1994), sendo que vários ensaios foram feitos para a sua verificação, empregando em torno de 200 seções (referente à parte 1 da edição de 1996 do AISI). A metodologia empregada para tal solução analítica é trabalhosa se realizada manualmente, sendo que envolve o cálculo de propriedades da seção que geralmente não estão disponíveis em tabelas, devido ao fato de que tais 
propriedades se referem não à seção como um todo, mas a uma parte da seção transversal, composta pela mesa comprimida e pelo enrijecedor de borda.

Após a verificação de tais dificuldades, ELLIFRITT et al. (1998) propuseram uma formulação simplificada para cálculo do momento fletor correspondente à flambagem por distorção, com base somente nas propriedades da seção transversal e na tensão de escoamento do aço empregado. Para tal, foi feito um estudo para a identificação de quais variáveis exerciam maior influência na formulação proposta por Hancock.

A conclusão do estudo levou à execução de curvas para o cálculo manual e simples de tal momento fletor, levando em consideração a espessura, tensão de escoamento, largura nominal da alma, da mesa e do enrijecedor de borda. Estas curvas são geradas por meio de uma expressão que depende do tipo de perfil (uma para perfis do tipo $U$ enrijecido e uma para perfis do tipo $Z$ enrijecido), e podem ser usadas para, de um modo simplificado, determinar se é necessário se verificar a flambagem por distorção para determinada seção, pois fornecem uma razoável estimativa do momento fletor correspondente à flambagem por distorção, como função do momento fletor de início de escoamento.

Soluções provenientes do método analítico formulado por HANCOCK (1994) foram equacionadas no programa computacional MathCAD e comparadas com os resultados oriundos deste método simplificado, notando-se que os resultados são próximos, o que o viabiliza para ser utilizado como uma análise inicial simples e rápida, considerando-se somente as dimensões da seção transversal do perfil. Se resultados mais exatos forem desejados é aconselhável empregar um método mais preciso.

Cabe lembrar que os resultados obtidos da análise dos perfis do tipo $Z$ enrijecido mostraram-se um pouco mais dispersos, mas tal fato se deve, provavelmente, à sensibilidade do ângulo do enrijecedor ao modelo que considera a flambagem por distorção, não somente verificado nos ensaios, mas também nos métodos de cálculo.

As curvas geradas são do tipo $X$ contra $M_{\text {dist }} / M_{y}$, sendo:

$$
X=\left(\frac{b_{f}}{t}\right)^{1,1}\left(\frac{b_{w}}{D}\right)^{0,4} \frac{f_{y}}{50}
$$


- $\quad b_{f}:$ largura nominal da mesa

- $\quad$ t: espessura

- $b_{\mathrm{w}}$ : largura nominal da alma

- $\quad$ D: largura nominal do enrijecedor

- $\quad \mathrm{M}_{\text {dist }}$ : momento fletor correspondente a flambagem por distorção

- $\quad \mathrm{M}_{\mathrm{y}}$ : momento fletor correspondente ao escoamento

- $\quad \mathrm{f}_{\mathrm{y}}$ : resistência ao escoamento $(\mathrm{ksi})$

Após o cálculo de $X$, que depende somente das dimensões da seção transversal do perfil e da tensão de escoamento, deve ser calculado:

a) Para perfis do tipo $U$ enrijecido:

$$
\begin{aligned}
& \frac{M_{\text {dist }}}{M_{y}}=-8 \times 10^{-9} X^{3}+10^{-5} X^{2}-0,0048 X+1,2685 \\
& \mathrm{M}_{\mathrm{y}}=\mathrm{W}_{\mathrm{x}} \mathrm{f}_{\mathrm{y}}
\end{aligned}
$$

Com isso calcula-se $M_{\text {dist. }}$

b) Para perfis do tipo $Z$ enrijecido:

$$
\begin{aligned}
& \frac{M_{\text {dist }}}{M_{y}}=-3 \times 10^{-8} X^{3}+2 \times 10^{-5} X^{2}-0,0063 X+1,2747 \\
& \mathrm{M}_{\mathrm{y}}=\mathrm{W}_{\mathrm{x}} \mathrm{f}_{\mathrm{y}}
\end{aligned}
$$

Com isso calcula-se $M_{\text {dist. }}$

Como exemplo, as curvas serão apresentadas a seguir (Figuras 2.14 e 2.15). 


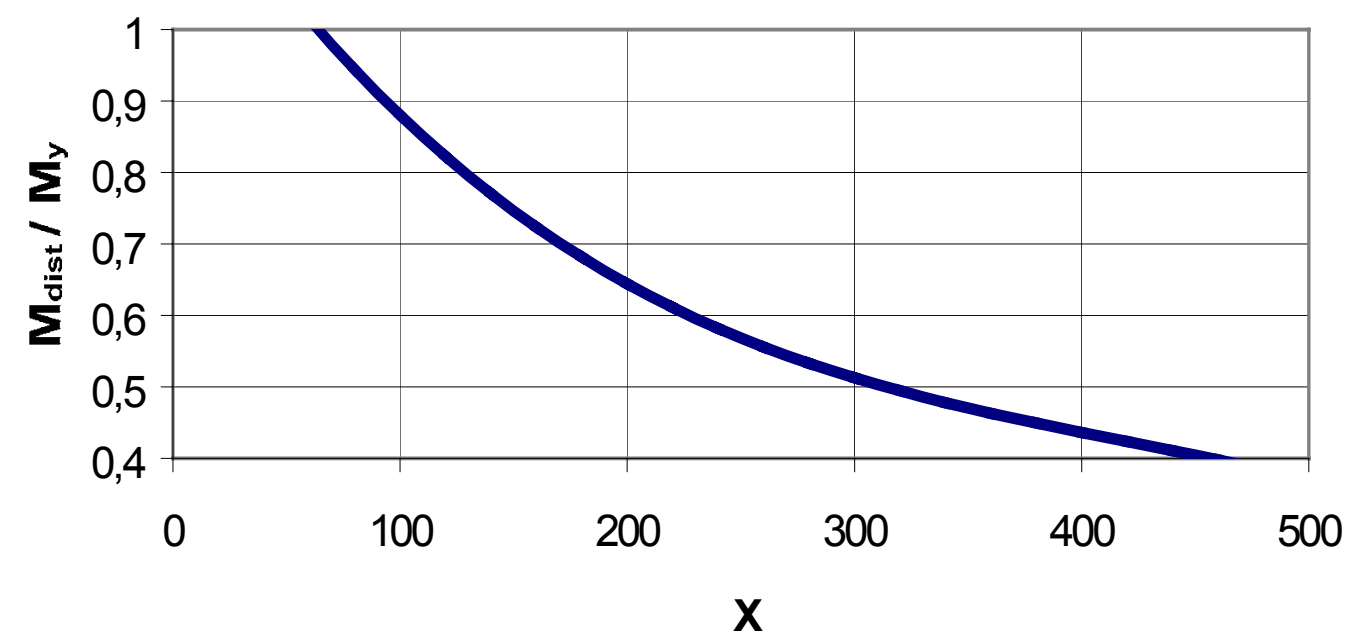

Figura 2.14 - Curva paramétrica proposta por Ellifritt et al. para perfil do tipo $U$ enrijecido

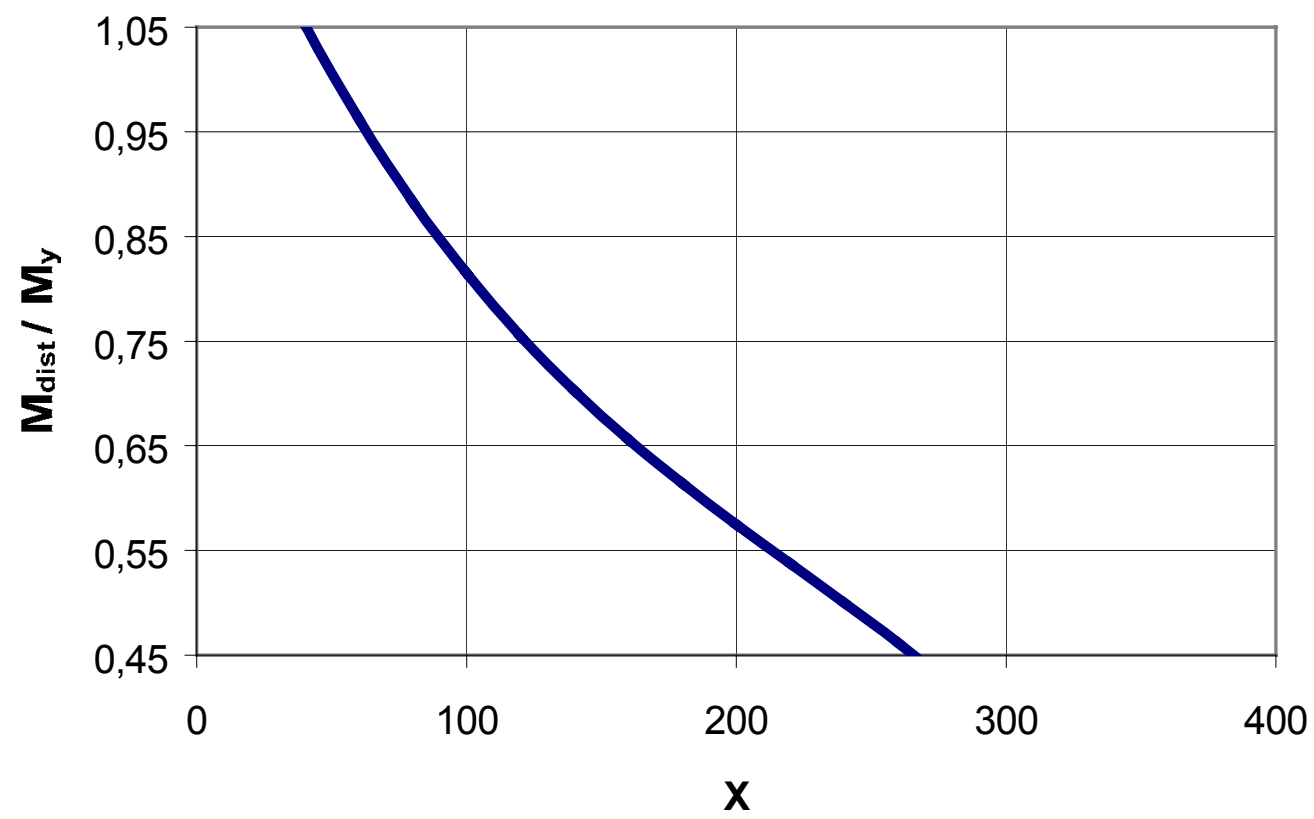

Figura 2.15 - Curva paramétrica proposta por Ellifritt et al. para perfil do tipo Z enrijecido 


\subsubsection{EXPRESSÃO AYRTON-PERRY}

Os modelos que utilizam a análise da seção como um todo (e serão também abordados no presente trabalho), diferentemente dos que somente analisam os elementos constituintes da seção em separado, são preferidos quando da análise da flambagem local, por distorção e global, e avaliação da interação entre as mesmas. Tais modelos se mostram como práticos atualmente devido aos avanços dos métodos numéricos. Entretanto, a análise de bifurcação somente fornece como resultado a tensão crítica para flambagem elástica.

Para se obter a resistência à compressão ou à flexão de uma seção referente à flambagem por distorção, deve-se corrigir tais curvas pelas expressões normalizadas, de acordo com o trecho (elástico / inelástico) em questão.

Com relação à expressão proposta por AYRTON-PERRY A mesma apresenta boa utilidade nas situações em que o modo de flambagem predominante é o global, sendo usada nas normas mais modernas para promover a interação entre o escoamento e a flambagem global. Cabe lembrar que para critérios de projeto se faz necessária a consideração da interação entre a flambagem e o escoamento, pois para um projeto econômico deve-se tirar proveito da resistência pós-flambagem.

É importante salientar que este modelo, diferentemente dos outros apresentados neste item 2.3, não é específico para o caso da flambagem por distorção.

Alguns métodos complementares para levar em consideração esta situação podem ser usados. Outros procedimentos serão abordados nos itens 2.7.5 e 2.7.6.

Soluções práticas podem geralmente ser obtidas pela combinação entre a força (ou tensão) teórica devida à flambagem por bifurcação elástica com a correspondente força (ou tensão) de escoamento usando a expressão a seguir:

$$
\chi=\frac{1}{\phi+\left[\phi^{2}-\lambda_{p}^{2}\right]^{0,5}} \leq 1,0
$$

Onde:

$$
\phi=0,5\left[1+\alpha\left(\lambda_{p}-0,2\right)+\lambda_{p}^{2}\right]
$$


$\chi$ :fator de redução devido à flambagem;

$\alpha$ : fator de imperfeição inicial;

$\lambda_{p}$ : índice de esbeltez reduzido do elemento;

Comparando-se a expressão acima de $\lambda_{\mathrm{p}}$ com o índice de esbeltez $\lambda$ da norma brasileira NBR 14762:2001, tem-se que:

$$
\lambda_{p}=\sqrt{\frac{\sigma}{\sigma_{e}}}=\lambda=\frac{b / t}{0,95(k E / \sigma)^{0,5}}
$$

No EUROCODE 3: Parte 1.3, esta expressão é aplicada à flambagem por flexão de elementos submetidos à compressão e à flambagem lateral com torção de elementos submetidos à flexão, com $\lambda_{\mathrm{p}}$ igual a $\sqrt{N / N_{c r}}$ e $\sqrt{M / M_{c r}}$, respectivamente.

A flambagem local pode ser considerada tomando-se a força (ou tensão) de escoamento na seção efetiva, sendo que até o presente momento tal cálculo tem se baseado no cálculo convencional da largura efetiva.

Provavelmente este método é conservativo em excesso, quando aplicado em situações em que a flambagem local seja significante. Devido a tal fato, SCHAFER \& PEKÖZ (1998) propuseram o método direto de resistência.

\section{LIMITAÇÕES DAS EQUAÇÕES PARA A FLAMBAGEM ELÁSTICA POR DISTORÇÃO}

Segundo BAMBACH et al. (1998), algumas limitações devem ser observadas.

\section{Aspectos importantes:}

Com relação a alguns aspectos a serem salientados relativos aos formulários apresentados segundo LAU \& HANCOCK $(1987,1997)$, para a 
determinação da tensão convencional de flambagem elástica por distorção de perfis do tipo $U$ e $Z$ enrijecido com ou sem enrijecedores de borda adicionais, são importantes serem consideradas algumas limitações:

\section{Largura nominal dos enrijecedores}

Recomenda-se a limitação da largura nominal dos enrijecedores, pois segundo LAU \& HANCOCK (1987) se os mesmos forem muito "curtos" o primeiro e segundo mínimo local se tornarão um só mínimo local correspondendo a um pequeno comprimento de meia onda, com a conexão mesa/alma permanecendo reta como se fosse o modo local puro. Conseqüentemente, o formulário será conservativo, desde que se assuma que a conexão mesa/alma é passível de sofrer flexão lateralmente.

Portanto, recomenda-se que os requerimentos relativos aos comprimentos dos enrijecedores de borda do AISI (1980) sejam satisfeitos, sendo:

$$
d_{\min }=2,8 t\left(\left(\frac{b}{t}\right)^{2}-\frac{27600}{f_{y}}\right)^{1 / 6} \geq 4,8 t
$$

Onde:

- $\quad f_{y}$ : tensão de escoamento do aço (MPa)

- $\quad$ b/t: relação largura/espessura da mesa

\section{- $\quad$ Para seções sob compressão:}

$b_{f} / b_{w}>1 / 3$

Onde:

- $\quad b_{w}$ : largura nominal da alma

- $\quad b_{f}$ : largura nominal da mesa 


\section{- $\quad$ Para seções sob flexão:}

\section{a) Valores negativos para $\mathbf{k}_{\phi}$}

Alguns perfis submetidos à flexão podem apresentar valores de $k_{\phi}$ negativos ou muito pequenos. Como conseqüência, a alma sofre flambagem antes da mesa, e a hipótese de que a alma trava a mesa não mais é válida.

Para evitar este problema sugere-se a relação: $b_{f} / b_{w}>1 / 3$

OBS.: A norma brasileira NBR 14762:2001 estabelece que para os casos em que resultar $\mathrm{k}_{\phi}<0$, o mesmo deve ser recalculado admitindo-se a condição $\sigma_{\text {dist }}=0$.

\section{b) Tensões constantes ao longo dos enrijecedores}

Os dados de entrada referentes ao estudo apresentado na Tabela 2.2 a seguir, relativos à flexão (programa THIN-WALL), foram ajustados para haver tensão uniforme nos enrijecedores de borda, para haver compatibilidade com o formulário da flambagem por distorção.

Entretanto, para se efetuar uma análise precisa de uma seção submetida à flexão utilizando o formulário, o mesmo deve levar em conta o gradiente de tensões que existirá ao longo do enrijecedor, e as tensões reduzidas no enrijecedor de borda adicional. Propõe-se que as tensões devidas à flambagem por distorção decorrentes do formulário sejam multiplicadas por um fator de ajuste $\frac{b_{w}}{\left(b_{w}-2 h_{y}\right)}$

Tal fator de ajuste foi obtido assumindo-se que a média das tensões no enrijecedores é a tensão no centróide do conjunto mesa/enrijecedor.

As análises foram feitas usando o programa THIN-WALL sem os ajustes das tensões na seção para se obter as tensões devidas à flambagem por distorção "reais". A diferença média foi de $3 \%$. 
Tabela 2.2 -Comparação entre tensões ajustadas provenientes da flambagem por distorção e o programa computacional THIN-WALL

\begin{tabular}{|c|c|c|c|c|c|c|c|c|}
\hline$b_{f}$ & $b_{w}$ & $\bar{D}$ & $\mathrm{t}$ & $\begin{array}{c}\text { Método da } \\
\text { flexão LAU } \\
\& \\
\text { HANCOCK }\end{array}$ & $\begin{array}{l}\text { Fator } \\
\text { de } \\
\text { ajuste }\end{array}$ & $\begin{array}{c}\text { Valor de } \\
\text { LAU \& } \\
\text { HANCOCK } \\
\text { ajustado }\end{array}$ & $\begin{array}{c}\text { Faixas finitas } \\
\text { sem } \\
\text { travamento } \\
\text { lateral } \\
\text { (tensões "reais") }\end{array}$ & $\begin{array}{c}\text { Diferença } \\
(\%)\end{array}$ \\
\hline 50 & 100 & 10 & 1,5 & 513 & 1,036 & 532 & 540 & 2 \\
\hline 50 & 100 & 15 & 1,5 & 643 & 1,082 & 696 & 797 & 13 \\
\hline 75 & 100 & 10 & 1,5 & 278 & 1,026 & 285 & 275 & -4 \\
\hline 75 & 100 & 15 & 1,5 & 392 & 1,060 & 415 & 420 & 1 \\
\hline 75 & 100 & 20 & 1,5 & 465 & 1,106 & 514 & 548 & 6 \\
\hline 50 & 200 & 10 & 1,5 & 348 & 1,018 & 355 & 351 & -1 \\
\hline 50 & 200 & 15 & 1,5 & 450 & 1,039 & 468 & 476 & 2 \\
\hline 75 & 200 & 10 & 1,5 & 204 & 1,013 & 206 & 206 & 0 \\
\hline 75 & 200 & 15 & 1,5 & 290 & 1,029 & 298 & 306 & 2 \\
\hline 75 & 200 & 20 & 1,5 & 347 & 1,050 & 364 & 397 & 8 \\
\hline & & & & & & \multicolumn{2}{|c|}{ Diferenca média } & $3 \%$ \\
\hline
\end{tabular}

\subsection{PERFIS DO TIPO U e $Z$ ENRIJECIDO COM ENRIJECEDOR DE BORDA ADICIONAL}

Segundo BAMBACH (1998), na tentativa de prevenir a flambagem por distorção, algumas empresas tiveram a idéia de construir perfis do tipo $U$ e $Z$ enrijecido com enrijecedor de borda adicional. A seguir apresenta-se um exemplo de configuração deformada para barras submetidas à flexão (Fig. 2.16).
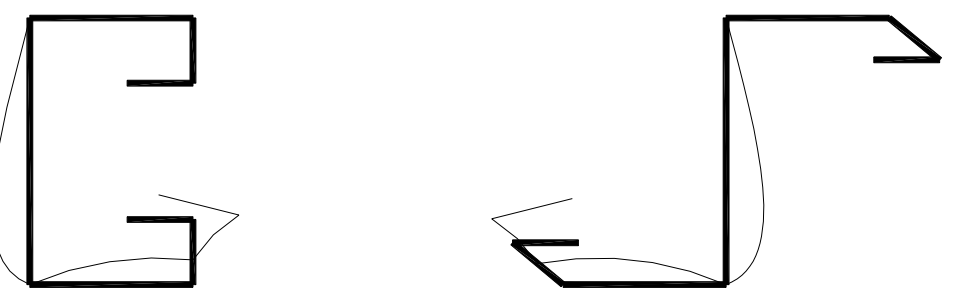

Figura 2.16 - Perfis do tipo U e Z enrijecido com enrijecedor de borda adicional:

Flambagem por distorção do conjunto mesa-enrijecedor 
Para estes tipos de perfis, as seções com enrijecedores adicionais curtos (com comprimento inferior a $20 \mathrm{~mm}$ ) normalmente apresentam o gráfico de tensão de referência versus comprimento de meia onda do modo convencional, apresentando os três pontos de mínimo.

Estes pontos podem ser denominados por A, B e C respectivamente da esquerda para a direita. $\mathrm{O}$ ponto $\mathrm{A}$ corresponde à flambagem local, o ponto $\mathrm{B}$ à flambagem por distorção e o ponto $C$ à flambagem lateral com torção (Fig. 2.17).

Por outro lado, nas seções com enrijecedores adicionais longos (com comprimento igual ou superior a $20 \mathrm{~mm}$ ) um modo de flambagem adicional é verificado, geralmente localizado no gráfico como um ponto $D$ de mínimo entre os correspondentes à flambagem local e por distorção (Fig. 2.18). Este "novo" modo causa a flambagem por distorção do enrijecedor, e pode ser chamado de flambagem por distorção do conjunto mesa-enrijecedor. Este tipo de distorção tem como conseqüência a rotação do enrijecedor comprimido em torno da conexão mesa-enrijecedor.

Cabe salientar que as duas figuras apresentadas (Figuras 2.17 e 2.18) não se referem somente a seções do tipo $U$ com enrijecedor de borda adicional, mas também a seções do tipo Z com enrijecedor de borda adicional.

Para propósitos práticos esse modo de flambagem por distorção não se apresenta usualmente como crítico, pois elevadas relações $D_{a} / b_{w}$ seriam necessárias para tornar tal modo crítico, sendo $D_{a}$ o comprimento do enrijecedor adicional. 


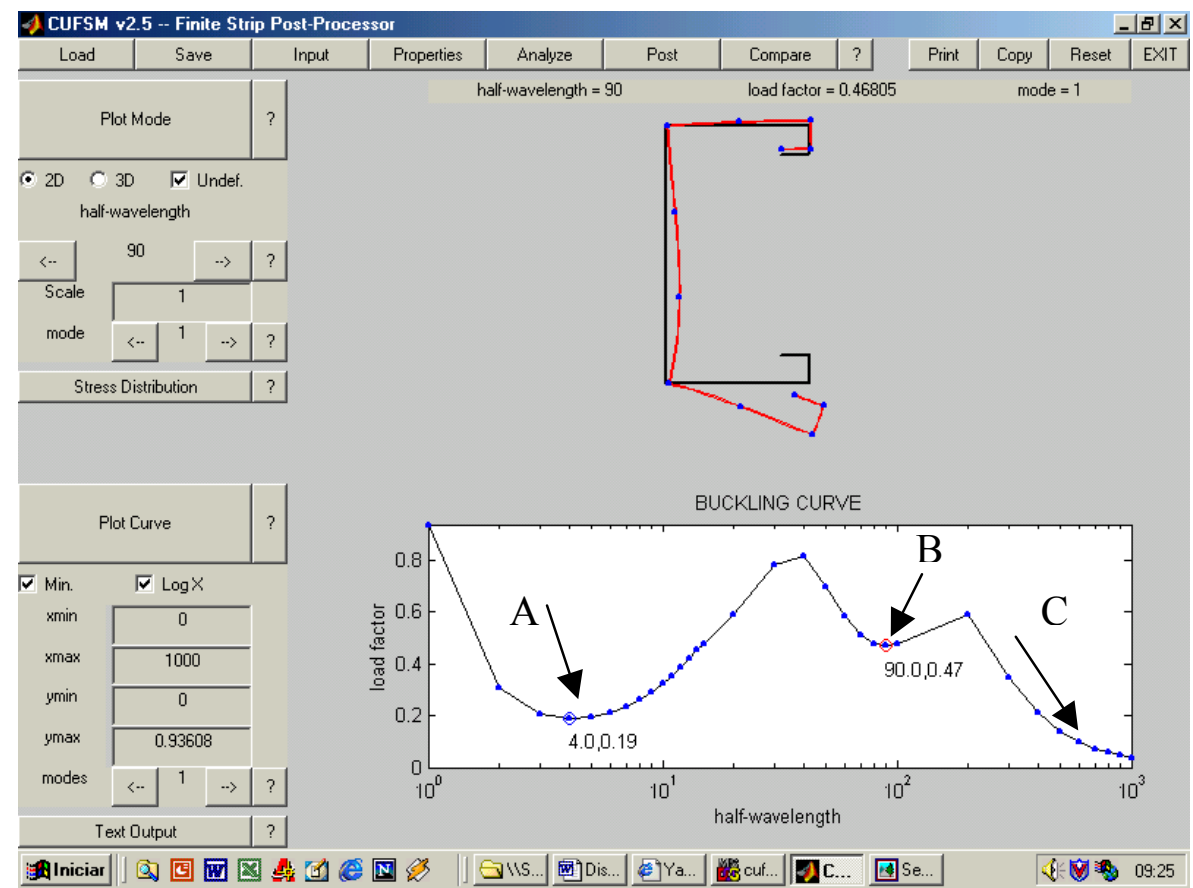

Figura 2.17 - Análise de instabilidade de perfil com enrijecedor de borda adicional via faixas finitas

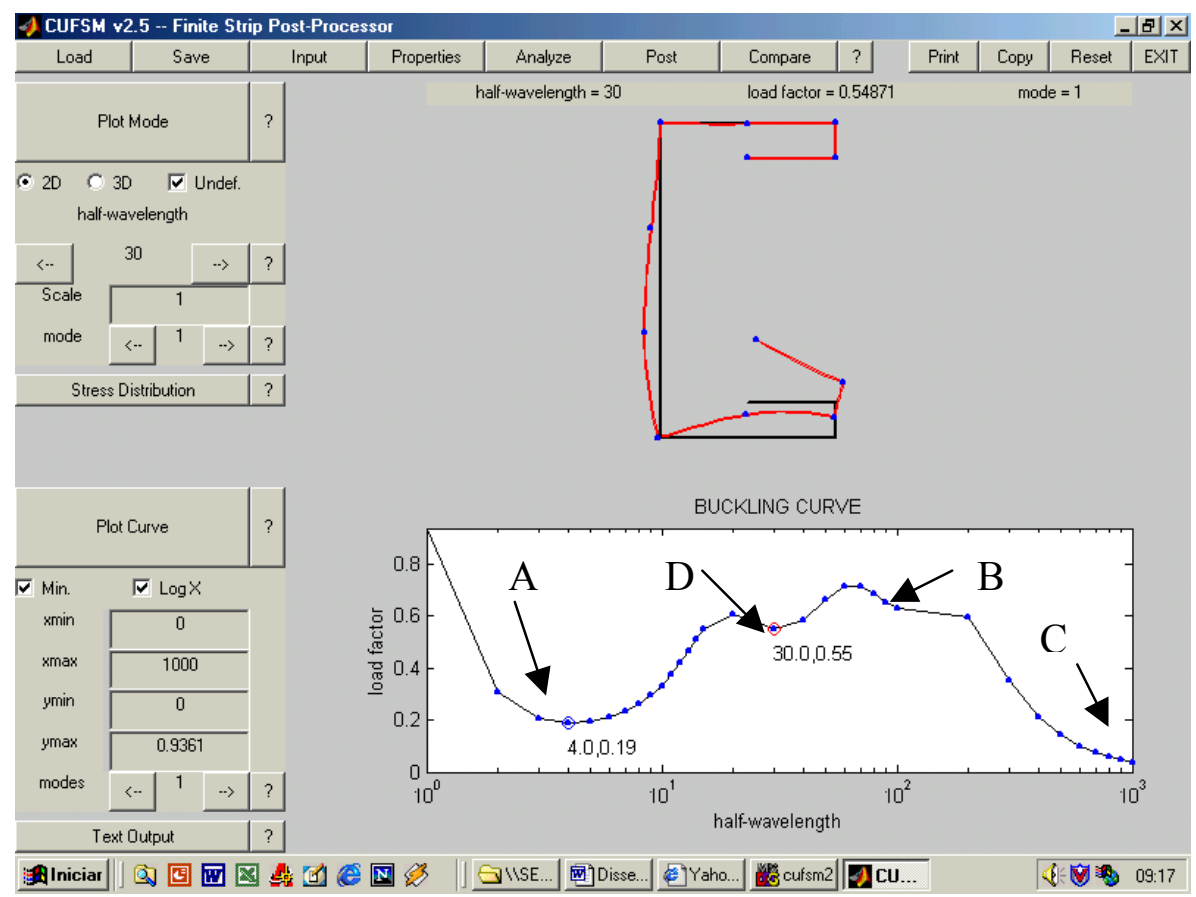

Figura 2.18 - Análise de instabilidade de perfil com enrijecedor de borda adicional via faixas finitas 


\subsection{INTERAÇÃO ENTRE MODOS DE FLAMBAGEM}

A interação entre modos de flambagem é um fenômeno muito comum em perfis formados por seções abertas de paredes delgadas, sendo verificada entre os modos local e global, e resultando em comportamento não-linear com possível redução da resistência da barra. Este fenômeno é chamado "erosão de resistência", e promoveu o abandono do conceito de resistência que simplesmente igualava as resistências devido aos modos local e global para o dimensionamento estrutural, o que seria aceitável em caso de comportamento linear.

Nos perfis do tipo $U$ enrijecido, utilizados como terças, o modo crítico pode passar da flambagem lateral com torção para o modo distorcional, quando, por exemplo, linhas de corrente entre as extremidades da mesma são adicionadas. Entretanto, cabe salientar que outros fatores também podem influir nesta mudança de comportamento.

Os métodos aproximados disponíveis atualmente nas principais normas internacionais consideram a interação não-linear entre o modo de flambagem local e global. Entretanto, a interação entre o modo local e distorcional não é considerada.

DUBINA et al. (1995, 2002) e DUBINA (2001) apresentam o ECBL (Erosion of Critical Bifurcation Load). Segundo os autores, devido às imperfeições iniciais e ao elevado valor da esbeltez dos elementos constituintes das seções transversais dos perfis de aço formados a frio, as interações entre os modos de instabilidade sempre ocorrem (local, distorcional, e global). Portanto, apresentam um procedimento para avaliar a interação entre os modos local e global, e também apresentam a continuação do estudo, porém considerando a interação entre o modo distorcional e global.

Por meio da expressão de Ayrton-Perry, adotada pelo EUROCODE 3 parte 1.3, para as curvas de flambagem relativas aos perfis laminados, aliada à introdução do coeficiente de erosão, $\psi$ (depende da flambagem local ou por distorção), e utilizando-se um novo coeficiente de imperfeição, $\alpha$, tais curvas podem ser utilizadas para se avaliar a interação entre os modos de flambagem local global e entre os modos distorcional - global.

Entende-se que este procedimento parece ser interessante no sentido de ser uma ferramenta útil e relativamente simples para se avaliar a interação entre os modos de flambagem. 
Cabe salientar que se o procedimento do EUROCODE 3 - parte 1.3, que somente aborda a interação no caso da flambagem local - global, for utilizado para a avaliação da interação da flambagem distorcional - global, os resultados serão muito conservativos. Neste caso, o ECBL pode ser uma alternativa interessante.

Apresenta-se a seguir um exemplo de interação entre o modo local e o distorcional (Figura 2.19).

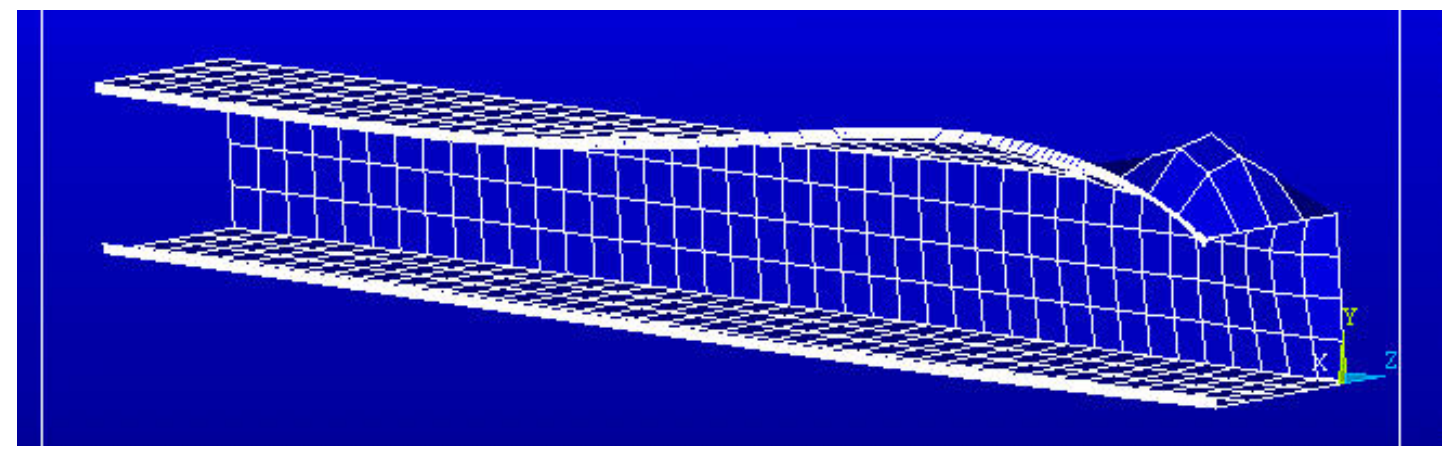

Figura 2.19 - Exemplo de interação: modo local e modo distorcional

\subsection{CONDIÇÕES DE EXTREMIDADE DAS BARRAS (EMPENAMENTO)}

Segundo KESTI (1999) as condições de extremidade dos perfis analisados exercem influência significativa na resistência à flambagem por distorção e também na capacidade resistente da barra à compressão, quando referente ao caso de colunas curtas.

Com relação às condições de extremidade dos elementos, segundo BATISTA et al. (2002), têm-se as seguintes observações:

Do ponto de vista de projeto, devem ser consideradas as condições de empenamento reais das extremidades, pois a flambagem pode ser afetada pelo empenamento. Se forem consideradas somente condições de empenamento livre, a análise pode ser muito conservativa, pois as tensões convencionais de flambagem elástica por distorção para o caso de empenamento impedido são geralmente superiores às referentes ao caso de empenamento livre. Percebe-se também que a diferença entre a condição de empenamento impedido (tensões de flambagem mais elevadas) e a condição de empenamento livre vai diminuindo 
conforme se aumenta o valor do comprimento de meia onda (que é usualmente relacionado ao comprimento do perfil analisado);

Quando a condição de empenamento impedido é considerada, os resultados referentes ao método dos elementos finitos e faixas finitas não se assemelham. As tensões de flambagem referentes ao modo distorcional obtidos pelo método das faixas finitas são aproximadamente $10 \%$ superiores às obtidas pelo método dos elementos finitos;

- Com relação ao modo global, também existem discrepâncias entre os resultados provenientes do método dos elementos finitos e das faixas finitas. $O$ método dos elementos finitos permite um maior refinamento na discretização da barra, quando comparado com o método das faixas finitas. Portanto, é de se esperar que os resultados referentes ao método das faixas finitas é que provavelmente não sejam confiáveis para o caso particular de colunas longas do tipo rack com a condição de empenamento impedido;

- Assim, recomenda-se que a força crítica de flambagem relativa ao modo global não seja calculada com base no método das faixas finitas, permitindo resultados conservativos. Logo, o método das faixas finitas deve se utilizado somente para cálculo relativo aos modos local e distorcional;

\subsection{PROCEDIMENTOS NORMATIVOS}

\subsubsection{AISI}

Um dos primeiros modelos que abordam o fenômeno da flambagem por distorção foi o proposto por DOUTY (1962), já explicado no presente trabalho, e posteriormente incorporado à norma do AISI. Este modelo, além de tratar de um caso particular, traz uma série de simplificações, o que tem limitado sua aplicação.

O AISI não aborda, entretanto, os casos mais comuns e gerais referentes ao fenômeno da flambagem por distorção, e nem mesmo a última edição de 2001 o faz. Entretanto, esta última edição já faz menção à possibilidade de se utilizar procedimentos numéricos para a análise do fenômeno (como por exemplo o programa computacional CUFSM, que será explicado adiante), mas ainda não incorporou o método direto de resistência, proposto SCHAFER \& PEKÖZ (1998). 
YU (2000) justifica a atual "omissão" de uma abordagem mais explícita do fenômeno por parte da norma do AISI, uma vez que a flambagem local da mesa de perfis com enrijecedores de borda é considerada por meio de valores reduzidos dos coeficientes de flambagem local $k$, portanto $k \leq 4$, considerando assim a "eficiência" estrutural dos enrijecedores de borda. Com isso, a dispensa da verificação da flambagem por distorção fica compensada. Hancock, citado por YU (2000), admite como razoável tal justificativa, porém alerta que esse procedimento é contrário à segurança para aços de elevada resistência mecânica.

\subsubsection{EUROCODE $3-1.3$}

O EUROCODE 3 - parte 1.3 aborda a flambagem por distorção, porém não apresenta um modelo a ser empregado nesse caso para avaliar o fenômeno, enfatizando que para elementos com enrijecedores intermediários ou de borda (por exemplo, perfis do tipo $U$ enrijecido) não são necessários maiores cuidados para com o fenômeno da flambagem por distorção se a área efetiva do enrijecedor for reduzida, como especificado na própria norma em questão.

Abrange as estruturas leves de aço formadas a frio, aplicando-se às barras, chapas e placas, sendo suas limitações, a menos que ensaios sejam feitos para validar espessuras maiores:

\footnotetext{
- $\quad$ barras: $\mathbf{1 , 0} \leq \mathbf{t} \leq \mathbf{8 , 0 m m}$

- $\quad$ chapas: $0,5 \leq \mathrm{t} \leq \mathbf{4 , 0 m m}$
}

Também fornece algumas indicações sobre o cálculo das larguras efetivas dos elementos constituintes das chapas, sendo que depois tais elementos contribuirão para a formação da seção efetiva como um todo. Entretanto, os elementos não sofrem flambagem separadamente, mas interagem entre si, fato que não é considerado. 


\subsubsection{MODELO AUSTRALIANO}

O método proposto por Hancock, e adotado pela norma brasileira NBR 14762:2001, tem por base o seguinte modelo físico do fenômeno:

a) A flambagem por distorção é associada à flambagem por flexo-torção da mesa da seção;

b) A mesa está conectada continuamente no elemento vizinho (alma), através de um apoio de mola elástica rotacional, de rigidez $k_{\phi}$;

c) Supõe-se a mesa deslocável no apoio junto ao elemento de vizinho (alma), assumindo-se $k_{x}=0$;

d) O modo de flexo-torção da mesa prevê os efeitos da compressão excêntrica em relação ao centro de cisalhamento, com a resultante de compressão posicionada no centróide da mesa;

e) A constante de rigidez à rotação $k_{\phi}$ está associada à rigidez à flexão do elemento vizinho (alma) à mesa. Tal rigidez é ainda dependente do valor da tensão de compressão aplicada nesse elemento (Expressão 2.37);

Do ponto de vista prático, a formulação presente no modelo australiano leva a cálculos demasiados para a determinação da tensão convencional de flambagem elástica por distorção $\sigma_{\text {dist }}$, resultando em um procedimento demorado para cálculos manuais. Diversos autores têm apresentado procedimentos simplificados tendo por base o modelo de Hancock, a maioria propondo expressões semiempíricas (Figura 2.20). 


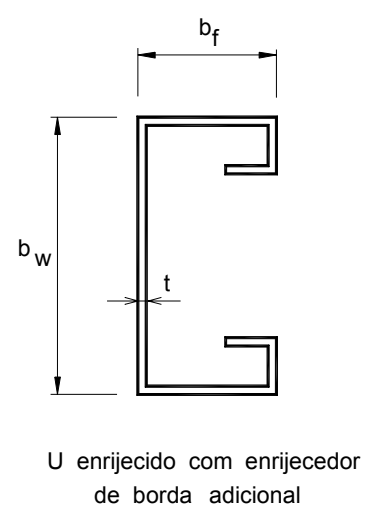

de borda adicional
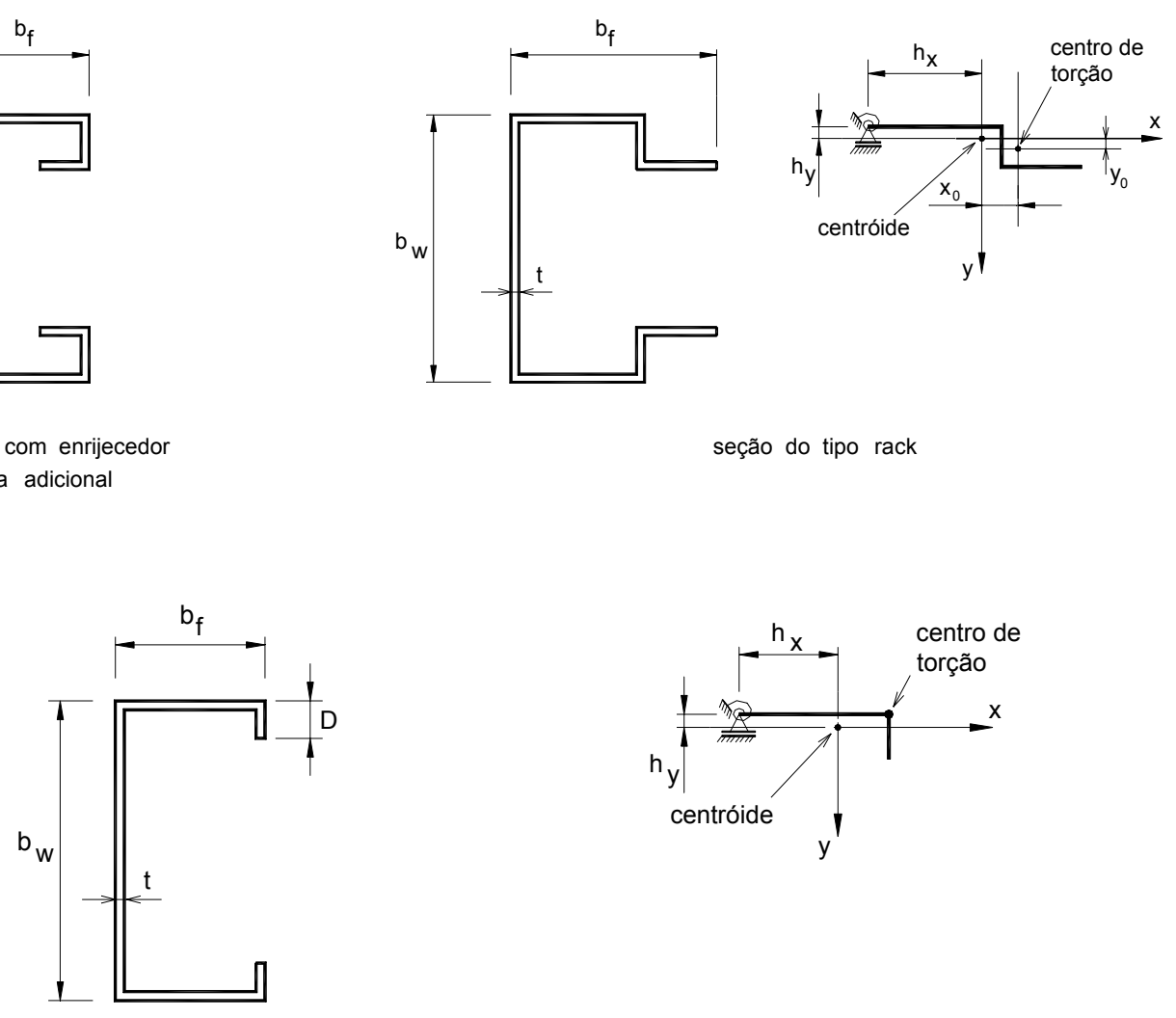

Seção tipo U enrijecido

Figura 2.20 - Modelo da norma australiana para flambagem por distorção

[NBR 14762:2001]

\subsubsection{NORMA AUSTRALIANA AS/NZS 4600:1996}

A norma australiana prevê o uso de aços com tensão de escoamento acima de $550 \mathrm{MPa}$ (elevada resistência mecânica), e apresenta um modelo simplificado que trata da flambagem por distorção, proposto por $\operatorname{HANCOCK}(1978,1987,1997)$, que em princípio é aplicável a perfis constituídos por qualquer tipo de enrijecedor de borda. Nesse modelo, também proposto pela nova norma brasileira em seu anexo $D$, é analisada a estabilidade elástica do conjunto formado pela mesa comprimida e seu enrijecedor de borda, admitindo vinculações elásticas com a alma sujeita à compressão uniforme ou a gradiente de tensões, portanto aplicável às barras submetidas à compressão centrada e à flexão (Figuras 2.9 e 2.10). 
Para a compressão centrada e flexão, as expressões que constam da NBR 14762:2001 são idênticas às da AS/NZS 4600:1996, apenas com alteração de formato e simbologia, o que também é válido para as expressões 2.43 e 2.44 apresentadas anteriormente. Em 1996, Hancock propôs uma curva de flambagem para a flexão, e que foi adotada pela norma AS/NZS 4600:1996. O próprio Hancock a modificou em 1997. Existem outras modificações apresentadas, como LAU \& HANCOCK $(1987,1990)$ apud ROGERS (1997), explicada a seguir, onde o ponto de inflexão da curva é diferente das outras duas curvas (Figura 2.21) - caso em que ocorre rotação e translação da mesa comprimida. Existe também um caso em que somente ocorre rotação da mesa comprimida, e que não é abordado pela norma NBR 14762:21001, portanto, não será enfatizado.

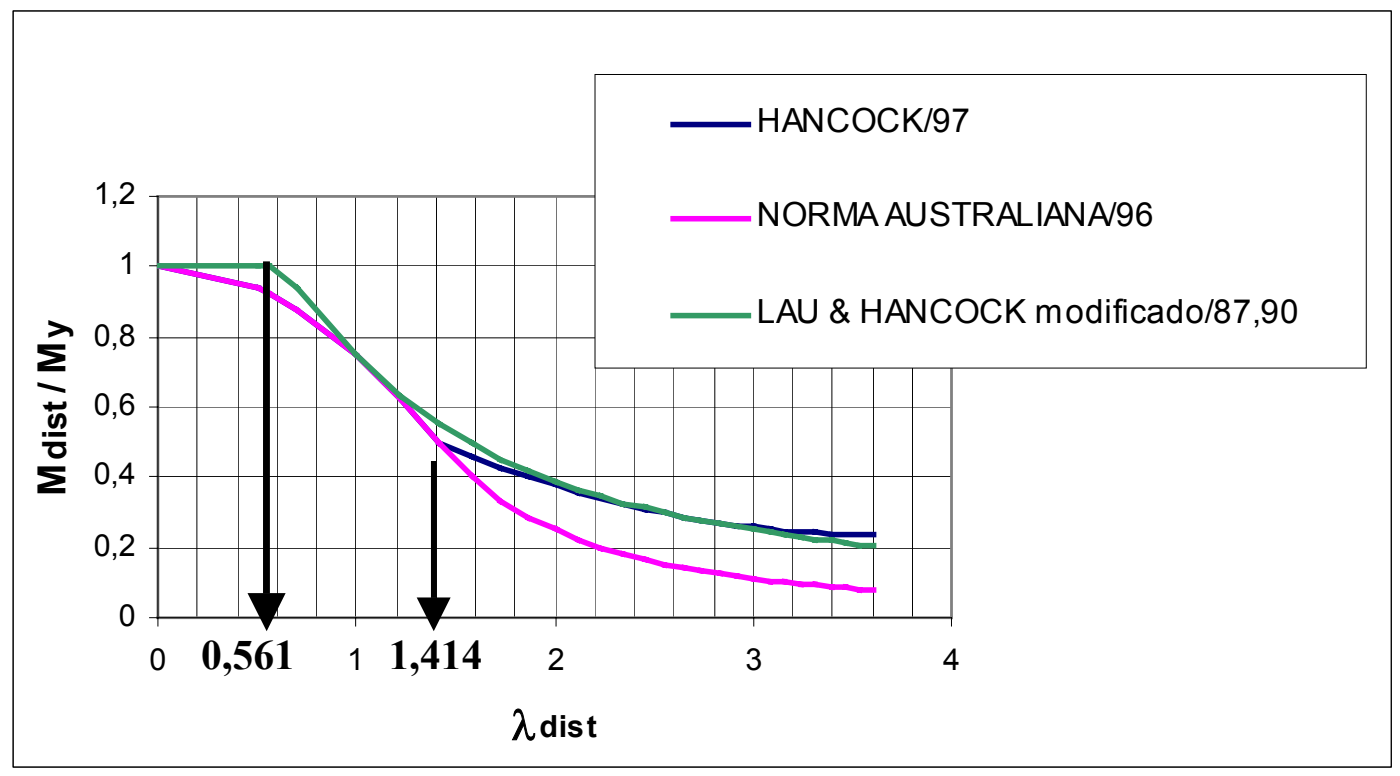

Fig. 2.21 - Curvas de flambagem por distorção na flexão: admitindo rotação e translação da mesa comprimida

\section{FLEXÃO: OUTRAS EXPRESSÕES}

Para o caso da flexão, existe uma hipótese que não é abordada pela norma brasileira NBR 14762:2001, pois se entendeu que não era crítica. Entretanto, será apresentada a seguir, evidentemente com a simbologia adaptada para a NBR 14762:2001. 
- Quando a flambagem por distorção envolve a rotação do conjunto mesa/enrijecedor em relação à conexão mesa/alma nas seções do tipo $U$ ou $Z$ enrijecido:

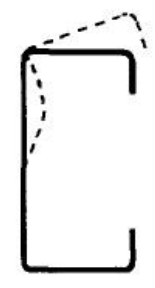

Para $\lambda_{\text {dist }} \leq 0,674 \Rightarrow M_{\text {dist }}=M_{y}$

Para $\lambda_{\text {dist }}>0,674 \Rightarrow M_{\text {dist }}=\frac{M_{y}}{\lambda_{d}}\left(1-\frac{0,22}{\lambda_{d}}\right)$

Com relação a este item da norma australiana AS/NZS 4600:1996, pode-se observar que as expressões de HANCOCK (1997), da AS/NZS 4600:1996 e a de LAU \& HANCOCK $(1987,1990)$ apud ROGERS (1997) são as mesmas (Figura 2.22).

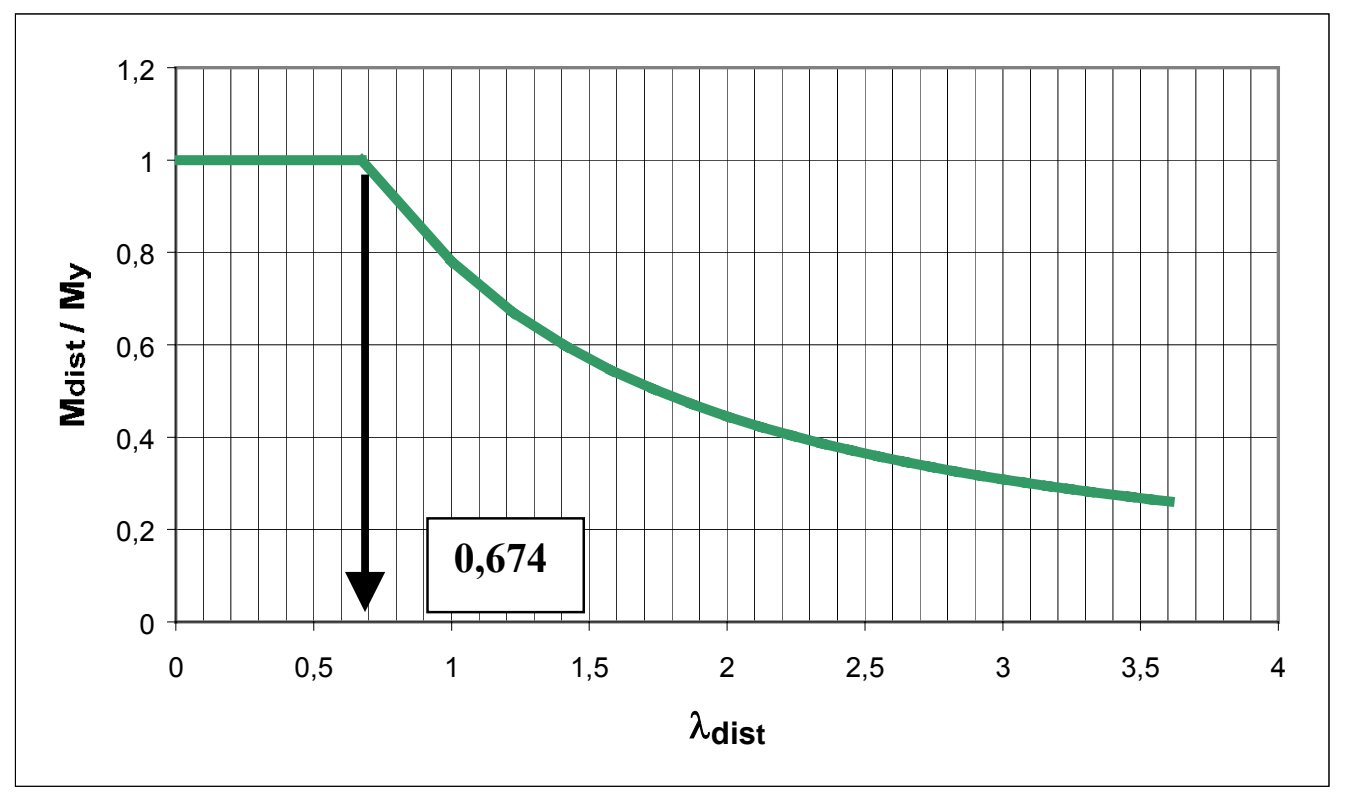

Figura 2.22 - Curva de flambagem por distorção para flexão - quando a flambagem por distorção envolve a rotação do conjunto mesa/enrijecedor em relação à junção mesa/alma nas seções do tipo $U$ ou $Z$ enrijecidos 
Para explicar duas das curvas da Figura 2.21, tem-se que:

A curva para a flexão, proposta por LAU \& HANCOCK $(1987,1990)$ apud ROGERS (1997), é uma modificação da curva para a compressão, proposta pelos mesmos autores. Possui data posterior à publicação da norma australiana, que é de 1996, e faz menção à uma expressão diferente para o cálculo de $M_{\text {dist }}$ (Expressões 2.64 e 2.65$)$.

Para $\quad \lambda_{\text {dist }}<0,56 \Rightarrow M_{\text {dist }}=M_{y}$

Para

$$
\lambda_{\text {dist }} \geq 0,56 \Rightarrow M_{\text {dist }}=M_{y}\left(\frac{1}{\lambda_{\text {dist }}{ }^{2}}\right)^{p, 6}\left(1-0,25\left(\frac{1}{\lambda_{\text {dist }}{ }^{2}}\right)^{p, 6}\right)
$$

HANCOCK (1997), por outro lado, como já citado anteriormente, descreve:

Para $\lambda_{d}<1,414 \Rightarrow M_{\text {dist }}=M_{y}\left(1-\frac{\lambda_{\text {dist }}^{2}}{4}\right)$

Para $\lambda_{d} \geq 1,414 \Rightarrow M_{\text {dist }}=M_{y}\left(0,055\left(\lambda_{\text {dist }}-3,6\right)^{2}+0,237\right)$

OBS.: Neste caso, a atualização proposta por HANCOCK (1997), em relação à proposta pelo mesmo e que consta da norma australiana AS/NZS 4600:1996, só ocorre para um dos trechos da curva (Expressão 2.67). 


\subsubsection{NORMA BRASILEIRA NBR 14762:2001}

É baseada na norma australiana AS/NZS 4600:1996.

Com o auxílio de uma análise via método das faixas finitas (análise elástica), foram elaboradas tabelas de uso simples para, em função das dimensões da seção transversal do perfil, poder dispensar o cálculo da flambagem por distorção, constatando que tal modo não é crítico. Tais tabelas foram inseridas na NBR 14762:2001. Assim, torna-se possível definir, a priori, as dimensões da seção de maneira que o modo distorcional não seja dominante.

Estas tabelas cobrem os casos dos perfis do tipo $U$ enrijecido, na compressão centrada, e perfis do tipo $U$ enrijecido e $Z$ enrijecido, na flexão, respeitando relações $b_{f} / b_{w}$. Não foram consideradas na elaboração das mesmas as curvas de correção para os trechos inelásticos, usadas no corpo da norma para se obter os valores da força normal de compressão resistente de cálculo e do momento fletor resistente de cálculo. Entretanto, é importante registrar que esse procedimento já se mostra como satisfatório para a identificação do modo crítico de perfis $U$ enrijecido e $Z$ enrijecido. Tais tabelas estão apresentadas a seguir (Tabelas 2.3 e 2.4$)$.

Tabela 2.3 - Valores mínimos da relação $D / b_{w}$ de seções do tipo $U$ enrijecido submetidas à compressão centrada para dispensar a verificação da flambagem por distorção

\begin{tabular}{|c|c|c|c|c|c|}
\hline & \multicolumn{5}{|c|}{$\mathbf{b}_{\mathbf{w}} / \mathbf{t}$} \\
\cline { 2 - 6 } $\mathbf{b}_{\mathbf{f}} / \mathbf{b}_{\mathbf{w}}$ & $\mathbf{2 5 0}$ & $\mathbf{2 0 0}$ & $\mathbf{1 2 5}$ & $\mathbf{1 0 0}$ & $\mathbf{5 0}$ \\
\hline $\mathbf{0 , 4}$ & 0,02 & 0,03 & 0,04 & 0,04 & 0,08 \\
\hline $\mathbf{0 , 6}$ & 0,03 & 0,04 & 0,06 & 0,06 & 0,15 \\
\hline $\mathbf{0 , 8}$ & 0,05 & 0,06 & 0,08 & 0,10 & 0,22 \\
\hline $\mathbf{1 , 0}$ & 0,06 & 0,07 & 0,10 & 0,12 & 0,27 \\
\hline $\mathbf{1 , 2}$ & 0,06 & 0,07 & 0,12 & 0,15 & 0,27 \\
\hline $\mathbf{1 , 4}$ & 0,06 & 0,08 & 0,12 & 0,15 & 0,27 \\
\hline $\mathbf{1 , 6}$ & 0,07 & 0,08 & 0,12 & 0,15 & 0,27 \\
\hline $\mathbf{1 , 8}$ & 0,07 & 0,08 & 0,12 & 0,15 & 0,27 \\
\hline $\mathbf{2 , 0}$ & 0,07 & 0,08 & 0,12 & 0,15 & 0,27 \\
\hline \multicolumn{7}{|c|}{ Para valores intermediários, interpolar linearmente } \\
\hline
\end{tabular}


Tabela 2.4 - Valores mínimos da relação $D / b_{w}$ de seções do tipo $U$ enrijecido e $Z$ enrijecido submetidas à flexão para dispensar a verificação da flambagem por distorção

\begin{tabular}{|c|c|c|c|c|c|}
\hline \multirow[b]{2}{*}{$b_{f} / b_{w}$} & \multicolumn{5}{|c|}{$b_{w} / t$} \\
\hline & 250 & 200 & 125 & 100 & 50 \\
\hline 0,4 & 0,05 & $\overline{0,06}$ & 0,10 & 0,12 & 0,25 \\
\hline 0,6 & 0,05 & 0,06 & 0,10 & 0,12 & 0,25 \\
\hline 0,8 & 0,05 & 0,06 & 0,09 & 0,12 & 0,22 \\
\hline 1,0 & 0,05 & 0,06 & 0,09 & 0,11 & 0,22 \\
\hline 1,2 & 0,05 & 0,06 & 0,09 & 0,11 & 0,20 \\
\hline 1,4 & 0,05 & 0,06 & 0,09 & 0,10 & 0,20 \\
\hline 1,6 & 0,05 & 0,06 & 0,09 & 0,10 & 0,20 \\
\hline 1,8 & 0,05 & 0,06 & 0,09 & 0,10 & 0,19 \\
\hline 2,0 & 0,05 & 0,06 & 0,09 & 0,10 & 0,19 \\
\hline
\end{tabular}

OBS: Para as barras com a mesa tracionada conectada a um painel e a mesa comprimida livre (terças com telhas de aço parafusadas e sujeitas à ação de vento de sucção, por exemplo), o momento fletor resistente de cálculo, considerando o efeito da referida contenção lateral, pode ser calculado conforme o anexo F da NBR 14762:2001.

Pode-se ressaltar também que após o cálculo da tensão convencional de flambagem elástica $\sigma_{\text {dist, }}$, pode-se dirigir ao corpo da norma para o cálculo da força normal de compressão resistente de cálculo $\mathrm{N}_{\mathrm{c}, \mathrm{Rd}}$ ou para o cálculo do momento fletor resistente de cálculo $M_{R d}$, como descrito a seguir:

\section{COMPRESSÃO CENTRADA}

Para as barras com seção transversal aberta sujeitas a flambagem por distorção, a força normal de compressão resistente de cálculo $N_{c, R d}$ deve ser calculada pelas expressões seguintes: 
$\mathrm{N}_{\mathrm{c}, \mathrm{Rd}}=\mathrm{N}_{\mathrm{dist}} / \gamma \quad(\gamma=1,1)$

Onde:

$\mathrm{N}_{\text {dist }}$ é a força normal de flambagem por distorção, dada por:

$\mathrm{N}_{\text {dist }}=\mathrm{Af}_{\mathrm{y}}\left(1-0,25 \lambda_{\text {dist }}{ }^{2}\right) \quad$ para $\lambda_{\text {dist }}<1,414$

$\mathrm{N}_{\text {dist }}=\operatorname{Af}_{\mathrm{y}}\left\{0,055\left[\lambda_{\text {dist }}-3,6\right]^{2}+0,237\right\} \quad$ para $1,414 \leq \lambda_{\text {dist }} \leq 3,6$

A é área bruta da seção transversal da barra;

$\lambda_{\text {dist }}$ é o índice de esbeltez reduzido referente à flambagem por distorção, dado por:

$\lambda_{\text {dist }}=\left(\mathrm{f}_{\mathrm{y}} / \sigma_{\text {dist }}\right)^{0,5}$

$\sigma_{\text {dist }}$ é a tensão convencional de flambagem elástica por distorção, calculada pela teoria da estabilidade elástica, análise numérica ou conforme anexo D.

Portanto, pode-se concluir que as curvas de flambagem da AS/NZS 4600:1996 e da NBR 14762:2001 são exatamente as mesmas (Figura 2.23).

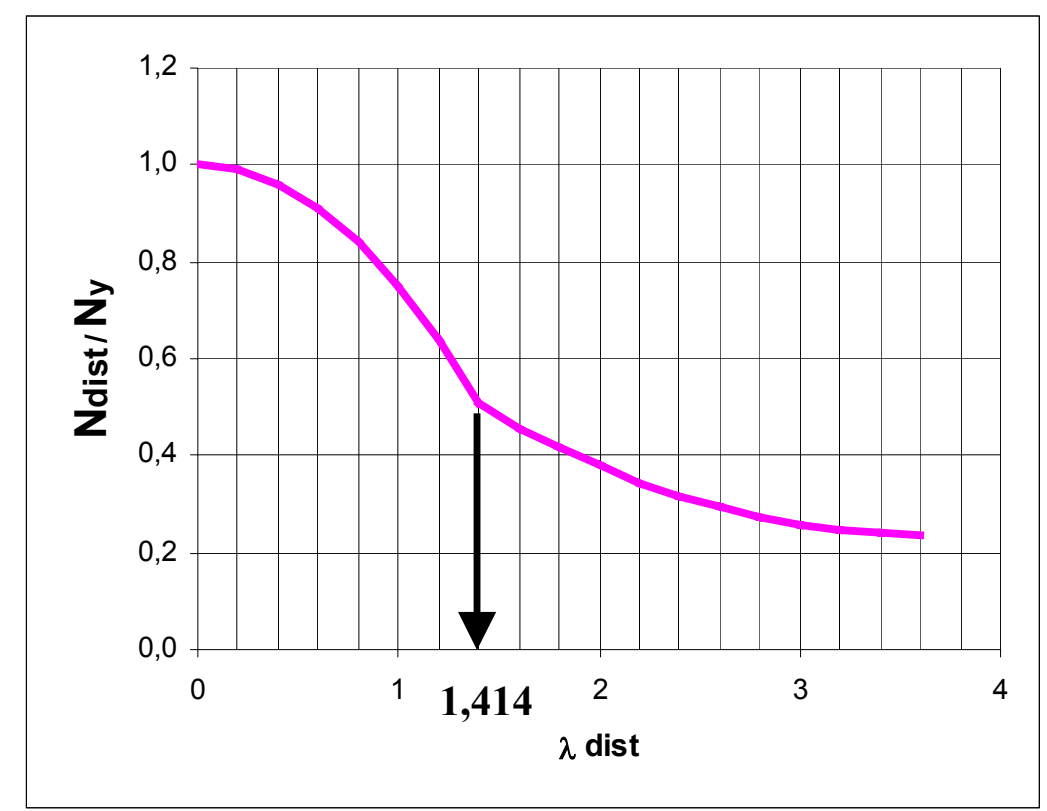

Figura 2.23 - Curva de resistência: flambagem por distorção para compressão centrada conforme AS/NZS 4600:1996 e NBR 14762:2001 


\section{FLEXÃO}

Para as barras com seção transversal aberta, sujeitas a flambagem por distorção, o momento fletor resistente de cálculo deve ser calculado pela seguinte expressão:

$\mathrm{M}_{\mathrm{Rd}}=\mathrm{M}_{\mathrm{dist}} / \gamma \quad(\gamma=1,1)$

Onde:

$M_{\text {dist }}$ é o momento fletor de flambagem por distorção, dado por:

$M_{\text {dist }}=W_{c} f_{y}\left(1-0,25 \lambda_{\text {dist }}{ }^{2}\right) \quad$ para $\lambda_{\text {dist }}<1,414$ :

$\mathrm{M}_{\text {dist }}=\mathrm{W}_{\mathrm{c}} \mathrm{f}_{\mathrm{y}} / \lambda_{\text {dist }}{ }^{2} \quad$ para $\lambda_{\text {dist }} \geq 1,414$ :

$W_{c}$ é o módulo de resistência elástico da seção bruta em relação à fibra comprimida;

$\lambda_{\text {dist }}$ e $\sigma_{\text {dist }}$ conforme explicado para a compressão centrada;

Portanto, pode-se concluir que as curvas de flambagem da AS/NZS 4600:1996 e da NBR 14762:2001 são exatamente as mesmas (Figura 2.24). 


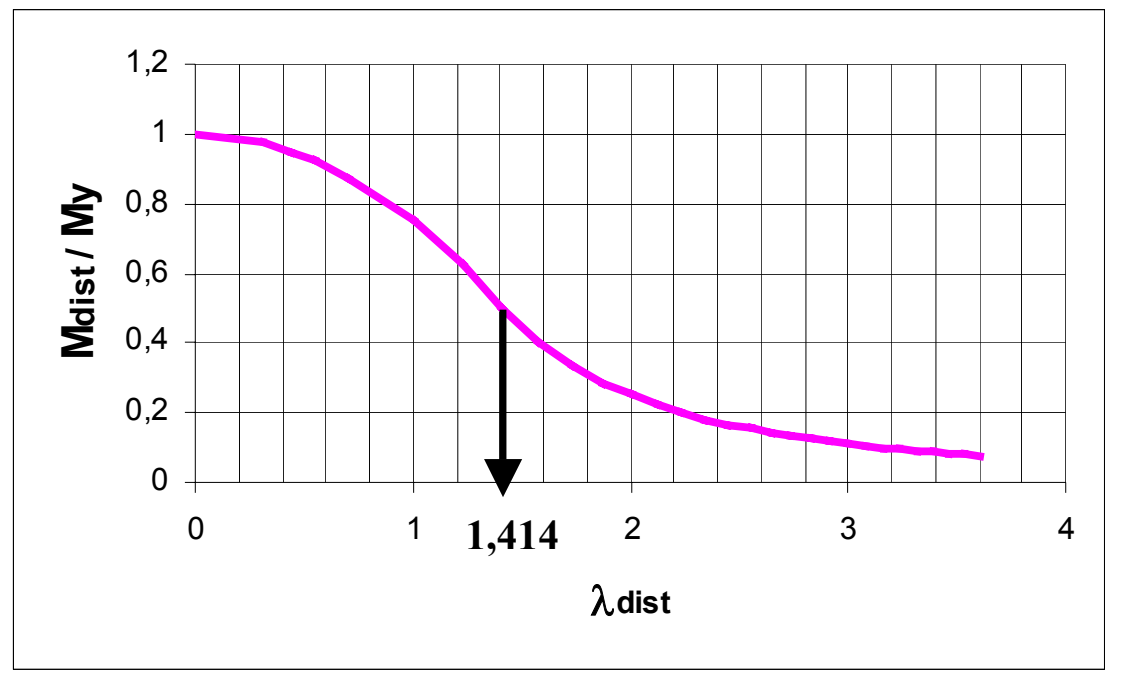

Figura 2.24 - Curva de resistência: flambagem por distorção para flexão conforme AS/NZS 4600:1996 e NBR 14762:2001

\subsubsection{MÉTODO DIRETO DE RESISTÊNCIA}

Tradicionalmente, o efeito da redução de resistência em perfis formados a frio de seção aberta e paredes delgadas, devido à flambagem local de seus elementos, é computada pelo método da largura efetiva dos elementos, o que leva ao cálculo de propriedades efetivas do perfil. Por tal cálculo ser trabalhoso, SCHAFER \& PEKÖZ (1998) propuseram o "método direto de resistência" como uma alternativa ao método da largura efetiva, para a determinação da resistência de perfis submetidos à compressão ou à flexão. Portanto, larguras e propriedades efetivas da seção não precisam ser calculadas, sendo que o método utiliza as propriedades da seção bruta. Além disso, permite que para o cálculo da flambagem local sejam consideradas as interações entre os elementos componentes da seção, sendo que são garantidas as condições de compatibilidade e equilíbrio entre os elementos. Portanto, a principal diferença entre os procedimentos usuais para análise da flambagem elástica e o método direto com relação à flambagem local é a consideração de interação entre os elementos componentes da seção.

O uso deste método requer a análise de estabilidade elástica da barra, que pode ser feito por diversos métodos. Por exemplo, podem ser utilizados métodos numéricos como faixas finitas, elementos finitos, elementos de contorno, diferenças 
finitas, teoria de viga generalizada, entre outros. Além destes, existem métodos manuais como o método dos elementos (que assume como tensão de flambagem da seção a menor tensão de flambagem entre os elementos componentes do mesmo) e o método de interação semi-empírico (que faz o cálculo entre pares de elementos componentes da seção). Após feita a análise elástica, os resultados são utilizados como dados de entrada para algumas curvas, no intuito de se prever a resistência da barra, sendo sua aplicação para a determinação do valor nominal da força normal de compressão resistente $N_{n}$ e para o valor nominal do momento fletor resistente $M_{n}$.

Para uma simples idéia comparativa para um perfil do tipo $U$ enrijecido submetido à compressão, segundo SCHAFER (2002), vale a pena comparar a força normal de compressão crítica calculada pelo método numérico das faixas finitas e pelos métodos manuais dos elementos e de interação semi-empírico. Tem-se a seguinte resposta referente à flambagem local:

- $\quad$ Método dos elementos: $\mathrm{N}_{\mathrm{cr} 1}=20,2 \mathrm{KN}$

- Método de interação semi-empírico: $\mathrm{N}_{\mathrm{cr} 2}=27,5 \mathrm{KN}$

- $\quad$ Método das faixas finitas: $\mathrm{N}_{\mathrm{cr} 3}=29,2 \mathrm{KN}$

Tal comparação é ínfima quanto à abrangência, mas fornece uma vaga idéia da variação dos resultados obtidos pelos diferentes métodos para uma análise simples.

Existem algumas seções que foram pré-qualificadas para o uso do método, e para as quais os fatores $\phi$ e $\Omega$ são especificados de acordo com critérios do método.

Portanto, para o uso do método é necessária a obtenção dos valores $\mathrm{N}_{\mathrm{crl}}$, $N_{\text {crd }}, N_{\text {cre }}, M_{\text {crl }}, M_{\text {crd }}, M_{\text {cre }}$, correspondentes à flambagem elástica, relativos aos modos local, distorcional e global (euler), referentes, respectivamente, à força normal e ao momento fletor. Os métodos utilizados para a obtenção destes valores devem considerar a seção como um todo, de modo que considerem a interação entre os elementos constituintes da seção transversal. 


\subsubsection{1 - BARRAS SUBMETIDAS À COMPRESSÃO}

O valor nominal da força normal de compressão resistente $\mathrm{N}_{\mathrm{n}}$ é o mínimo entre os valores de $N_{g}, N_{l}$ e $N_{\text {dist }}$, como a seguir:

\subsubsection{1 - Flambagem por flexão, torção ou flexo-torção}

O valor nominal da força normal de compressão resistente $\mathrm{N}_{\mathrm{g}}$, para flambagem por flexão, torção ou flexo-torção é:

$$
\begin{array}{ll}
N_{g}=\left(0,658^{\lambda_{c}^{2}}\right) N_{y} & \text { para } \lambda_{c} \leq 1,5 \\
N_{g}=\left(\frac{0,877}{\lambda_{c}^{2}}\right) N_{y} & \text { para } \lambda_{c}>1,5
\end{array}
$$

Onde:

$$
\lambda_{c}=\sqrt{\frac{N_{y}}{N_{c r e}}}
$$

$\mathrm{N}_{\mathrm{y}}=\mathrm{A}_{\mathrm{g}} \mathrm{f}_{\mathrm{y}}$

$\mathrm{N}_{\text {cre }}=$ valor mínimo da força relativa à flambagem crítica elástica entre a flexão, torção e flexo-torção

A seguir apresenta-se a curva acima descrita (Figura 2.25). 


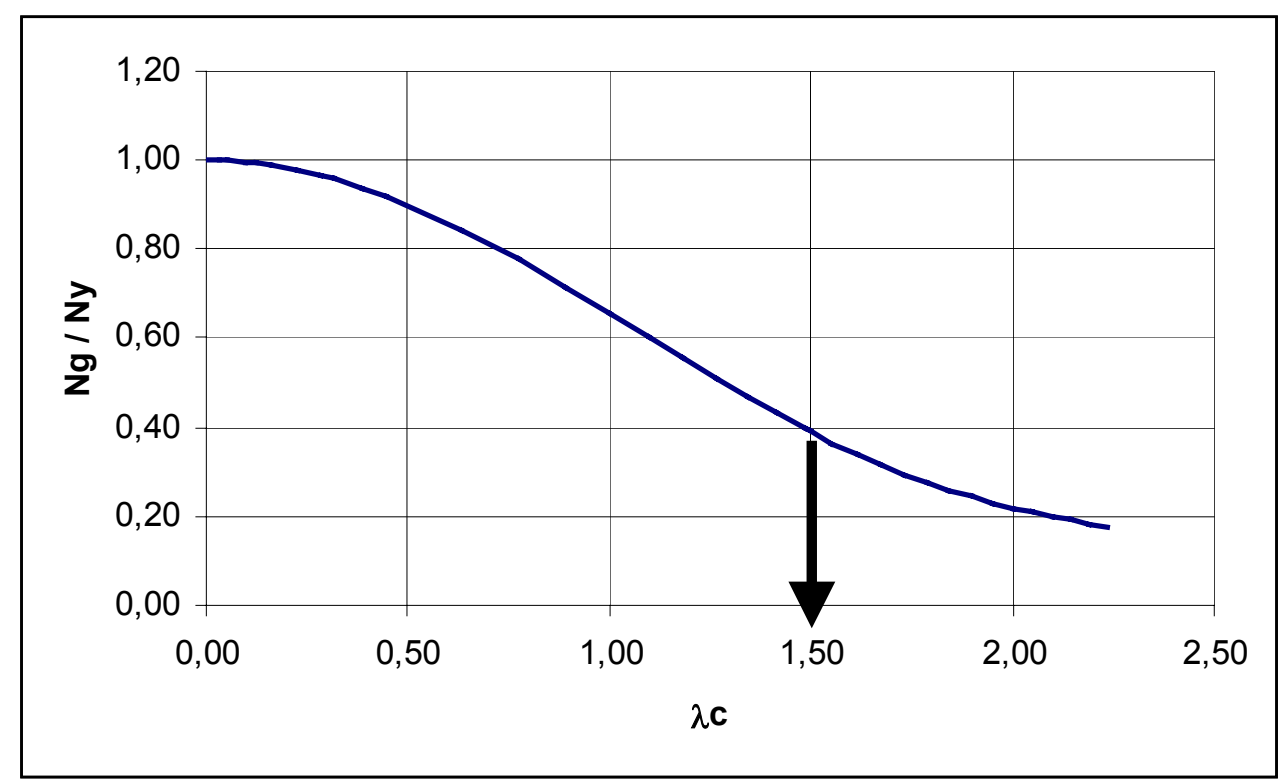

Figura 2.25 - Curva de flambagem: modo global

\subsubsection{2 - Flambagem local}

O valor nominal da força normal de compressão resistente $N_{l}$, para flambagem local é:

$N_{l}=N_{g} \quad$ para $\lambda_{1} \leq 0,776$

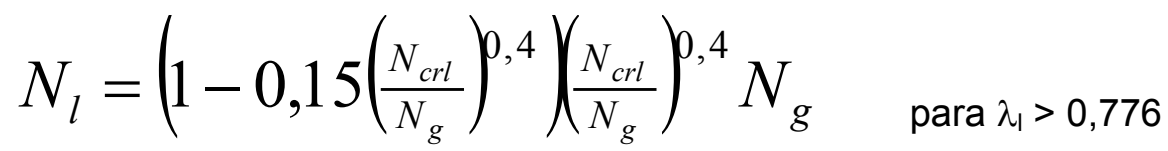

Onde:

$$
\lambda_{l}=\sqrt{\frac{N_{g}}{N_{c r l}}}
$$

$\mathrm{N}_{\mathrm{crl}}=$ valor da força relativa à flambagem crítica elástica local 
A seguir apresenta-se a curva acima descrita (Figura 2.26).

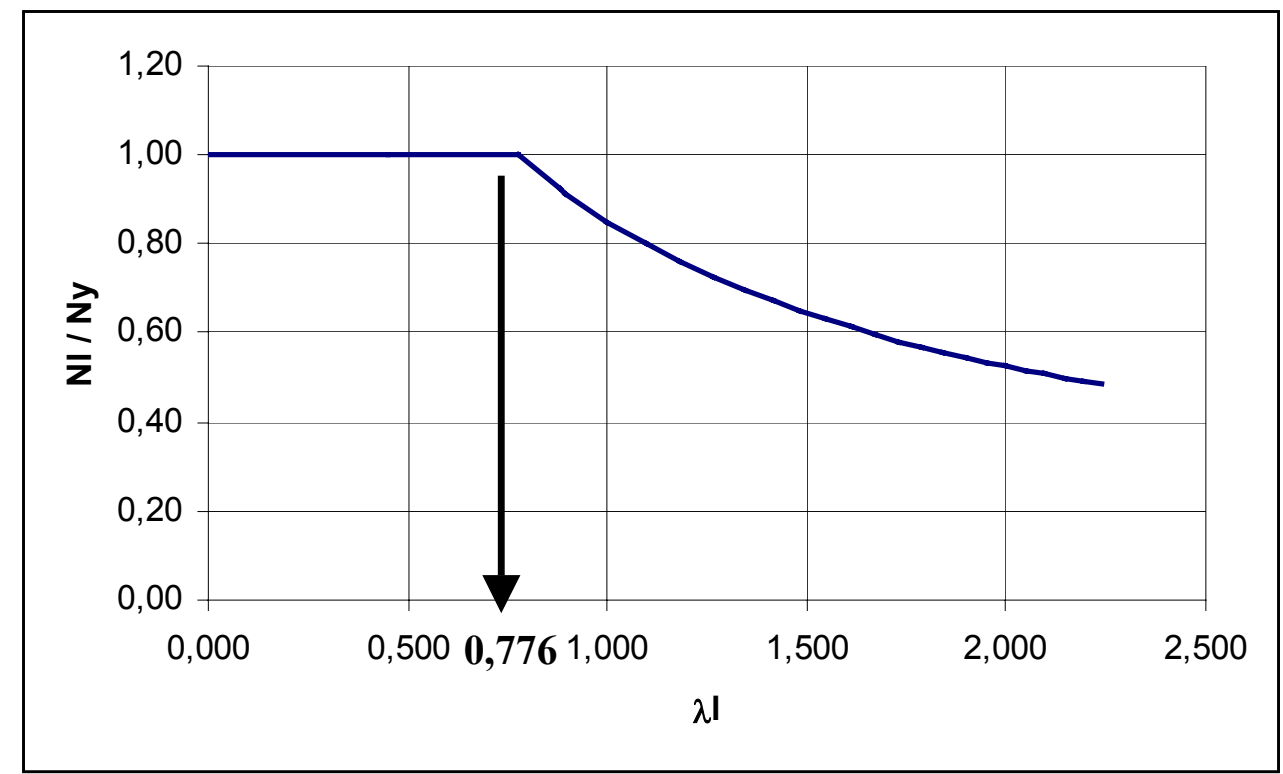

Figura 2.26 - Curva de flambagem: modo local

\subsubsection{3 - Flambagem por distorção}

O valor nominal da força normal de compressão resistente $N_{\text {dist, }}$ para flambagem por distorção é:

$$
\begin{array}{ll}
N_{\text {dist }}=N_{y} & \text { para } \lambda_{\text {dist }} \leq 0,561 \\
N_{\text {dist }}=\left(1-0,25\left(\frac{N_{c r d}}{N_{y}}\right)^{0,6}\left(\frac{N_{c r d}}{N_{y}}\right)^{0,6} N_{y} \quad \text { para } \lambda_{\text {dist }}>0,561\right.
\end{array}
$$

Onde:

$$
\lambda_{\text {dist }}=\sqrt{\frac{N_{y}}{N_{c r d}}}
$$


$\mathrm{N}_{\text {crd }}=$ valor da força relativa à flambagem crítica elástica por distorção

A seguir apresenta-se a curva acima descrita (Figura 2.27).

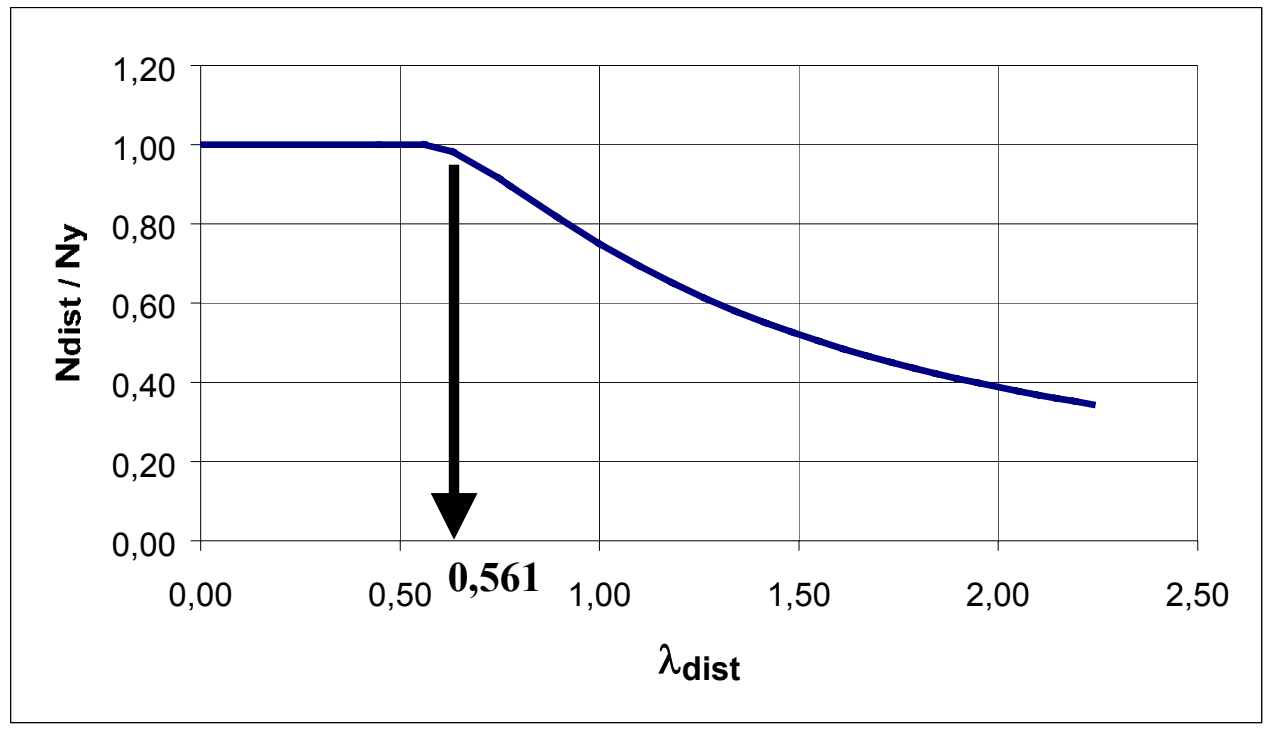

Figura 2.27 - Curva de flambagem: modo distorcional

OBS.: Neste caso, estas expressões são idênticas às expressões segundo LAU \& HANCOCK (87,90), apresentadas anteriormente (Expressões 2.64 e 2.65). Também são idênticas, porém com simbologia diferente, à expressão 2.42 .

\subsubsection{2 - BARRAS SUBMETIDAS À FLEXÃO}

O valor nominal do momento fletor resistente $M_{n}$ é o mínimo entre os valores de $M_{g}, M_{l}$ e $M_{\text {dist }}$, como a seguir:

Os fatores $\phi$ e $\Omega$, utilizados para a determinação da resistência à flexão de cálculo, variam entre tais barras que respeitam ou não as dimensões das seções pré-qualificadas, como descrito anteriormente. 


\subsubsection{1 - Flambagem lateral com torção}

$O$ valor nominal do momento fletor resistente $M_{g}$, para flambagem lateral com torção é:

$$
\begin{array}{ll}
M_{g}=M_{c r e} & \text { para } \mathrm{M}_{\text {cre }}<0,56 \mathrm{M}_{\mathrm{y}} \\
M_{g}=\frac{10}{9} M_{y}\left(1-\frac{10 M_{y}}{36 M_{c r e}}\right) & \text { para } 2,78 \mathrm{M}_{\mathrm{y}} \geq \mathrm{M}_{\mathrm{cre}} \geq 0,56 \mathrm{M}_{\mathrm{y}} \\
M_{g}=M_{y} & \text { para } \mathrm{M}_{\text {cre }}>2,78 \mathrm{M}_{\mathrm{y}}
\end{array}
$$

Onde:

$M_{y}=W_{x} f_{y}$, sendo $W_{x}$ relativo à fibra extrema

$\mathrm{M}_{\text {cre }}=$ valor do momento relativo à flambagem crítica elástica relativa à flambagem lateral com torção

OBS.: Para perfis travados lateralmente ao longo do comprimento, $M_{g}=M_{y}$

A seguir apresenta-se a curva acima descrita (Figura 2.28). 


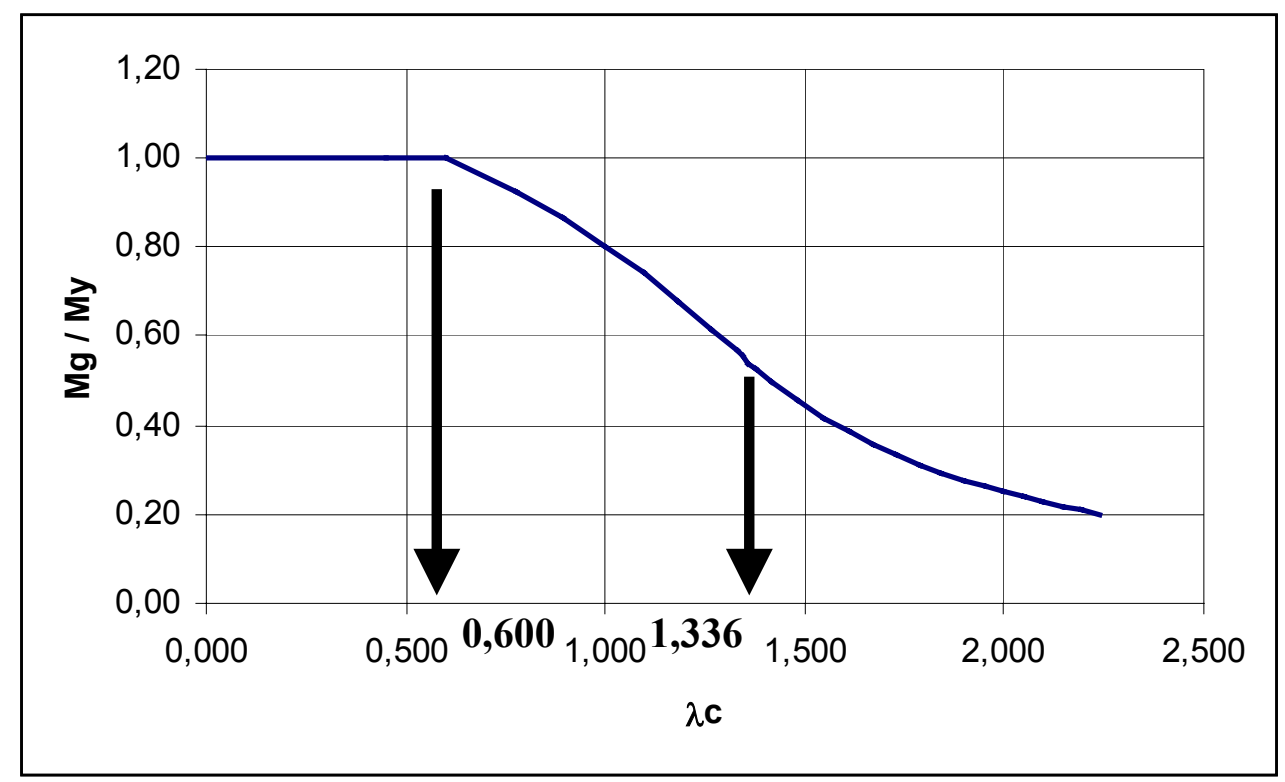

Figura 2.28 - Curva de flambagem: modo global

\subsubsection{2 - Flambagem local}

O valor nominal do momento fletor resistente $M_{1}$, para flambagem local é:

$$
\begin{array}{ll}
M_{l}=M_{g} & \text { para } \lambda_{1} \leq 0,776 \\
M_{l}=\left(1-0,15\left(\frac{M_{c r l}}{M_{g}}\right)^{p, 4}\right)^{\left(\frac{M_{c r l}}{M_{g}}\right)^{0,4} M_{g}} \quad \text { para } \lambda_{1}>0,776
\end{array}
$$

Onde:

$$
\lambda_{l}=\sqrt{\frac{M_{g}}{M_{c r l}}}
$$

$\mathrm{M}_{\mathrm{crl}}=$ valor do momento relativo à flambagem crítica elástica local 


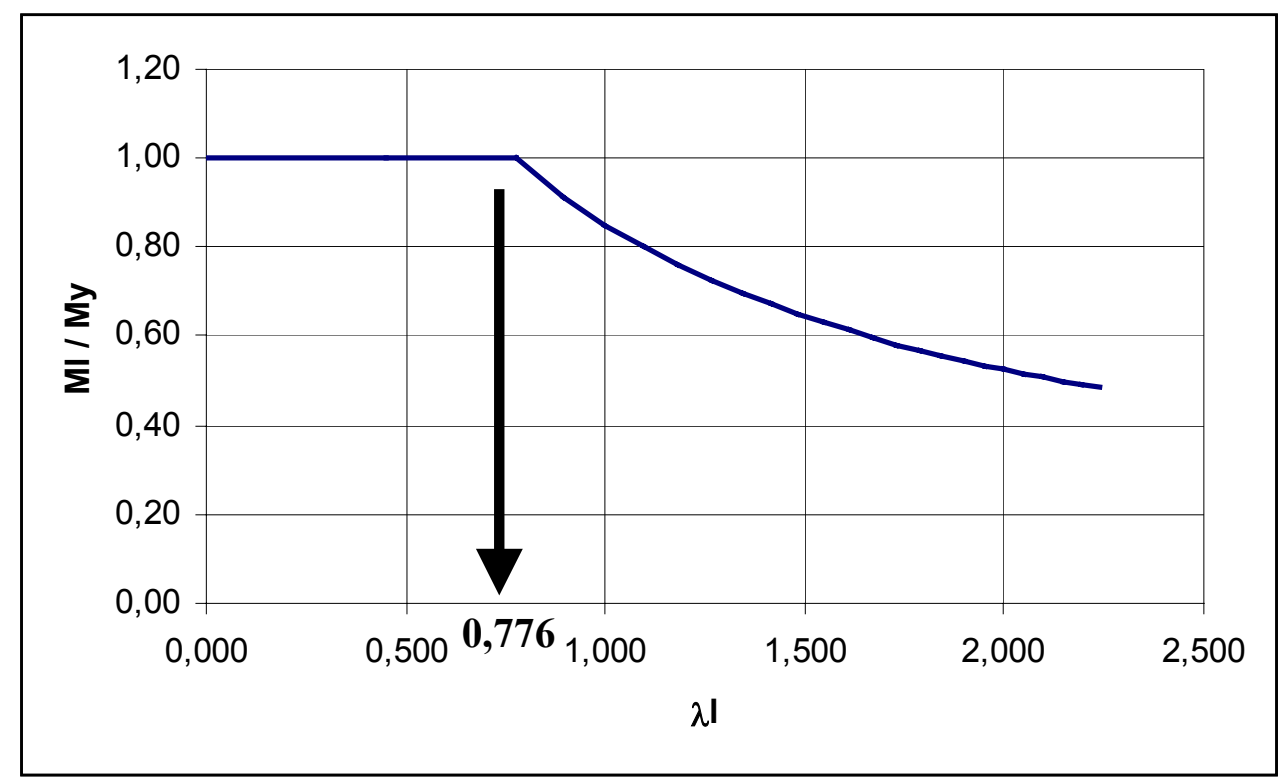

Figura 2.29 - Curva de flambagem: modo local

\subsubsection{3 - Flambagem por distorção}

O valor nominal do momento fletor resistente $M_{\text {dist, }}$ para flambagem por distorção é:

$M_{\text {dist }}=M_{y}$ para $\lambda_{\text {dist }} \leq 0,673$

$M_{\text {dist }}=\left(1-0,22\left(\frac{M_{c r d}}{M_{y}}\right)^{0,5}\right)\left(\frac{M_{c r d}}{M_{y}}\right)^{0,5} M_{y} \quad$ para $\lambda_{d}>0,673$

Onde:

$\lambda_{\text {dist }}=\sqrt{\frac{M_{y}}{M_{c r d}}}$

$M_{c r d}=$ valor do momento relativo à flambagem crítica elástica por distorção

A seguir apresenta-se a curva acima descrita (Figura 2.30). 


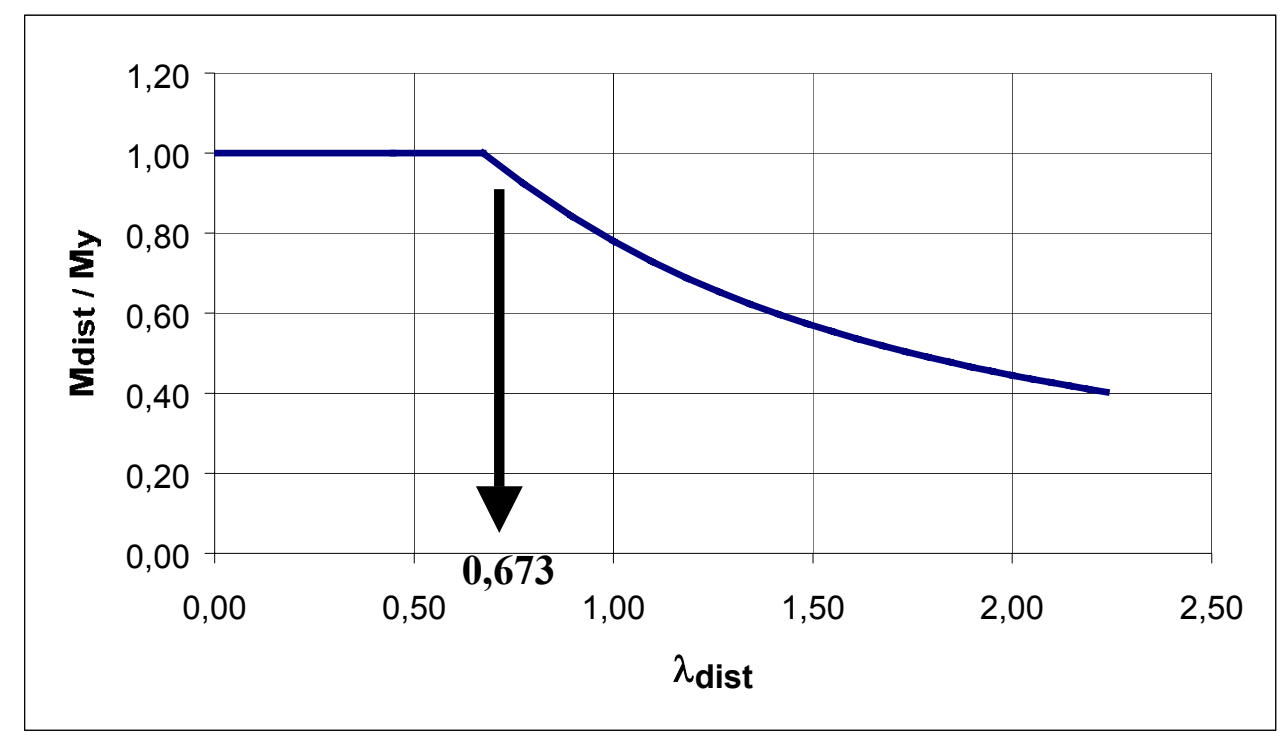

Figura 2.30 - Curva de flambagem: modo distorcional

\section{OBS.:}

- $\quad$ Para os casos da flambagem local (itens 2.7.4.1.2 e 2.7.4.2.2) em vez de usar nas expressões $\mathrm{N}_{\mathrm{g}}$ e $\mathrm{M}_{\mathrm{g}}$, respectivamente, para se considerar a interação entre o modo global e local, pode-se substitui-los por $N_{y}$ e $M_{y}$, respectivamente, para considerar o escoamento.

- $\quad$ Por outro lado, para os casos da flambagem por distorção (itens 2.7.4.1.3 e 2.7.4.2.3) em vez de usar nas expressões $N_{y}$ e $M_{y}$, respectivamente, para se considerar o escoamento, pode-se substitui-los por $\mathrm{N}_{\mathrm{g}}$ e $\mathrm{M}_{\mathrm{g}}$, respectivamente, para considerar interação entre o modo global e distorcional.

- $\quad$ Os itens 2.7.4.1.1 e 2.7.4.2.1 (correspondentes à flambagem global) são calculados de acordo com o item $\mathrm{C}$ do AISI.

As expressões relativas ao método direto de resistência, no que se referem à flambagem por distorção, foram desenvolvidas por HANCOCK et al. (1994). As expressões 2.90 e 2.91 (barras submetidas à flexão) foram alteradas por Schafer não somente com relação ao ponto de inflexão da curva, mas também com relação aos valores dos multiplicadores e expoentes. Tais mudanças resultaram de 
ensaios, onde se concluiu que na flexão a capacidade pós-flambagem é maior que na compressão, no que se refere à flambagem por distorção.

Segundo SCHAFER (2002), após testes realizados por LINDNER (2001), verificou-se que o método direto de resistência reflete o estado limite último de forma considerável, mas não é tão preciso quanto o método da largura efetiva.

OBS.: Cabe lembrar que as expressões apresentadas nas figuras anteriormente apresentadas (Figuras 2.25 a 2.30) são relacionadas ao escoamento $\left(N_{y}\right.$ ou $\left.M_{y}\right)$ em vez de explicitar a interação entre a flambagem local ou por distorção com a global $\left(\mathrm{N}_{\mathrm{g}}\right.$ ou $\left.\mathrm{M}_{\mathrm{g}}\right)$.

Como uma comparação para a flambagem local, entre o método direto de resistência e a expressão de Winter, tem-se a figura 2.31 a seguir, válida tanto para a compressão quanto para a flexão. As setas relativas às três próximas figuras explicitam os pontos de inflexão das curvas.

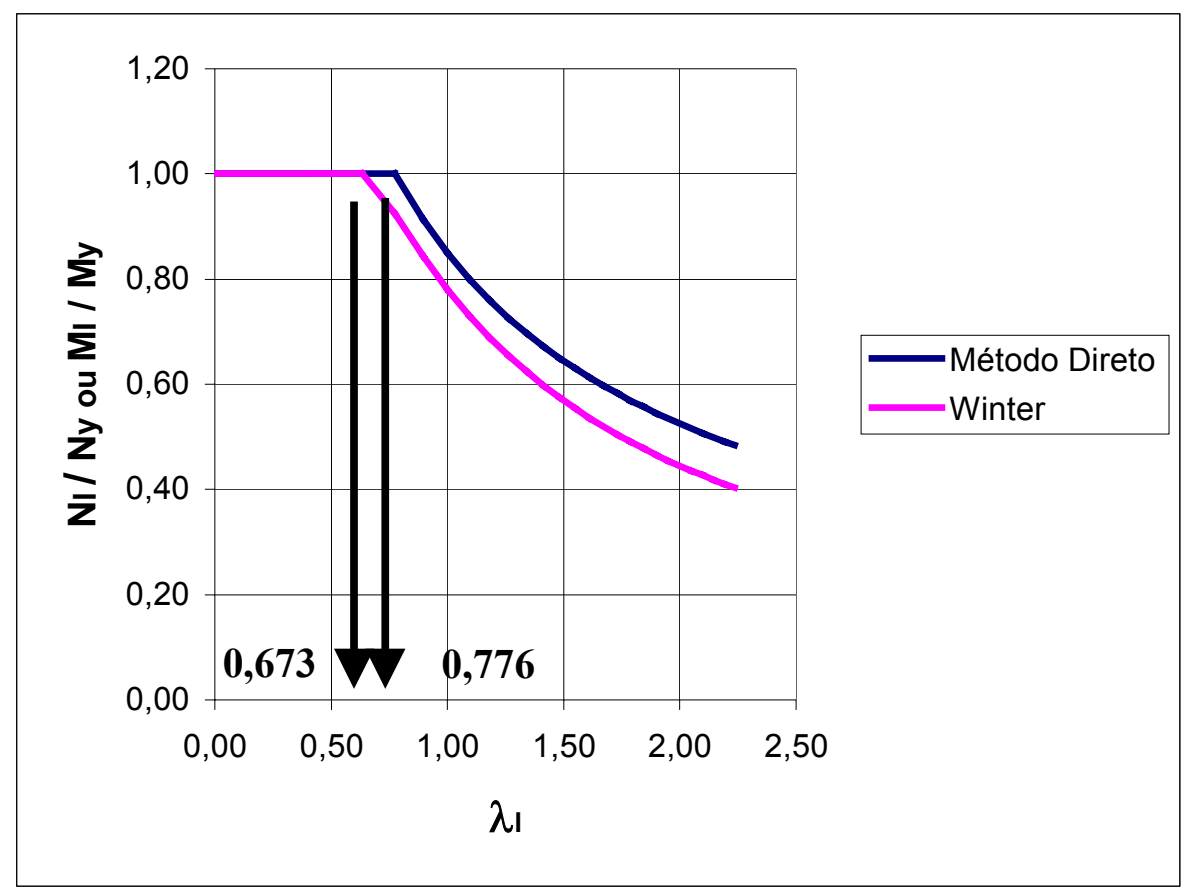

Figura 2.31 - Método Direto de Resistência versus Winter: modo local (compressão ou flexão) 
Como uma comparação para a flambagem por distorção, entre o Método Direto de Resistência e a expressão da norma brasileira NBR 14762:2001, apresenta-se a figura a seguir relativa ao caso de barras submetidas à compressão (Figura 2.32).

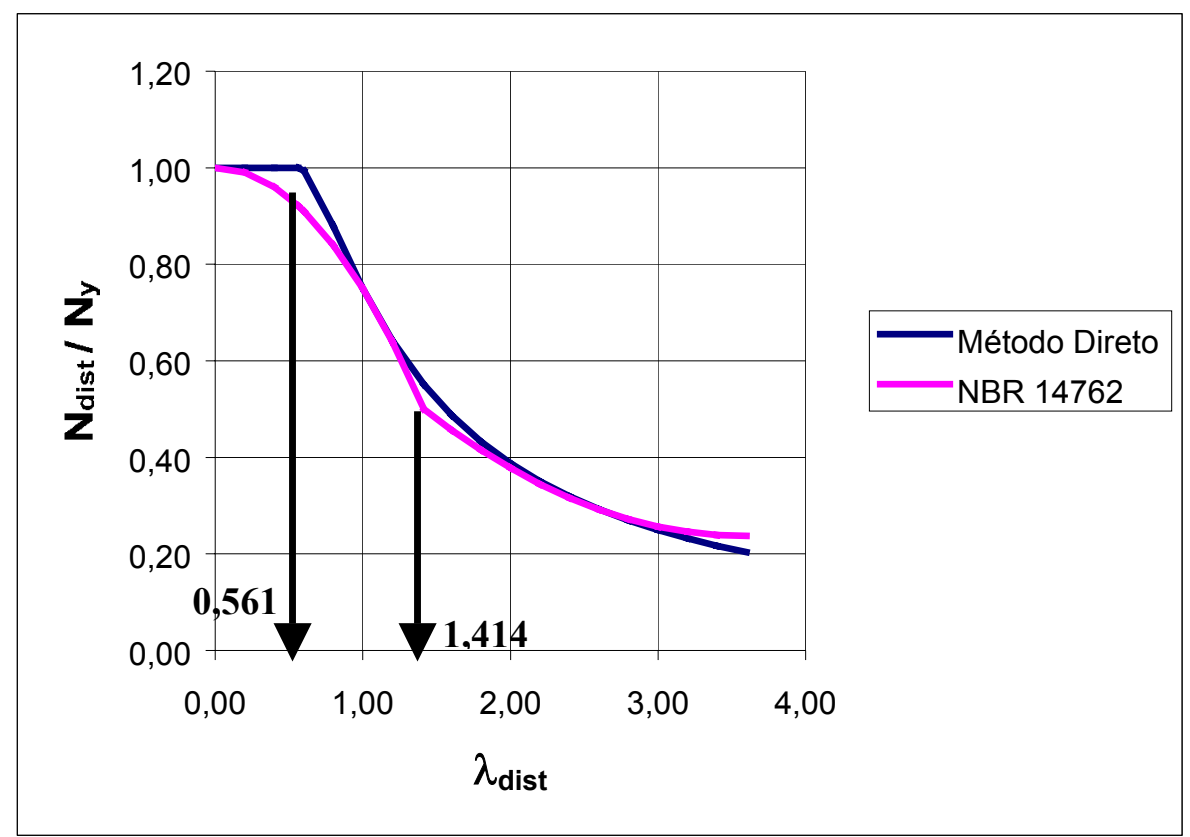

Figura 2.32 - Método Direto de Resistência versus NBR 14762:2001: modo distorcional (compressão)

Apresenta-se a seguir uma comparação para a flambagem por distorção, entre o Método Direto de Resistência e a expressão da norma brasileira NBR 14762:2001, relativa ao caso de barras submetidas à flexão (Figura 2.33). 


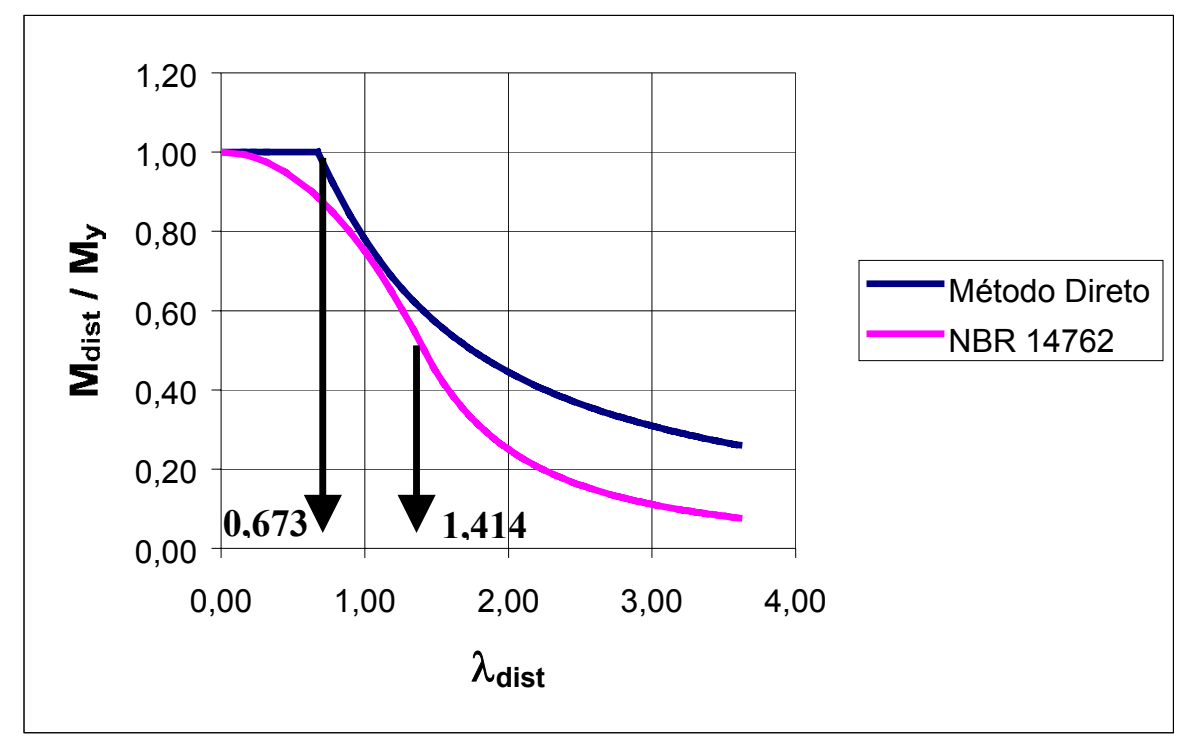

Figura 2.34 - Método Direto de Resistência versus NBR 14762:2001: modo distorcional (flexão)

\subsubsection{GBT: TEORIA DE VIGA GENERALIZADA}

Foi desenvolvida por SCHARDT (1989), estendida por DAVIES et al. (1994) e implementada por DAVIES \& JIANG $(1996,1998)$. Os códigos foram desenvolvidos na Inglaterra pelo grupo de Davies e em Portugal pelo grupo de Dinar Camotim.

Tal modelo preza a análise da seção toda como um conjunto, em vez de se analisar os elementos componentes da seção em separado, o que permite a consideração da interação entre os elementos constituintes da seção transversal. $O$ conceito essencial da Teoria de Viga Generalizada é a separação do comportamento de um membro prismático em uma série de modos de deslocamentos ortogonais. Estes modos podem ser considerados em separado ou combinados com outros modos, no sentido de se investigar diferentes aspectos da resposta estrutural. Cada modo tem uma equação e, negligenciando os termos oriundos da deformação por cisalhamento, a equação do modo k é apresentada a seguir: 
$E{ }^{k} C{ }^{k} V, " '-G{ }^{k} D{ }^{k} V^{\prime \prime}+{ }^{k} B{ }^{k} V+\sum_{i=1}^{n} \sum_{i=j}^{n}{ }^{i j k} k\left(W^{j} V\right)={ }^{k} q \quad($ para $k=1,2, \ldots n)$

Onde:

- $\quad$ k: modo de deslocamento ortogonal;

- $\quad{ }^{k} C$ : constante de empenamento generalizada;

- $\quad$ kD: constante de torção generalizada;

- $\quad$ kB: rigidez transversal à flexão;

Estas são as propriedades generalizadas da seção que dependem somente da geometria da seção transversal. Tem-se também:

- $\quad$ ijk: propriedades de segunda ordem da seção, as quais relacionam deformações da seção transversal com as distribuições de tensão;

- $\quad$ E: módulo de elasticidade longitudinal;

- $\quad$ G: módulo de elasticidade transversal;

- $\quad{ }^{k} V$ : resultante generalizada de deformação;

- $\quad{ }^{k} W$ : resultante generalizada de tensão;

- $\quad$ k: força uniformemente distribuída;

- $\quad$ n: número de modos na análise

As propriedades geométricas das seções transversais e os valores de ${ }^{i \mathrm{jk} k}$ podem ser calculados manualmente, o que é trabalhoso, e, portanto, deve ser calculado por um programa computacional destinado a tal.

Se o termo do lado direito da expressão $2.93,{ }^{k} \mathrm{q}$, for nulo, a expressão fornece como solução a tensão crítica resultante, 'W. Isto em geral requer a solução de um problema de autovalor.

Quando uma tensão resultante constante, como por exemplo devido à aplicação de uma força normal ou momento fletor constante, é aplicada ao longo do membro (o qual é assumido sofrer flambagem em comprimento de meia onda seno $\lambda$ ), tal teoria conduz a resultados simples.

A tensão crítica resultante relativa ao modo simples de flambagem é: 


$$
{ }^{i, k} \mathbf{W}_{c r}=\frac{1}{i_{k k}}\left(\frac{\pi^{2}}{\lambda^{2}} \mathbf{E}^{k} C+G^{k} D+\frac{\lambda^{2}}{\pi^{2}}{ }^{k} B\right)
$$

Como o comprimento de onda é variável, a tensão crítica resultante mínima resulta:

$$
{ }^{\mathrm{i}, \mathrm{k}} \mathbf{W}_{\mathrm{cr}}=\frac{1}{\mathrm{ikk}_{\mathrm{k}}}\left(2 \sqrt{\mathbf{E}^{\mathrm{k}} \mathrm{CB}}+\mathbf{G}^{\mathrm{k}} \mathbf{D}\right)
$$

E o correspondente comprimento de meia onda é:

$$
{ }^{k} \lambda=\pi\left(\frac{\mathbf{E}^{k} \mathbf{C}}{{ }^{k} B}\right)^{0,25}
$$

As expressões 2.94 a 2.96 permitem uma análise particularmente simples a ser feita para algum modo de flambagem individual, incluindo o modo distorcional. Nenhum outro método, segundo DAVIES (2000), propicia o isolamento do modo distorcional deste modo. Pode ser notado que tensões críticas resultantes relativas à flambagem local ou por distorção no modo $k$ dependem somente das propriedades da seção transversal.

Comparações referentes ao cálculo da tensão convencional de flambagem elástica por distorção foram realizadas por KESTI (1999), para perfis do tipo $U$ enrijecido, e serão apresentadas e discutidas a seguir (Tabela 2.5). 
Tabela 2.5 - Comparação entre valores de tensão convencional de flambagem elástica por distorção

\begin{tabular}{|c|c|c|c|c|c|c|c|c|c|c|}
\hline Seção & \multicolumn{3}{|c|}{$\mathrm{t}=1,5 \mathrm{~mm}$} & \multicolumn{3}{|c|}{$\mathrm{t}=2,0 \mathrm{~mm}$} & \multicolumn{2}{|c|}{$\mathrm{t}=1,5 \mathrm{~mm}$} & \multicolumn{2}{|c|}{$\mathrm{t}=2,0 \mathrm{~mm}$} \\
\hline & AS & EC3 & GBT & AS & EC3 & GBT & $\frac{A S}{G B T}$ & $\frac{E C 3}{G B T}$ & $\frac{A S}{G B T}$ & $\frac{E C 3}{G B T}$ \\
\hline $200 \times 75 \times 20$ & 165 & 79 & & 230 & 234 & & 0,98 & 1,07 & 0,98 & 1,00 \\
\hline $200 \times 75 \times 15$ & 129 & 129 & & 183 & 172 & & 0,95 & 0,95 & 0,95 & 0,90 \\
\hline $200 \times 50 \times 20$ & $167^{*}$ & 331 & & $236^{*}$ & 441 & & 0,94 & 1,85 &, 94 & 1,10 \\
\hline $200 \times 50 \times 15$ & $135^{*}$ & 251 & 49 & $195^{*}$ & 335 & & 0,91 & 1,68 &, 91 & $1,5 /$ \\
\hline $200 \times 50 \times 10$ & $101^{*}$ & 163 & 13 & $153^{*}$ & 218 & 67 & 0,90 & 1,45 &, 91 & 1,30 \\
\hline $150 \times 75 \times 20$ & 217 & 203 & & 303 & 262 & & 0,96 & 0,90 & 0,97 & 0,84 \\
\hline $150 x$ & 176 & 144 & 33 & 248 & 192 & 257 & 0,96 & 0,79 & 0,96 & 0,75 \\
\hline $150 \times 50 \times 20$ & 295 & 373 & 290 & 411 & 498 & 404 & 1,02 & 1,29 & 1,02 & 1,23 \\
\hline $150 \times 50 \times 15$ & 243 & 283 & 247 & 343 & 377 & 349 & 0,98 & 1,15 & 0,98 & 1,08 \\
\hline $150 \times 50 \times 10$ & 173 & 184 & 189 & 253 & 246 & 276 & 0,91 & 0,97 & 0,92 & 0,89 \\
\hline $100 \times 100 \times 30$ & 234 & 209 & & 325 & 289 & & 0,91 & 0,81 & 0,93 & 0,82 \\
\hline $100 \times 100 \times 20$ & 182 & 151 & & 254 & 188 & & 0,94 & 0,78 &, 96 & 0,71 \\
\hline $100 x$ & 146 & 103 & & 205 & 131 & & 0,96 & 0,68 & 0,98 & 0,62 \\
\hline 100 & 420 & 438 & 441 & 584 & 583 & 609 & 0,95 & 0,99 & 0,96 & 0,96 \\
\hline $100 \times 5$ & 372 & 332 & 383 & 523 & 443 & 535 & 0,97 & 0,87 & 0,98 & 0,83 \\
\hline $100 \times 50 \times 10$ & 287 & 216 & 296 & 411 & 288 & 423 & 0,97 & 0,73 & 0,97 & 0,68 \\
\hline $100 \times 30 \times 15$ & 503 & 725 & 493 & 707 & 967 & 699 & 1,02 & 1,47 & 1,01 & 1,38 \\
\hline $100 \times 30 \times 10$ & 401 & 501 & 417 & 583 & 668 & 607 & 0,96 & 1,20 & 0,96 & 1,10 \\
\hline & & & & \multicolumn{3}{|c|}{ Média } & 0,96 & 1,09 & 0,96 & 1,02 \\
\hline & & & & \multicolumn{3}{|c|}{ Desvio Padrão } & 0,04 & 0,34 & 0,03 & 0,32 \\
\hline \multicolumn{11}{|c|}{$\begin{array}{l}\text { Valores foram calculados de acordo com o método proposto por DAVIES } \\
\text { \& JIANG (1995) para o caso de } \mathrm{k}_{\phi} \text { ser negativo }\end{array}$} \\
\hline \multicolumn{11}{|c|}{$\mathrm{E}=210.000 \mathrm{MPa}$ (módulo de elasticidade longitudinal) } \\
\hline \multicolumn{11}{|c|}{ AS: norma australiana AS/NZS 4600:1996; } \\
\hline \multicolumn{11}{|c|}{ EC3: EUROCODE 3: Parte 1.3 (1996); } \\
\hline \multicolumn{11}{|c|}{ GBT: Generalized Beam Theory - Teoria de Viga Generalizada } \\
\hline
\end{tabular}

O método da norma australiana fornece resultados, na média, $4 \%$ inferiores aos relativos a GBT, tanto para espessuras de $1,5 \mathrm{~mm}$ como para de 2,0 mm. $O$ método do EC3, por outro lado, fornece valores $9 \%$ superiores aos relativos a GBT para espessuras de $1,5 \mathrm{~mm}$ e $2 \%$ superiores para espessuras de $2,0 \mathrm{~mm}$. Entretanto, o desvio padrão resultou elevado nos dois casos.

Nos casos em que a alma apresenta instabilidade antes do que a mesa ( $\left.{ }^{*}\right)$, o método relativo ao EC3 fornece valores bem superiores aos relativos ao GBT, pois o modelo do EC3 não leva em consideração a redução da rigidez a flexão da alma. 


\section{ANÁLISE VIA MÉTODO DAS FAIXAS FINITAS}

\subsection{BREVE NOÇÃO SOBRE O MÉTODO}

O método das faixas finitas foi desenvolvido originalmente por $\mathrm{Y}$. K. CHEUNG (1976). CHEUNG \& THAM (1998) explicam a teoria básica, enquanto HANCOCK et al. (2001) e SCHAFER (1997) fornecem detalhes específicos para a análise da estabilidade com o uso do método. O uso do mesmo para com os elementos estruturais de aço foi intensificado devido em grande parte a Hancock. Este usou as matrizes de rigidez oriundas do método proposto por Cheung, e com alguma modificação criou o BFINST - programa computacional para a análise do fenômeno da flambagem elástica em perfis de aço de paredes delgadas, via faixas finitas.

Tal método é bem aplicado a seções com geometria da seção transversal "complexa", ou seja, em que a seção transversal possui uma forma não convencional (por exemplo, com vário enrijecedores), mas ao longo da barra devem atuar esforços e condições de contorno constantes, pois pela própria definição do método, as faixas finitas não se subdividem ao longo do comprimento da barra.

Para a análise de um tipo de perfil de seção arbitrária pode-se identificar os modos e as tensões de flambagem associadas, sendo o modo crítico detectado em função do comprimento da barra, que poderá estar submetida à compressão centrada, flexão simples ou flexão composta. 
Do ponto de vista prático, o método das faixas finitas é particularmente importante, pois soluções de bifurcação de equilíbrio podem ser obtidas simplesmente, com o uso de funções de deslocamento. Isto propicia a análise da seção considerando a interação entre seus elementos constituintes, para todos os modos de flambagem.

Um dos programas computacionais de uso público que realizam a análise geral de instabilidade da barra, permitindo a interação entre seus elementos constituintes, é o CUFSM, o qual será apresentado no item 3.2.

$\mathrm{O}$ método das faixas finitas tem sido bastante utilizado atualmente para $\mathrm{O}$ cálculo da tensão convencional de flambagem elástica por distorção, $\sigma_{\text {dist }}$, pois permite uma discretização dos perfis com um grau de indeterminação e sistema de equações menor do que no caso do método dos elementos finitos.

Além disso, é um dos mais indicados métodos numéricos já desenvolvidos para a análise de perfis de parede delgada, baseado no conceito de separação de variáveis. Em tal método, a interpolação do deslocamento é formada de duas partes, sendo um polinômio definido na seção transversal e uma parte da série de Fourier truncada que governa o comportamento da função de deslocamento na direção axial, satisfazendo as condições de contorno nas extremidades do perfil. Se o perfil for prismático e as condições de carregamento e de contorno forem simples, o método das faixas finitas será bem econômico com relação à eficiência computacional.

A implementação do método das faixas finitas no programa CUFSM impõe basicamente duas limitações:

- $\quad$ Empenamento livre nas extremidades da barra, isto é, não é possível admitir restrição ao empenamento;

- Seção transversal, esforços solicitantes e vinculações constantes ao longo do comprimento da barra;

A seleção das funções de deslocamento utilizadas no método das faixas finitas é a chave do método. Segundo o programa CUFSM, são utilizadas, na direção transversal, funções polinomiais e, na direção longitudinal, funções harmônicas (formato de uma meia onda seno). Tal fato é consistente com a 
condição de contorno de extremidades simplesmente apoiadas, o que leva a uma simplificação da solução.

A análise do fenômeno da flambagem elástica pode ser representada no formato matricial por um problema padrão de autovalor, sendo $\lambda$ representativo da força de flambagem, como um autovalor, e os modos de flambagem como autovetores (Equação 3.1).

$$
[K]\{\delta\}-\lambda[G]\{\delta\}=\{0\}
$$

Onde:

$[K]:$ matriz de rigidez da chapa

$[G]$ : matriz de estabilidade da chapa

$\lambda$ : fator de carga

$\{\delta\}$ : vetor dos deslocamentos nodais

Os valores de $\lambda$ para os quais o determinante dos coeficientes de $\{\delta\}$ na equação 3.1 se anulam são os autovalores. Os correspondentes valores de $\{\delta\}$ são os autovetores.

Uma alternativa ao método convencional das faixas finitas é o "Spline método das faixas finitas", no qual as séries de Fourier são substituídas por Splines cúbicas, mantendo a interpolação transversal das funções, segundo, por exemplo, PERTOLLA (2000). A introdução da Spline na direção transversal permite que sua aplicação para estruturas com formas arbitrárias da seção transversal seja melhor do que quando realizada pelo método convencional das faixas finitas, e permite a possibilidade de que condições de contorno de extremidade da barra impeçam o empenamento.

KOUHIA (1992) comparou a eficiência computacional entre o "Spline método das faixas finitas" e o método dos elementos finitos. Como sugestão, recomenda que para análise de estruturas de chapas o uso das Splines cúbicas como funções interpoladoras não trazem vantagens significativas quando comparadas ao uso do método dos elementos finitos. De acordo com o mesmo, a única vantagem do "Spline método das faixas finitas" é a simplicidade de se fazer 
um modelo de deslocamentos compatíveis para estruturas de chapa, sendo que por outro lado a mesma simplicidade pode ser conseguida com o uso do método dos elementos finitos.

BATISTA (2002) apresenta o uso de funções Spline cúbicas aplicadas como funções de forma no método das faixas finitas para modelar as extremidades da barra como sendo engastadas (empenamento impedido).

A figura 3.1 ilustra a comparação entre a discretização de um perfil do tipo $U$ enrijecido via método dos elementos finitos e via método das faixas finitas.

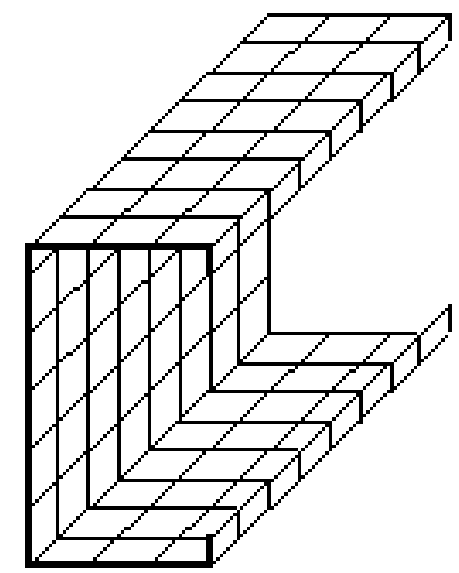

Elementos finitos

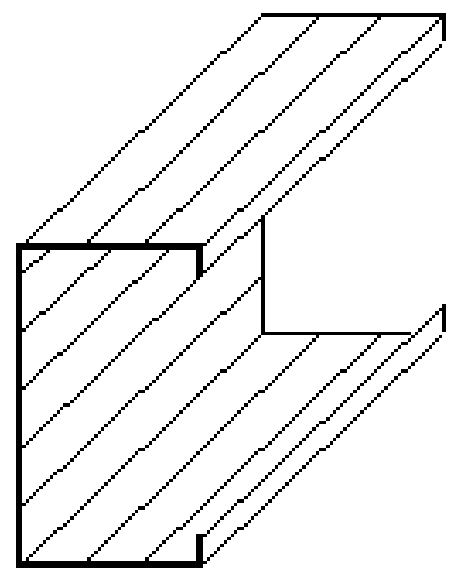

Faixas finitas

Figura 3.1 - Discretização de um perfil do tipo U enrijecido para análise via elementos finitos e via faixas finitas

Pode-se perceber, comparando o método das faixas finitas com o método dos elementos finitos, que:

- O método dos elementos finitos permite a variação das condições de contorno nos apoios (extremidades das barras) e ao longo da barra analisada. Além disso, a seção transversal não necessita permanecer constante ao longo do comprimento da barra; 
- O método das faixas finitas, após alguns estudos, se mostrou muito eficiente quando da análise de elementos de aço formados a frio, além de necessitar de um tempo de processamento baixo, quando comparado a outros métodos numéricos. Também considera a interação da flambagem elástica entre os elementos que formam a seção transversal em análise;

\subsection{O PROGRAMA COMPUTACIONAL CUFSM}

O CUFSM é um programa via Método das Faixas Finitas, elaborado por Benjamim W. Schafer, para análise de estabilidade elástica de perfis com seção aberta e paredes delgadas submetidas à distribuição qualquer de tensões normais nas extremidades, permitindo ainda restringir graus de liberdade dos nós. $O$ programa examina uma variedade de comprimentos para a barra. A tensão crítica e a correspondente configuração deformada da barra, indicando o modo de flambagem são arquivados para cada um dos comprimentos. Como resultado é obtida a curva de flambagem com os modos de flambagem explicitados, os quais podem ser usados para um melhor entendimento do comportamento da barra.

Devido ao fato da solução ser numérica, seções transversais com geometrias mais "complexas" não acarretam maiores dificuldades ao usuário do programa, habilitando o engenheiro a considerar seções transversais mais inovadoras sem acarretar complicações para o mesmo. Comparado com métodos manuais, a solução é muito mais direta. Além disso, pelo fato de seções transversais completas (sem haver necessidade da separação dos elementos constituintes da seção transversal) poderem ser modeladas, a interação entre os elementos é prontamente arquivada.

Para que a discretização da malha de faixas finitas de uma barra forneça resultados com precisão satisfatória, cada elemento da seção transversal deve ser subdividido em no mínimo quatro faixas finitas.

A discretização em questão, feita pela entrada de dados por coordenadas $x$ e z não leva em consideração o raio de dobramento nas junções entre os elementos. Após analisar algumas variações de discretizações, tanto para a mesa quanto para a alma dos perfis, optou-se por utilizar uma outra discretização do programa, a qual considera os raios de dobramento, podendo inclusive considerar enrijecedores com qualquer inclinação em relação à mesa do perfil, e que também 
resulta em uma malha mais refinada de 37 nós (tal fato, entretanto não resulta em diferença significativa, como mostrado a seguir na tabela 3.1, quanto aos valores de $L_{d}$ e $\sigma_{\text {dist }}$, mas propicia grande rapidez no que se refere à entrada dos dados, pois não é necessária a especificação das coordenadas dos nós, mas somente as dimensões planas da seção transversal do perfil e o valor do raio médio).

Com relação aos perfis do tipo $U$ e $Z$ enrijecido analisados, as dimensões nominais (externas) fornecidas pelos catálogos dos fabricantes, $b_{w}, b_{f}, D, t$, devem ser alteradas para dimensões planas da seguinte forma, com o objetivo de entrada de dados no programa (o sub-índice 1 se refere às larguras nominais requeridas pelo programa):

$$
\begin{array}{ll}
\text { - } & \mathrm{b}_{\mathrm{w} 1}=\mathrm{b}_{\mathrm{w}}-4 \mathrm{t} \text { (alma) } \\
\text { - } & \mathrm{b}_{\mathrm{f} 1}=\mathrm{b}_{\mathrm{f}}-4 \mathrm{t} \text { (mesa) } \\
\text { - } & \mathrm{D}_{1}=\mathrm{D}-2 \mathrm{t} \text { (enrijecedor) } \\
\text { - } & \mathrm{r}_{1}=1,5 \mathrm{t} \text { (raio médio) }
\end{array}
$$

Para este tipo de entrada de dados o próprio programa escolhe o número de elementos para a discretização da seção transversal e os comprimentos de meia onda para a execução da varredura, segundo critério embutido no mesmo.

As constantes adotadas pelo programa são as seguintes:

$$
\begin{aligned}
& E=203.000 \mathrm{MPa} \\
& v=0.3 \\
& G=78076 \mathrm{MPa}
\end{aligned}
$$

Vale ressaltar que para a análise de perfis do tipo $Z$ enrijecido deve-se escolher a opção restrained bending no passo referente ao cálculo das tensões atuantes na seção, para que a flexão ocorra em torno dos eixos x e z, e não em torno dos eixos principais de inércia, que no caso do perfil $Z$ não são coincidentes com os eixos $x$ e $z$ adotados pelo programa.

Como justificativa referente ao parágrafo supracitado, tem-se que para um perfil $U$ enrijecido de $200 \times 125 \times 15 \times 1,5 \mathrm{~mm}$ os seguintes resultados foram verificados para a análise do mesmo submetido à compressão e adotando-se como tensão de referência $\mathrm{f}_{\mathrm{y}}=250 \mathrm{MPa}$, de acordo com a tabela 3.1: 
Tabela $3.1-\sigma_{\text {dist }}$ e $L_{d}$ em função da quantidade de faixas finitas - perfil do tipo $U$ enrijecido submetido à compressão centrada

\begin{tabular}{|c|c|c|}
\hline & $\sigma_{\text {dist }}\left(\mathrm{kN} / \mathrm{cm}^{2}\right)$ & $L_{d}(\mathrm{~cm})$ \\
\hline NBR 14762:2001 & 7,35 & 94,00 \\
\hline \multicolumn{3}{|c|}{ CU-FSM (FAIXAS FINITAS) } \\
\hline $\begin{array}{l}10 \text { nós } \\
\text { Enrijecedor: } 1 \text { faixa } \\
\text { Mesa: } 2 \text { faixas } \\
\text { Alma: } 3 \text { faixas }\end{array}$ & 7,50 & 100,00 \\
\hline $\begin{array}{l}11 \text { nós } \\
\text { Enrijecedor: } 1 \text { faixa } \\
\text { Mesa: } 2 \text { faixas } \\
\text { Alma: } 4 \text { faixas }\end{array}$ & 7,50 & 100,00 \\
\hline $\begin{array}{l}15 \text { nós } \\
\text { Enrijecedor: } 1 \text { faixa } \\
\text { Mesa: } 2 \text { faixas } \\
\text { Alma: } 8 \text { faixas }\end{array}$ & 7,50 & 100,00 \\
\hline $\begin{array}{l}21 \text { nós } \\
\text { Enrijecedor: } 1 \text { faixa } \\
\text { Mesa: } 5 \text { faixas } \\
\text { Alma: } 8 \text { faixas }\end{array}$ & 7,50 & 100,00 \\
\hline $\begin{array}{l}37 \text { nós } \\
\text { Enrijecedor: } 4 \text { faixas } \\
\text { Mesa: } 4 \text { faixas } \\
\text { Alma: } 4 \text { faixas } \\
\text { Total nas dobras: } 17 \text { faixas }\end{array}$ & 7,75 & 100,00 \\
\hline $\begin{array}{l}73 \text { nós (Double Elements) } \\
\text { Enrijecedor: } 8 \text { faixas } \\
\text { Mesa: } 8 \text { faixas } \\
\text { Alma: } 8 \text { faixas } \\
\text { Total nas dobras: } 33 \text { faixas }\end{array}$ & 7,75 & 100,00 \\
\hline
\end{tabular}


Usualmente, a flambagem local ocorre para comprimentos de meia onda da ordem de grandeza da maior dimensão da seção transversal do perfil analisado, a flambagem por distorção ocorre para comprimentos de meia onda da ordem de grandeza de 2 a 8 vezes a maior dimensão da seção transversal do perfil, e a flambagem global ocorre para comprimentos maiores.

Sobre a apresentação dos resultados pelo programa, até 8 análises podem ser realizadas e visualizadas graficamente, simultaneamente, na curva de flambagem, o que propicia a liberdade de se variar a força normal e/ou momento fletor aplicados e a seção transversal, procedendo a comparações simultâneas.

Para efeito de projeto utilizando as seções analisadas pelo programa, como o mesmo fornece como resultado apenas tensões críticas de flambagem elástica, tais valores fornecidos devem ser corrigidos por curvas de resistência para a obtenção dos esforços resistentes da barra analisada.

Para o uso do programa CUFSM como uma fácil ferramenta para se fazer a análise elástica de uma seção, e a fim de se viabilizar a aplicação do Método Direto de Resistência, os valores que devem ser obtidos do programa são $N_{\text {crl, }} N_{\text {crd }}, N_{\text {cre }}$, $M_{c r}, M_{c r d}, M_{c r e}$, correspondentes à flambagem crítica elástica, relativos aos modos local, distorcional e global (euler), referentes, respectivamente, à força de compressão e ao momento fletor.

Como resposta do programa, tem-se para os casos de flambagem local, por distorção e global:

$$
\begin{array}{ll}
\text { - } & \mathrm{N}_{\mathrm{cr}}=\text { (load factor) } \mathrm{N}_{\mathrm{y}} \\
\text { - } & \mathrm{N}_{\mathrm{y}}=\mathrm{A}_{\mathrm{g}} \mathrm{f}_{\mathrm{y}} \\
\text { - } & \mathrm{M}_{\mathrm{cr}}=\text { (load factor) } \mathrm{M}_{\mathrm{y}} \\
\text { - } & \mathrm{M}_{\mathrm{y}}=\mathrm{M}_{\mathrm{xx}}
\end{array}
$$

Onde:

Load factor: fator de tensão obtido do gráfico fornecido como resposta do programa, sendo este o valor que multiplicado pela tensão de referência adotada pelo usuário (normalmente a tensão de escoamento) fornece a tensão crítica de flambagem elástica referente ao modo analisado; 
$\mathrm{M}_{\mathrm{xx}}$ : momento fornecido como resposta do programa após o cálculo das tensões nos nós da seção transversal, com a condição restrained bending ativada (faz com que para o cálculo da flexão, esta ocorra em torno dos eixos x e z, mesmo que os eixos principais de inércia do perfil não sejam os eixos $x$ e $z$ adotados pelo programa);

A figura 3.3 llustra um exemplo de saída de resultados para um perfil do tipo $U$ enrijecido submetido à flexão (mesa superior comprimida), na qual se apresenta o gráfico entre o fator de tensão e comprimento de meia onda. Observa-se no gráfico que o modo distorcional (ponto de mínimo com load factor igual a 0,30 ) é crítico em relação ao modo local (ponto de mínimo com load factor igual a 0,36 ).

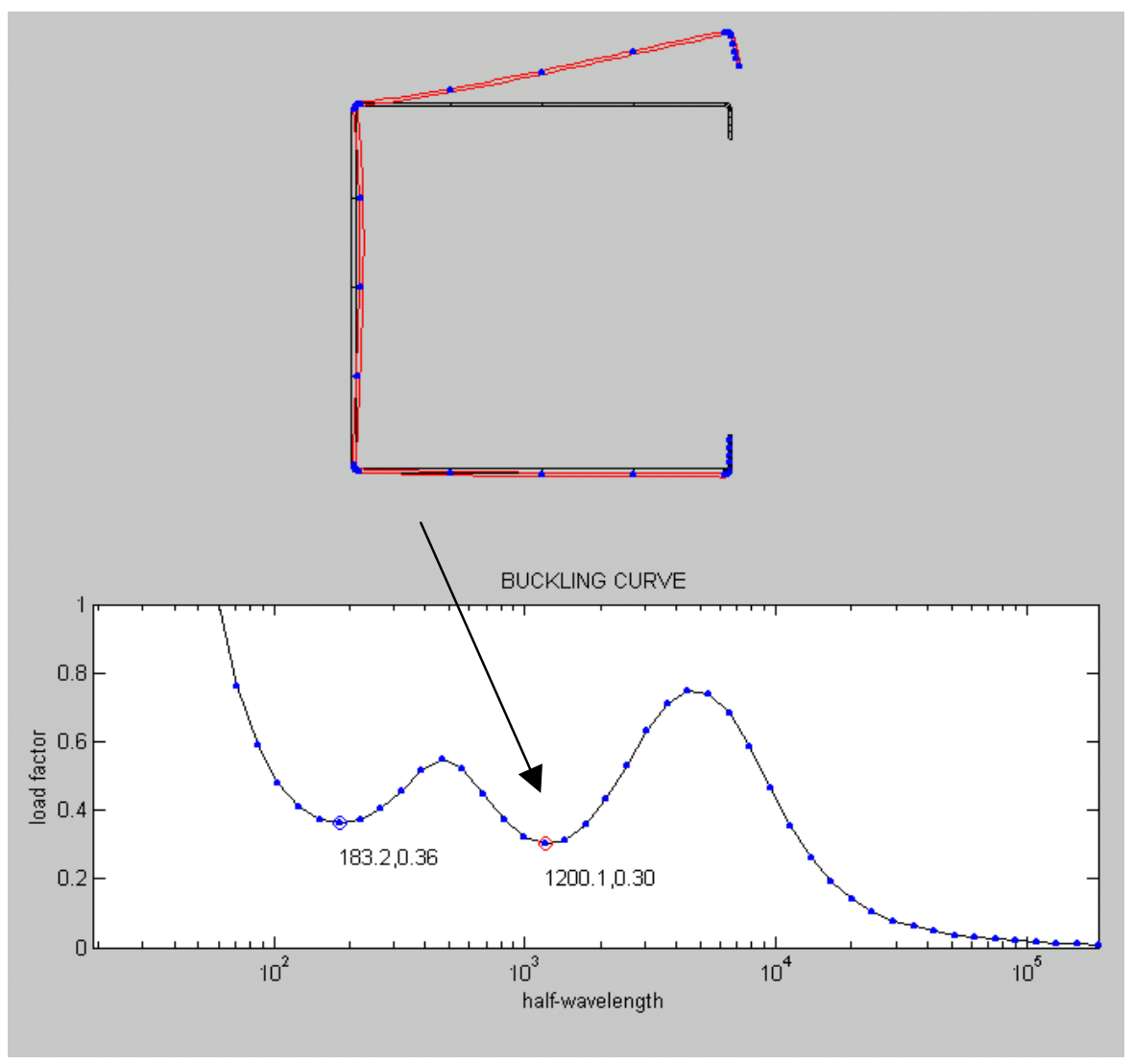

Figura 3.3 - Exemplo de varredura para análise da flambagem elástica de perfil U enrijecido 
O elemento utilizado pelo programa possui 4 nós, com 4 graus de liberdade em cada nó, sendo 3 translações $\left(u_{x}=u, u_{y}=v\right.$ e $\left.u_{z}=w\right)$ e 1 rotação $\left(\phi_{y}=\theta\right)$, conforme ilustrado na figura 3.4 .

Vale ressaltar algumas características do programa com relação às condições de contorno (deslocamentos e solicitações):

O plano da seção transversal das barras é definido pelos eixos x e z, sendo que o eixo y representa a barra ao longo de seu comprimento (eixo longitudinal).

Com relação aos exemplos analisados, observa-se que:

\section{DESLOCAMENTOS IMPEDIDOS APLICADOS ÀS BARRAS:}

- $\quad$ Somente os nós referentes à seção transversal de ambas extremidades da barra tiveram seus deslocamentos impedidos em relação em x e z (condição simétrica de condições de contorno);

\section{SOLICITAÇÕES APLICADAS ÀS BARRAS:}

- $\quad$ Somente os nós referentes à seção transversal de ambas extremidades da barra receberam solicitação externa, sendo aplicada ao longo da linha média da seção transversal, por força por unidade de comprimento.

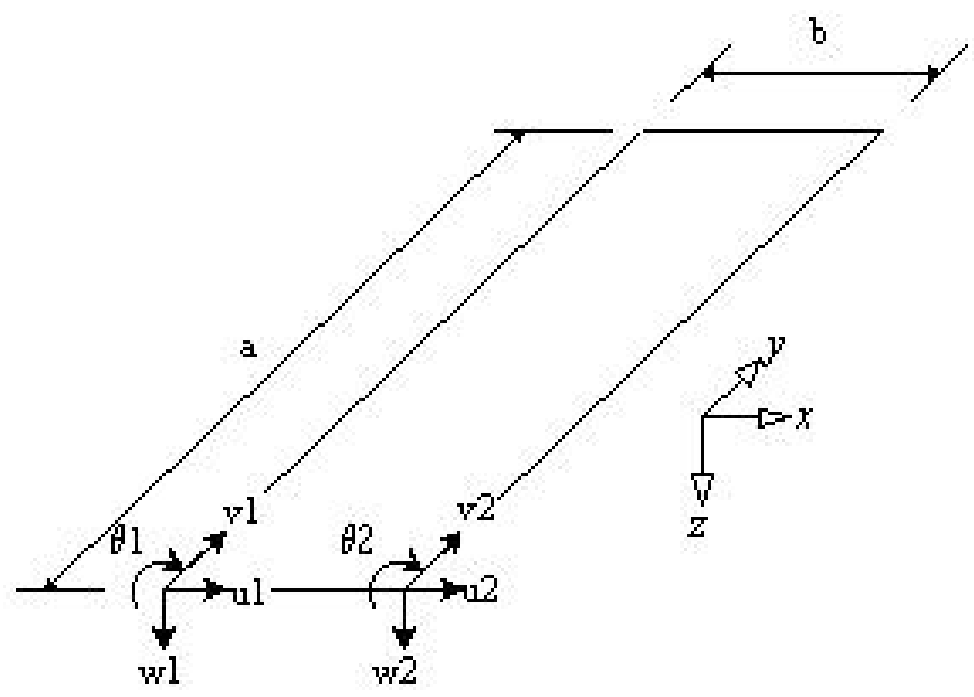

Figura 3.4 - Faixa finita utilizada pelo programa CUFSM 


\subsection{PERFIS ADOTADOS NA ANÁLISE}

Os parâmetros adotados, referentes às relações geométricas dos perfis adotados na análise, nos quais o trabalho está baseado, são apresentados na tabela 3.2 .

Tabela 3.2 - Parâmetros analisados

\begin{tabular}{|c|c|c|c|}
\hline $\mathbf{b}_{\mathbf{f}} / \mathbf{b}_{\mathbf{w}}$ & $\begin{array}{c}0,25 \\
\text { (mínimo NBR-6355) }\end{array}$ & $\begin{array}{c}0,5 \\
\text { (usual) }\end{array}$ & 1,0 \\
\hline $\mathbf{D} / \mathbf{b}_{\mathbf{w}}$ & 0,05 & 0,1 & 0,15 \\
\hline $\mathbf{b}_{\mathbf{w}} / \mathbf{t}$ & 50 & 100 & 200 \\
\hline
\end{tabular}

O próximo passo foi a definição das seções transversais das barras, que foram modeladas tanto para a compressão centrada quanto para a flexão. Tais seções foram utilizadas para se calcular a tensão convencional de flambagem por distorção, $\sigma_{\text {dist, }}$ e o comprimento da meia onda longitudinal associada à tensão convencional de flambagem elástica por distorção, $L_{d}$.

Foram estudadas 35 seções transversais do tipo $U$ enrijecido (Tabela 3.3) para a análise relativa ao procedimento da NBR 14762:2001 e relativa ao método das faixas finitas (programa CUFSM). Com relação à análise via método dos elementos finitos, somente algumas dessas seções foram analisadas, e serão explicitadas durante a apresentação dos resultados correspondentes.

Com relação aos perfis do tipo $Z$ enrijecido, também foram estudadas algumas seções transversais, sendo analisadas seções com o enrijecedor de borda a $90^{\circ}$ e também a $45^{\circ}$. Estas análises serão apresentadas mais adiante. 
Tabela 3.3 - Perfis do tipo U enrijecido analisados

\begin{tabular}{|c|c|c|c|c|}
\hline DESIGNAÇÃO & $b_{w}(m m)$ & $b_{f}(m m)$ & $D(\mathrm{~mm})$ & $t(\mathrm{~mm})$ \\
\hline $\begin{array}{l}\text { Ue } 200 \times 50 \times 10 \times 1,0 \\
\text { Ue } 200 \times 50 \times 10 \times 2,0 \\
\text { Ue } 200 \times 75 \times 10 \times 2,0 \\
\text { Ue } 200 \times 50 \times 10 \times 4,0\end{array}$ & $\begin{array}{l}200 \\
200 \\
200 \\
200\end{array}$ & $\begin{array}{l}50 \\
50 \\
75 \\
50\end{array}$ & $\begin{array}{l}10 \\
10 \\
10 \\
10\end{array}$ & $\begin{array}{l}1,0 \\
2,0 \\
2,0 \\
4,0\end{array}$ \\
\hline $\begin{array}{l}\text { Ue } 200 \times 50 \times 20 \times 1,0 \\
\text { Ue } 200 \times 50 \times 20 \times 2,0 \\
\text { Ue } 200 \times 50 \times 20 \times 4,0\end{array}$ & $\begin{array}{l}200 \\
200 \\
200 \\
\end{array}$ & $\begin{array}{l}50 \\
50 \\
50\end{array}$ & $\begin{array}{l}20 \\
20 \\
20 \\
\end{array}$ & $\begin{array}{l}1,0 \\
2,0 \\
4,0 \\
\end{array}$ \\
\hline $\begin{array}{l}\text { Ue } 200 \times 50 \times 30 \times 1,0 \\
\text { Ue } 200 \times 50 \times 30 \times 2,0 \\
\text { Ue } 200 \times 50 \times 30 \times 4,0\end{array}$ & $\begin{array}{l}200 \\
200 \\
200 \\
\end{array}$ & $\begin{array}{l}50 \\
50 \\
50 \\
\end{array}$ & $\begin{array}{l}30 \\
30 \\
30 \\
\end{array}$ & $\begin{array}{l}1,0 \\
2,0 \\
4,0 \\
\end{array}$ \\
\hline $\begin{array}{l}\text { Ue } 200 \times 100 \times 10 \times 1,0 \\
\text { Ue } 200 \times 100 \times 10 \times 1,5 \\
\text { Ue } 200 \times 100 \times 10 \times 2,0 \\
\text { Ue } 200 \times 150 \times 10 \times 2,0 \\
\text { Ue } 200 \times 100 \times 15 \times 2,0 \\
\text { Ue } 200 \times 100 \times 10 \times 2,5 \\
\text { Ue } 200 \times 100 \times 10 \times 3,0 \\
\text { Ue } 200 \times 100 \times 10 \times 3,5 \\
\text { Ue } 200 \times 100 \times 10 \times 4,0\end{array}$ & $\begin{array}{l}200 \\
200 \\
200 \\
200 \\
200 \\
200 \\
200 \\
200 \\
200\end{array}$ & $\begin{array}{l}100 \\
100 \\
100 \\
100 \\
100 \\
100 \\
100 \\
100 \\
100\end{array}$ & $\begin{array}{l}10 \\
10 \\
10 \\
10 \\
15 \\
10 \\
10 \\
10 \\
10\end{array}$ & $\begin{array}{l}1,0 \\
1,5 \\
2,0 \\
2,0 \\
2,0 \\
2,5 \\
3,0 \\
3,5 \\
4,0\end{array}$ \\
\hline $\begin{array}{l}\text { Ue } 200 \times 100 \times 20 \times 1,0 \\
\text { Ue } 200 \times 100 \times 20 \times 2,0 \\
\text { Ue } 200 \times 100 \times 25 \times 2,0 \\
\text { Ue } 200 \times 100 \times 20 \times 4,0\end{array}$ & $\begin{array}{l}200 \\
200 \\
200 \\
200\end{array}$ & $\begin{array}{l}100 \\
100 \\
100 \\
100\end{array}$ & $\begin{array}{l}20 \\
20 \\
25 \\
20\end{array}$ & $\begin{array}{l}1,0 \\
2,0 \\
2,0 \\
4,0\end{array}$ \\
\hline $\begin{array}{l}\text { Ue } 200 \times 100 \times 30 \times 1,0 \\
\text { Ue } 200 \times 100 \times 30 \times 2,0 \\
\text { Ue } 200 \times 100 \times 30 \times 4,0\end{array}$ & $\begin{array}{l}200 \\
200 \\
200\end{array}$ & $\begin{array}{l}100 \\
100 \\
100\end{array}$ & $\begin{array}{l}30 \\
30 \\
30\end{array}$ & $\begin{array}{l}1,0 \\
2,0 \\
4,0\end{array}$ \\
\hline $\begin{array}{l}\text { Ue } 200 \times 200 \times 10 \times 1,0 \\
\text { Ue } 200 \times 200 \times 10 \times 2,0 \\
\text { Ue } 200 \times 200 \times 10 \times 4,0\end{array}$ & $\begin{array}{l}200 \\
200 \\
200 \\
\end{array}$ & $\begin{array}{l}200 \\
200 \\
200 \\
\end{array}$ & $\begin{array}{l}10 \\
10 \\
10 \\
\end{array}$ & $\begin{array}{l}1,0 \\
2,0 \\
4,0 \\
\end{array}$ \\
\hline $\begin{array}{l}\text { Ue } 200 \times 200 \times 20 \times 1,0 \\
\text { Ue } 200 \times 200 \times 20 \times 2,0 \\
\text { Ue } 200 \times 200 \times 20 \times 4,0\end{array}$ & $\begin{array}{l}200 \\
200 \\
200\end{array}$ & $\begin{array}{l}200 \\
200 \\
200\end{array}$ & $\begin{array}{l}20 \\
20 \\
20\end{array}$ & $\begin{array}{l}1,0 \\
2,0 \\
4,0\end{array}$ \\
\hline $\begin{array}{l}\text { Ue } 200 \times 200 \times 30 \times 1,0 \\
\text { Ue } 200 \times 200 \times 30 \times 2,0 \\
\text { Ue } 200 \times 200 \times 30 \times 4,0\end{array}$ & $\begin{array}{l}200 \\
200 \\
200\end{array}$ & $\begin{array}{l}200 \\
200 \\
200\end{array}$ & $\begin{array}{l}30 \\
30 \\
30\end{array}$ & $\begin{array}{l}1,0 \\
2,0 \\
4,0\end{array}$ \\
\hline
\end{tabular}

Entende-se que estes perfis apresentados na tabela 3.3 cobrem uma gama razoável dentre os perfis interessantes de serem analisados com relação ao fenômeno da flambagem por distorção. Obviamente, para que os resultados apresentados no presente trabalho fossem suficientes para se afirmar algumas conclusões com total certeza, mais perfis deveriam ser analisados. Entretanto, 
entende-se que o objetivo do trabalho não é encerrar o assunto, mas dar um direcionamento criterioso à abordagem do fenômeno da flambagem.

Além disso, tentou-se abranger não somente os perfis que atendem a relação $b_{f} / b_{w}$, referente às tabelas $D .1$ e $D .2$ do Anexo $D$ da NBR 14762:2001, e que são apresentadas no presente trabalho como as tabelas 2.3 e 2.4 , mas também perfis que não atendem esta relação, de modo a verificar, mesmo que de uma forma superficial, a validade de tais tabelas.

OBS.:

Para todas as tabelas de perfis apresentadas, os perfis abaixo (e inclusive) do perfil com dimensões $b_{w}, b_{f}$, $D$ e $t$, sendo, respectivamente $200 \times 100 \times 10 \times 1$ $\mathrm{mm}$ (designados por Ue 2111 - caso de perfis do tipo enrijecido, ou Ze 2111 - caso de perfis do tipo $Z$ enrijecido) respeitam as tabelas D.1 e D.2 do Anexo D da NBR 14762:2001, e que são apresentadas no presente trabalho como as tabelas $2.3 \mathrm{e}$ 2.4. Os demais perfis não respeitam as relações destas tabelas.

\subsection{COMPARAÇÃO: MÉTODO DAS FAIXAS FINITAS E PROCEDIMENTO DA NBR 14762: 2001 - PERFIS DO TIPO Ue}

Apresentam-se os resultados das análises elásticas realizadas via método das faixas finitas (programa CUFSM) e via procedimento da NBR 14762:2001 (Tabelas 3.4 a 3.7), além dos resultados comparativos entre os dois procedimentos (Tabelas 3.8 e 3.9 e Figuras 3.5 a 3.18), com relação à compressão centrada e à flexão. 
Tabela 3.4 - Resultados via método das faixas finitas para compressão centrada

\begin{tabular}{|c|c|c|c|c|c|}
\hline \multirow{3}{*}{ PERFIL Ue } & \multicolumn{5}{|c|}{ FAIXAS FINITAS - CUFSM } \\
\hline & $\mathbf{L}_{d}$ & $\sigma_{\text {dist }}$ & $L_{\text {local }}$ & $\sigma_{\text {local }}$ & \multirow{2}{*}{ MODO } \\
\hline & $(\mathrm{cm})$ & $\left(\mathrm{kN} / \mathrm{cm}^{2}\right)$ & $(\mathrm{cm})$ & $\left(\mathrm{kN} / \mathrm{cm}^{2}\right)$ & \\
\hline Ue $200 \times 50 \times 10 \times 1,0$ & * & $*$ & 15,50 & 2,69 & $\mathrm{~L}$ \\
\hline Ue $200 \times 50 \times 10 \times 2,0$ & 18,32 & 10,40 & * & * & $\mathrm{D}$ \\
\hline Ue $200 \times 50 \times 10 \times 4,0$ & 21,19 & 35,25 & * & * & $\mathrm{D}$ \\
\hline Ue $200 \times 50 \times 20 \times 1,0$ & $*$ & * & 15,50 & 2,72 & $\mathrm{~L}$ \\
\hline Ue $200 \times 50 \times 20 \times 2,0$ & * & * & 15,18 & 10,94 & $L$ \\
\hline Ue $200 \times 50 \times 20 \times 4,0$ & 17,56 & 42,38 & $*$ & $*$ & $\mathrm{D}$ \\
\hline Ue $200 \times 50 \times 30 \times 1,0$ & 101,52 & 10,35 & 15,50 & 2,73 & $\mathrm{~L}$ \\
\hline Ue $200 \times 50 \times 30 \times 2,0$ & 68,28 & 21,85 & 15,18 & 11,02 & $\mathrm{~L}$ \\
\hline Ue $200 \times 50 \times 30 \times 4,0$ & 44,93 & 48,83 & 14,55 & 44,53 & $\mathrm{~L}$ \\
\hline Ue $200 \times 100 \times 10 \times 1,0$ & 69,71 & 4,00 & 15,50 & 2,52 & $L$ \\
\hline Ue $200 \times 100 \times 10 \times 2,0$ & 46,89 & 9,46 & 15,18 & 10,09 & $\mathrm{D}$ \\
\hline Ue $200 \times 100 \times 10 \times 4,0$ & 30,85 & 26,56 & * & $*$ & $D$ \\
\hline Ue $200 \times 100 \times 20 \times 1,0$ & 122,51 & 7,77 & 15,50 & 2,53 & L \\
\hline Ue $200 \times 100 \times 20 \times 2,0$ & 82,41 & 16,81 & 15,18 & 10,24 & $\mathrm{~L}$ \\
\hline Ue $200 \times 100 \times 20 \times 4,0$ & 54,23 & 39,26 & 14,55 & 41,90 & $\mathrm{D}$ \\
\hline Ue $200 \times 100 \times 30 \times 1,0$ & 178,42 & 10,82 & 15,50 & 2,53 & L \\
\hline Ue $200 \times 100 \times 30 \times 2,0$ & 120,01 & 22,68 & 15,18 & 10,26 & $\mathrm{~L}$ \\
\hline Ue $200 \times 100 \times 30 \times 4,0$ & 78,97 & 50,18 & 14,55 & 42,2 & $L$ \\
\hline Ue $200 \times 200 \times 10 \times 1,0$ & 122,51 & 1,33 & 22,57 & 1,86 & $\mathrm{D}$ \\
\hline Ue $200 \times 200 \times 10 \times 2,0$ & 82,41 & 3,04 & * & $*$ & $\mathrm{D}$ \\
\hline Ue $200 \times 200 \times 10 \times 4,0$ & 54,23 & 8,20 & * & * & $\mathrm{D}$ \\
\hline Ue $200 \times 200 \times 20 \times 1,0$ & 178,42 & 2,90 & 18,70 & 1,92 & $\mathrm{~L}$ \\
\hline Ue $200 \times 200 \times 20 \times 2,0$ & 120,01 & 6,20 & 22,11 & 7,68 & $\mathrm{D}$ \\
\hline Ue $200 \times 200 \times 20 \times 4,0$ & 95,30 & 13,91 & $*$ & $*$ & $\mathrm{D}$ \\
\hline Ue $200 \times 200 \times 30 \times 1,0$ & 259,84 & 4,42 & 18,70 & 1,93 & $L$ \\
\hline Ue $200 \times 200 \times 30 \times 2,0$ & 174,78 & 9,21 & 18,32 & 7,80 & $\mathrm{~L}$ \\
\hline Ue $200 \times 200 \times 30 \times 4,0$ & 115,01 & 20,03 & 21,19 & 31,23 & $\mathrm{D}$ \\
\hline \multicolumn{6}{|l|}{$\begin{array}{l}\text { (*) Modo não evidenciado } \\
\text { L: Modo local crítico } \\
\text { D: Modo distorcional crítico }\end{array}$} \\
\hline
\end{tabular}


Tabela 3.5 - Resultados via NBR 14762:2001 para compressão centrada

\begin{tabular}{|c|c|c|c|}
\hline \multirow{3}{*}{ PERFIL Ue } & \multicolumn{3}{|c|}{ ANEXO D - NBR 14762:2001 } \\
\hline & $\mathbf{L}_{d}$ & $\sigma_{\text {dist }}$ & MODO \\
\hline & $(\mathrm{cm})$ & $\left(\mathrm{kN} / \mathrm{cm}^{2}\right)$ & $\begin{array}{c}\text { NBR } 14762 \\
\text { (TAB. D1) }\end{array}$ \\
\hline Ue $200 \times 50 \times 10 \times 1,0$ & 52,90 & 1,76 & NA \\
\hline Ue $200 \times 50 \times 10 \times 2,0$ & 37,80 & 7,25 & NA \\
\hline Ue $200 \times 50 \times 10 \times 4,0$ & 27,80 & 34,00 & NA \\
\hline Ue $200 \times 50 \times 20 \times 1,0$ & 86,40 & 9,41 & NA \\
\hline Ue $200 \times 50 \times 20 \times 2,0$ & 61,20 & 20,91 & NA \\
\hline Ue $200 \times 50 \times 20 \times 4,0$ & 43,50 & 52,56 & NA \\
\hline Ue $200 \times 50 \times 30 \times 1,0$ & 114,50 & 14,00 & NA \\
\hline Ue $200 \times 50 \times 30 \times 2,0$ & 81,00 & 30,06 & NA \\
\hline Ue $200 \times 50 \times 30 \times 4,0$ & 57,40 & 67,45 & NA \\
\hline Ue $200 \times 100 \times 10 \times 1,0$ & 76,30 & 4,14 & $\mathrm{~L}$ \\
\hline Ue $200 \times 100 \times 10 \times 2,0$ & 55,00 & 9,93 & $L^{*}$ \\
\hline Ue $200 \times 100 \times 10 \times 4,0$ & 41,40 & 27,33 & $\mathrm{D}$ \\
\hline Ue $200 \times 100 \times 20 \times 1,0$ & 125,60 & 7,79 & $\mathrm{~L}$ \\
\hline Ue $200 \times 100 \times 20 \times 2,0$ & 89,00 & 17,22 & $\mathrm{~L}$ \\
\hline Ue $200 \times 100 \times 20 \times 4,0$ & 63,60 & 40,17 & $\mathrm{D}$ \\
\hline Ue $200 \times 100 \times 30 \times 1,0$ & 167,70 & 10,46 & $\mathrm{~L}$ \\
\hline Ue $200 \times 100 \times 30 \times 2,0$ & 118,70 & 22,78 & $\mathrm{~L}$ \\
\hline Ue $200 \times 100 \times 30 \times 4,0$ & 84,20 & 51,04 & $\mathrm{~L}$ \\
\hline Ue $200 \times 200 \times 10 \times 1,0$ & 109,50 & 1,39 & $D$ \\
\hline Ue $200 \times 200 \times 10 \times 2,0$ & 80,20 & 3,39 & $D$ \\
\hline Ue $200 \times 200 \times 10 \times 4,0$ & 62,90 & 9,66 & $\mathrm{D}$ \\
\hline Ue $200 \times 200 \times 20 \times 1,0$ & 180,50 & 2,78 & $\mathrm{~L}$ \\
\hline Ue $200 \times 200 \times 20 \times 2,0$ & 128,30 & 6,21 & $D$ \\
\hline Ue $200 \times 200 \times 20 \times 4,0$ & 92,40 & 14,65 & $\mathrm{D}$ \\
\hline Ue $200 \times 200 \times 30 \times 1,0$ & 242,50 & 4,05 & $\mathrm{~L}$ \\
\hline Ue $200 \times 200 \times 30 \times 2,0$ & 171,70 & 8,88 & $\mathrm{~L}$ \\
\hline Ue $200 \times 200 \times 30 \times 4,0$ & 122,10 & 20,02 & $\mathrm{D}$ \\
\hline \multicolumn{4}{|c|}{$\begin{array}{l}\text { Notas: } \\
\left({ }^{\star}\right) \text { Para este perfil, o modo crítico conforme a NBR } 14762 \text { é o local e conforme } \\
\text { a análise via faixas finitas é o distorcional } \\
\text { L: Modo local crítico } \\
\text { D: Modo distorcional crítico } \\
\text { NA: O perfil não atende a relação } \mathrm{b}_{\mathrm{f}} / \mathrm{b}_{\mathrm{w}} \text {, referente às tabelas D. } 1 \text { e D. } 2 \text { do } \\
\text { Anexo D da NBR } 14762: 2001 \text {, e que são apresentadas no presente trabalho } \\
\text { como as tabelas } 2.3 \text { e } 2.4\end{array}$} \\
\hline
\end{tabular}


Tabela 3.6 - Resultados via método das faixas finitas para flexão

\begin{tabular}{|c|c|c|c|c|c|}
\hline \multirow{3}{*}{ PERFIL Ue } & \multicolumn{5}{|c|}{ FAIXAS FINITAS - CUeFSM } \\
\hline & $\mathbf{L}_{d}$ & $\sigma_{\text {dist }}$ & $L_{\text {local }}$ & $\sigma_{\text {local }}$ & \multirow{2}{*}{ MODO } \\
\hline & $(\mathrm{cm})$ & $\left(\mathrm{kN} / \mathrm{cm}^{2}\right)$ & $(\mathrm{cm})$ & $\left(\mathrm{kN} / \mathrm{cm}^{2}\right)$ & \\
\hline Ue $200 \times 50 \times 10 \times 1,0$ & 39,66 & 16,89 & 10,64 & 14,65 & $\mathrm{~L}$ \\
\hline Ue $200 \times 50 \times 10 \times 2,0$ & 26,68 & 41,08 & $*$ & * & $\mathrm{D}$ \\
\hline Ue $200 \times 50 \times 10 \times 4,0$ & 17,56 & 121,4 & $*$ & * & $\mathrm{D}$ \\
\hline Ue $200 \times 50 \times 20 \times 1,0$ & 69,71 & 28,04 & 10,64 & 14,74 & $\mathrm{~L}$ \\
\hline Ue $200 \times 50 \times 20 \times 2,0$ & 46,89 & 61,64 & 10,42 & 2,39 & $\mathrm{~L}$ \\
\hline Ue $200 \times 50 \times 20 \times 4,0$ & 30,85 & 148,92 & $*$ & $*$ & $\mathrm{D}$ \\
\hline Ue $200 \times 50 \times 30 \times 1,0$ & 84,12 & 33,66 & 10,64 & 14,66 & $\mathrm{~L}$ \\
\hline Ue $200 \times 50 \times 30 \times 2,0$ & 68,28 & 71,07 & 10,42 & 59,52 & $\mathrm{~L}$ \\
\hline Ue $200 \times 50 \times 30 \times 4,0$ & 44,93 & 158,91 & 12,05 & 243,00 & $\mathrm{D}$ \\
\hline Ue $200 \times 100 \times 10 \times 1,0$ & 69,71 & 6,05 & 10,64 & 8,63 & $\mathrm{D}$ \\
\hline Ue $200 \times 100 \times 10 \times 2,0$ & 46,89 & 13,86 & * & $*$ & $\mathrm{D}$ \\
\hline Ue $200 \times 100 \times 10 \times 4,0$ & 30,85 & 36,86 & $*$ & $*$ & $\mathrm{D}$ \\
\hline Ue $200 \times 100 \times 20 \times 1,0$ & 122,51 & 12,51 & 10,64 & 8,93 & $\mathrm{~L}$ \\
\hline Ue $200 \times 100 \times 20 \times 2,0$ & 82,41 & 26,68 & 10,42 & 36,03 & $\mathrm{D}$ \\
\hline Ue $200 \times 100 \times 20 \times 4,0$ & 54,23 & 61,16 & $*$ & $*$ & $\mathrm{D}$ \\
\hline Ue $200 \times 100 \times 30 \times 1,0$ & 147,85 & 18,03 & 10,64 & 8,87 & $\mathrm{~L}$ \\
\hline Ue $200 \times 100 \times 30 \times 2,0$ & 99,45 & 38,00 & 10,42 & 36,03 & $\mathrm{~L}$ \\
\hline Ue $200 \times 100 \times 30 \times 4,0$ & 65,44 & 84,22 & 10,00 & 148,44 & $\mathrm{D}$ \\
\hline Ue $200 \times 200 \times 10 \times 1,0$ & 101,52 & 1,58 & 18,70 & 2,17 & $\mathrm{D}$ \\
\hline Ue $200 \times 200 \times 10 \times 2,0$ & 68,28 & 3,58 & * & * & $\mathrm{D}$ \\
\hline Ue $200 \times 200 \times 10 \times 4,0$ & 54,23 & 9,42 & * & * & $\mathrm{D}$ \\
\hline Ue $200 \times 200 \times 20 \times 1,0$ & 178,42 & 3,59 & 18,70 & 2,27 & $\mathrm{~L}$ \\
\hline Ue $200 \times 200 \times 20 \times 2,0$ & 120,01 & 7,56 & 18,32 & 9,06 & $\mathrm{D}$ \\
\hline Ue $200 \times 200 \times 20 \times 4,0$ & 78,97 & 16,82 & $*$ & $*$ & $\mathrm{D}$ \\
\hline Ue $200 \times 200 \times 30 \times 1,0$ & 259,84 & 5,76 & 18,70 & 2,31 & $\mathrm{~L}$ \\
\hline Ue $200 \times 200 \times 30 \times 2,0$ & 174,78 & 11,87 & 18,32 & 9,29 & $\mathrm{~L}$ \\
\hline Ue $200 \times 200 \times 30 \times 4,0$ & 115,01 & 25,41 & 17,56 & 37,41 & $\mathrm{D}$ \\
\hline \multicolumn{6}{|c|}{$\begin{array}{l}\text { (*) Modo não evidenciado } \\
\text { L: Modo local crítico } \\
\text { D: Modo distorcional crítico }\end{array}$} \\
\hline
\end{tabular}


Tabela 3.7 - Resultados via NBR 14762:2001 para flexão

\begin{tabular}{|c|c|c|c|}
\hline \multirow{3}{*}{ PERFIL Ue } & \multicolumn{3}{|c|}{ ANEXO D - NBR 14762:2001 } \\
\hline & $L_{d}$ & $\sigma_{\text {dist }}$ & MODO \\
\hline & $(\mathrm{cm})$ & $\left(\mathrm{kN} / \mathrm{cm}^{2}\right)$ & $\begin{array}{c}\text { NBR } 14762 \\
\text { (TAB. D2) }\end{array}$ \\
\hline Ue $200 \times 50 \times 10 \times 1,0$ & 44,5 & 17,58 & NA \\
\hline Ue $200 \times 50 \times 10 \times 2,0$ & 31,8 & 40,95 & NA \\
\hline Ue $200 \times 50 \times 10 \times 4,0$ & 23,4 & 107,22 & NA \\
\hline Ue $200 \times 50 \times 20 \times 1,0$ & 72,7 & 27,31 & NA \\
\hline Ue $200 \times 50 \times 20 \times 2,0$ & 51,5 & 59,24 & NA \\
\hline Ue $200 \times 50 \times 20 \times 4,0$ & 36,6 & 134,42 & NA \\
\hline Ue $200 \times 50 \times 30 \times 1,0$ & 96,3 & 26,84 & NA \\
\hline Ue $200 \times 50 \times 30 \times 2,0$ & 68,1 & 56,83 & NA \\
\hline Ue $200 \times 50 \times 30 \times 4,0$ & 48,3 & 122,55 & NA \\
\hline Ue $200 \times 100 \times 10 \times 1,0$ & 64,2 & 6,74 & $\mathrm{D}$ \\
\hline Ue $200 \times 100 \times 10 \times 2,0$ & 46,2 & 15,64 & $\mathrm{D}$ \\
\hline Ue $200 \times 100 \times 10 \times 4,0$ & 34,8 & 41,16 & $\mathrm{D}$ \\
\hline Ue $200 \times 100 \times 20 \times 1,0$ & 105,6 & 12,22 & $\mathrm{~L}$ \\
\hline Ue $200 \times 100 \times 20 \times 2,0$ & 74,9 & 26,60 & $\mathrm{D}$ \\
\hline Ue $200 \times 100 \times 20 \times 4,0$ & 53,5 & 60,42 & D \\
\hline Ue $200 \times 100 \times 30 \times 1,0$ & 141,0 & 16,14 & $\mathrm{~L}$ \\
\hline Ue $200 \times 100 \times 30 \times 2,0$ & 99,8 & 34,78 & $\mathrm{~L}$ \\
\hline Ue $200 \times 100 \times 30 \times 4,0$ & 70,8 & 76,44 & $\mathrm{D}$ \\
\hline Ue $200 \times 200 \times 10 \times 1,0$ & 92,1 & 1,96 & $\mathrm{D}$ \\
\hline Ue $200 \times 200 \times 10 \times 2,0$ & 67,4 & 4,66 & $\mathrm{D}$ \\
\hline Ue $200 \times 200 \times 10 \times 4,0$ & 52,9 & 12,89 & $\mathrm{D}$ \\
\hline Ue $200 \times 200 \times 20 \times 1,0$ & 151,8 & 4,02 & $L$ \\
\hline Ue $200 \times 200 \times 20 \times 2,0$ & 107,9 & 8,81 & $\mathrm{D}$ \\
\hline Ue $200 \times 200 \times 20 \times 4,0$ & 77,7 & 20,28 & $\mathrm{D}$ \\
\hline Ue $200 \times 200 \times 30 \times 1,0$ & 203,9 & 5,90 & $\mathrm{~L}$ \\
\hline Ue $200 \times 200 \times 30 \times 2,0$ & 144,4 & 12,77 & $L$ \\
\hline Ue $200 \times 200 \times 30 \times 4,0$ & 102,7 & 28,24 & $\mathrm{D}$ \\
\hline \multicolumn{4}{|c|}{$\begin{array}{l}\text { Notas: } \\
\text { L: Modo local crítico } \\
\text { D: Modo distorcional crítico } \\
\text { NA: O perfil não atende a relação } b_{\mathrm{f}} / \mathrm{b}_{\mathrm{w}} \text {, referente às tabelas } D .1 \text { e D.2 } \\
\text { do Anexo D da NBR } 14762: 2001 \text {, e que são apresentadas no presente } \\
\text { trabalho como as tabelas } 2.3 \text { e } 2.4\end{array}$} \\
\hline
\end{tabular}


Algumas conclusões parciais podem ser elaboradas, quando da análise das tabelas 3.4 a 3.7 :

Tanto para a análise via faixas finitas quanto para a análise via procedimento da NBR 14762:2201, os mesmos perfis, quando submetidos à flexão, apresentam maiores valores de $\sigma_{\text {dist }}$, quando comparados com os submetidos à compressão. Estas diferenças podem ser explicadas (com mais segurança nos casos dos perfis que atendem as relações de condições das tabelas D.1 e D.2 da NBR 14762:2001), em parte, pois os perfis submetidos a flexão possuem uma das mesas e mais uma porção da alma tracionada, e portanto, não sujeita à instabilidade. Tal fato faz com que o conjunto de elementos da seção transversal que são conectados ao conjunto comprimido (mesa e enrijecedor) seja mais eficiente no sentido de evitar a instabilidade.

Em particular para a análise via faixas finitas, a diferença entre estes valores é mais pronunciada (em torno de $300 \%$ ) para os perfis que não respeitam as condições das tabelas D.1 e D.2 da NBR 14762:2001, pois para os perfis que respeitam tais relações, a diferença é menor (de 20 a 45\%). Por outro lado, os valores de $L_{d}$ dos perfis submetidos à flexão, quando comparados com os submetidos à compressão centrada são iguais ou um pouco menores (em torno de $20 \%$ ou menos). No que se refere à flambagem local, em alguns casos os valores de $\sigma_{l}$ são próximos dos referentes à flambagem por distorção, mas tal proximidade depende de vários fatores, como, por exemplo, larguras nominais dos elementos que compõem a seção transversal e relações entre eles.

Para o caso da análise via procedimento da NBR 14762:2001, a diferença entre estes valores também é mais pronunciada (varia de $80 \%$ a $500 \%$ ) para os perfis que não respeitam as condições das tabelas D.1 e D.2 da NBR 14762:2001, pois para os perfis que respeitam tais relações, a diferença é menor (em torno de $50 \%$ ). Por outro lado, os valores de $L_{d}$ dos perfis submetidos à flexão, quando comparados com os submetidos à compressão centrada também são iguais ou um pouco menores (em torno de $20 \%$ ou menos).

Dentre os perfis analisados, os modos críticos relativos à análise via faixas finitas e via o procedimento da NBR 14762:2001 sempre foram os mesmos, com exceção do perfil Ue 200 x 10010 x 2,0, que apresentou conforme a NBR 14762 o modo local como crítico, e conforme a análise via faixas finitas o modo distorcional. 
Alguns resultados são apresentados nas tabelas 3.8 e 3.9 e nas figuras 3.5 a 3.18, no que se refere à comparação entre o procedimento das faixas finitas e o procedimento da NBR 14762:2001, podendo-se perceber que:

Com relação à compressão centrada, os valores de $\sigma_{\text {dist }}$ referentes ao procedimento da NBR 14762:2001, para os perfis que não respeitam as relações das tabelas D.1 e D.2 da NBR 14762:2001, são iguais ou superiores (de 20 a 40\%) aos valores referentes à análise via faixas finitas, o que mostra que o procedimento da NBR 14762:2001 estaria de certo modo contra a segurança (pois, teoricamente, os perfis, conforme a NBR 14762:2001 atingem a instabilidade por distorção após atingirem a tensão que deveria ser a responsável pela instabilidade conforme a análise via faixas finitas). Por outro lado, para os perfis que respeitam as relações das tabelas D.1 e D.2 da NBR 14762:2001, os valores de $\sigma_{\text {dist }}$ referentes ao procedimento da NBR 14762:2001 são aproximadamente iguais (variação média em torno de 3,6\%) aos valores referentes à análise via faixas finitas, o que mostra que o procedimento da NBR 14762:2001 estaria de certo modo a favor da segurança.

No que se refere aos valores de $L_{d}$, observa-se que os valores referentes ao procedimento da NBR 14762:2001, para os perfis que não respeitam as relações das tabelas D.1 e D.2 da NBR 14762:2001, são superiores (de 13 a 150\%) aos valores referentes à análise via faixas finitas. Por outro lado, para os perfis que respeitam as relações das tabelas D.1 e D.2 da NBR 14762:2001, os valores de $L_{d}$ referentes ao procedimento da NBR 14762:2001 são aproximadamente iguais (variação média em torno de $5 \%$ ) aos valores referentes à análise via faixas finitas.

Com relação à flexão, os valores de $\sigma_{\text {dist }}$ referentes ao procedimento da NBR 14762:2001, para os perfis que não respeitam as relações das tabelas D.1 e D.2 da NBR 14762:2001, são iguais ou inferiores (de 3 a 23\%) aos valores referentes à análise via faixas finitas, o que mostra que o procedimento da NBR 14762:2001 estaria de certo modo a favor da segurança (pois, teoricamente, os perfis, conforme a NBR 14762:2001 atingem a instabilidade por distorção antes de atingirem a tensão que deveria ser a responsável pela instabilidade conforme a análise via faixas finitas). Por outro lado, para os perfis que respeitam as relações das tabelas D.1 e D.2 da NBR 14762:2001, os valores de $\sigma_{\text {dist }}$ referentes ao procedimento da NBR 14762:2001 são aproximadamente iguais (variação média 
em torno de 5\%) aos valores referentes à análise via faixas finitas, o que mostra que o procedimento da NBR 14762:2001 estaria também de certo modo a favor da segurança. Como exceção, cabe salientar que os perfis Ue $200 \times 200 \times 10 \times 1,0$, Ue $200 \times 200 \times 10 \times 2,0$ e também o perfil Ue $200 \times 200 \times 10 \times 4,0$ apresentaram valores de $\sigma_{\text {dist }}$ referentes ao procedimento da NBR 14762:2001 superiores (24, 30 e $37 \%$, respectivamente) aos valores referentes à análise via faixas finitas, o que mostra que o procedimento da NBR 14762:2001 estaria de certo modo contra a segurança. De antemão, pode-se dizer que estes três casos foram melhor analisados quando comparados com a análise via elementos finitos, no capítulo 4 (Tabela 4.8), por meio de um método que assim como o método das faixas finitas, considera a interação entre os elementos da seção transversal. Com isso, pôde-se perceber que os resultados relativos à análise via elementos finitos foram inferiores aos relativos à análise via NBR 14762:2001, mas superiores aos referentes à análise via faixas finitas. Entretanto, ficaram mais próximos aos resultados da análise via faixas finitas. Portanto, para estes perfis, o procedimento da norma NBR 14762:2001 parece apresentar resultados contra a segurança no que se refere ao cálculo de $\sigma_{\text {dist }}$.

No que se refere aos valores de $L_{d}$, observa-se que os valores referentes ao procedimento da NBR 14762:2001, para os perfis que não respeitam as relações das tabelas D.1 e D.2 da NBR 14762:2001, são iguais ou superiores (de 4 a 30\%) aos valores referentes à análise via faixas finitas. Por outro lado, para os perfis que respeitam as relações das tabelas D.1 e D.2 da NBR 14762:2001, os valores de $L_{d}$ referentes ao procedimento da NBR 14762:2001 são aproximadamente iguais (variação média em torno de 6\%) aos valores referentes à análise via faixas finitas.

Deve-se entender, que, por outro lado, a análise via faixas finitas considera explicitamente a interação entre os elementos que constituem a seção transversal (devido ao modelo considerar a seção toda como um conjunto, o que proporciona uma análise mais próxima da realidade), diferentemente do procedimento da NBR 14762:2001, que considera tal interação por meio de "molas", denominadas constantes de rigidez à rotação e à flexão. 
Tabela 3.8 - Relação entre NBR 14762 e faixas finitas para compressão centrada

\begin{tabular}{|c|c|c|}
\hline PERFIL Ue & $L_{d}$ & $\sigma_{\text {dist }}$ \\
\hline Ue $200 \times 50 \times 10 \times 1,0$ & * & * \\
\hline Ue $200 \times 50 \times 10 \times 2,0$ & 2,06 & 0,70 \\
\hline Ue $200 \times 50 \times 10 \times 4,0$ & 1,31 & 0,96 \\
\hline Ue $200 \times 50 \times 20 \times 1,0$ & $*$ & * \\
\hline Ue $200 \times 50 \times 20 \times 2,0$ & * & * \\
\hline Ue $200 \times 50 \times 20 \times 4,0$ & 2,48 & 1,24 \\
\hline Ue $200 \times 50 \times 30 \times 1,0$ & 1,13 & 1,35 \\
\hline Ue $200 \times 50 \times 30 \times 2,0$ & 1,19 & 1,38 \\
\hline Ue $200 \times 50 \times 30 \times 4,0$ & 1,28 & 1,38 \\
\hline Ue $200 \times 100 \times 10 \times 1,0$ & 1,09 & 1,04 \\
\hline Ue $200 \times 100 \times 10 \times 2,0$ & 1,17 & 1,05 \\
\hline Ue $200 \times 100 \times 10 \times 4,0$ & 1,34 & 1,03 \\
\hline Ue $200 \times 100 \times 20 \times 1,0$ & 1,02 & 1,00 \\
\hline Ue $200 \times 100 \times 20 \times 2,0$ & 1,08 & 1,02 \\
\hline Ue $200 \times 100 \times 20 \times 4,0$ & 1,17 & 1,02 \\
\hline Ue $200 \times 100 \times 30 \times 1,0$ & 0,94 & 0,97 \\
\hline Ue $200 \times 100 \times 30 \times 2,0$ & 0,99 & 1,00 \\
\hline Ue $200 \times 100 \times 30 \times 4,0$ & 1,07 & 1,02 \\
\hline Ue $200 \times 200 \times 10 \times 1,0$ & 0,89 & 1,05 \\
\hline Ue $200 \times 200 \times 10 \times 2,0$ & 0,97 & 1,12 \\
\hline Ue $200 \times 200 \times 10 \times 4,0$ & 1,16 & 1,18 \\
\hline Ue $200 \times 200 \times 20 \times 1,0$ & 1,01 & 0,96 \\
\hline Ue $200 \times 200 \times 20 \times 2,0$ & 1,07 & 1,00 \\
\hline Ue $200 \times 200 \times 20 \times 4,0$ & 0,97 & 1,05 \\
\hline Ue $200 \times 200 \times 30 \times 1,0$ & 0,93 & 0,92 \\
\hline Ue $200 \times 200 \times 30 \times 2,0$ & 0,98 & 0,96 \\
\hline Ue $200 \times 200 \times 30 \times 4,0$ & 1,06 & 1,00 \\
\hline \multicolumn{3}{|l|}{$\begin{array}{l}\text { Nota: } \\
\left(^{\star}\right) \text { Modo não evidenciad }\end{array}$} \\
\hline
\end{tabular}


Tabela 3.9 - Relação entre NBR 14762 e faixas finitas para flexão

\begin{tabular}{|l|c|c|}
\hline \multicolumn{1}{|c|}{ PERFIL Ue } & $\mathbf{L}_{d}$ & $\sigma_{\text {dist }}$ \\
\hline Ue $200 \times 50 \times 10 \times 1,0$ & 1,12 & 1,04 \\
\hline Ue $200 \times 50 \times 10 \times 2,0$ & 1,19 & 1,00 \\
\hline Ue $200 \times 50 \times 10 \times 4,0$ & 1,33 & 0,88 \\
\hline Ue $200 \times 50 \times 20 \times 1,0$ & 1,04 & 0,97 \\
\hline Ue $200 \times 50 \times 20 \times 2,0$ & 1,10 & 0,96 \\
\hline Ue $200 \times 50 \times 20 \times 4,0$ & 1,19 & 0,90 \\
\hline Ue $200 \times 50 \times 30 \times 1,0$ & 1,14 & 0,80 \\
\hline Ue $200 \times 50 \times 30 \times 2,0$ & 1,00 & 0,80 \\
\hline Ue $200 \times 50 \times 30 \times 4,0$ & 1,07 & 0,77 \\
\hline Ue $200 \times 100 \times 10 \times 1,0$ & 0,92 & 1,11 \\
\hline Ue $200 \times 100 \times 10 \times 2,0$ & 0,99 & 1,13 \\
\hline Ue $200 \times 100 \times 10 \times 4,0$ & 1,13 & 1,12 \\
\hline Ue $200 \times 100 \times 20 \times 1,0$ & 0,86 & 0,98 \\
\hline Ue $200 \times 100 \times 20 \times 2,0$ & 0,91 & 1,00 \\
\hline Ue $200 \times 100 \times 20 \times 4,0$ & 0,99 & 0,99 \\
\hline Ue $200 \times 100 \times 30 \times 1,0$ & 0,95 & 0,90 \\
\hline Ue $200 \times 100 \times 30 \times 2,0$ & 1,00 & 0,92 \\
\hline Ue $200 \times 100 \times 30 \times 4,0$ & 1,08 & 0,91 \\
\hline Ue $200 \times 200 \times 10 \times 1,0$ & 0,91 & 1,24 \\
\hline Ue $200 \times 200 \times 10 \times 2,0$ & 0,99 & 1,30 \\
\hline Ue $200 \times 200 \times 10 \times 4,0$ & 0,97 & 1,37 \\
\hline Ue $200 \times 200 \times 20 \times 1,0$ & 0,85 & 1,12 \\
\hline Ue $200 \times 200 \times 20 \times 2,0$ & 0,90 & 1,17 \\
\hline Ue $200 \times 200 \times 20 \times 4,0$ & 0,98 & 1,21 \\
\hline Ue $200 \times 200 \times 30 \times 1,0$ & 0,78 & 1,02 \\
\hline Ue $200 \times 200 \times 30 \times 2,0$ & 0,83 & 1,08 \\
\hline Ue $200 \times 200 \times 30 \times 4,0$ & 0,89 & 1,11 \\
\hline
\end{tabular}

São apresentados a seguir resultados comparativos relativos às tabelas 3.8 e 3.9, sendo que cabe explicar o significado de alguns símbolos importantes para o entendimento das figuras em questão, além de se apresentar uma legenda referente às siglas adotadas para fazer menção aos perfis analisados. 
$\sigma_{\text {dist }}$ é a tensão convencional de flambagem elástica por distorção, calculada pela teoria da estabilidade elástica, análise numérica ou conforme modelo simplificado da norma $\left(\mathrm{kN} / \mathrm{cm}^{2}\right)$.

$L_{d}$ é o comprimento da meia onda longitudinal associada à tensão convencional de flambagem elástica por distorção (cm).

Legenda (exemplo para o perfil do tipo Ue com dimensões $200 \times 100 \times 10 \times 2$ mm):

\section{U $2112-t=2 \mathrm{~mm}$}
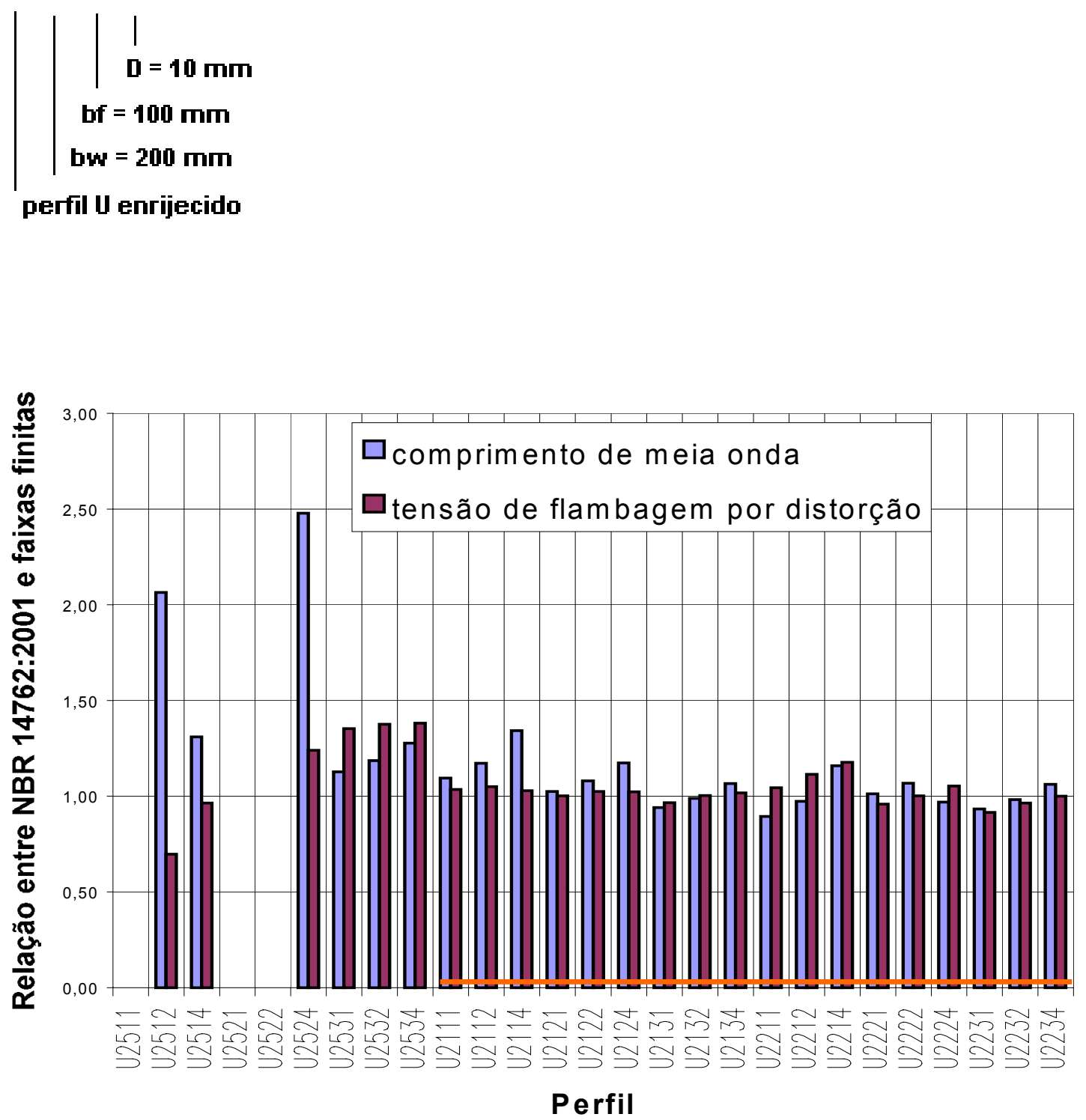

Figura $3.5-L_{d}$ e $\sigma_{\text {dist }}$ obtidos pela NBR 14762:2001 e via faixas finitas (CUFSM) para compressão centrada 


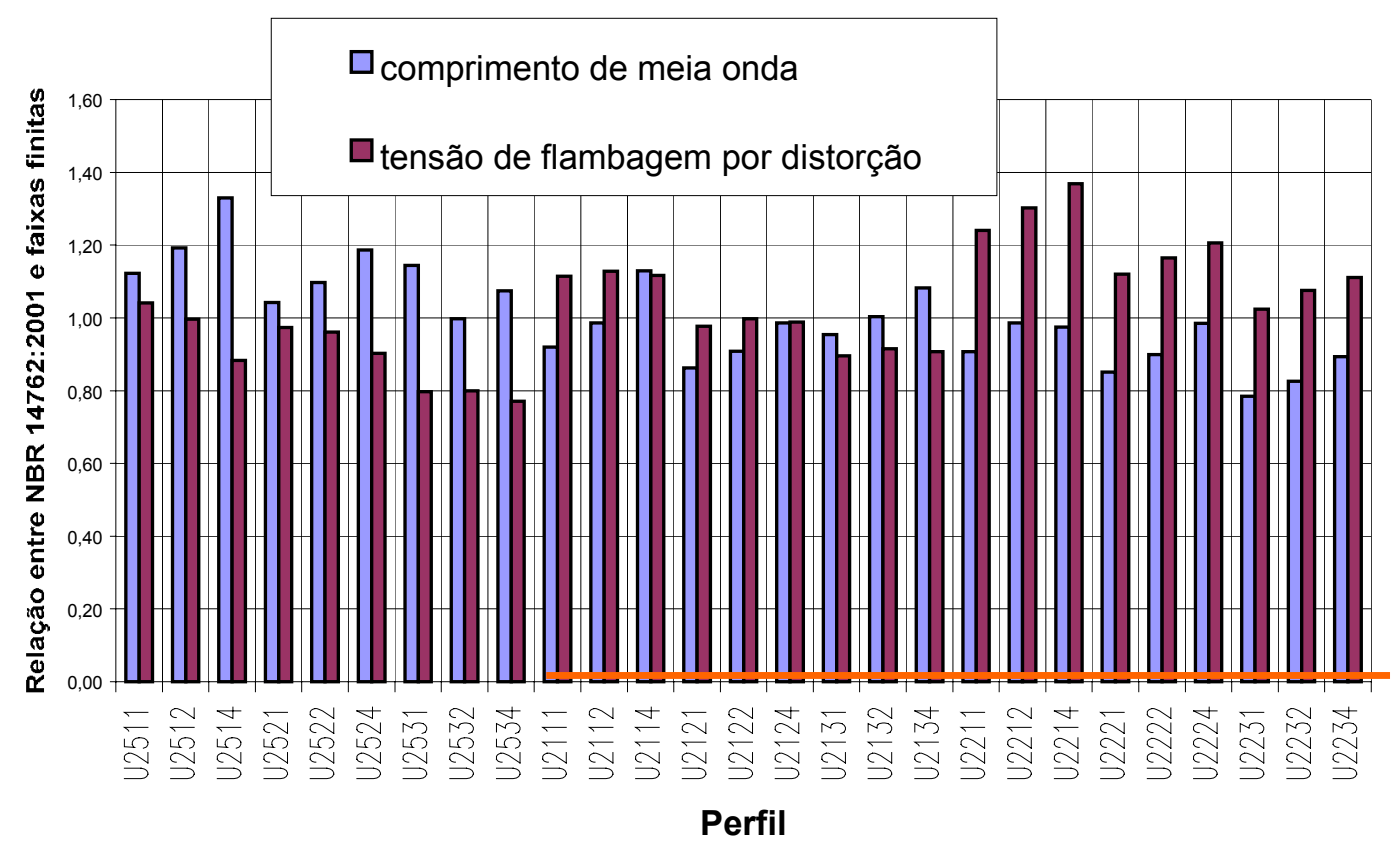

Figura 3.6 $-L_{d}$ e $\sigma_{\text {dist }}$ obtidos pela NBR 14762:2001 e via faixas finitas (CU-FSM) para flexão

OBS.: Com relação às figuras 3.5 e 3.6, existem alguns perfis que satisfazem as relações $b_{f} / b_{w}$ referentes ao Anexo D da NBR 14762:2001, e que portanto para os mesmos se pode utilizar o procedimento para o cálculo da flambagem por distorção (a partir do perfil Ue 2111, para a direita - perfis sublinhados com a linha de cor laranja).

A figura 3.5 não apresenta valores para alguns perfis. Tal fato ocorre, pois via faixas finitas, estes perfis não apresentaram ponto de mínimo relativo à flambagem por distorção, isto é, o modo distorcional não fica bem caracterizado na curva de flambagem, conforme ilustra a figura 3.7. 


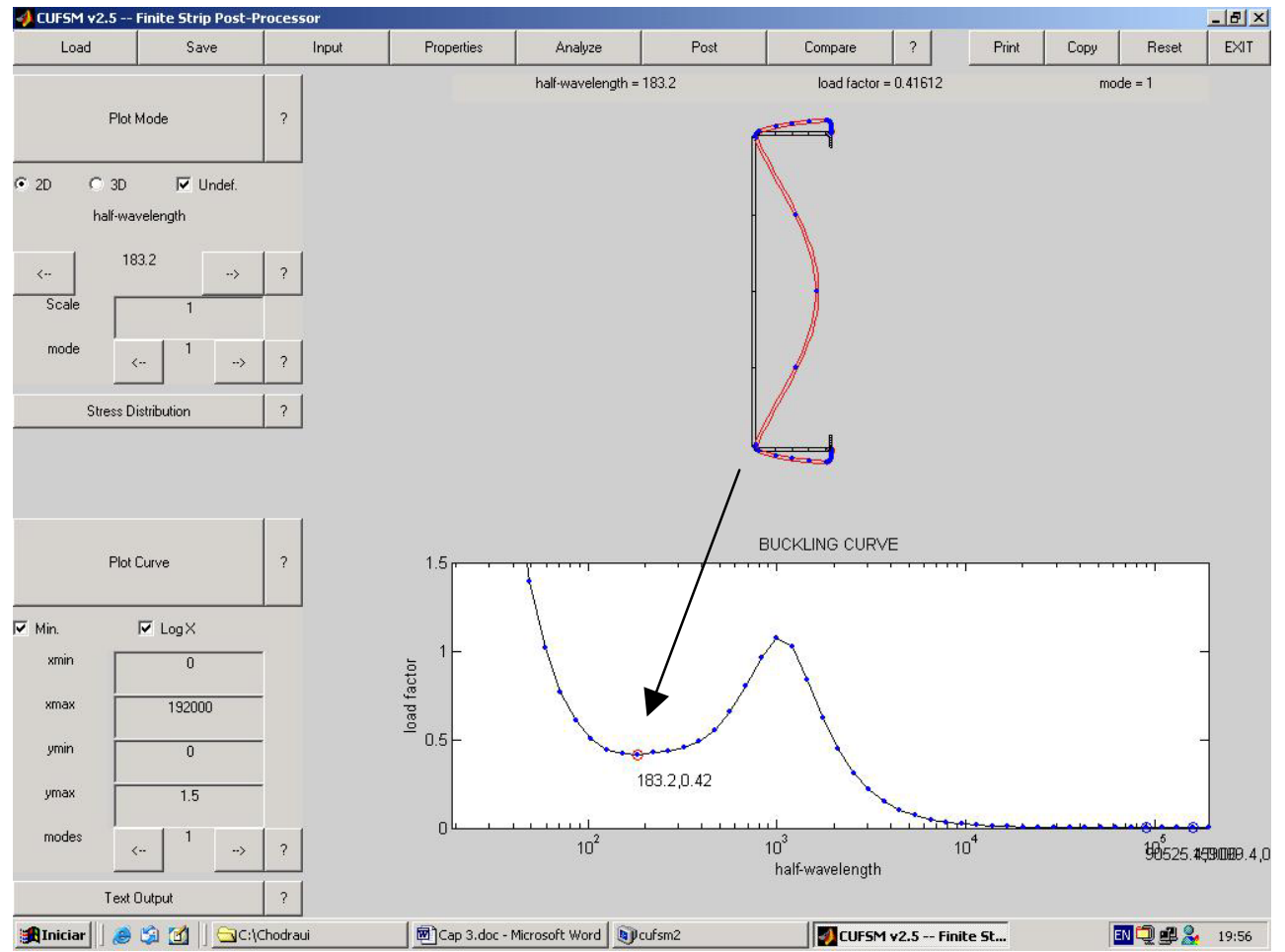

Figura 3.7 - Exemplo de caso: modo distorcional não evidenciado na curva de resistência apresentada pelo programa CUFSM. A figura ilustra a deformada da seção e o ponto de mínimo relativo ao modo local para compressão centrada

As figuras 3.8 a 3.19 a seguir ilustram análises realizadas para perfis do tipo $U$ enrijecido submetidos à compressão centrada e à flexão, para a avaliação da influência causada pela variação da dimensão da largura nominal de algum elemento da seção transversal da barra, quando da obtenção dos valores de $\sigma_{\text {dist }} \mathrm{e}$ $L_{d}$.

Pode-se perceber, com base nas figuras 3.8 a 3.13 , que a tensão de flambagem elástica por distorção $\sigma_{\text {dist }}$ aumenta em função do aumento da espessura e da largura do enrijecedor de borda, e diminui em função do aumento da largura da mesa. Na figura 3.10 pode-se observar uma faixa de valores da largura da mesa com diferenças relativamente elevadas entre o procedimento da NBR 14762 e os valores obtidos via faixas finitas, reforçando assim a necessidade de se atender a limitação da relação $b_{f} / b_{w}$ estabelecida pelo anexo $D$ da norma.

Pode-se perceber, com base nas figuras 3.14 a 3.19 , que os valores de $L_{d}$ também aumentam em função do aumento da espessura e da largura do enrijecedor de borda, e diminuem em função do aumento da largura da mesa. $\mathrm{Na}$ figura 3.16 pode-se observar uma faixa de valores da largura da mesa com 
diferenças relativamente elevadas entre o procedimento da NBR 14762 e os valores obtidos via faixas finitas, reforçando assim a necessidade de se atender a limitação da relação $b_{f} / b_{w}$ estabelecida pelo anexo $D$ da norma.

Portanto, com relação às figuras 3.10 e 3.16, de fato, os pontos relativos aos perfis que não atendem as relações $\mathbf{b}_{\mathbf{f}} / \mathbf{b}_{\mathbf{w}}$ prescritas pelo Anexo $D$ da NBR 14762:2001, apresentam discordâncias entre os resultados via faixas fintas e via procedimento da NBR 14762:2001. Tal fato pode ser um indício, mesmo que sem ampla análise quantitativa de dados para um julgamento, de uma possível confirmação da coerência, validade e necessidade de respeito às relações $\mathbf{b}_{\mathrm{f}} / \mathbf{b}_{\mathbf{w}}$ adotadas pela NBR 14762:2001. Entretanto, na figura 3.16, o "salto" no gráfico foi referente à análise via faixas finitas e não referente ao procedimento da NBR 14762:2001, como na figura 3.10.

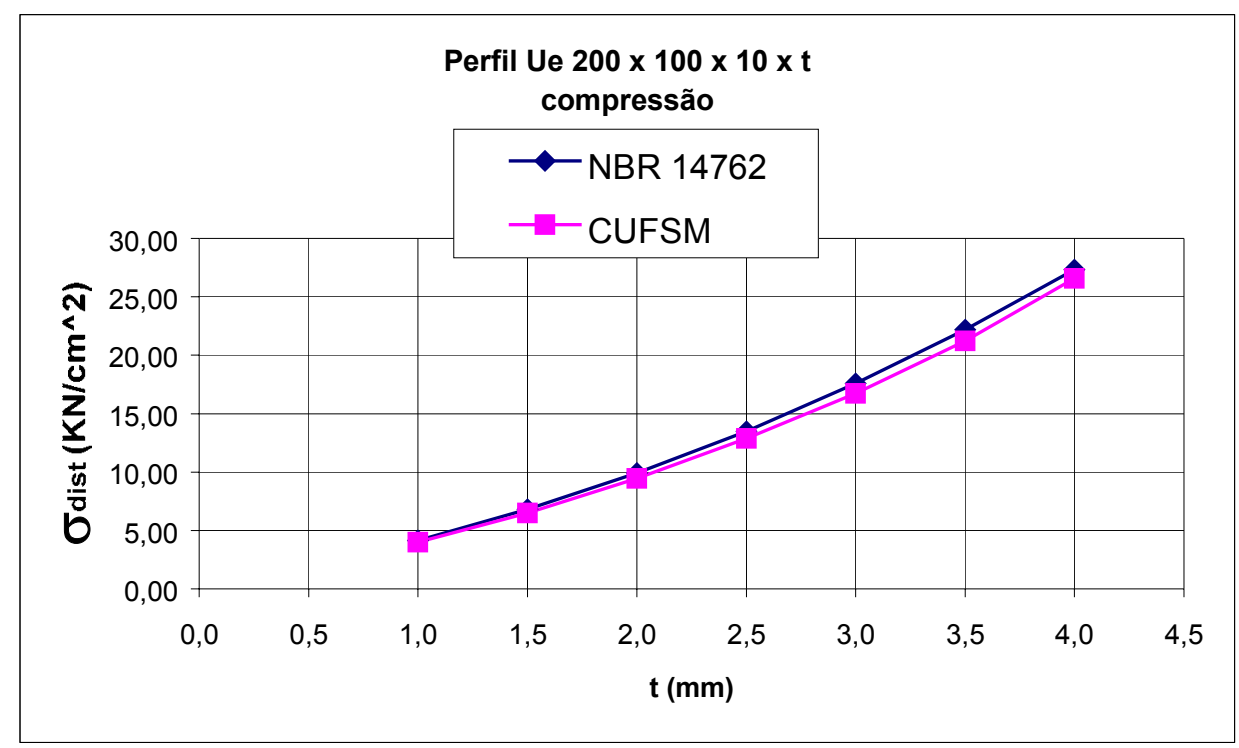

Figura $3.8-\sigma_{\text {dist }}$ versus $t$ 


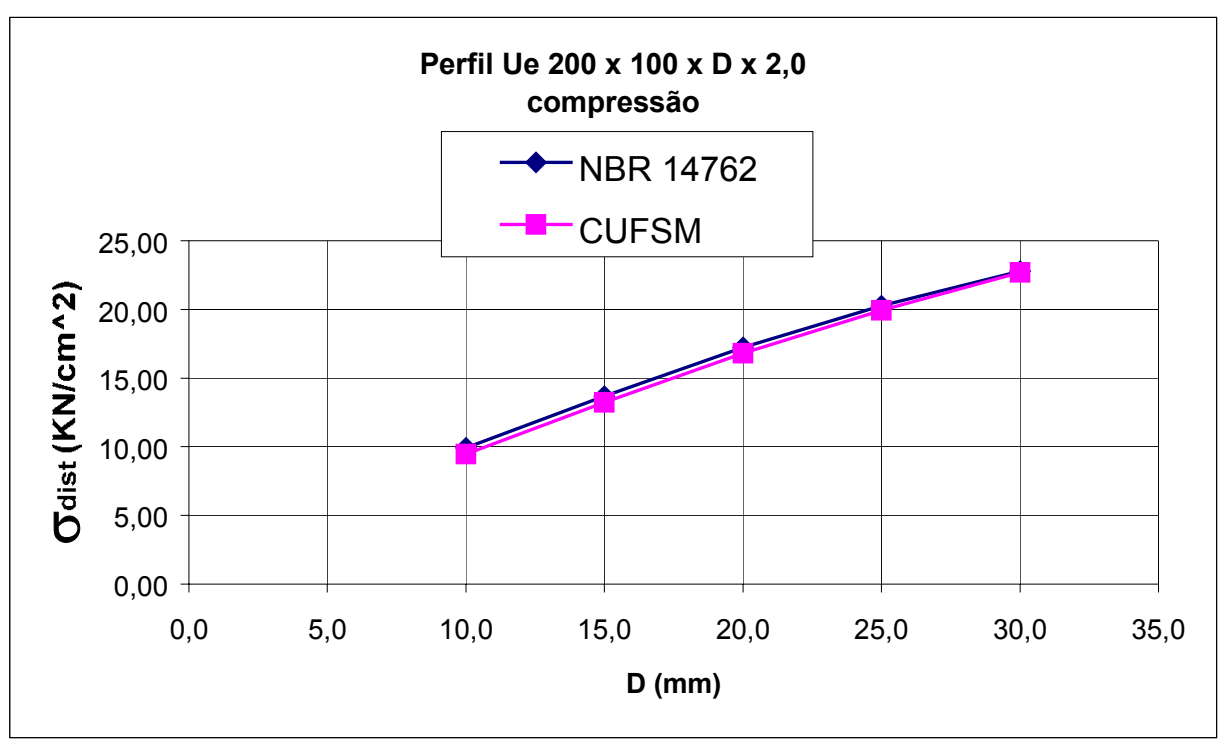

Figura $3.9-\sigma_{\text {dist }}$ versus D

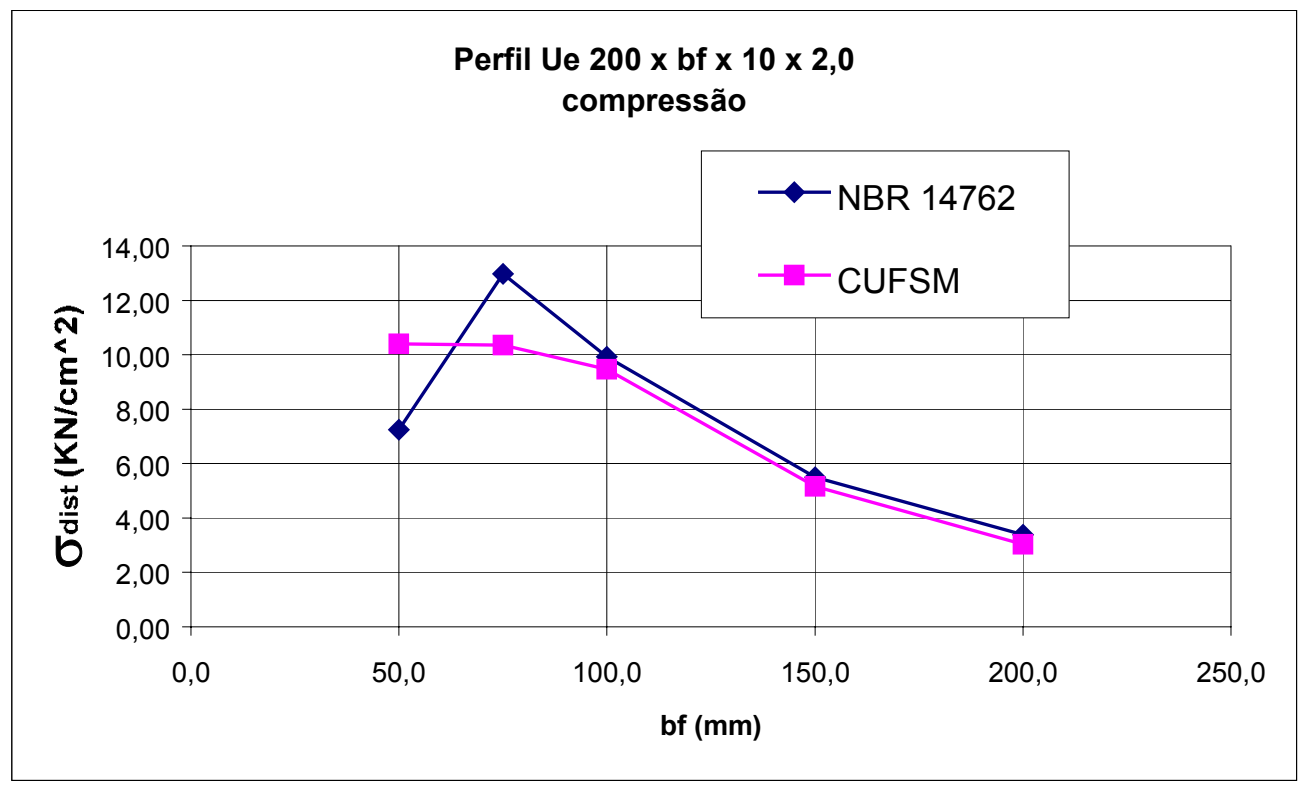

Figura $3.10-\sigma_{\text {dist }}$ versus $b_{f}$ 


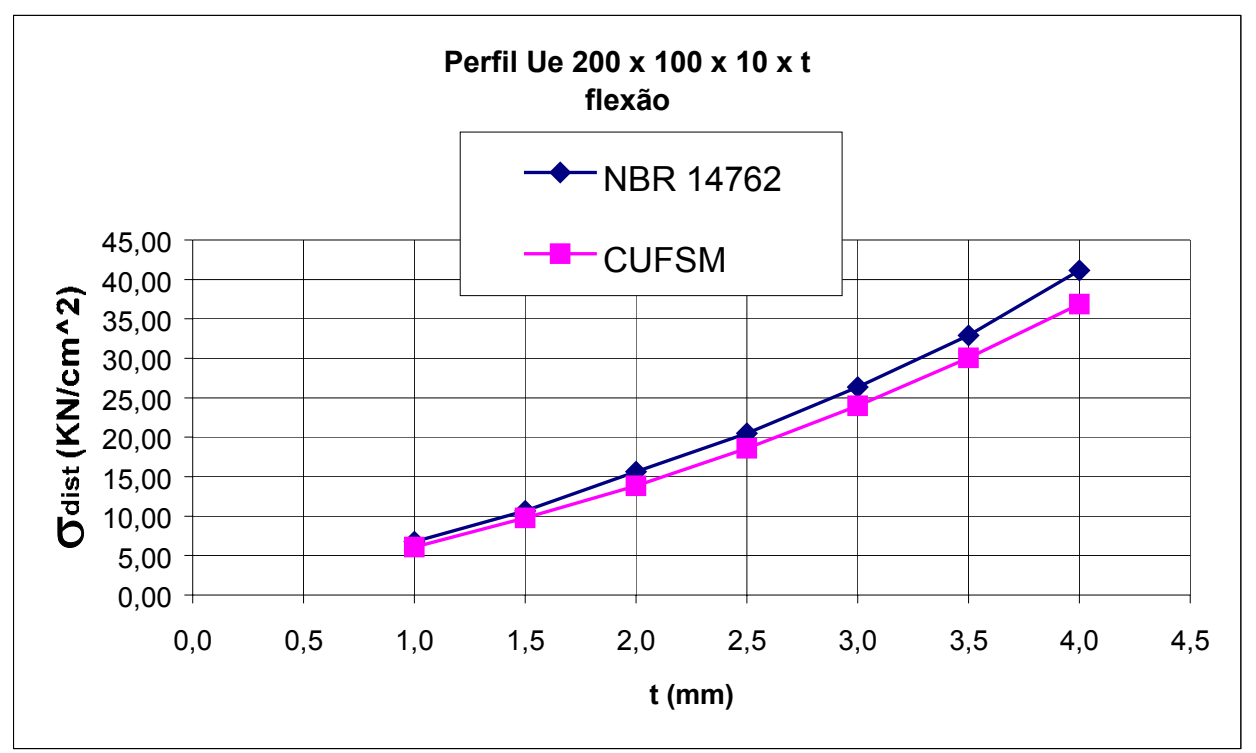

Figura $3.11-\sigma_{\text {dist }}$ versus $\mathrm{t}$

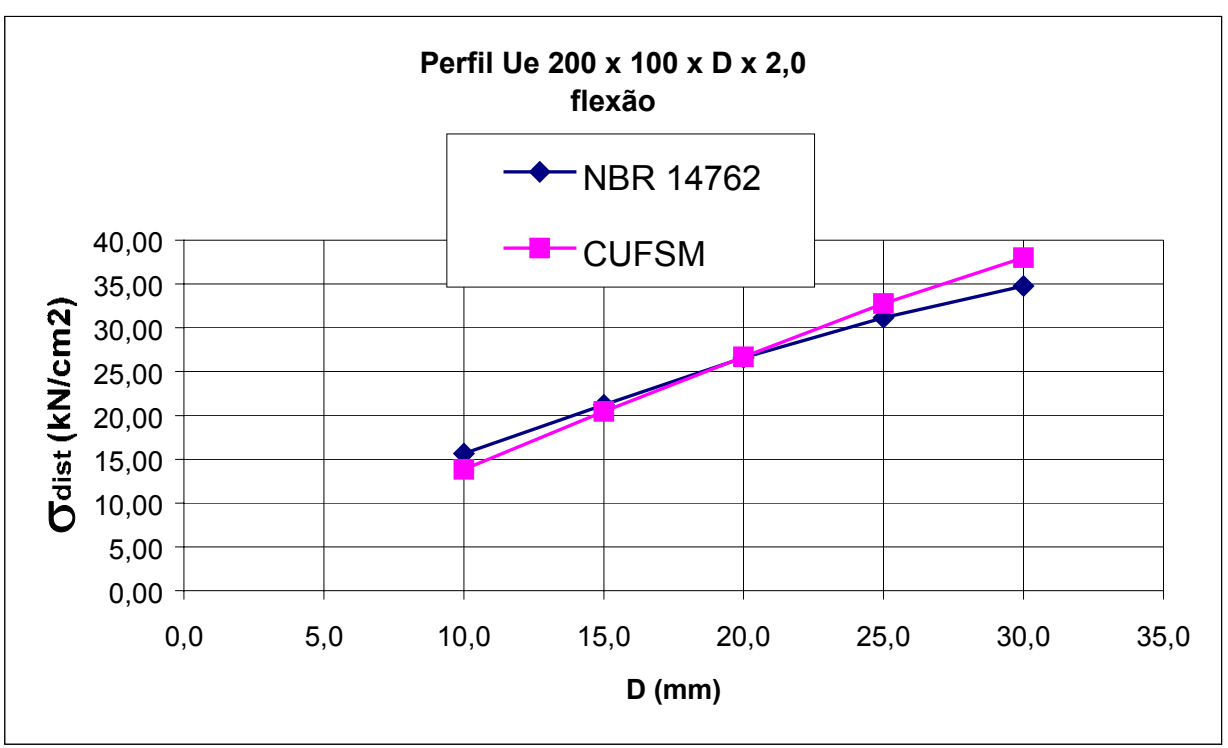

Figura $3.12-\sigma_{\text {dist }}$ versus $D$ 


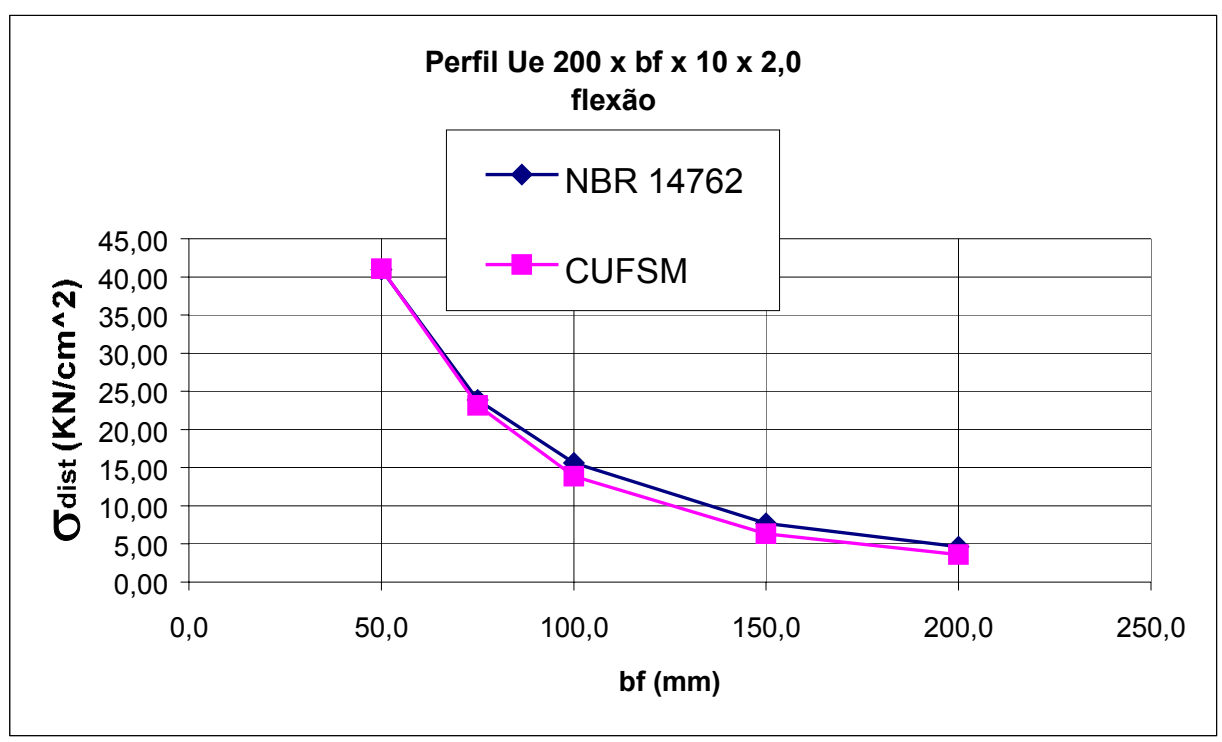

Figura $3.13-\sigma_{\text {dist }}$ versus $b_{f}$

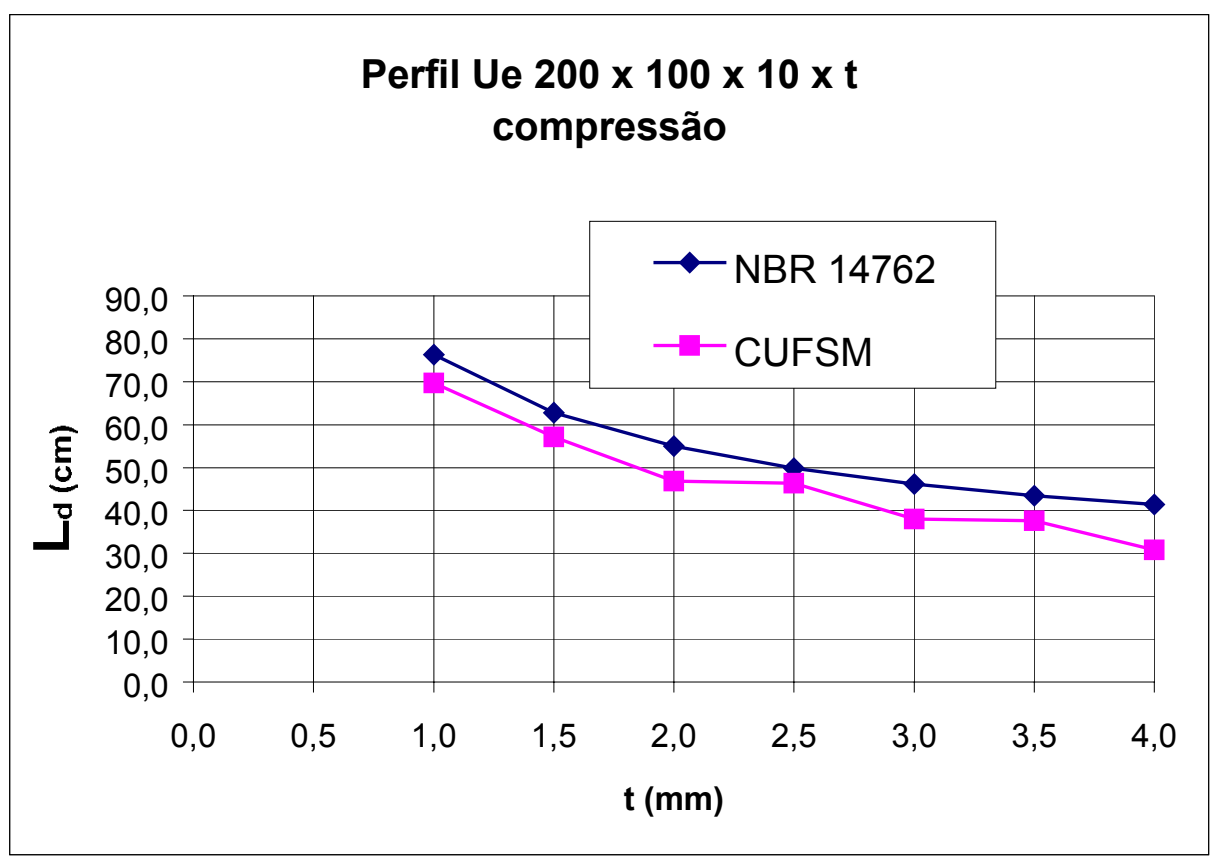

Figura $3.14-L_{d}$ versus $t$ 


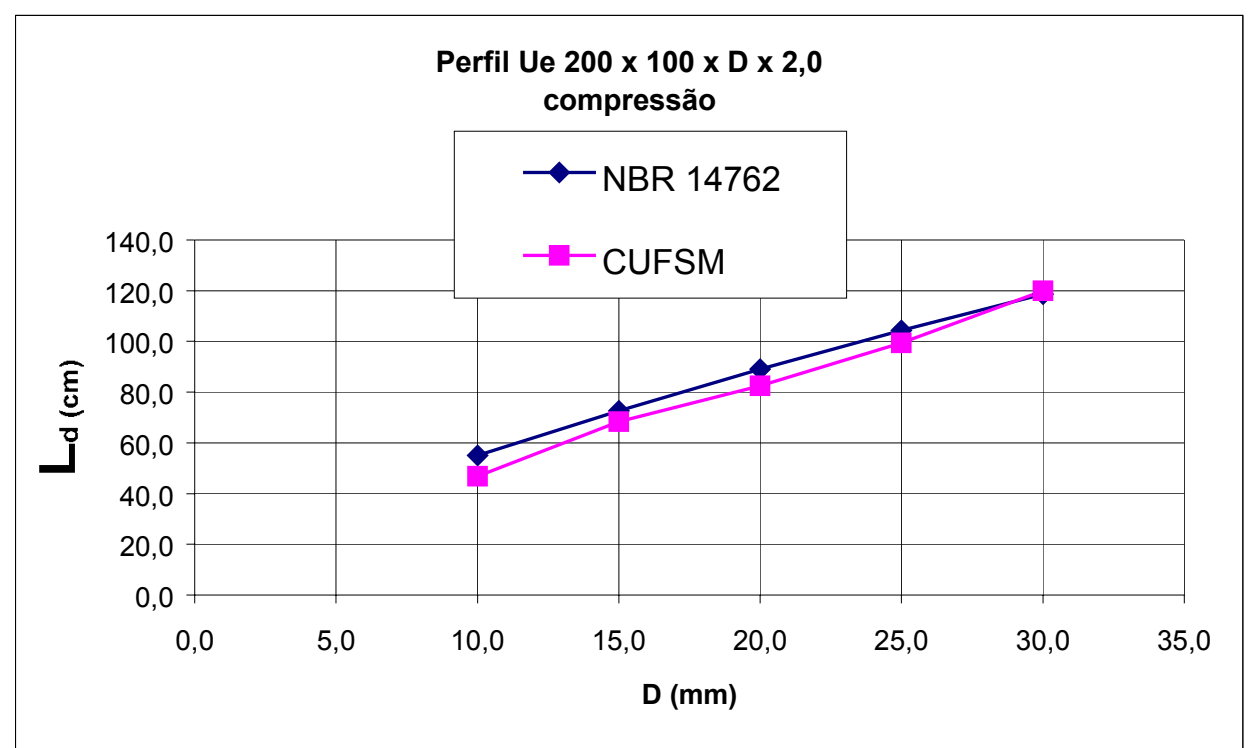

Figura $3.15-L_{d}$ versus $D$

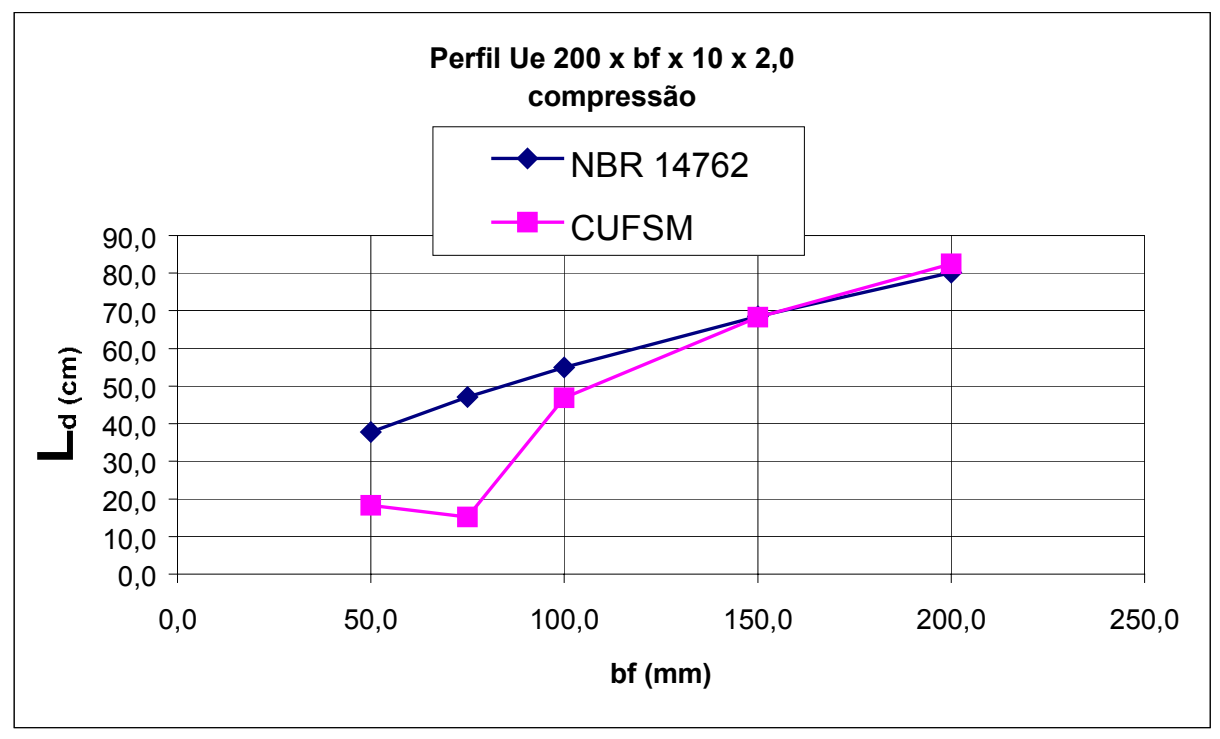

Figura $3.16-L_{d}$ versus $b_{f}$ 


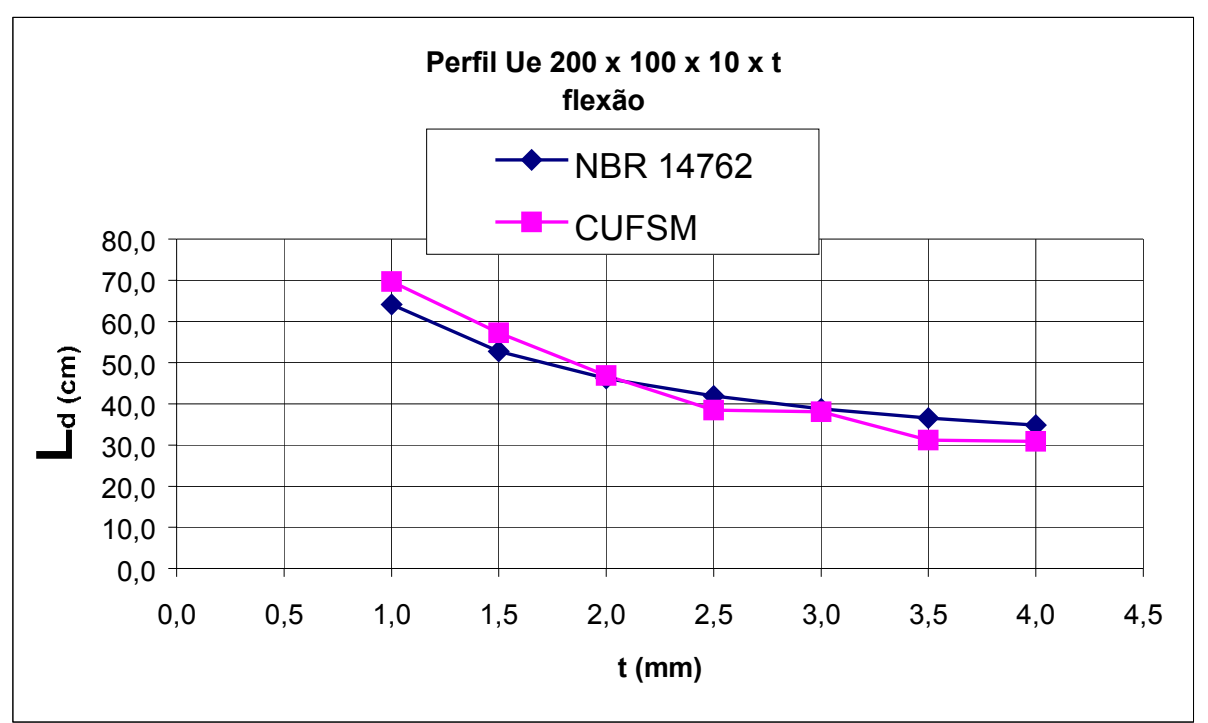

Figura $3.17-L_{d}$ versus $t$

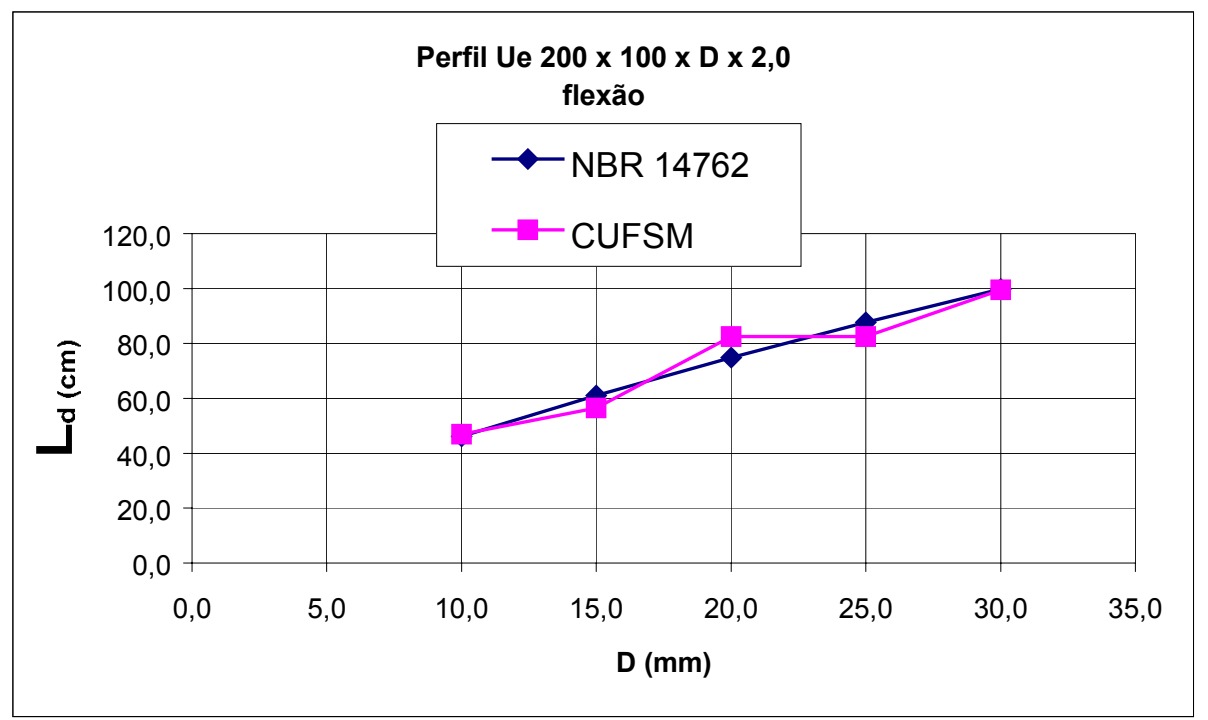

Figura $3.18-L_{d}$ versus $D$ 


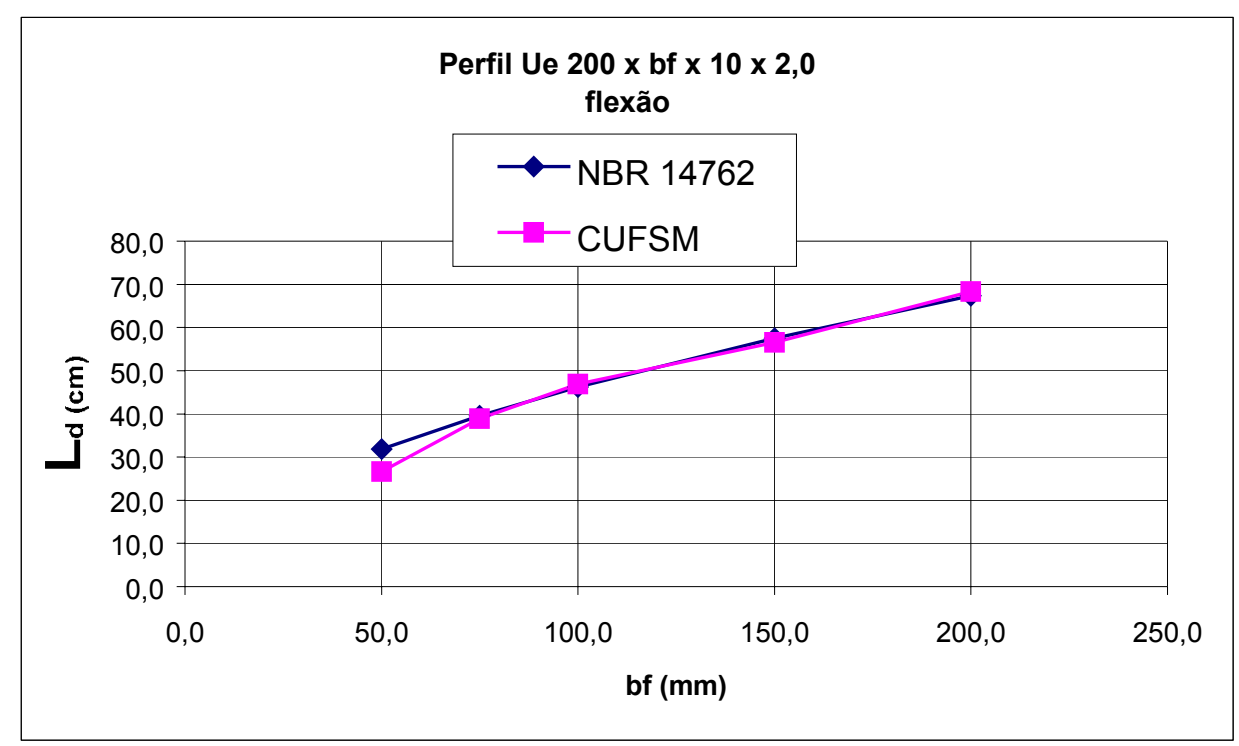

Figura $3.19-L_{d}$ versus $b_{f}$

\subsection{COMPARAÇÃO ADICIONAL: MÉTODO DAS FAIXAS FINITAS - PERFIS DO TIPO Ue E PERFIS DO TIPO Ze}

Algumas análises via faixas finitas, no que se refere à tensão convencional de flambagem elástica, $\sigma_{\text {dist }}$, e ao comprimento da meia onda longitudinal associada à tensão convencional de flambagem elástica por distorção, $L_{d}$, foram realizadas para os perfis do tipo $Z$ enrijecido. Foram analisados tanto perfis com enrijecedores de borda a $90^{\circ}$ (denominados por Ze90), como os perfis com enrijecedores de borda a $45^{\circ}$ (denominados por Ze45). Os resultados são comparados com os perfis do tipo $U$ enrijecido de mesma seção transversal, e são apresentados nas tabelas 3.10 e 3.11 e nas figuras 3.20 e 3.21 a seguir. 
Tabela 3.10 - Perfil Ue e Ze90 para compressão centrada

\begin{tabular}{|c|c|c|c|c|c|c|c|c|c|c|}
\hline \multirow{3}{*}{ PERFIL } & \multicolumn{5}{|c|}{ FAIXAS FINITAS - CUFSM (Ue) } & \multicolumn{5}{|c|}{ FAIXAS FINITAS - CUFSM (Ze90) } \\
\hline & $L_{d}$ & $\sigma_{\text {dist }}$ & L local & $\sigma_{\text {local }}$ & MODO & $L_{d}$ & $\sigma_{\text {dist }}$ & L local & $\sigma_{\text {local }}$ & MODO \\
\hline & $(\mathrm{cm})$ & $(\mathrm{KN} / \mathrm{cm} 2)$ & $(\mathrm{cm})$ & $(\mathrm{KN} / \mathrm{cm} 2)$ & & (cm) & $(\mathrm{KN} / \mathrm{cm} 2)$ & (cm) & (KN/cm2) & \\
\hline 2511(NA) & * & * & 15,50 & 2,69 & $\mathrm{~L}$ & * & * & 15,50 & 2,68 & $\mathrm{~L}$ \\
\hline 2514(NA) & 21,19 & 35,25 & * & * & D & 21,19 & 35,02 & * & * & D \\
\hline 2111 & 69,71 & 4,00 & 15,50 & 2,52 & L & 69,71 & 3,98 & 15,50 & 2,52 & $\mathrm{~L}$ \\
\hline 2211 & 122,51 & 1,33 & 22,57 & 1,86 & D & 122,51 & 1,33 & 22,57 & 1,86 & D \\
\hline 2212 & 82,41 & 3,04 & * & * & D & 82,41 & 3,05 & * & * & D \\
\hline 2214 & 54,23 & 8,20 & * & * & D & 54,23 & 8,21 & * & * & D \\
\hline 2234 & 115,01 & 20,03 & 21,19 & 31,23 & D & 115,01 & 20,23 & 21,19 & 31,23 & D \\
\hline $\begin{array}{l}\text { Notas: } \\
\\
\text { (*) Modc } \\
\text { L: Modo } \\
\text { D: Modc } \\
\text { NA: O p } \\
\text { 14762:2 }\end{array}$ & $\begin{array}{l}\text { lão evi } \\
\text { cal crí } \\
\text { listorci } \\
\text { fil não } \\
\text { 11, e q }\end{array}$ & $\begin{array}{l}\text { lenciado } \\
\text { ico } \\
\text { nal crítico } \\
\text { atende a r } \\
\text { le são apr }\end{array}$ & & is no pres & & tabelic & como as & & $\begin{array}{l}0 \mathrm{D} \text { da } \\
3 \text { e } 2.4\end{array}$ & $\mathrm{BR}$ \\
\hline
\end{tabular}

Tabela 3.11 - Perfil Ue e Ze45 para compressão centrada

\begin{tabular}{|c|c|c|c|c|c|c|c|c|c|c|}
\hline \multirow{3}{*}{ PERFIL } & \multicolumn{5}{|c|}{ FAIXAS FINITAS - CUFSM (Ue) } & \multicolumn{5}{|c|}{ FAIXAS FINITAS - CUFSM (Ze45) } \\
\hline & $\mathrm{L}_{\mathrm{d}}$ & $\sigma_{\text {dist }}$ & Llocal & $\sigma_{\text {local }}$ & MODO & $\mathrm{L}_{\mathrm{d}}$ & $\sigma_{\text {dist }}$ & L local & $\sigma_{\text {local }}$ & MODO \\
\hline & $(\mathbf{c m})$ & $(\mathrm{KN} / \mathrm{cm} 2)$ & $(\mathrm{cm})$ & $(\mathrm{KN} / \mathrm{cm} 2)$ & & $(\mathrm{cm})$ & $(\mathrm{KN} / \mathrm{cm} 2)$ & $(\mathrm{cm})$ & $(\mathrm{KN} / \mathrm{cm} 2)$ & \\
\hline 2511(NA) & * & * & 15,50 & 2,69 & $\mathrm{~L}$ & * & * & 15,5 & 2,64 & $\mathrm{~L}$ \\
\hline 2514(NA) & 21,19 & 35,25 & * & * & $\mathrm{D}$ & 21,19 & 34,06 & * & * & $\mathrm{D}$ \\
\hline 2111 & 69,71 & 4,00 & 15,50 & 2,52 & $\mathrm{~L}$ & 57,76 & 2,79 & 15,5 & 2,51 & $\mathrm{~L}$ \\
\hline 2211 & 122,51 & 1,33 & 22,57 & 1,86 & $\mathrm{D}$ & 84,12 & 0,91 & * & * & D \\
\hline 2212 & 82,41 & 3,04 & * & $*$ & $D$ & 56,58 & 2,18 & $*$ & $*$ & D \\
\hline 2214 & 54,23 & 8,20 & * & * & D & 44,93 & 6,96 & * & * & D \\
\hline 2234 & 115,01 & 20,03 & 21,19 & 31,23 & $\mathrm{D}$ & 95,30 & 13,47 & * & * & $\mathrm{D}$ \\
\hline \multicolumn{11}{|c|}{$\begin{array}{l}\text { Notas: } \\
\left({ }^{*}\right) \text { Modo não evidenciado } \\
\text { L: Modo local crítico } \\
\text { D: Modo distorcional crítico } \\
\text { NA: O perfil não atende a relação } b_{f} / b_{w} \text {, referente às tabelas D. } 1 \text { e D.2 do Anexo D da NBR } \\
\text { 14762:2001, e que são apresentadas no presente trabalho como as tabelas } 2.3 \text { e } 2.4\end{array}$} \\
\hline
\end{tabular}


Tabela 3.12 - Perfil Ue e Ze90 para flexão

\begin{tabular}{|c|c|c|c|c|c|c|c|c|c|c|}
\hline \multirow{3}{*}{ PERFIL } & \multicolumn{5}{|c|}{ FAIXAS FINITAS - CUFSM (Ue) } & \multicolumn{5}{|c|}{ FAIXAS FINITAS - CUFSM (Ze90) } \\
\hline & $L_{d}$ & $\sigma_{\text {dist }}$ & L local & $\sigma_{\text {local }}$ & MODO & $L_{d}$ & $\sigma_{\text {dist }}$ & L local & $\sigma_{\text {local }}$ & MODO \\
\hline & $(\mathrm{cm})$ & $(\mathrm{KN} / \mathrm{cm} 2)$ & $(\mathrm{cm})$ & (KN/cm2) & & (cm) & $(\mathrm{KN} / \mathrm{cm} 2)$ & (cm) & (KN/cm2) & \\
\hline 2511(NA) & 39,66 & 16,89 & 10,64 & 14,65 & $\mathrm{~L}$ & 39,66 & 16,86 & 10,64 & 14,65 & $\mathrm{~L}$ \\
\hline 2514(NA) & 17,56 & 121,4 & * & * & D & 17,56 & 121,01 & * & * & D \\
\hline 2111 & 69,71 & 6,05 & 10,64 & 8,63 & D & 69,71 & 6,05 & 10,64 & 8,63 & D \\
\hline 2211 & 101,52 & 1,58 & 18,70 & 2,17 & D & 101,52 & 1,58 & 18,7 & 2,17 & D \\
\hline 2212 & 68,28 & 3,58 & * & * & D & 68,28 & 3,58 & * & * & D \\
\hline 2214 & 54,23 & 9,42 & * & * & D & 54,23 & 9,42 & * & * & D \\
\hline 2234 & 115,01 & 25,41 & 17,56 & 37,41 & $\mathrm{D}$ & 115,01 & 25,74 & 17,56 & 37,41 & D \\
\hline $\begin{array}{l}\text { Notas: } \\
\\
\left.{ }^{\star}\right) \text { Mod } \\
\text { L: Modd } \\
\text { D: Mod } \\
\text { NA: O } \\
\text { 14762: }\end{array}$ & $\begin{array}{l}\text { lão evi } \\
\text { cal crí } \\
\text { listorci } \\
\text { fil não } \\
\text { 11, e q }\end{array}$ & $\begin{array}{l}\text { enciado } \\
0\end{array}$ & & is no pre & & & como as & & $\begin{array}{l}0 \mathrm{D} \text { da } \\
3 \text { e } 2.4\end{array}$ & BR \\
\hline
\end{tabular}

Tabela 3.13 - Perfil Ue e Ze45 para flexão

\begin{tabular}{|c|c|c|c|c|c|c|c|c|c|c|}
\hline \multirow{3}{*}{ PERFIL } & \multicolumn{5}{|c|}{ FAIXAS FINITAS - CUFSM (Ue) } & \multicolumn{5}{|c|}{ FAIXAS FINITAS - CUFSM (Ze45) } \\
\hline & $\mathrm{L}_{\mathrm{d}}$ & $\sigma_{\text {dist }}$ & $L_{\text {local }}$ & $\sigma_{\text {local }}$ & MODO & $\mathrm{L}_{\mathrm{d}}$ & $\sigma_{\text {dist }}$ & $\mathrm{L}_{\text {local }}$ & $\sigma_{\text {local }}$ & MODO \\
\hline & $(\mathrm{cm})$ & $(\mathrm{KN} / \mathrm{cm} 2)$ & $(\mathrm{cm})$ & $(\mathrm{KN} / \mathrm{cm} 2)$ & & $(\mathrm{cm})$ & $(\mathrm{KN} / \mathrm{cm} 2)$ & $(\mathrm{cm})$ & $(\mathrm{KN} / \mathrm{cm} 2)$ & \\
\hline 2511(NA) & 39,66 & 16,89 & 10,64 & 14,65 & $\mathrm{~L}$ & 32,87 & 11,68 & 10,64 & 14,49 & D \\
\hline 2514(NA) & 17,56 & 121,4 & * & * & D & 14,55 & 113,72 & * & * & $\mathrm{D}$ \\
\hline 2111 & 69,71 & 6,05 & 10,64 & 8,63 & $\mathrm{D}$ & 57,76 & 4,14 & 10,64 & 8,41 & $\mathrm{D}$ \\
\hline 2211 & 101,52 & 1,58 & 18,70 & 2,17 & $\mathrm{D}$ & 84,12 & 1,07 & * & * & D \\
\hline 2212 & 68,28 & 3,58 & * & * & $\mathrm{D}$ & 56,58 & 2,48 & * & * & $\mathrm{D}$ \\
\hline 2214 & 54,23 & 9,42 & * & * & D & 37,23 & 7,80 & * & * & D \\
\hline 2234 & 115,01 & 25,41 & 17,56 & 37,41 & D & 78,97 & 16,50 & * & * & D \\
\hline \multicolumn{11}{|c|}{$\begin{array}{l}\text { Notas: } \\
\left({ }^{*}\right) \text { Modo não evidenciado } \\
\text { L: Modo local crítico } \\
\text { D: Modo distorcional crítico } \\
\text { NA: O perfil não atende a relação } b_{f} / b_{w} \text {, referente às tabelas D. } 1 \text { e D.2 do Anexo D da NBR } \\
\text { 14762:2001, e que são apresentadas no presente trabalho como as tabelas } 2.3 \text { e } 2.4\end{array}$} \\
\hline
\end{tabular}


Por meio da análise das figuras 3.10 a 3.13 , algumas explicações são pertinentes:

\section{Com relação à compressão centrada:}

Cabe salientar inicialmente que o procedimento da NBR 14762:2001 não faz distinção entre a análise de perfis do tipo Ue e de perfis do tipo Ze. Confirmando tal fato, pode-se observar nas análises que os perfis do tipo Ue e Ze90 apresentam os mesmos valores tanto para $\sigma_{\text {dist }}$ quanto para $\sigma_{\text {local }}$ (tensão correspondente à flambagem local). Os dois tipos de perfis também apresentam os mesmo valores de $L_{d}$ e de $L_{\text {local }}$ (comprimento de meia onda correspondente à flambagem local). Também apresentam os mesmos modos críticos.

Os perfis do tipo Ze45, quando comparados aos perfis do tipo Ue, apresentam valores inferiores para $\sigma_{\text {dist }}$ (média em torno de $25 \%$ ). No que se refere aos valores de $\sigma_{\text {local }}$ (tensão correspondente à flambagem local), os perfis do tipo Ze45, quando comparados aos perfis do tipo Ue, apresentam valores aproximadamente iguais. Os perfis do tipo Ze45, quando comparados aos perfis do tipo Ue, apresentam valores ligeiramente inferiores para $L_{d}$ (média em torno de $20 \%$ ). Os dois tipos de perfis apresentam os mesmos valores de $L_{\text {local. }}$ Também apresentam os mesmos modos críticos.

\section{Com relação à flexão:}

Assim como para o caso da compressão centrada, os perfis do tipo Ue e Ze90 apresentam os mesmos valores tanto para $\sigma_{\text {dist }}$ quanto para $\sigma_{\text {local }}$ (tensão correspondente à flambagem local). Os dois tipos de perfis também apresentam os mesmo valores de $L_{d}$ e de $L_{\text {local }}$ (comprimento de meia onda correspondente à flambagem local). Também apresentam os mesmos modos críticos.

Os perfis do tipo Ze45, quando comparados aos perfis do tipo Ue, apresentam valores inferiores para $\sigma_{\text {dist }}$ (média em torno de $27 \%$ ). No que se refere aos valores de $\sigma_{\text {local }}$ (tensão correspondente à flambagem local), os perfis do tipo Ze45, quando comparados aos perfis do tipo Ue, apresentam valores 
aproximadamente iguais. Os perfis do tipo Ze45, quando comparados aos perfis do tipo Ue, apresentam valores ligeiramente inferiores para $L_{d}$ (média em torno de $22 \%$ ). Os dois tipos de perfis apresentam os mesmos valores de $L_{\text {local }}$ Também apresentam os mesmos modos críticos, com exceção do perfil $200 \times 50 \times 10 \times 1$ (não respeita as relações das tabelas D.1 e D.2 da NBR 14762:2001), pois, neste caso, o modo crítico verificado para o perfil do tipo Ze45 foi o distorcional, mas para tanto o perfil do tipo Ue quanto para o perfil do tipo Ze90, o modo crítico foi o local. Tal fato evidencia, mesmo que superficialmente devido à escassez de análises para este caso, que a variação do ângulo do enrijecedor de borda influi no fenômeno da distorção. Quanto menor o ângulo do enrijecedor de borda em relação à mesa da seção, menor será o enrijecimento de tal conjunto, e menores serão os valores de $\sigma_{\text {dist }}$ 


\section{ANÁLISE VIA MÉTODO DOS ELEMENTOS FINITOS}

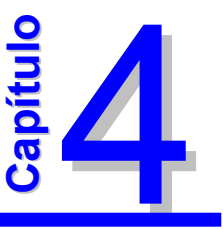

\subsection{BREVE NOÇÃO SOBRE O MÉTODO}

O método dos elementos finitos é um método numérico utilizado para gerar funções de aproximação. Em princípio, serve para abordar praticamente todos os fenômenos, desde que os mesmos sejam modelados de maneira coerente. Podem ser consideradas variações das condições de contorno e da seção transversal ao longo do eixo longitudinal, bem como imperfeições e não-linearidades. Como desvantagem, tem-se em alguns casos um elevado tempo para a preparação da entrada de dados e análise propriamente dita, dependendo da velocidade do computador a ser utilizado e da complexidade da malha a ser discretizada, o que às vezes o torna um método trabalhoso para a aplicação em alguns problemas práticos.

\subsection{O PROGRAMA COMPUTACIONAL ANSYS 5.7}

É um programa comercial difundido para análise estrutural via método dos elementos finitos. Foi utilizado no presente trabalho com o intuito de se comparar os resultados obtidos via elementos finitos com os obtidos por meio de análises via faixas finitas e segundo os procedimentos normativos. 
O elemento adotado foi o elemento de casca SHELL 63 , o qual possui 4 nós, com 6 graus de liberdade em cada, sendo 3 translações $\left(u_{x}, u_{y}\right.$ e $\left.u_{z}\right)$ e 3 rotações $\left(\phi_{x}, \phi_{y}, \phi_{z}\right)$, conforme ilustrado na figura 4.1 .

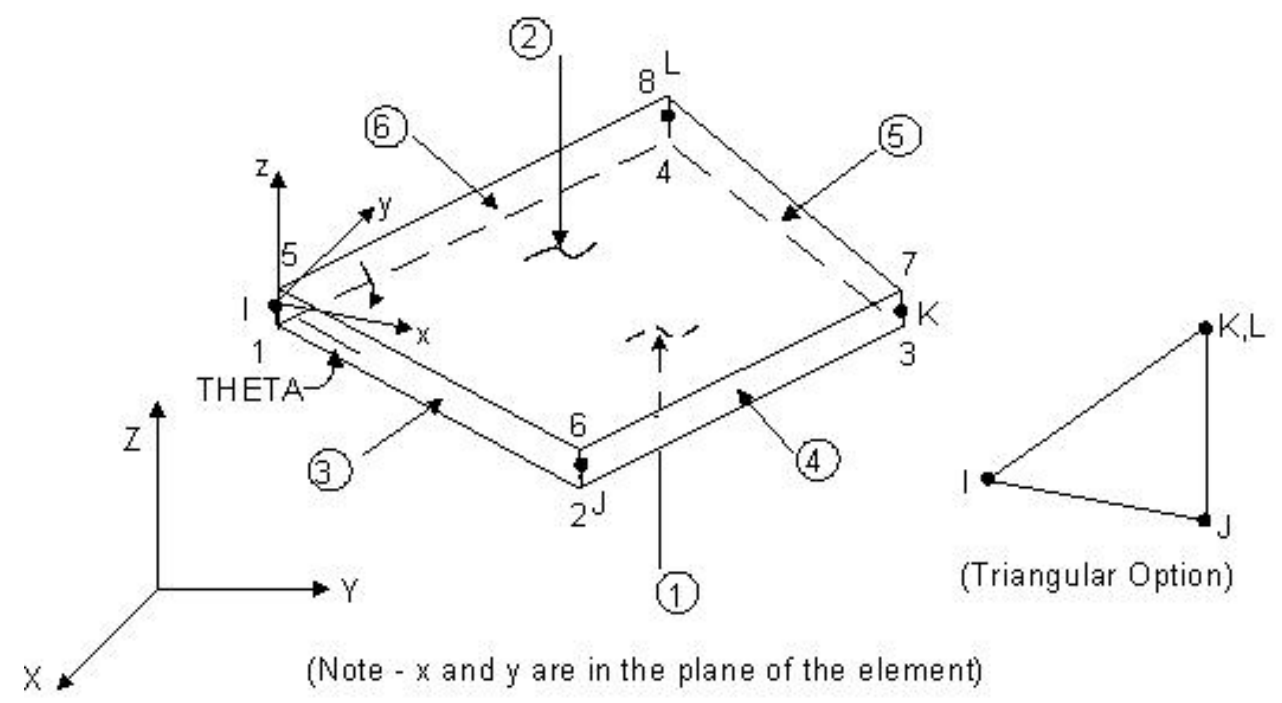

Figura 4.1 - Elemento de casca SHELL 63 (ANSYS 5.7)

O plano da seção transversal das barras é definido pelos eixos y e z, sendo que o eixo $x$ representa a barra ao longo de seu comprimento (eixo longitudinal).

Vale lembrar que somente os nós referentes à seção transversal das extremidades da barra tiveram alguns de seus deslocamentos (translações) impedidos, sendo estes dependentes das hipóteses a seguir. Em nenhum caso foram restringidas as rotações em torno dos nós.

Foram admitidas quatro hipóteses para as análises:

1) Análise de autovalor. Uma das extremidades com os deslocamentos de todos os seus nós restringidos em $x, y$ e $z$ e a outra somente com os deslocamentos em y e $z$ restringidos. Portanto, nesta hipótese foi analisado o caso de engaste em uma das extremidades da barra, o que a diferencia de todas as outras hipóteses; 
2) Análise de autovalor também. Entretanto, neste caso, ambas extremidades com os deslocamentos de todos os seus nós restringidos em y e $z$ somente (condição simétrica de condições de contorno);

3) Análise considerando não-linearidade geométrica (NLG) sem a admissão de imperfeições iniciais. Ambas extremidades com os deslocamentos de todos os seus nós restringidos em y e z somente (condição simétrica de condições de contorno);

4) Análise considerando não-linearidade geométrica (NLG) com a admissão de imperfeições iniciais. Ambas extremidades com deslocamentos de todos seus nós restringidos em y e z somente (condição simétrica de condições de contorno), com exceção de 1 nó na meia altura da alma no meio do vão que foi restringido em $x$ para evitar o deslocamento da barra ao longo do eixo $\mathrm{x}$, conforme de aplica o carregamento, devido à introdução da imperfeição inicial;

Todos os nós referentes à seção transversal das extremidades da barra receberam solicitação externa, sendo esta aplicada ao longo da linha média da seção transversal, por meio de força por unidade de comprimento $(\mathrm{kN} / \mathrm{cm})$, com sentido de atuação paralelo ao comprimento da barra, para que se pudesse haver coerência com a análise via faixas finitas, pois o programa CUFSM utiliza somente este tipo de solicitação.

Quando da primeira hipótese, somente na extremidade com deslocamentos livres em relação ao eixo x (ao longo da barra), foi aplicado o carregamento, ao contrário da condição da segunda hipótese, em que em ambas as extremidades houve aplicação do mesmo (Figuras 4.2 e 4.3). 


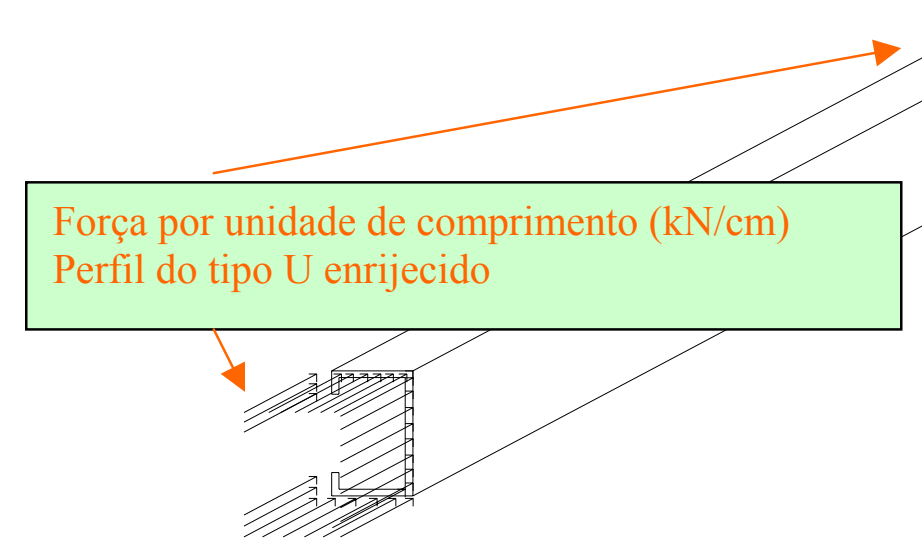

Figura 4.2 - Esquema de aplicação de carregamento na barra (compressão)

Quando da análise da flexão, houve a aplicação de um gradiente linear de tensão na alma da seção transversal. Nos enrijecedores de borda, foi adotada tensão constante e igual à atuante na respectiva mesa. Vale salientar que foi aplicada compressão na mesa superior da seção transversal.

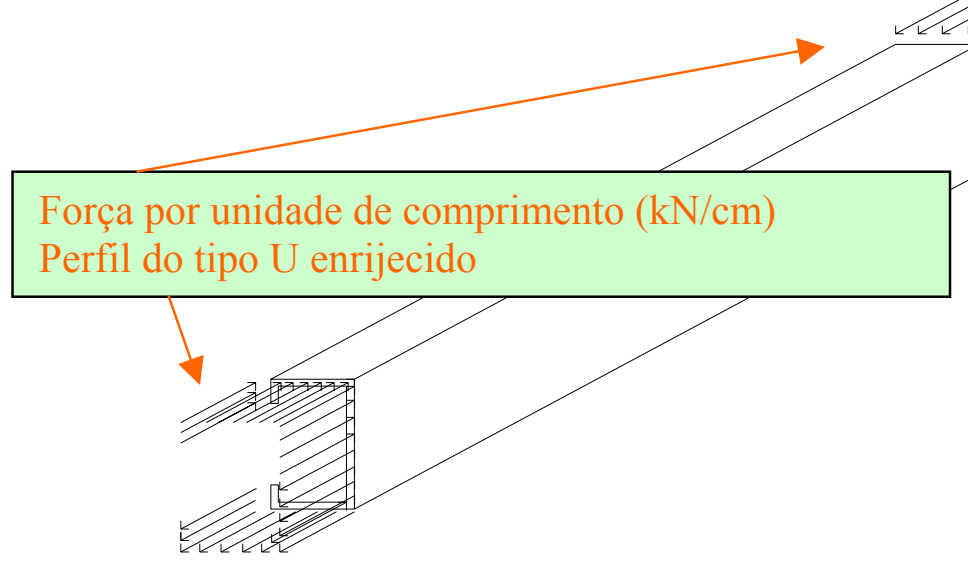

Figura 4.3 - Esquema de aplicação de carregamento na barra (flexão)

\subsection{PERFIS ADOTADOS NA ANÁLISE}

Os parâmetros adotados, relativos à escolha dos perfis nos quais o trabalho está baseado, são os mesmos que foram analisados via faixas finitas. Entretanto, depois de realizadas as análises via faixas finitas e via procedimento da NBR 
14762:2001, somente foram analisadas as seções que apresentaram o modo distorcional como crítico, por ser este o objetivo do trabalho. Portanto, as seções utilizadas para esta fase da análise serão apresentadas na ocasião da apresentação dos resultados obtidos via elementos finitos, que, assim como os obtidos via faixas finitas, também foram a tensão convencional de flambagem por distorção, $\sigma_{\text {dist, }}$ e o comprimento da meia onda longitudinal associada à tensão convencional de flambagem elástica por distorção, $L_{d}$, para que se pudesse comparar com os resultados já obtidos devido aos outros procedimentos. Cabe salientar que os resultados serão apresentados separados por hipóteses e tipo de solicitação.

\subsection{COMPARAÇÃO: MÉTODO DOS ELEMENTOS FINITOS, PROCEDIMENTO DA NBR 14762: 2001 E MÉTODO DAS FAIXAS FINITAS}

As tabelas 4.1 a 4.6 ilustram os resultados das análises realizadas via método dos elementos finitos, além dos resultados comparativos entre os três procedimentos acima citados (Tabelas 4.7 e 4.8 e Figuras 4.4 a 4.13), com relação à compressão centrada e à flexão.

Para as tabelas 4.1 a 4.6, pode-se observar que os mesmos perfis, quando submetidos à flexão, apresentam maiores valores de $\sigma_{\text {dist }}$, quando comparados com os submetidos à compressão. Além disso, nesses casos, todos os perfis respeitam as condições das tabelas D.1 e D.2 da NBR 14762:2001. Vale lembrar, mais uma vez, que estas diferenças podem ser explicadas, em parte, pois os perfis submetidos à flexão possuem uma das mesas e mais uma porção da alma tracionada, e, portanto, não sujeita à instabilidade. Tal fato faz com que o conjunto de elementos da seção transversal que são conectados ao conjunto comprimido (mesa e enrijecedor) seja mais eficiente no sentido de evitar a instabilidade.

Para as tabelas 4.1 e 4.2, relativas à primeira hipótese, pode-se observar que os mesmos perfis, quando submetidos à flexão, apresentam maiores valores de $\sigma_{\text {dist, }}$ quando comparados com os submetidos à compressão (média em torno de $56 \%$ ). Por outro lado, os valores de $L_{d}$ dos perfis submetidos à flexão, quando comparados com os submetidos à compressão centrada são aproximadamente 
iguais ou um pouco menores (variação entre 5 e 17\%, com média de 6\%). No que se refere à flambagem local, o mesmo perfil, quando submetido à flexão, apresenta maior valor de $\sigma_{l}$, quando comparado com o submetido à compressão (26\%). O valor de $L_{d}$ é igual para os dois casos. Um dos perfis submetidos à compressão centrada (Ue $200 \times 200 \times 20 \times 2,0$ ) apresentou o modo local como crítico. Entretanto, nas análises via faixas finitas e procedimento da NBR 14762 o mesmo havia apresentado o modo distorcional como crítico.

\section{HIPÓTESE 1}

As tabelas 4.1 e 4.2 ilustram a hipótese 1.

\section{COMPRESSÃO CENTRADA}

Tabela 4.1 - Resultados via ANSYS 5.7 - hipótese 1 (compressão)

\begin{tabular}{|c|c|c|c|}
\hline \multicolumn{4}{|c|}{ ANSYS 5.7} \\
\hline \multirow{2}{*}{ PERFIL Ue } & $L_{d}$ ou $L_{\text {local }}$ & $\sigma_{\text {dist }}$ ou $\sigma_{\text {local }}$ & MODO \\
\hline & $(\mathbf{c m})$ & $\left(\mathrm{kN} / \mathrm{cm}^{2}\right)$ & \\
\hline Ue $200 \times 100 \times 10 \times 2,0$ & 55,0 & 9,30 & $\mathrm{D} / \mathrm{L}$ \\
\hline Ue $200 \times 100 \times 10 \times 4,0$ & 40,0 & 27,54 & $D$ \\
\hline Ue $200 \times 100 \times 20 \times 4,0$ & 75,0 & 37,21 & $\mathrm{D} / \mathrm{L}$ \\
\hline Ue $200 \times 200 \times 10 \times 1,0$ & 115,0 & 1,60 & $\mathrm{D}$ \\
\hline Ue $200 \times 200 \times 10 \times 2,0$ & 90,0 & 3,85 & $\mathrm{D}$ \\
\hline Ue $200 \times 200 \times 10 \times 4,0$ & 70,0 & 9,78 & $\mathrm{D}$ \\
\hline Ue $200 \times 200 \times 20 \times 1,0$ & 20,0 & 1,84 & $\mathrm{~L}$ \\
\hline Ue $200 \times 200 \times 20 \times 2,0$ & 20,0 & 7,29 & $L^{*}$ \\
\hline Ue $200 \times 200 \times 20 \times 4,0$ & 95,0 & 15,33 & $\mathrm{D}$ \\
\hline Ue $200 \times 200 \times 30 \times 4,0$ & 135,0 & 23,83 & $D$ \\
\hline \multicolumn{4}{|c|}{$\begin{array}{l}\text { Notas: } \\
\text { D: modo distorcional é o crítico } \\
\text { L: modo local é o crítico } \\
\text { D/L: ocorre interação entre o modo local e distorcional } \\
\left({ }^{*}\right) \text { o perfil apresentou o modo distorcional tanto para análise via faixas } \\
\text { fintas quanto para análise via procedimento da NBR 14762:2001 }\end{array}$} \\
\hline
\end{tabular}




\section{FLEXÃO}

Tabela 4.2 - Resultados via ANSYS 5.7 - hipótese 1 (flexão)

\begin{tabular}{|c|c|c|c|}
\hline \multicolumn{4}{|c|}{ ANSYS 5.7} \\
\hline \multirow{2}{*}{ PERFIL Ue } & $L_{d}$ ou $L_{\text {local }}$ & $\sigma_{\text {dist }}$ ou $\sigma_{\text {local }}$ & MODO \\
\hline & $(\mathrm{cm})$ & $\left(\mathrm{kN} / \mathrm{cm}^{2}\right)$ & \\
\hline Ue $200 \times 100 \times 10 \times 2,0$ & 50,00 & 18,35 & $\mathrm{D}$ \\
\hline Ue $200 \times 100 \times 10 \times 4,0$ & 35,0 & 48,62 & $D$ \\
\hline Ue $200 \times 100 \times 20 \times 4,0$ & 60,0 & 75,45 & $\mathrm{D}$ \\
\hline Ue $200 \times 200 \times 10 \times 1,0$ & 130,0 & 2,21 & $\begin{array}{c}\mathrm{D} / \mathrm{L} \\
\text { (mesa) }\end{array}$ \\
\hline Ue $200 \times 200 \times 10 \times 2,0$ & 75,0 & 5,81 & $\mathrm{D}$ \\
\hline Ue $200 \times 200 \times 10 \times 4,0$ & 60,0 & 14,10 & $\mathrm{D}$ \\
\hline Ue $200 \times 200 \times 20 \times 1,0$ & 20,0 & 2,33 & $\mathrm{~L}$ \\
\hline Ue $200 \times 200 \times 20 \times 2,0$ & 140,0 & 9,16 & $\begin{array}{c}\mathrm{D} / \mathrm{L} \\
\text { (mesa) }\end{array}$ \\
\hline Ue $200 \times 200 \times 20 \times 4,0$ & 100,0 & 24,11 & $\mathrm{D}$ \\
\hline Ue $200 \times 200 \times 30 \times 4,0$ & 145,0 & 35,63 & $\mathrm{D}$ \\
\hline \multicolumn{4}{|l|}{$\begin{array}{l}\text { Notas: } \\
\text { D: modo distorcional é o cr } \\
\text { L: modo local é o crítico } \\
\text { D/L: ocorre interação entre }\end{array}$} \\
\hline
\end{tabular}

Para as tabelas 4.3 e 4.4, relativas à segunda hipótese, pode-se observar que os mesmos perfis, quando submetidos à flexão, também apresentam maiores valores de $\sigma_{\text {dist }}$, quando comparados com os submetidos à compressão (média em torno de $25 \%$ ). Por outro lado, os valores de $L_{d}$ dos perfis submetidos à flexão, quando comparados com os submetidos à compressão centrada são aproximadamente iguais ou um pouco menores (média em torno de 6\%). 


\section{HIPÓTESE 2}

As tabelas 4.3 e 4.4 ilustram a hipótese 2.

\section{COMPRESSÃO CENTRADA}

Tabela 4.3 - Resultados via ANSYS 5.7 - hipótese 2 (compressão)

\begin{tabular}{|c|c|c|c|}
\hline \multicolumn{4}{|c|}{ ANSYS 5.7} \\
\hline \multirow{2}{*}{ PERFIL Ue } & $L_{d}$ ou $L_{\text {local }}$ & $\sigma_{\text {dist }}$ ou $\sigma_{\text {local }}$ & MODO \\
\hline & $(\mathrm{cm})$ & (kN/cm2) & \\
\hline Ue $200 \times 100 \times 10 \times 2,0$ & 55,0 & 9,30 & $\mathrm{D} / \mathrm{L}$ \\
\hline Ue $200 \times 100 \times 10 \times 4,0$ & 35,0 & 27,32 & D \\
\hline Ue $200 \times 200 \times 10 \times 1,0$ & 100,0 & 1,40 & $\mathrm{D}$ \\
\hline Ue $200 \times 200 \times 10 \times 2,0$ & 90,0 & 3,35 & $\mathrm{D}$ \\
\hline Ue $200 \times 200 \times 10 \times 4,0$ & 50,0 & 9,15 & $\mathrm{D}$ \\
\hline Ue $200 \times 200 \times 30 \times 4,0$ & 100,0 & 22,14 & D \\
\hline \multicolumn{4}{|c|}{$\begin{array}{l}\text { Notas: } \\
\text { D: modo distorcional é o crítico } \\
\text { L: modo local é o crítico } \\
\text { D/L: ocorre interação entre o modo local e distorcional }\end{array}$} \\
\hline
\end{tabular}

\section{FLEXÃO}

Tabela 4.4 - Resultados via ANSYS 5.7 - hipótese 2 (flexão)

\begin{tabular}{|l|c|c|c|}
\hline \multicolumn{4}{|c|}{ ANSYS 5.7 } \\
\hline \multirow{2}{*}{ PERFIL Ue } & $\mathrm{L}_{\mathrm{d}}$ Ou $\mathrm{L}_{\text {local }}$ & $\sigma_{\text {dist }}$ ou $\sigma_{\text {local }}$ & MODO \\
\hline Ue $200 \times 100 \times 10 \times 2,0$ & 50,0 & 14,07 & $\mathrm{D}$ \\
\hline Ue $200 \times 100 \times 10 \times 4,0$ & 33,0 & 36,40 & $\mathrm{D}$ \\
\hline Ue $200 \times 200 \times 10 \times 1,0$ & 100,0 & 1,67 & $\mathrm{D}$ \\
\hline Ue $200 \times 200 \times 10 \times 2,0$ & 70,0 & 4,10 & $\mathrm{D}$ \\
\hline Ue $200 \times 200 \times 10 \times 4,0$ & 50,0 & 10,12 & $\mathrm{D}$ \\
\hline Ue $200 \times 200 \times 20 \times 4,0$ & 100,0 & 17,00 & $\mathrm{D}$ \\
\hline Ue $200 \times 200 \times 30 \times 4,0$ & 100,0 & 25,60 & $\mathrm{D}$ \\
\hline Notas: & \\
\hline \\
D: modo distorcional é o crítico & \\
\hline
\end{tabular}


Para as tabelas 4.5 e 4.6, relativas à terceira hipótese, pode-se observar que os mesmos perfis, quando submetidos à flexão, mais uma vez apresentam maiores valores de $\sigma_{\text {dist }}$, quando comparados com os submetidos à compressão (média em torno de 17\%). Por outro lado, os valores de $L_{d}$ dos perfis submetidos à flexão, quando comparados com os submetidos à compressão centrada são aproximadamente iguais ou um pouco menores (média de 10\%). Como exceção, o perfil Ue $200 \times 100 \times 10 \times 2,0$ apresentou, para a flexão, valor de $L_{d} 65 \%$ superior ao referente à compressão centrada.

\section{HIPÓTESE 3}

As tabelas 4.5 e 4.6 ilustram a hipótese 3.

\section{COMPRESSÃO CENTRADA}

Tabela 4.5 - Resultados via ANSYS 5.7 - hipótese 3 (compressão)

\begin{tabular}{|c|c|c|c|}
\hline \multicolumn{4}{|c|}{ ANSYS 5.7} \\
\hline \multirow{2}{*}{ PERFIL Ue } & $L_{d}$ ou $L_{\text {local }}$ & $\sigma_{\text {dist }}$ ou $\sigma_{\text {local }}$ & MODO \\
\hline & $(\mathbf{c m})$ & (kN/cm2) & \\
\hline Ue $200 \times 100 \times 10 \times 2,0$ & 40,0 & 11,44 & $\mathrm{D} / \mathrm{L}$ \\
\hline Ue $200 \times 100 \times 10 \times 4,0$ & 35,0 & 28,44 & $\mathrm{D}$ \\
\hline Ue $200 \times 200 \times 10 \times 1,0$ & 140,0 & 2,30 & $\mathrm{D}$ \\
\hline Ue $200 \times 200 \times 10 \times 2,0$ & 100,0 & 3,84 & $\bar{D}$ \\
\hline Ue $200 \times 200 \times 10 \times 4,0$ & 75,0 & 10,60 & $\mathrm{D}$ \\
\hline Ue $200 \times 200 \times 30 \times 4,0$ & 120,00 & 24,00 & $\mathrm{D}$ \\
\hline \multicolumn{4}{|c|}{$\begin{array}{l}\text { Notas: } \\
\text { D: modo distorcional é o crítico } \\
\text { D/L: ocorre interação entre o modo local e distorcional }\end{array}$} \\
\hline
\end{tabular}




\section{FLEXÃO}

Tabela 4.6 - Resultados via ANSYS 5.7 - hipótese 3 (flexão)

\begin{tabular}{|c|c|c|c|}
\hline \multicolumn{4}{|c|}{ ANSYS 5.7} \\
\hline \multirow{2}{*}{ PERFIL Ue } & $\mathrm{L}_{d}$ ou $\mathrm{L}_{\text {local }}$ & $\sigma_{\text {dist }}$ ou $\sigma_{\text {local }}$ & MODO \\
\hline & $(\mathbf{c m})$ & $(\mathrm{KN} / \mathrm{cm} 2)$ & \\
\hline Ue $200 \times 100 \times 10 \times 2,0$ & 66,0 & 15,30 & D \\
\hline Ue $200 \times 100 \times 10 \times 4,0$ & 33,0 & 38,33 & $\mathrm{D}$ \\
\hline Ue $200 \times 200 \times 10 \times 1,0$ & 120,0 & 2,16 & $\mathrm{D}$ \\
\hline Ue $200 \times 200 \times 10 \times 2,0$ & 75,0 & 4,39 & $\mathrm{D}$ \\
\hline Ue $200 \times 200 \times 10 \times 4,0$ & 75,0 & 11,80 & $\mathrm{D}$ \\
\hline
\end{tabular}

As tabelas 4.7 e 4.8 ilustram uma comparação entre os resultados obtidos devido à análise via método dos elementos finitos, faixas finitas e procedimento da NBR 14762:2001. Os valores são ilustrados sob o formato de gráficos nas figuras 4.4 a 4.13 , onde podem ser melhor visualizados.

A análise crítica de tais tabelas e figuras será feita a seguir. Entretanto, cabe lembrar que estes três procedimentos (procedimento da NBR 14762:2001, análise via faixas finitas e análise via elementos finitos) têm suas particularidades e, portanto, são um pouco diferentes entre si em suas concepções.

No que se refere à compressão centrada, pode-se observar que:

\section{Para a hipótese 1:}

Com relação ao valor de $\sigma_{\text {dist, }}$ os resultados referentes à análise via elementos finitos são ligeiramente superiores aos valores via faixas finitas (variação entre -5 e $27 \%$, com média de $11 \%$ ), e também superiores aos valores via procedimento da NBR 14762 (variação entre -7 e 19\%, com média de 5\%), o que evidencia, provavelmente, que a análise via faixas finitas conduz a resultados mais conservadores, seguido do procedimento da NBR 14762:2001. É interessante 
observar que os resultados via elementos finitos se aproximam mais dos referentes ao procedimento da NBR 14762:2001.

Com relação ao valor de $L_{d}$, os resultados referentes à análise via elementos finitos são ligeiramente superiores aos valores via faixas finitas (variação entre -6 e $38 \%$, com média de $16 \%$ ), e também superiores aos valores via procedimento da NBR 14762 (variação entre -3 e 18\%, com média de 7\%).

\section{Para a hipótese 2:}

Com relação ao valor de $\sigma_{\text {dist, }}$ os resultados referentes à análise via elementos finitos são ligeiramente superiores aos valores via faixas finitas (variação entre -2 e $12 \%$, com média de $6 \%$ ), e próximos aos valores via procedimento da NBR 14762 (variação entre -6 e 11\%), o que evidencia, provavelmente, que novamente a análise via faixas finitas conduz a resultados mais conservadores, seguido do procedimento da NBR 14762:2001. Além disso, mais uma vez os resultados via elementos finitos se aproximam mais dos referentes ao procedimento da NBR 14762:2001.

Observa-se, nesta segunda hipótese, quando comparada à primeira, que os valores relativos ao método dos elementos finitos são mais próximos aos relativos à análise via faixas finitas e via procedimento da NBR 14762. Este fato é explicável, pois esta hipótese em questão adota simetria referente às condições de contorno, o que é adotado nos outros procedimentos.

Com relação ao valor de $L_{d}$, os resultados referentes à análise via elementos finitos são próximos aos valores via faixas finitas (variação entre -18 e 17\%), e também próximos aos valores via procedimento da NBR 14762 (variação entre -20 e $12 \%)$.

\section{Para a hipótese 3:}

Com relação ao valor de $\sigma_{\text {dist, }}$ os resultados referentes à análise via elementos finitos com não-linearidade geométrica são ligeiramente superiores aos valores via elementos finitos sem não-linearidade geométrica (variação entre $4 \mathrm{e}$ $23 \%$, com média de $13 \%$ ). Entretanto, tal fato não é suficiente para que se possa afirmar que o uso da não-linearidade geométrica conduz a valores de $\sigma_{\text {dist }}$ menos 
conservadores, pois muitos fatores estão envolvidos quando uma análise não-linear é realizada. Ao menos, os valores estão próximos entre si.

Com relação ao valor de $L_{d}$, os resultados referentes à análise via elementos finitos com não-linearidade geométrica não são próximos aos valores via elementos finitos sem não-linearidade geométrica (variação entre -27 e 50\%).

No que se refere à flexão, pode-se observar que:

\section{Para a hipótese 1:}

Com relação ao valor de $\sigma_{\text {dist, }}$ diferentemente do caso da compressão centrada, os resultados referentes à análise via elementos finitos são consideravelmente superiores aos valores via faixas finitas (variação entre $21 \mathrm{e}$ $50 \%$, com média de $35 \%$ ), e também superiores aos valores via procedimento da NBR 14762 (variação entre 4 e 26\%, com média de 17\%), o que evidencia, provavelmente, que a análise via faixas finitas conduz a resultados mais conservadores, seguido do procedimento da NBR 14762:2001.

Com relação ao valor de $L_{d}$, os resultados referentes à análise via elementos finitos são ligeiramente superiores aos valores via faixas finitas (variação entre 7 e $28 \%$, com média de $16 \%$ ), e também superiores aos valores via procedimento da NBR 14762 (variação média de 20\%).

\section{Para a hipótese 2:}

Com relação ao valor de $\sigma_{\text {dist, }}$ os resultados referentes à análise via elementos finitos são praticamente iguais aos valores via faixas finitas (variação entre -9 e $15 \%$, com média de somente $3 \%$ ), e inferiores aos valores via procedimento da NBR 14762 (em torno de -10\%), o que evidencia, provavelmente, que o procedimento da NBR está contra a segurança. Observa-se também, nesta segunda hipótese, que quando comparados à primeira hipótese, os valores relativos ao método dos elementos finitos são novamente mais próximos aos relativos à análise via faixas finitas e via procedimento da NBR 14762. Este fato é explicável, pois esta hipótese em questão adota simetria referente às condições de contorno, o que é adotado nos outros procedimentos.

Com relação ao valor de $L_{d}$, os resultados referentes à análise via elementos finitos são próximos aos valores via faixas finitas (variação entre -13 e 27\%, com 
média de $3 \%$ ), e próximos aos valores referentes ao procedimento da NBR 14762 (média de $5 \%$ ).

\section{Para a hipótese 3:}

Com relação ao valor de $\sigma_{\text {dist, }}$ os resultados referentes à análise via elementos finitos com não-linearidade geométrica são ligeiramente superiores aos valores via elementos finitos sem não-linearidade geométrica (variação entre $-7 \mathrm{e}$ $17 \%$, com média de 6\%). Entretanto, dois perfis apresentaram valores mais discrepantes. Tal fato, como já dito anteriormente, não é suficiente para que se possa afirmar que o uso da não-linearidade geométrica conduz a valores de $\sigma_{\text {dist }}$ mais conservadores, pois muitos fatores estão envolvidos quando uma análise nãolinear é realizada. Ao menos, os valores, mais uma vez, estão próximos entre si.

Com relação ao valor de $L_{d}$, os resultados referentes à análise via elementos finitos com não-linearidade geométrica não são próximos aos valores via faixas finitas.

A seguir são, então, apresentadas as tabelas 4.7 e 4.8 , e as figuras 4.4 a 4.13, já comentadas. 
Tabela 4.7 - Relação entre resultados obtidos via elementos finitos, faixas finitas e procedimento da NBR 14762:2001 para compressão

\begin{tabular}{|c|c|c|c|c|c|c|c|c|c|c|}
\hline HIPÓTESE & 1 & 1 & 1 & & 2 & & 2 & 2 & 3 & 3 \\
\hline \multirow{3}{*}{$\begin{array}{l}\text { RELAÇÃO ENTRE } \\
\text { ANÁLISES }\end{array}$} & \multicolumn{2}{|c|}{$\begin{array}{l}\text { ANSYS } \\
5.7 \\
\end{array}$} & \multicolumn{2}{|c|}{$\begin{array}{c}\text { ANSYS } \\
5.7\end{array}$} & \multicolumn{2}{|c|}{$\begin{array}{c}\text { ANSYS } \\
5.7 \\
\end{array}$} & \multicolumn{2}{|c|}{$\begin{array}{c}\text { ANSYS } \\
5.7 \\
\end{array}$} & \multicolumn{2}{|c|}{$\begin{array}{c}\text { ANSYS } 5.7 \\
\text { (NLG) }\end{array}$} \\
\hline & \multicolumn{2}{|c|}{ CUFSM } & \multicolumn{2}{|c|}{ ANEXO D } & \multicolumn{2}{|c|}{ CUFSM } & \multicolumn{2}{|c|}{ ANEXO D } & \multicolumn{2}{|c|}{ ANSYS 5.7} \\
\hline & $\mathrm{L}_{d}$ & $\sigma_{\text {dist }}$ & $L_{d}$ & $\sigma_{\text {dist }}$ & $\mathrm{L}_{d}$ & $\sigma_{\text {dist }}$ & $L_{d}$ & $\sigma_{\text {dist }}$ & $\mathrm{L}_{d}$ & $\sigma_{\text {dist }}$ \\
\hline \multicolumn{11}{|l|}{ PERFIL Ue } \\
\hline Ue $200 \times 100 \times 10 \times 2,0$ & 1,17 & 0,98 & 1,00 & 0,94 & 1,17 & 0,98 & 1,00 & 0,94 & 0,73 & 1,23 \\
\hline Ue $200 \times 100 \times 10 \times 4,0$ & 1,30 & 1,04 & 0,97 & 1,01 & 1,13 & 1,03 & 0,84 & 1,00 & 1,00 & 1,04 \\
\hline Ue $200 \times 100 \times 20 \times 4,0$ & 1,38 & 0,95 & 1,18 & 0,93 & ${ }^{*}$ & * & $*$ & ${ }^{*}$ & ${ }^{*}$ & * \\
\hline Ue $200 \times 200 \times 10 \times 1,0$ & 0,94 & 1,20 & 1,05 & 1,15 & 0,82 & 1,05 & 0,91 & 1,01 & 1,40 & 1,64 \\
\hline Ue $200 \times 200 \times 10 \times 2,0$ & 1,09 & 1,27 & 1,12 & 1,14 & 1,09 & 1,10 & 1,12 & 0,99 & 1,11 & 1,15 \\
\hline Ue $200 \times 200 \times 10 \times 4,0$ & 1,29 & 1,19 & 1,11 & 1,01 & 0,92 & 1,12 & 0,80 & 0,95 & 1,50 & 1,16 \\
\hline Ue $200 \times 200 \times 20 \times 4,0$ & 1,00 & 1,10 & 1,03 & 1,05 & ${ }^{*}$ & $*$ & $*$ & $*$ & $*$ & $*$ \\
\hline Ue $200 \times 200 \times 30 \times 4,0$ & 1,17 & 1,19 & 1,11 & 1,19 & 0,87 & 1,11 & 0,82 & 1,11 & 1,20 & 1,08 \\
\hline$\left.{ }^{*}\right)$ valores não ficaram $\epsilon$ & deti & 100 & 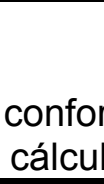 & 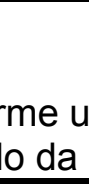 & $\begin{array}{l}n \text { dos } \\
\text { nédia }\end{array}$ & & 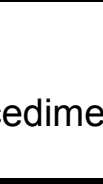 & tos & & \\
\hline
\end{tabular}


Tabela 4.8 - Relação entre resultados obtidos via elementos finitos, faixas finitas e procedimento da NBR 14762:2001 para flexão

\begin{tabular}{|c|c|c|c|c|c|c|c|c|c|c|}
\hline HIPÓTESE & 1 & | & 1 & & 2 & & 2 & 2 & 3 & 3 \\
\hline \multirow{3}{*}{$\begin{array}{l}\text { RELAÇÃO ENTRE } \\
\text { ANÁLISES }\end{array}$} & \multicolumn{2}{|c|}{$\begin{array}{c}\text { ANSYS } \\
5.7\end{array}$} & \multicolumn{2}{|c|}{$\begin{array}{c}\text { ANSYS } \\
5.7\end{array}$} & \multicolumn{2}{|c|}{$\begin{array}{c}\text { ANSYS } \\
5.7\end{array}$} & \multicolumn{2}{|c|}{$\begin{array}{c}\text { ANSYS } \\
5.7\end{array}$} & \multicolumn{2}{|c|}{$\begin{array}{c}\text { ANSYS } 5.7 \\
\text { (NLG) }\end{array}$} \\
\hline & \multicolumn{2}{|c|}{ CUFSM } & \multicolumn{2}{|c|}{ ANEXO D } & \multicolumn{2}{|c|}{ CUFSM } & \multicolumn{2}{|c|}{ ANEXO D } & \multicolumn{2}{|c|}{ ANSYS 5.7} \\
\hline & $\mathrm{L}_{d}$ & $\sigma_{\text {dist }}$ & $\mathrm{L}_{d}$ & $\sigma_{\text {dist }}$ & $\mathrm{L}_{d}$ & $\sigma_{\text {dist }}$ & $L_{d}$ & $\sigma_{\text {dist }}$ & $\mathrm{L}_{d}$ & $\sigma_{\text {dist }}$ \\
\hline \multicolumn{11}{|l|}{ PERFIL Ue } \\
\hline Ue $200 \times 100 \times 10 \times 2,0$ & 1,07 & 1,32 & 1,08 & 1,17 & 1,07 & 1,02 & 1,08 & 0,90 & 1,32 & 1,09 \\
\hline Ue $200 \times 100 \times 10 \times 4,0$ & 1,13 & 1,32 & 1,00 & 1,18 & 1,07 & 0,99 & 0,95 & 0,88 & 1,00 & 1,05 \\
\hline Ue $200 \times 100 \times 20 \times 4,0$ & 1,11 & 1,23 & 1,12 & 1,25 & 1,22 & 0,91 & 1,23 & 0,92 & 3,03 & 0,93 \\
\hline Ue $200 \times 200 \times 10 \times 1,0$ & 1,28 & 1,40 & 1,41 & 1,13 & 0,99 & 1,06 & 1,09 & 0,85 & 1,20 & 1,29 \\
\hline Ue $200 \times 200 \times 10 \times 2,0$ & 1,10 & 1,62 & 1,11 & 1,25 & 1,03 & 1,15 & 1,04 & 0,88 & 1,07 & 1,07 \\
\hline Ue $200 \times 200 \times 10 \times 4,0$ & 1,11 & 1,50 & 1,14 & 1,09 & 0,92 & 1,07 & 0,95 & 0,79 & 1,50 & 1,17 \\
\hline Ue $200 \times 200 \times 20 \times 2,0$ & 1,17 & 1,21 & 1,30 & 1,04 & 0,83 & 1,07 & 0,93 & 0,92 & 0,66 & 1,39 \\
\hline Ue $200 \times 200 \times 20 \times 4,0$ & 1,27 & 1,43 & 1,29 & 1,19 & 1,27 & 1,01 & 1,29 & 0,84 & 1,90 & 1,06 \\
\hline Ue $200 \times 200 \times 30 \times 4,0$ & 1,26 & 1,40 & 1,41 & 1,26 & 0,87 & 1,01 & 0,97 & 0,91 & 1,90 & 1,11 \\
\hline Notas: & & & & & & & & & & \\
\hline
\end{tabular}

A seguir serão apresentadas Figuras 4.4 a 4.13, comparativas com relação aos valores resultantes das análises em questão. Tais figuras simplesmente apresentam os valores das tabelas 4.7 e 4.8 sob o formato de gráficos, para se facilitar o entendimento do leitor. Para o entendimento da designação dos perfis que constam das figuras, a legenda abaixo exemplifica um caso padrão.

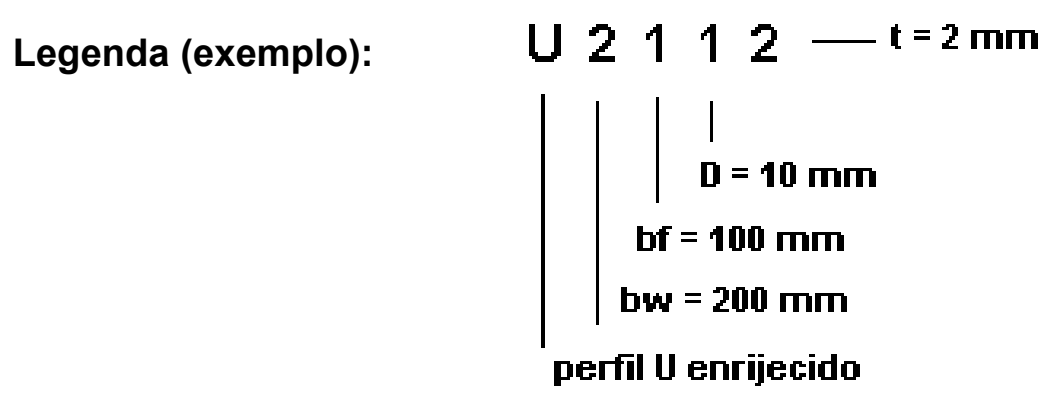




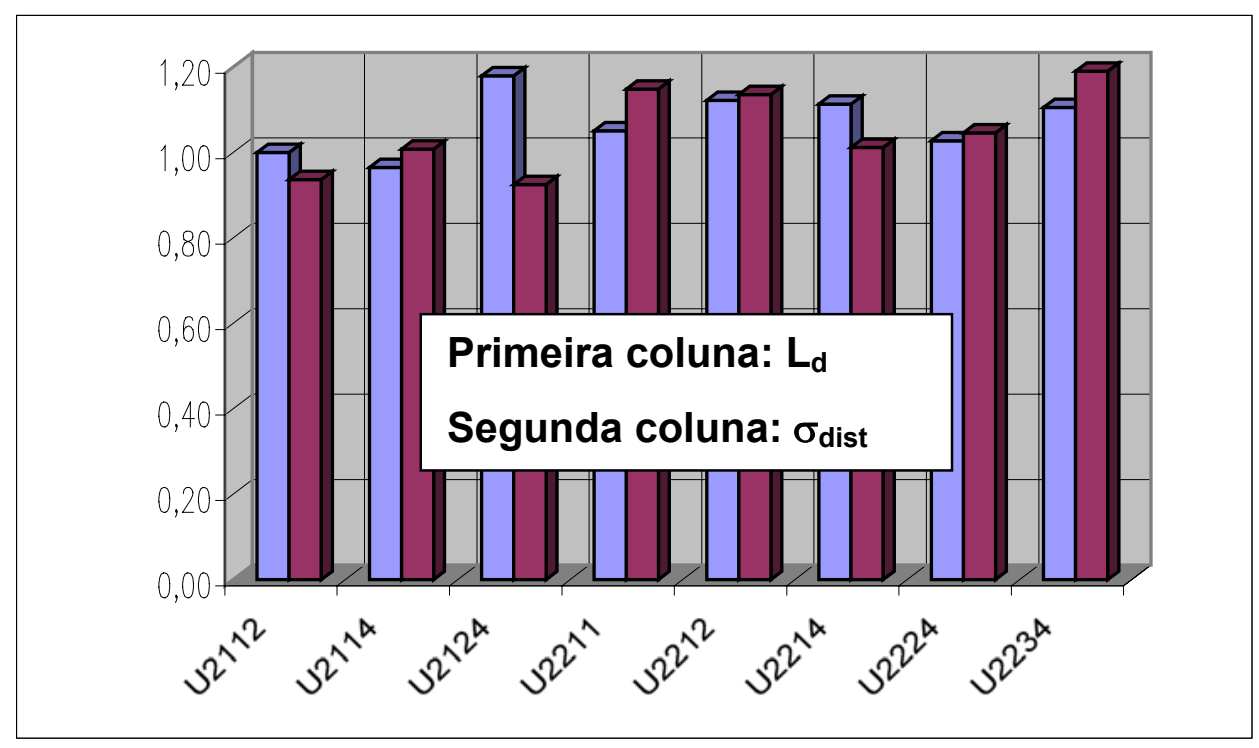

Figura 4.4 - ANSYS / NBR 14762 (compressão) - hipótese 1

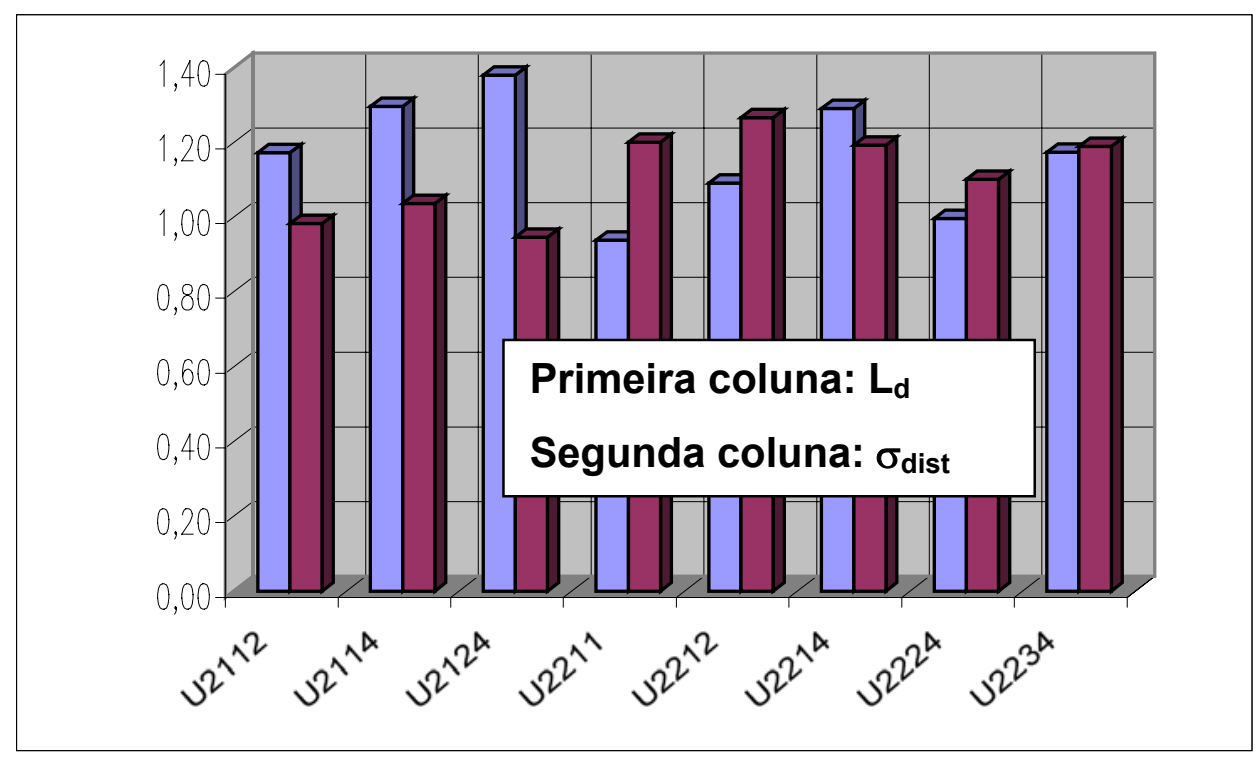

Figura 4.5 - ANSYS / CUFSM (compressão) - hipótese 1 


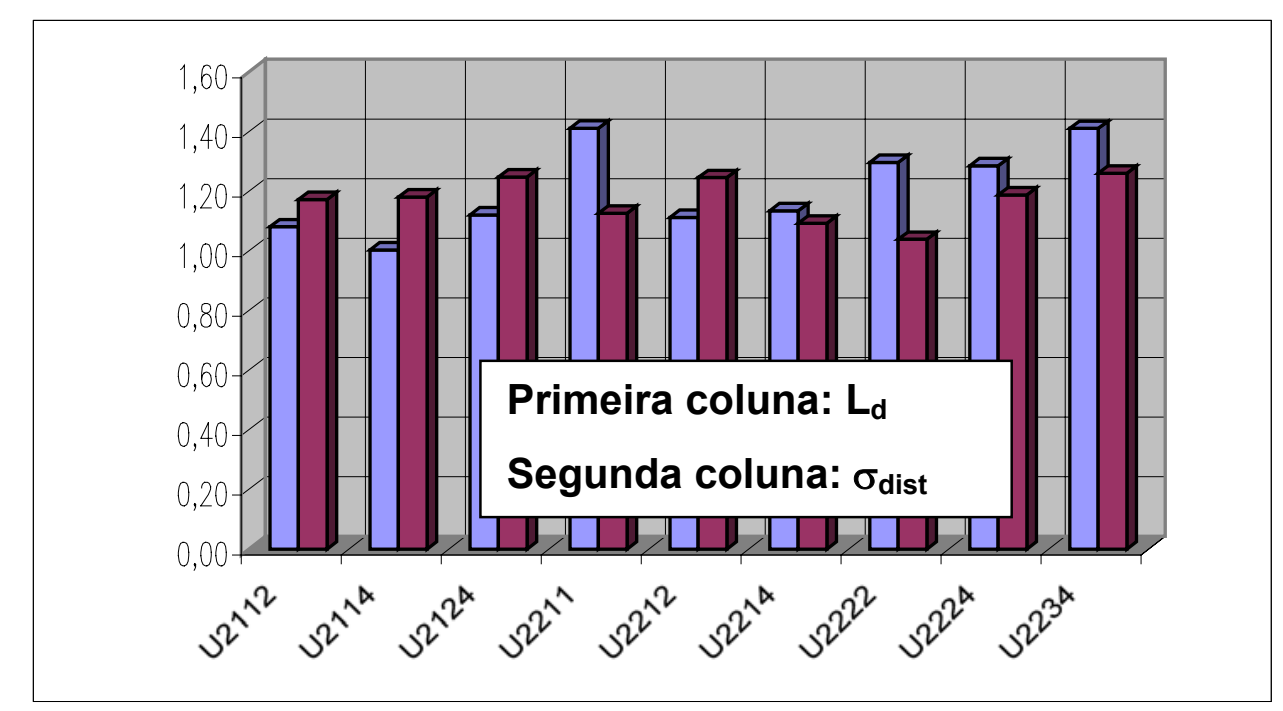

Figura 4.6 - ANSYS / NBR 14762 (flexão) - hipótese 1

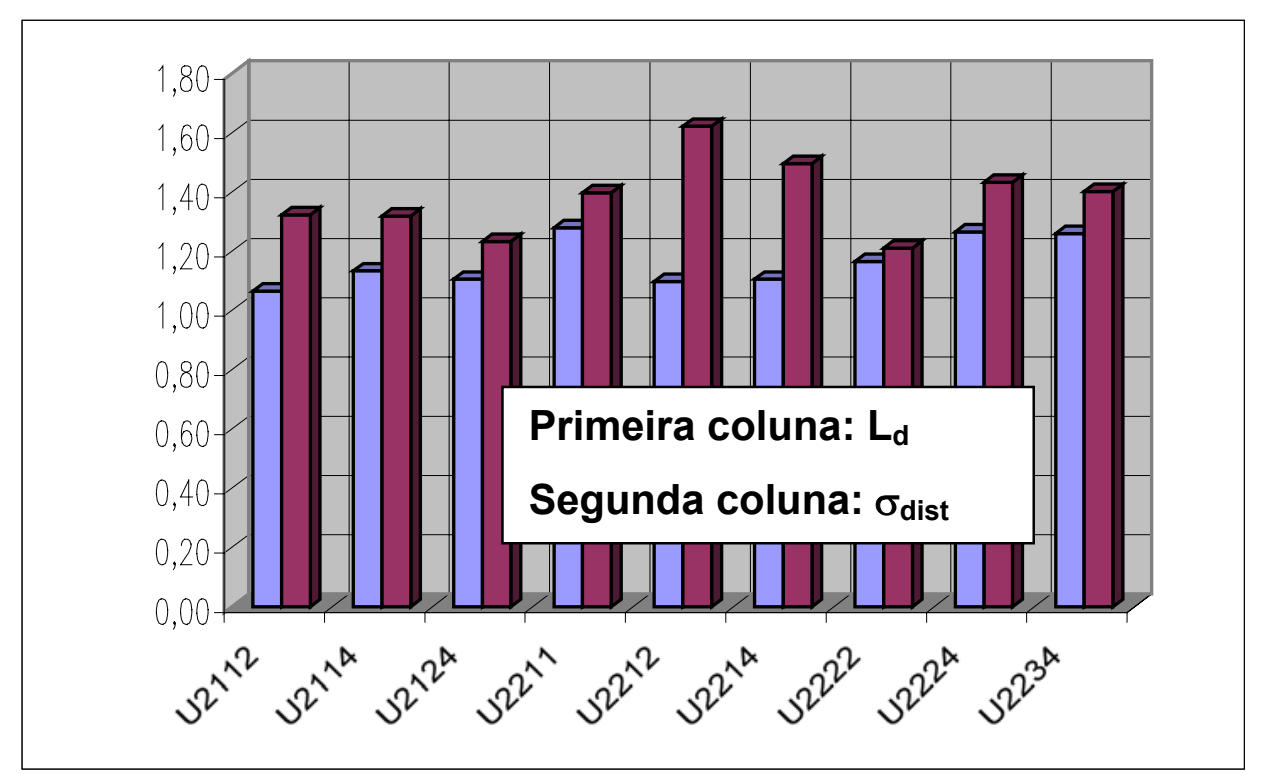

Figura 4.7 - ANSYS / CUFSM (flexão) - hipótese 1 


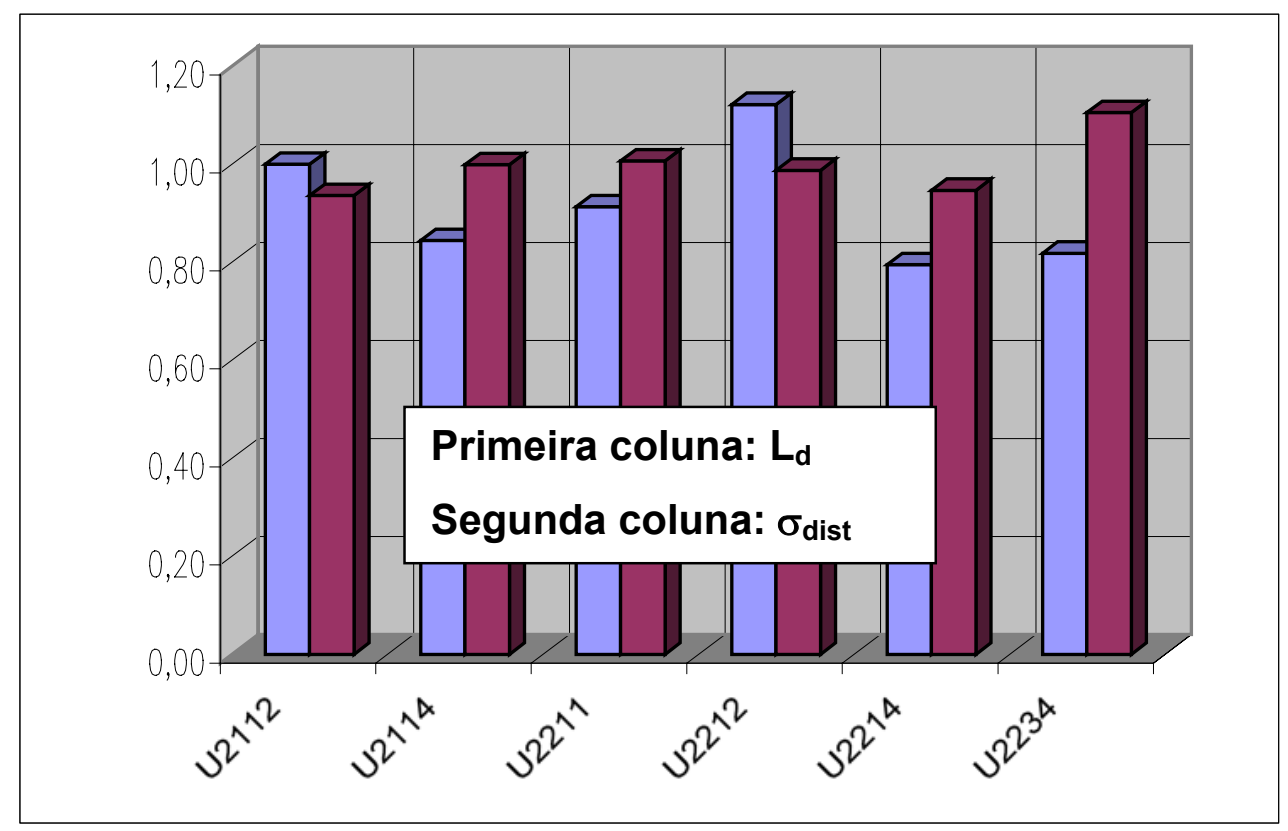

Figura 4.8 - ANSYS / NBR 14762 (compressão) - hipótese 2

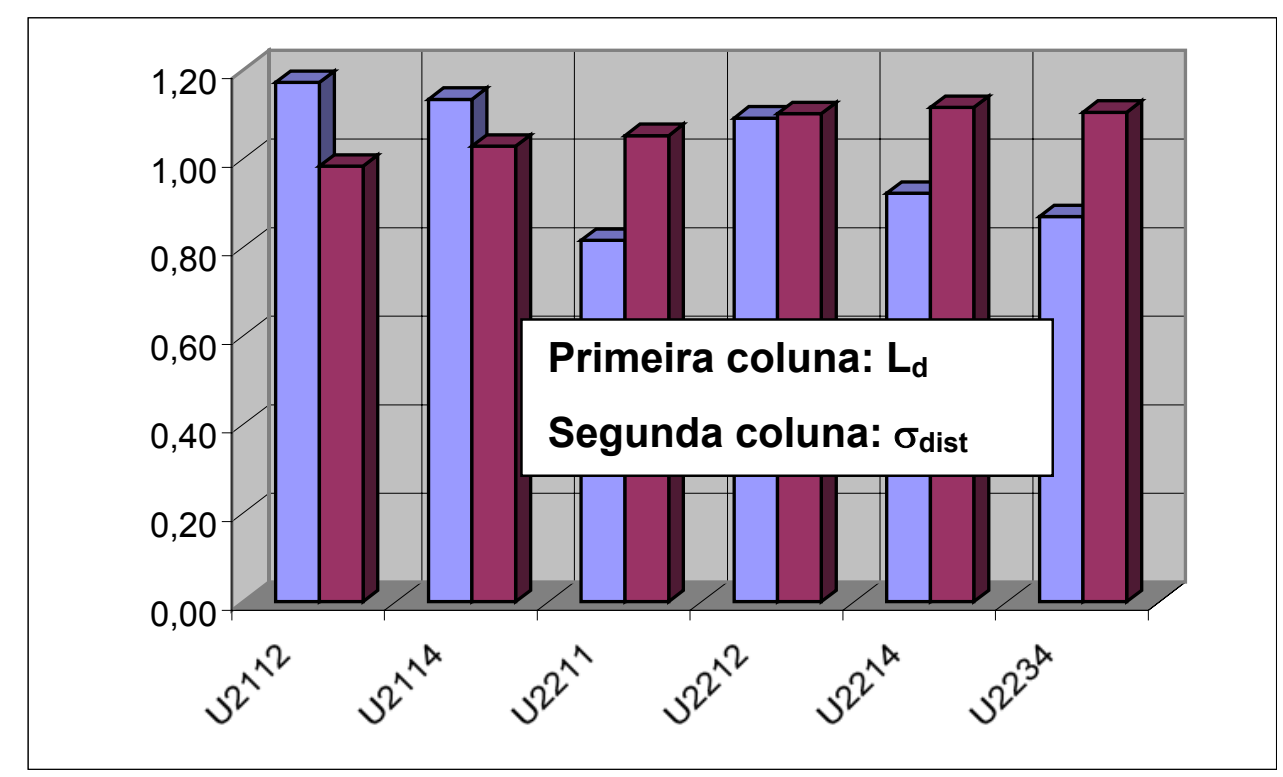

Figura 4.9 - ANSYS / CUFSM (compressão) - hipótese 2 


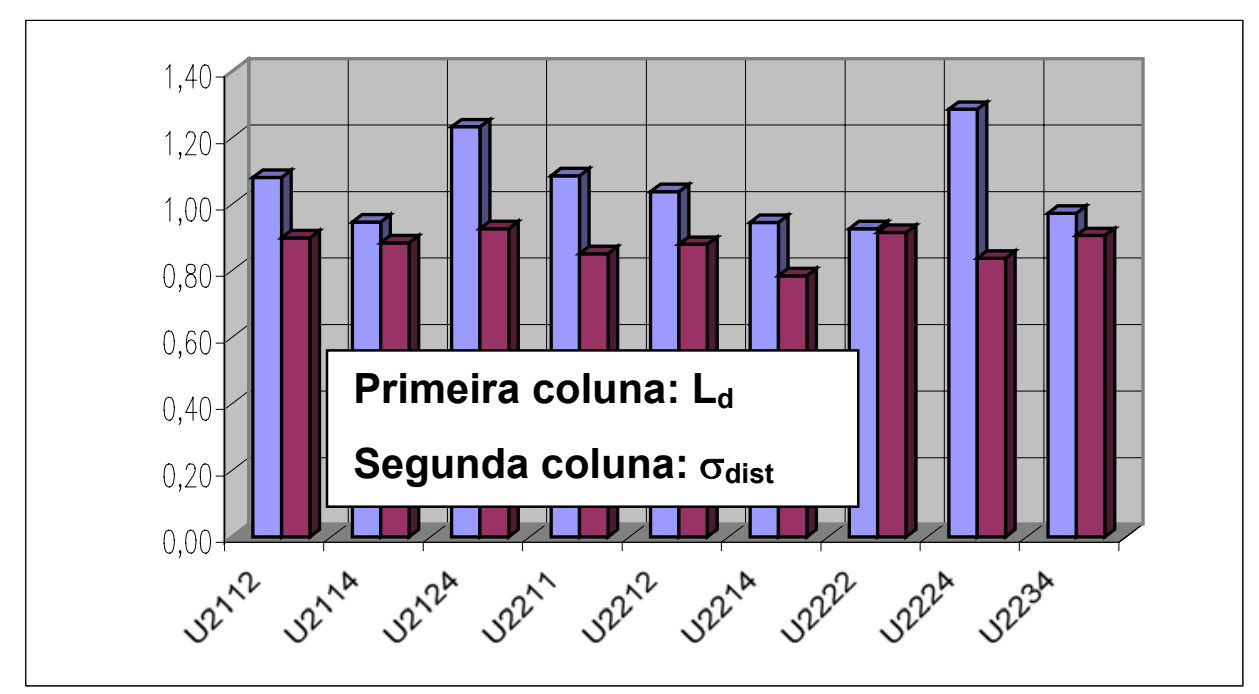

Figura 4.10 - ANSYS / NBR 14762 (flexão) - hipótese 2

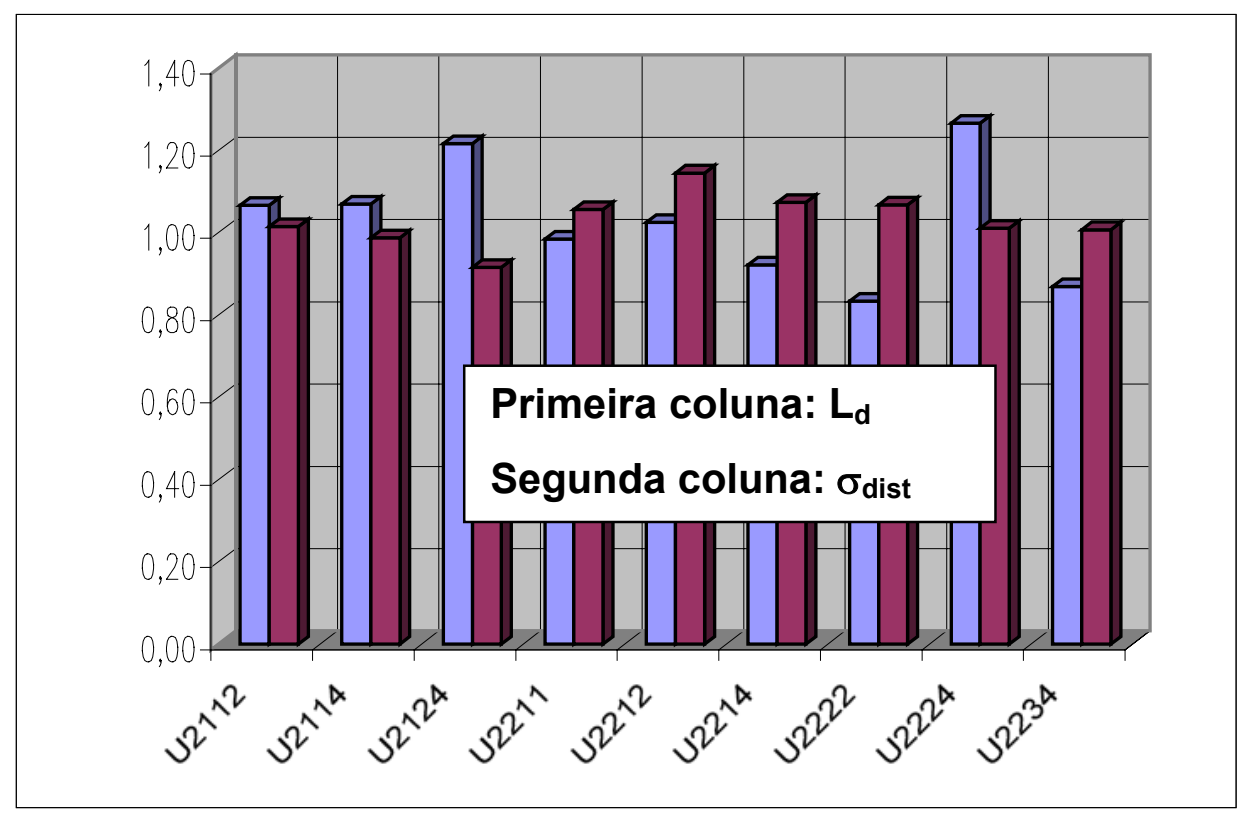

Figura 4.11 - ANSYS / CUFSM (flexão) - hipótese 2 


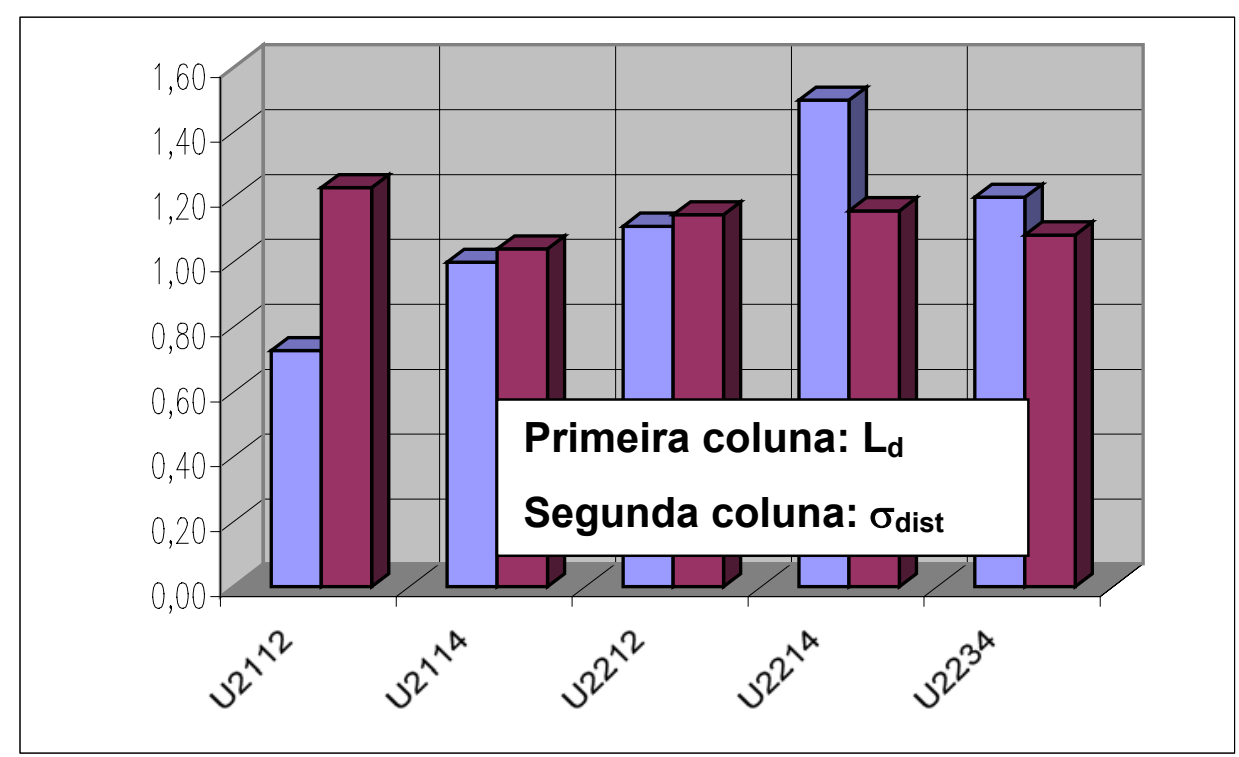

Figura 4.12 - ANSYS NLG/ ANSYS (compressão) - hipótese 3

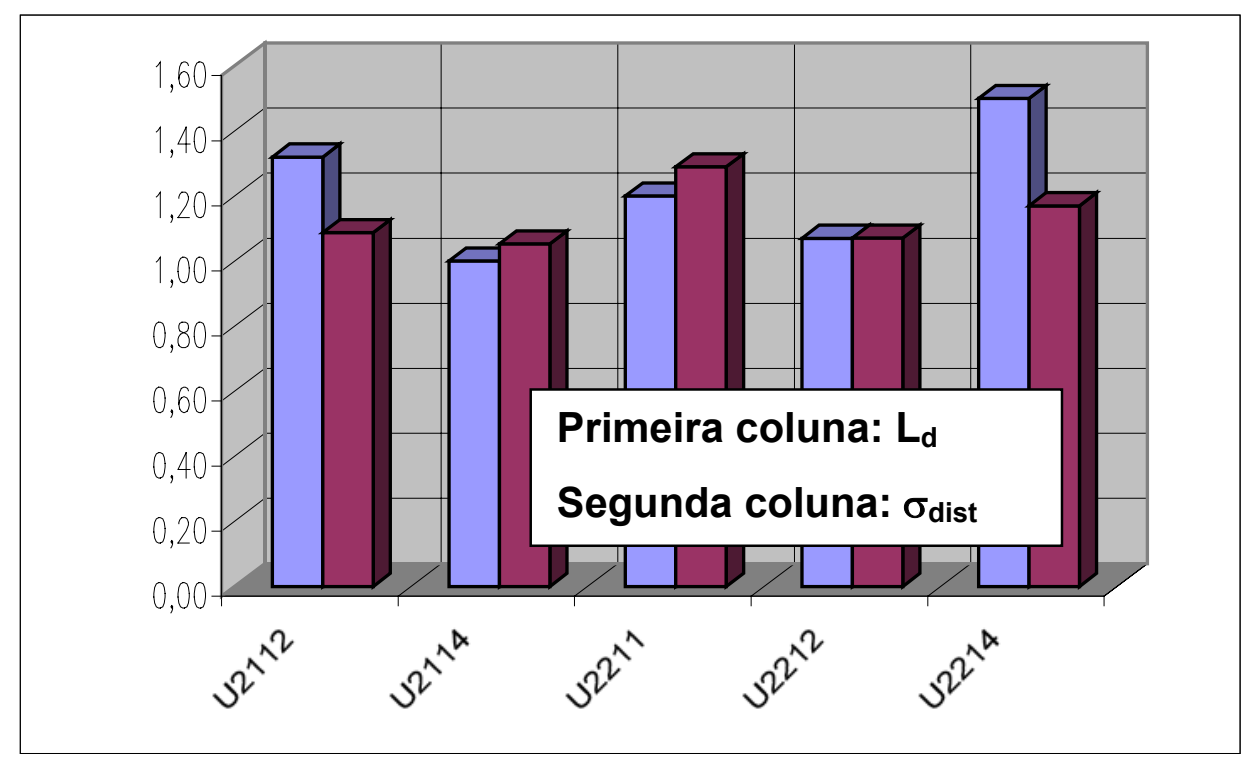

Figura 4.13 - ANSYS NLG/ ANSYS (flexão) - hipótese 3 


\section{NÃO-LINEARIDADE GEOMÉTRICA - EXPLICACÕES}

O critério adotado para se justificar a escolha do passo de carga correspondente à instabilidade das barras analisadas, e, portanto, correspondente à tensão crítica obtida como resposta das análises, foi o de se fazer um gráfico de força versus o deslocamento segundo o eixo y (deslocamento paralelo à alma, característico do modo distorcional com relação às mesas) relativo a três nós correspondentes aos terços da barra, situados na borda do enrijecedor.

Com isso se pôde avaliar o passo de carga correspondente à instabilidade da barra, e, portanto, registrar o valor da tensão correspondente.

As figuras 4.14 e 4.15 a seguir ilustram os gráficos fornecidos pelo programa ANSYS 5.7, conforme a legenda:

VALU: valor do deslocamento dos nós analisados

TIME: valor do fator de tensão (passo de carga)

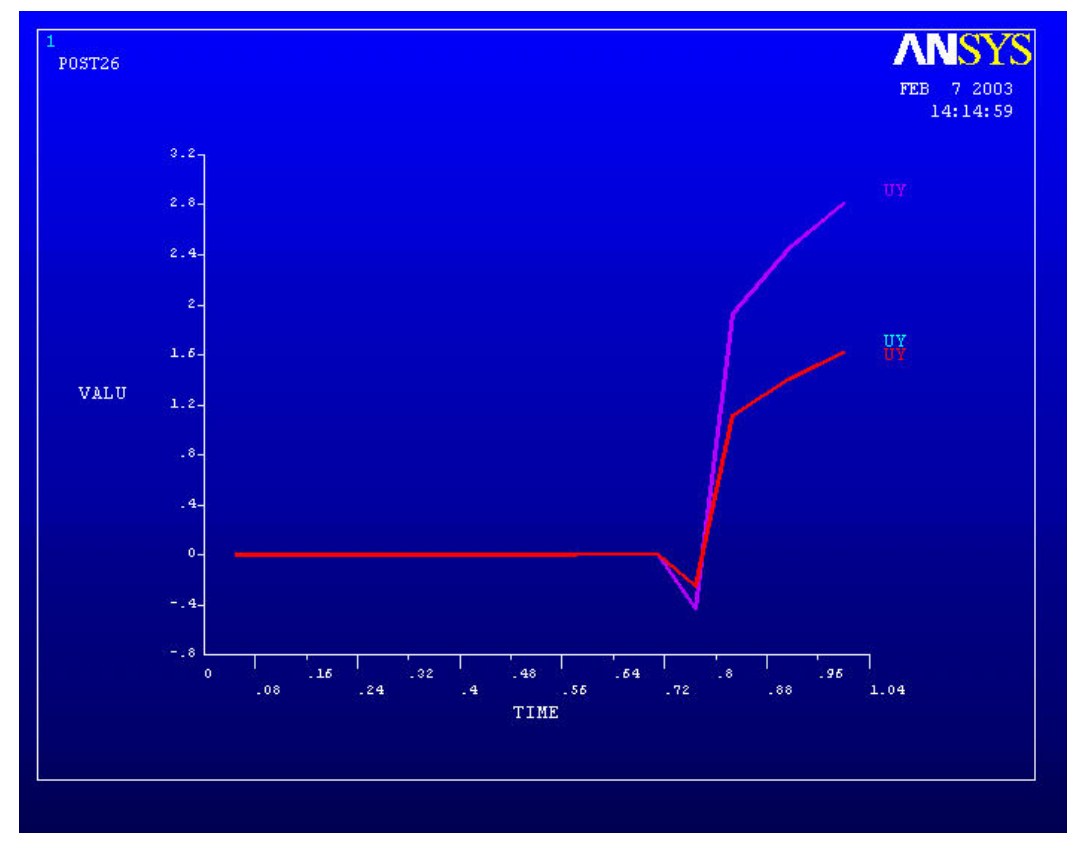

Figura 4.14 - Análise não-linear geométrica: Ue 200×200×10×2 - hipótese 3

(compressão) 


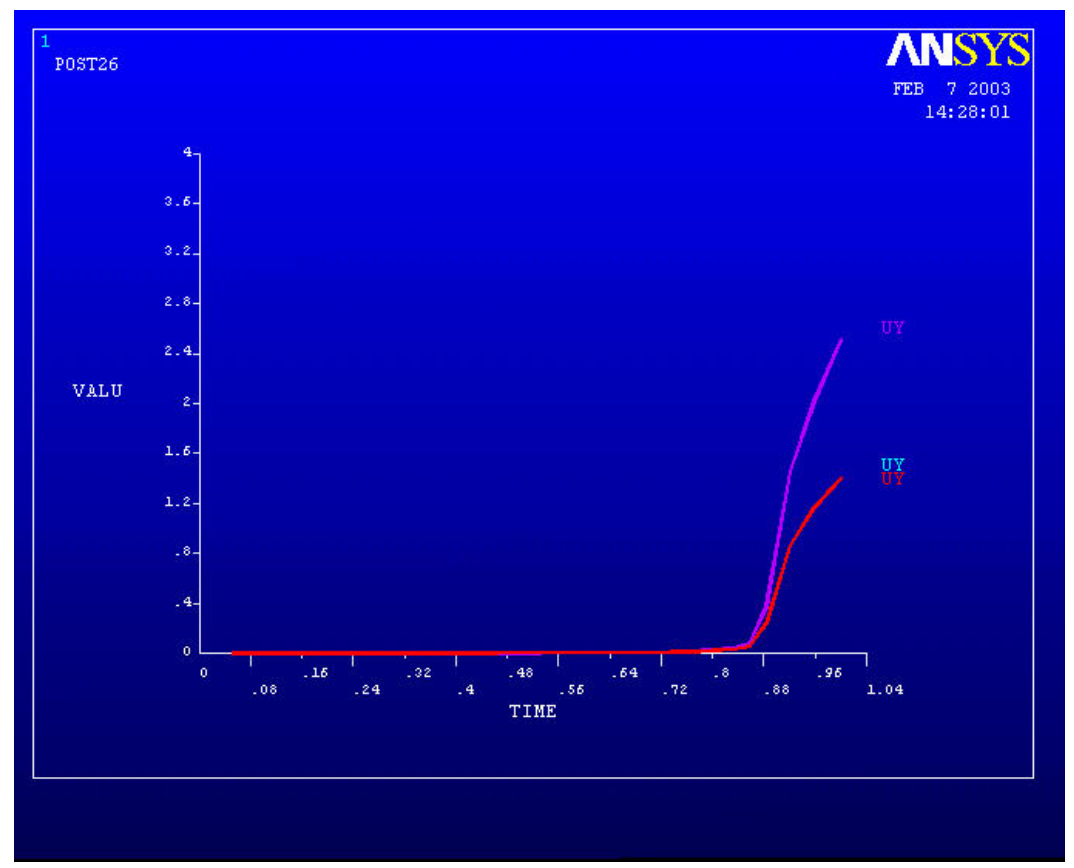

Figura 4.15 - Análise não-linear geométrica: Ue 200×200×10×4 - hipótese 3 (compressão)

Pode-se observar, conforme as duas figuras apresentadas (nos trechos em que a curva do diagrama abruptamente sofre uma variação, após vários passos de carga com o deslocamento dos enrijecedores praticamente sem alteração) os valores correspondentes aos passos de carga adotados como indicativos da ocorrência do fenômeno da instabilidade.

\section{HIPÓTESE 4}

Com relação à hipótese 4 , ou seja, modelagem em elementos finitos, admitindo-se não-linearidade geométrica e imperfeições iniciais, cabem algumas explicações.

Foi utilizado o programa computacional ANSYS 5.7, pois como já havia sido feita a análise de autovalor, o mesmo permite que através de um comando de atualização da geometria deformada da barra (autovetor), calculda previamente quando da análise do autovalor e armazenada, se possam inserir imperfeições iniciais na estrutura (barra). 
A inserção da imperfeição inicial na barra é feita então com a utilização de um fator multiplicativo de redução desta deformada.

Segundo SCHAFER \& PEKÖZ (1998), ainda não existe consenso sobre as distribuições e magnitudes que devam ser usadas como dados de entrada nos programas computacionais para a modelagem destes fatores para os perfis de aço formados a frio.

A norma brasileira NBR 6355:1980 prescreve, no que se refere às imperfeições iniciais, um ângulo máximo de tolerância de variação (em relação aos $90^{\circ}$ entre a mesa e a alma) de $1^{\circ}$. Portanto, como os deslocamento máximos obtidos quando da análise do autovalor ficaram em torno de $1,4 \mathrm{~cm}$, fixou-se em 0,15 o fator multiplicativo relativo ao comando de atualização da geometria. Com isso, a estrutura com imperfeições iniciais tornou-se a estrutura deformada após a análise do autovalor, porém com somente $15 \%$ dos deslocamentos em todos seus nós considerados.

Entretanto, no final deste capítulo, são apresentados resultados relativos à variação deste fator multiplicativo, com relação a um perfil escolhido como modelo, tanto no que se refere à compressão quanto à flexão.

Os perfis utilizados, tanto no caso da compressão centrada quanto no caso da flexão são apresentados a seguir, obedecendo a legenda de designação dos perfis apresentada anteriormente e são apresentadas as comparações entre a hipótese 3 e a hipótese 4 (Figura 4.16 e 4.17).

Somente foram considerados valores de $\sigma_{\text {dist }}$ para tal análise comparativa. 


\section{COMPRESSÃO CENTRADA}

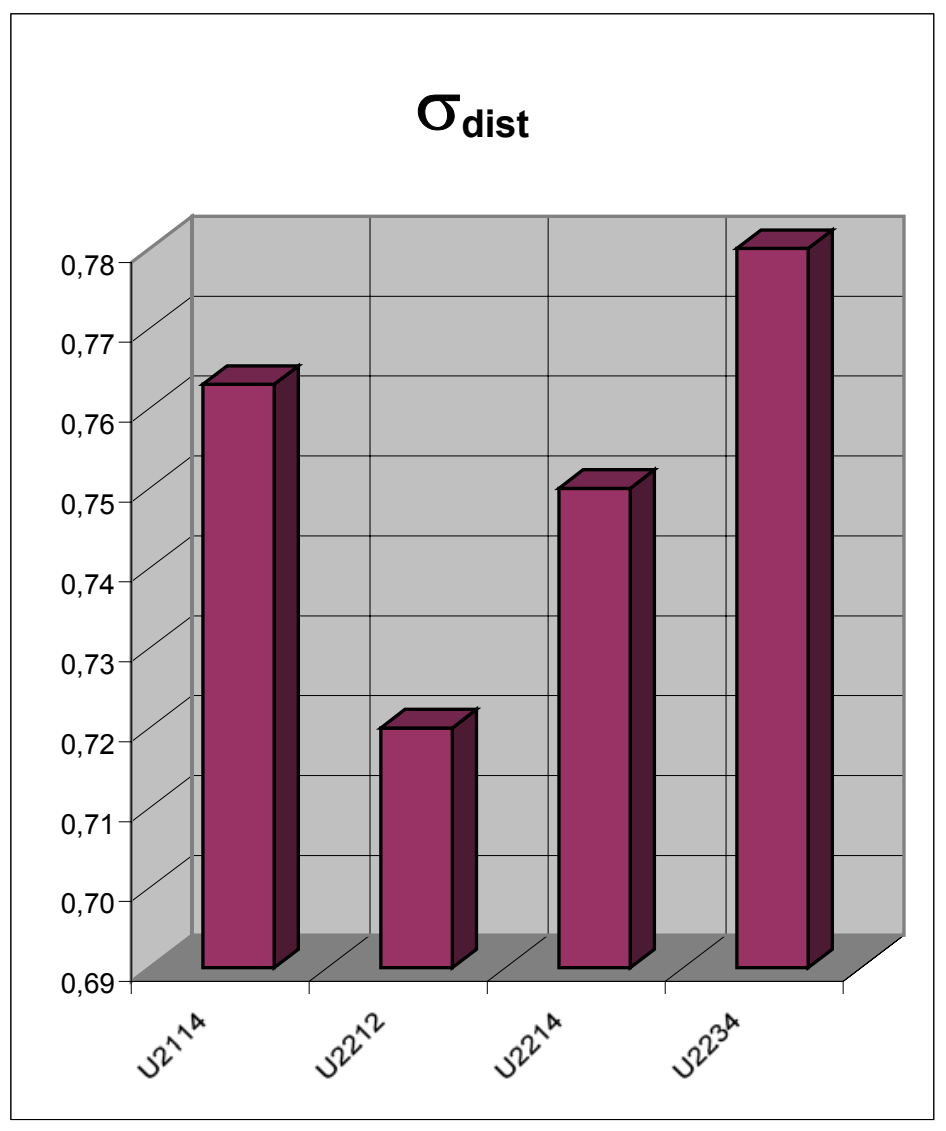

Figura 4.16 - Relação de $\sigma_{\text {dist }}$ para valores analisados via elementos finitos, entre modelos com imperfeição inicial e sem imperfeição inicial, para compressão centrada

Após a análise da figura 4.16, pode-se observar que a introdução de imperfeição inicial ao modelo causa uma redução no valor de $\sigma_{\text {dist }}$ (redução de 20 a $30 \%$ ), quando comparado à resultados obtidos de modelos que não consideram as imperfeições iniciais. Tal fato é importante, mesmo porque os perfis "reais" apresentam imperfeições iniciais. 


\section{FLEXÃO}

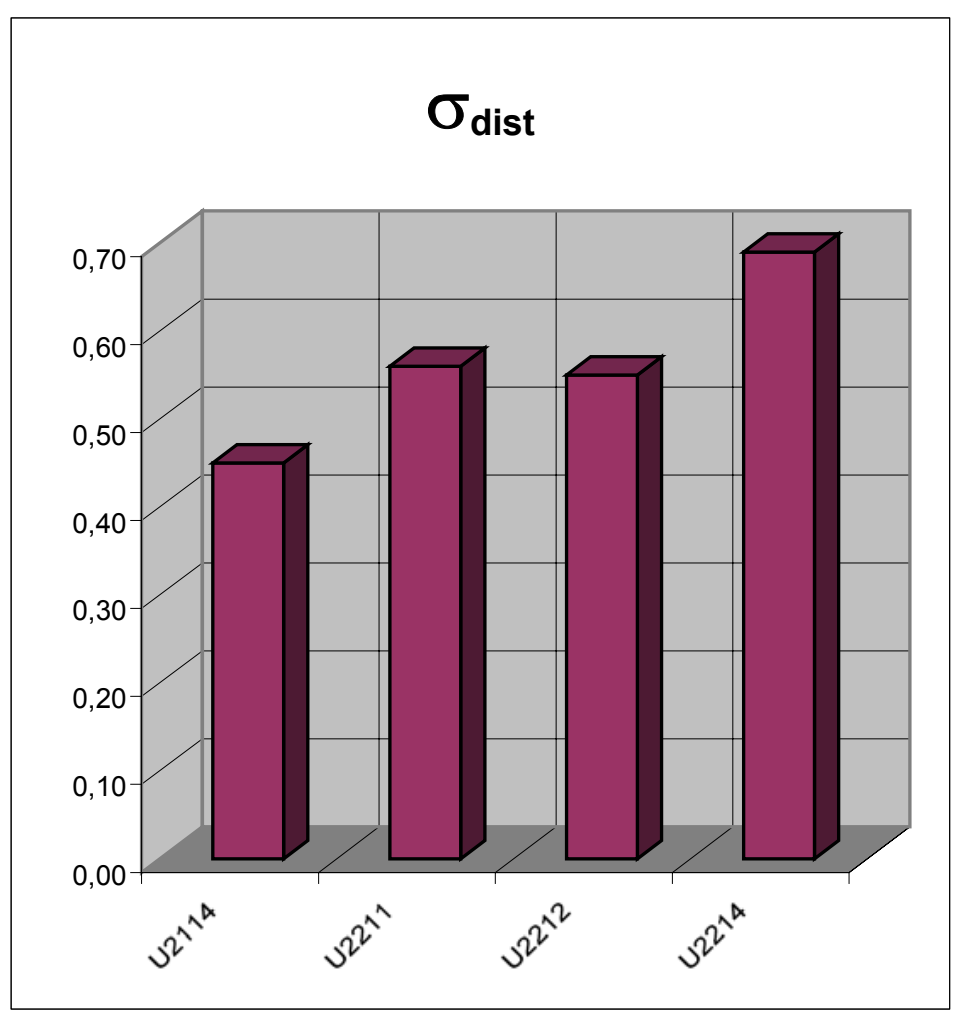

Figura 4.17 - Relação de $\sigma_{\text {dist }}$ para valores analisados via elementos finitos, entre modelos com imperfeição inicial e sem imperfeição inicial, para flexão

Após a análise da figura 4.17, pode-se observar também que a introdução de imperfeição inicial ao modelo causa uma redução no valor de $\sigma_{\text {dist }}$ (redução de 30 a $57 \%$ ), quando comparado à resultados obtidos de modelos que não consideram as imperfeições iniciais. Do mesmo modo que para a compressão centrada, tal fato é importante, mesmo porque os perfis "reais" apresentam imperfeições iniciais.

No caso da flexão, portanto, a sensibilidade dos perfis à imperfeição inicial parece ser mais pronunciada.

Tanto para o caso da compressão centrada como para o caso da flexão, é importante dizer que mesmo que esta análise seja pouco abrangente no que diz 
respeito ao número de perfis analisados, entende-se que a influência da imperfeição inicial deve ser melhor estudada.

\section{CRITÉRIO ADOTADO PARA A ESCOLHA DO PASSO DE CARGA CORRESPONDENTE À INSTABILIDADE DAS BARRAS ANALISADAS:}

O critério adotado, para se justificar a escolha do passo de carga correspondente à instabilidade das barras analisadas, e, portanto, correspondente à tensão crítica obtida como resposta das análises, foi o de se fazer um gráfico de força versus deslocamento segundo o eixo y (deslocamento vertical, característico do modo local com relação às mesas) relativo a três nós correspondentes aos terços da barra, situados na borda do enrijecedor, como já adotado anteriormente, sendo que as Figuras 4.18 a 4.20 apresentam tais critérios, conforme a legenda a seguir:

VALU: valor do deslocamento dos nós analisados

TIME: valor do fator de tensão (passo de carga)

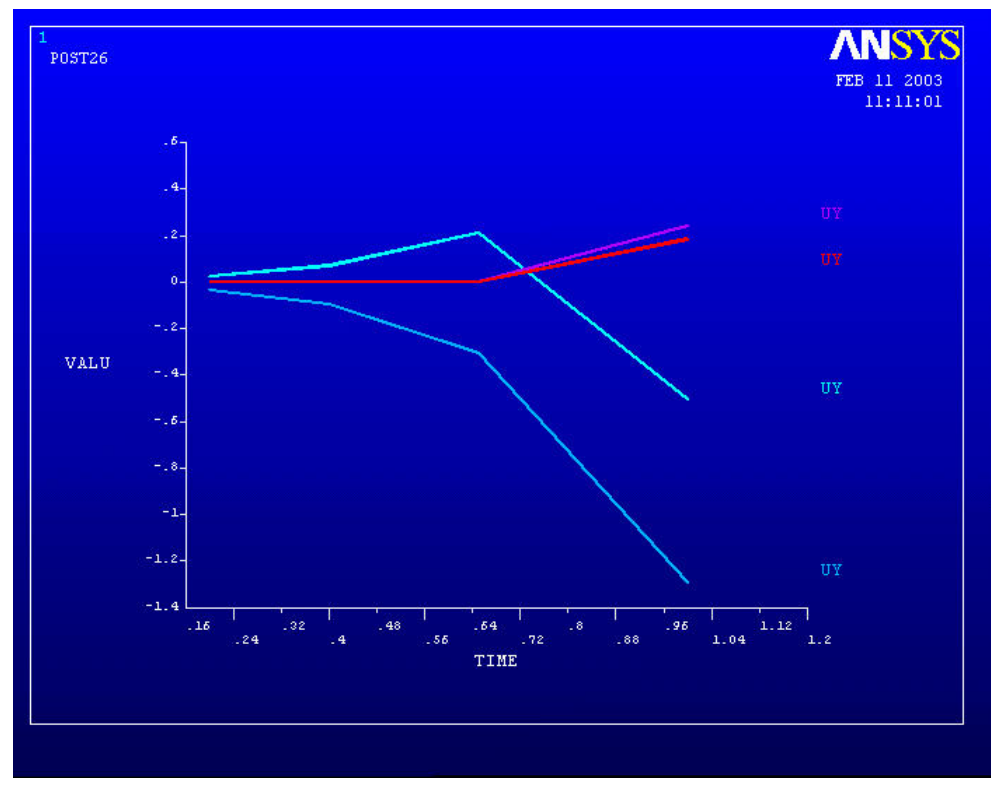

Figura 4.18 - Análise não-linear geométrica com imperfeição inicial: adoção da

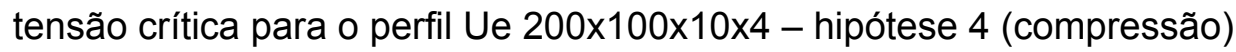




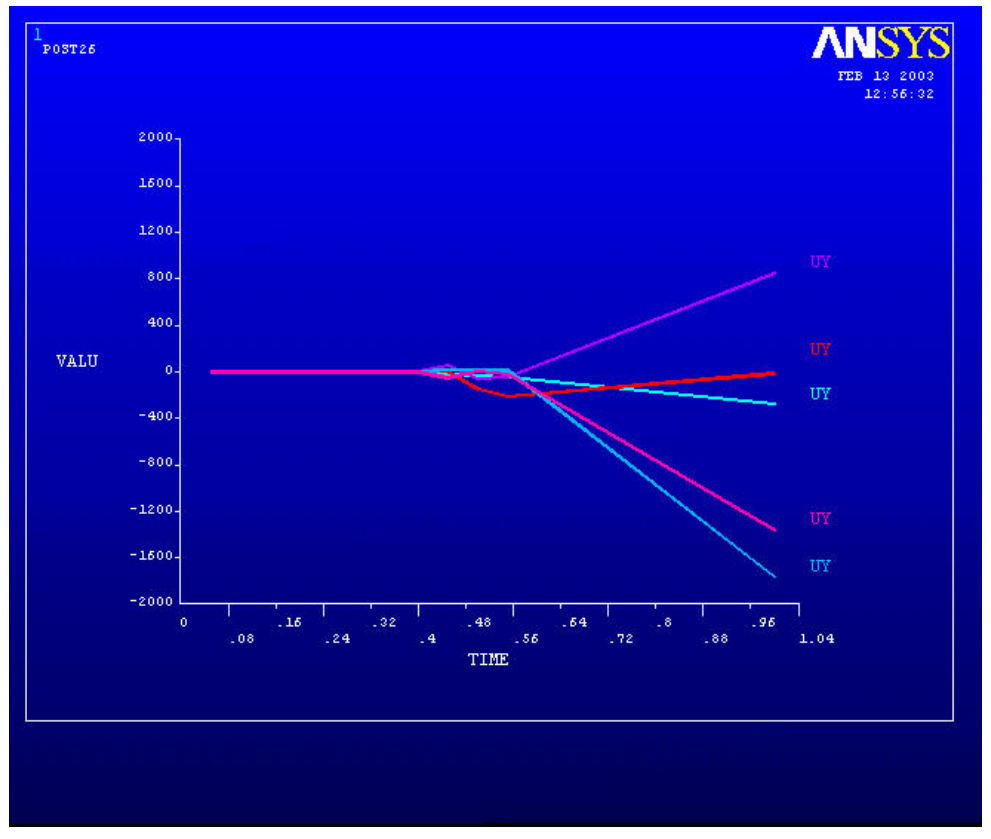

Figura 4.19 - Análise não-linear geométrica com imperfeição inicial: adoção da

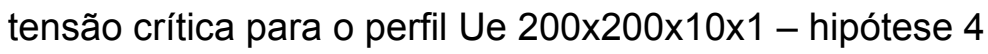
(flexão)

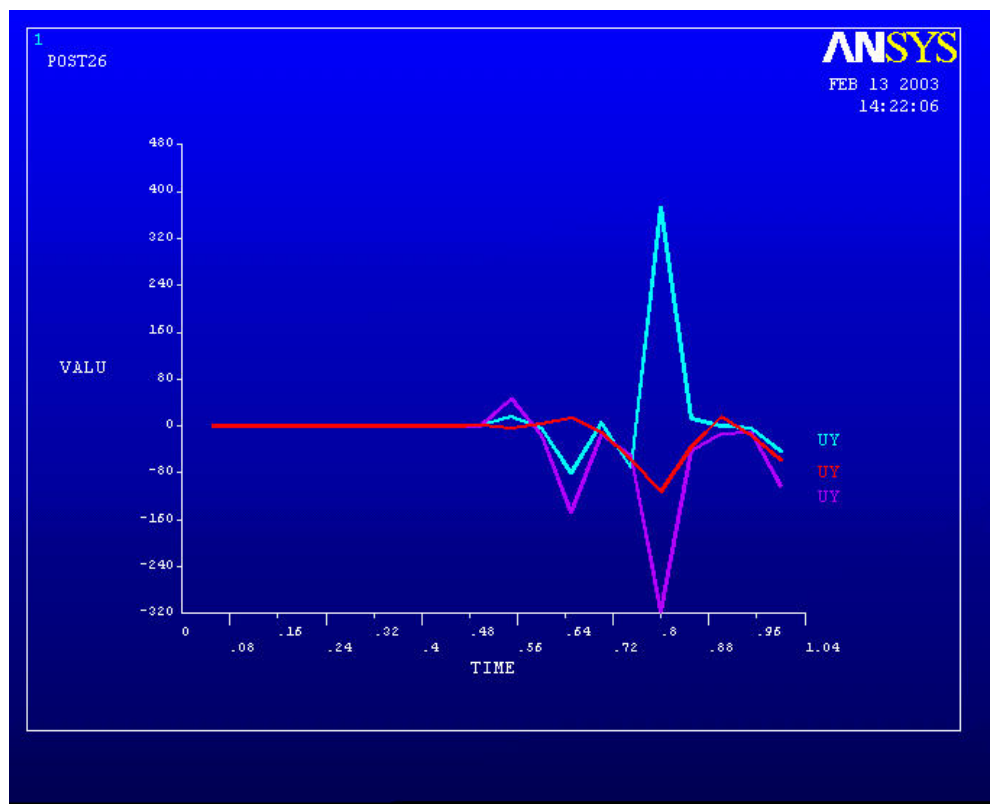

Figura 4.20 - Análise não-linear geométrica com imperfeição inicial: adoção da

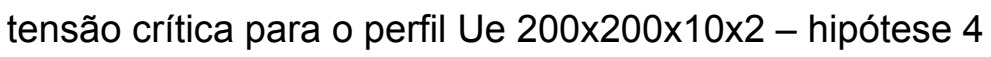
(flexão) 


\subsection{ANÁlise dA INFLUÊNCIA REFERENTE À PORCENTAGEM DA CONFIGURAÇÃO DEFORMADA ADOTADA PARA A IMPERFEIÇÃO INICIAL}

Para se observar a influência da escolha da porcentagem da configuração deformada, relativa à imperfeição inicial adotada nos modelos, apresentam-se a seguir alguns resultados referentes às análises realizadas com o perfil do tipo $U$ enrijecido $200 \times 100 \times 10 \times 4$ (escolhido como exemplo), tanto para o caso da compressão centrada quanto para o caso da flexão (Tabela 4.9 e Figura 4.21).

Tabela 4.9 - Resultados comparativos: perfil Ue 200 x 100 x 10 × 4

\begin{tabular}{|c|c|c|}
\hline & $\begin{array}{c}\text { Tensão crítica por distorção } \\
\text { (kN/cm2) }\end{array}$ \\
\hline Fator multiplicativo ANSYS & Compressão & Flexão \\
\hline 0,05 & 22,75 & 19,50 \\
\hline 0,15 & 21,70 & 17,22 \\
\hline 0,30 & 11,40 & 19,00 \\
\hline 0,40 & 8,13 & 17,88 \\
\hline
\end{tabular}

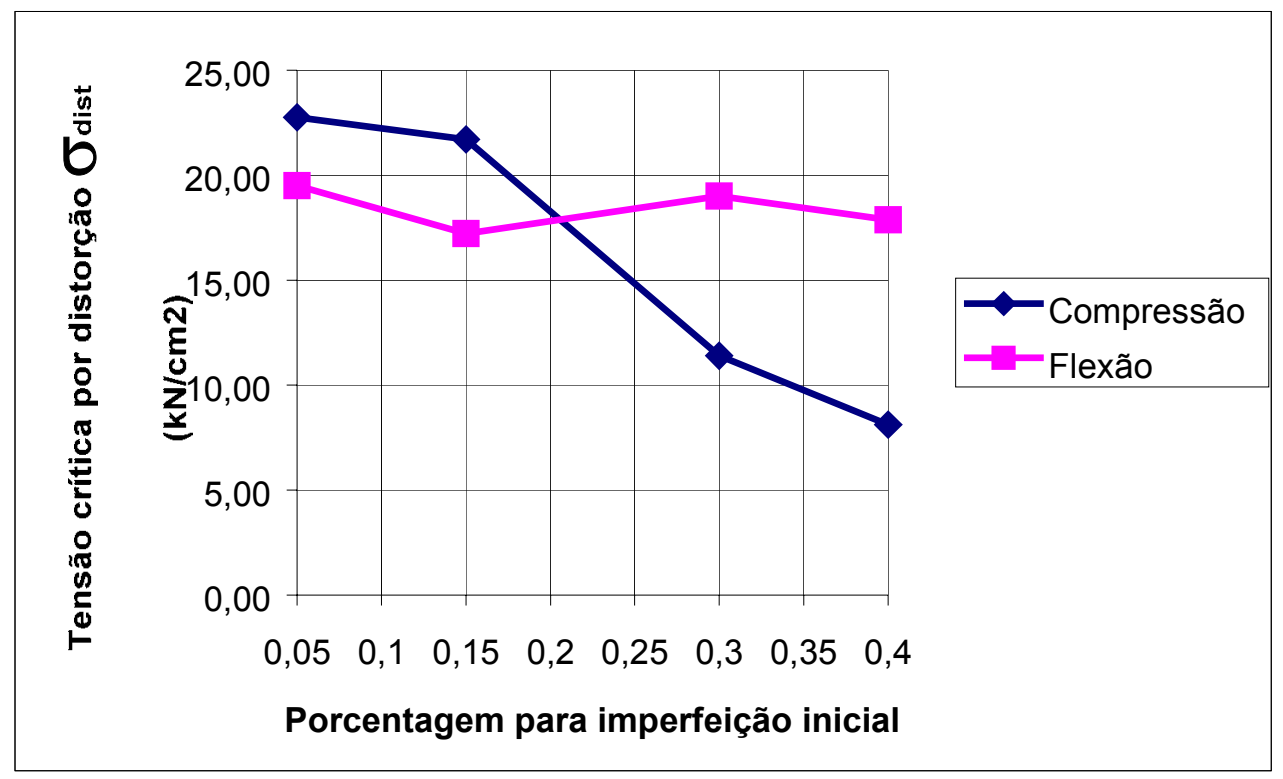

Figura 4.21 - Resultados comparativos: Ue 200 x $100 \times 10 \times 4$ 
Após a análise dos resultados, mesmo entendendo-se que devido ao pequeno número de análises efetuadas não seja prudente fazer nenhuma afirmação com total segurança, pode-se perceber que nestes casos analisados, a influência da imperfeição inicial é mais significativa para os perfis submetidos à compressão do que nos perfis submetidos à flexão, reduzindo o valor de $\sigma_{\text {dist }}$ conforme se eleva o valor da imperfeição inicial adotada em função da deformada da barra devido à análise de autovalor.

Neste caso analisado, o valor de $\sigma_{\text {dist }}$ é muito mais afetado para a compressão do que quando submetido à flexão. No entanto, cabe alertar que este caso possa não servir de padrão para os outros casos, e portanto, recomenda-se que sejam realizados novos testes, para que se possa entender melhor a influência do acréscimo de imperfeição inicial adotado nos modelos. 


\section{CONSIDERAÇÕES FINAIS E CONCLUSÕES}

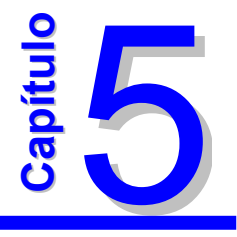

\subsection{SOBRE A REVISÃO BIBLIOGRÁFICA}

O modo de instabilidade distorcional tem sido abordado pelas normas mais recentes, inclusive pela nova norma brasileira NBR 14762:2001, e pode constituirse no modo crítico em perfis de seção aberta e paredes delgadas, sendo mais sensíveis à distorção os perfis com mesas largas e com enrijecedores de borda, como, por exemplo, os perfis do tipo $\mathrm{U}$ e $\mathrm{Z}$ enrijecido, cartola e rack.

A tendência do mercado da construção metálica leve é adotar aços de alta resistência mecânica e à corrosão atmosférica, e também aços revestidos, o que conduz a perfis com elevadas relações largura-espessura e, portanto, mais suscetíveis a apresentarem a flambagem por distorção como modo crítico.

A análise da flambagem elástica, via método das faixas finitas, tem sido amplamente utilizada para a avaliação dos parâmetros de interesse na flambagem por distorção, permitindo determinar com facilidade a tensão de flambagem elástica para vários comprimentos de meia onda e assim construir as curvas de flambagem referentes ao modo local, distorcional e global (Figura 3.3). 
Análises realizadas via elementos finitos e faixas finitas têm indicado que o método das faixas finitas conduz a resultados amplamente satisfatórios, principalmente para os modos local e distorcional. Entretanto, para o modo global, em alguns casos a diferença pode ser significativa e contra a segurança.

O procedimento da NBR 14762:2001 foi elaborado com base na norma australiana e corresponde ao modelo simplificado proposto por Hancock, que consiste na análise da estabilidade do conjunto constituído pela mesa comprimida e enrijecedor de borda. Quando comparado aos resultados obtidos via método das faixas finitas, tal procedimento tem indicado pequenas diferenças, em geral a favor da segurança. Portanto, pode ser considerado satisfatório para a verificação da flambagem por distorção, desde que respeitadas as limitações estabelecidas pela norma. Entretanto, para alguns casos de barras submetidas à flexão (perfis estudados) apresentados no trabalho, o procedimento da NBR 14762:2001 conduziu a resultados de $\sigma_{\text {dist }}$ contrários à segurança - portanto, entende-se que a utilização deste procedimento para os perfis analisados deve ser melhor analisada. Além disso, o modelo de Hancock mostrou-se muito sensível aos valores associados para a rigidez a rotação do conjunto mesa-enrijecedor, $\mathrm{k}_{\phi}$, além de não considerar a interação entre os elementos que compõem a seção transversal de um modo explícito, por não permitir a análise da seção transversal como um todo ( $a$ interação é considerada por meio de "molas" - constantes de rigidez à rotação e à flexão).

A flambagem por distorção é função de diversos parâmetros, envolvendo não somente a relação largura-espessura, mas também a forma da seção. Portanto, torna-se complicado estabelecer limites gerais para identificar se o modo distorcional é crítico. Assim, como procedimento geral de projeto, é importante e recomendável verificar sempre a flambagem por distorção. Por outro lado, para perfis do tipo $U$ enrijecido e $Z$ enrijecido, as tabelas paramétricas do anexo $D$ da NBR 14762:2001 permitem avaliar satisfatoriamente se o perfil apresenta o modo distorcional como crítico, do ponto de vista da flambagem elástica. Entretanto, tais tabelas não contemplam o esforço resistente, isto é, não consideram correções para o regime inelástico. 
Com relação à compressão centrada e à flexão, as curvas de flambagem são idênticas, quando se faz a comparação entre a NBR 14762:2001 e a AS/NZS 4600:1996.

Com relação à flexão, para o item 3.3.3.3a da AS/NZS 4600:1996 (a flambagem por distorção provoca a rotação do conjunto mesa/enrijecedor em relação à junção mesa/alma nas seções do tipo $U$ enrijecido ou $Z$ enrijecido), não abordado pela NBR 14762:2001, as curvas de flambagem apresentadas por Lau \& Hancock apud Rogers (1987,1990), pela AS/NZS 4600:1996 e por Hancock (1997) são idênticas. Por outro lado, para o item 3.3.3.3b da AS/NZS 4600:1996 (a flambagem por distorção provoca a flexão transversal da alma vertical com deslocamento lateral da mesa comprimida) as curvas de flambagem apresentadas por Lau \& Hancock apud Rogers (1987,1990), pela AS/NZS 4600:1996 e por Hancock (1997) são diferentes, lembrando que o ponto de inflexão da curva referente à expressão de Lau \& Hancock apud Rogers $(1987,1990)$ é diferente dos demais.

\subsection{SOBRE A ANÁLISE VIA FAIXAS FINITAS}

Tanto para as análises via faixas finitas quanto para as análises via procedimento da NBR 14762:2001, os mesmos perfis, quando submetidos à flexão, apresentam maiores valores de $\sigma_{\text {dist }}$, quando comparados com os submetidos à compressão centrada. A diferença entre estes valores foi mais pronunciada para os perfis que não respeitam as condições das tabelas D.1 e D.2 da NBR 14762:2001. Por outro lado, os valores de $L_{d}$ referentes aos perfis submetidos à flexão, quando comparados com os submetidos à compressão centrada são iguais ou um pouco menores (em torno de $20 \%$ ou menos).

Dentre os perfis analisados, os modos críticos relativos à análise via faixas finitas e via procedimento da NBR 14762:2001 sempre foram os mesmos, com exceção do perfil Ue $200 \times 100 \times 10 \times 2,0$, que apresentou, conforme a NBR 14762:2001 o modo local como crítico e conforme a análise via faixas finitas o modo distorcional. 
Pode-se perceber, que, com algumas exceções, as relações $b_{f} / b_{w}$ das tabelas D.1 e D.2 da NBR 14762:2001 devem ser respeitadas, pois para os perfis que não as respeitam, os resultados relativos ao procedimentos da NBR 14762:2001 são contrários à segurança, quando comparados a análise via faixas finitas (com exceção dos perfis submetidos à flexão, que apresentaram resultados ligeiramente a favor da segurança inclusive para perfis que não respeitam tais relações). Deve-se entender que a análise via faixas finitas considera a interação entre os elementos que constituem a seção transversal (o que proporciona uma análise mais próxima da realidade), diferentemente do procedimento da NBR 14762:2001.

\section{PERFIS DO TIPO Z ENRIJECIDO}

Com relação à compressão centrada e à flexão, os perfis do tipo Ue e Ze $e_{90}$ apresentam os mesmos resultados, confirmando o procedimento da NBR 14762:2001, que não faz distinção entre a análise de perfis do tipo Ue e de perfis do tipo Ze. Os perfis do tipo $\mathrm{Ze}_{45}$, quando comparados aos perfis do tipo Ue,

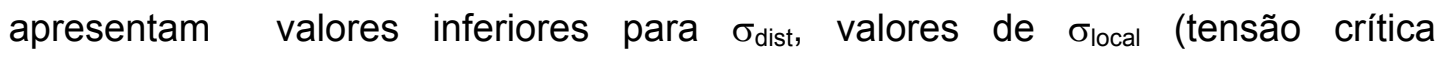
correspondente à flambagem local) aproximadamente iguais, e apresentam valores ligeiramente inferiores para $L_{d}$. Os dois tipos de perfis apresentam também os mesmos valores de $L_{\text {local }}$ (comprimento de meia onda associado à flambagem local) e também apresentam os mesmos modos críticos. Tal fato evidencia, mesmo que superficialmente - devido à escassez de análises para estes casos - que a variação do ângulo do enrijecedor de borda influi no fenômeno da distorção. Quanto menor o ângulo do enrijecedor de borda em relação à mesa da seção, menor será o enrijecimento de tal conjunto, e menores serão os valores de $\sigma_{\text {dist. }}$.

\subsection{SOBRE A ANÁLISE VIA ELEMENTOS FINITOS}

Comparando-se as análises via elementos finitos, procedimento da NBR 14762:2001 e via faixas finitas, percebe-se que após a avaliação dos resultados referentes às três hipóteses iniciais (cálculo do autovalor, com condição de contorno não simétrica e simétrica, e análise considerando não-linearidade geométrica sem a admissão de imperfeições iniciais com condição simétrica de 
condições de contorno) pode-se observar que os mesmos perfis, quando submetidos à flexão, apresentam maiores valores de $\sigma_{\text {dist, }}$ quando comparados com os submetidos à compressão, sendo que todos os perfis respeitam as condições das tabelas D.1 e D.2 da NBR 14762:2001. Por outro lado, os valores de $L_{d}$ dos perfis submetidos à flexão, quando comparados com os submetidos à compressão são aproximadamente iguais ou ligeiramente menores.

Pode-se também observar que, em geral, com relação ao valor de $\sigma_{\text {dist, }}$ os resultados são ligeiramente superiores aos relativos à análise via faixas finitas e ao procedimento da NBR 14762 (entretanto, no caso da flexão, para a primeira hipótese - caso de condição não-simétrica de condições de contorno - a diferença é maior, e para a segunda hipótese - caso de condição simétrica de condições de contorno - a norma se apresentou como contrária à segurança para os casos analisados, especialmente para os perfis $b_{f}=b_{w}=200 \mathrm{~mm}$ ). A introdução da nãolinearidade geométrica aos modelos conduz a resultados ligeiramente superiores de $\sigma_{\text {dist. }}$

Entretanto, tal fato não é suficiente para que se possa afirmar que o uso da não-linearidade geométrica conduz a valores de $\sigma_{\text {dist }}$ menos conservadores, pois muitos fatores estão envolvidos quando da análise não-linear. Ao menos, os valores estão próximos entre si. Cabe lembrar mais uma vez que estes três procedimentos têm suas particularidades e, portanto, são um pouco diferentes entre si em suas concepções.

Por outro lado, admitindo-se não-linearidade geométrica e imperfeições iniciais (hipótese 4), percebe-se, no caso de barras submetidas à compressão, uma redução no valor de $\sigma_{\text {dist }}$ (redução entre 20 e $30 \%$ ), quando comparado a resultados obtidos de modelos que não consideram as imperfeições iniciais. Tal fato é importante, mesmo porque os perfis "reais" apresentam imperfeições iniciais. Vale salientar que no caso da flexão a variação nos resultados foi mais pronunciada (redução entre 30 e 57\%). As figuras 4.16 e 4.17 ilustram este fato. Mesmo que esta análise tenha sido pouco abrangente no que diz respeito ao número de perfis analisados, entende-se que a influência da imperfeição inicial deve ser melhor estudada. 
Nas análises considerando somente perfis com não-linearidade geométrica e imperfeições iniciais, a influência da variação da magnitude da imperfeição inicial mostrou-se mais significativa para os perfis submetidos à compressão do que para os perfis submetidos à flexão, reduzindo o valor de $\sigma_{\text {dist }}$ conforme se eleva o valor da imperfeição inicial adotada (Figura 4.21). Entretanto, entende-se que devido ao pequeno número de análises efetuadas, ainda não é prudente fazer nenhuma afirmação. Recomenda-se que sejam realizadas novas análises.

\subsection{SOBRE O ANEXO}

No que se refere ao exemplo de cálculo (item A.1.), percebe-se que não houve diferença significativa entre os valores obtidos pelo procedimento da NBR 14762:2001 e pela análise via faixas finitas (programa CUFSM), sendo os valores relativos à análise via faixas finitas ligeiramente menores ( $3 \%$ para a compressão centrada e $11 \%$ para a flexão), indicando que neste caso o procedimento da NBR 14762:2001 é satisfatório. Vale salientar que as resistências $N_{R d}$ e $M_{R d}$ obtidas pelos diferentes métodos foram muito próximas.

Pela comparação de resultados com base em vários procedimentos (item A.2.), percebe-se que, em geral, os resultados via faixas finitas, elementos finitos e procedimento da NBR 14762:2001 se mostraram próximos para o caso de barras submetidas à compressão, sendo que para o caso de barras submetidas à flexão houve diferenças mais significativas. Os valores de $\sigma_{\text {dist }}$ foram reduzidos quando da inserção de imperfeições iniciais e não-linearidade geométrica à análise via elementos finitos. Com relação à flexão em particular, a condição de contorno não simétrica (deslocamentos impedidos em somente uma das extremidades) apresentou valores um pouco discrepantes, e em alguns casos algumas diferenças mais significativas foram percebidas, o que é razoável, pois esta condição de contorno é diferente das demais analisadas, e mostra que exerce influência nas análises.

Pelas análises das figuras pode-se perceber que para os casos analisados, o procedimento da NBR 14762:2001 conduz a resultados de $\sigma_{\text {dist }}$ ligeiramente contrários à segurança, quando comparados aos resultados referentes à análise via faixas finitas. Entretanto, os resultados referentes à análise via elementos finitos 
conduziu à resultados mais próximos aos relativos à norma brasileira que aos referentes à análise via faixas finitas.

\subsection{SUGESTÕES PARA TRABALHOS FUTUROS}

Com relação a sugestões propostas para estudo em trabalhos futuros, alguma idéias podem ser apresentadas:

- $\quad$ Análise de uma gama maior de perfis, por exemplo, com relação a um dos itens críticos analisados, de modo a obter um maior número de resultados, o que provavelmente proporcionaria uma maior abrangência de possíveis problemas identificados;

- Verificação mais profunda dos casos referentes a alguns tipos de perfis, relativos às barras submetidas à flexão, no que se refere à análise da tensão convencional de flambagem por distorção por meio do procedimento da NBR 14762:2001 (contrária à segurança para tais casos), e comparando com a análise via faixas finitas e elementos finitos;

- Verificação mais abrangente dos casos de análise não-linear geométrica com introdução de imperfeições iniciais, com relação à variação do valor de tensão convencional de flambagem por distorção, quando comparados aos casos de análise não-linear geométrica nos quais não se consideram imperfeições iniciais;

- Verificação mais profunda para o caso da influência de variação da magnitude da imperfeição inicial dos perfis (casos de barras submetidas à compressão e também os casos de barras submetidas à flexão); 


\section{A.1. EXEMPLOS DE CÁLCULO: FORÇA NORMAL RESISTENTE E MOMENTO FLETOR RESISTENTE}

Neste item serão apresentados exemplos de cálculo da força normal resistente e do momento fletor resistente, relativos à flambagem por distorção, com relação ao perfil do tipo $U$ enrijecido com dimensões $200 \times 100 \times 10 \times 4 \mathrm{~mm}$, segundo três procedimentos: norma brasileira NBR 14762:2001 (idêntica à norma australiana AS/NZS 4600:1996), modelo proposto por Hancock em 1997 e Método Direto de Resistência.

Para o cálculo da resistência do perfil, tanto à compressão centrada quanto à flexão, é necessário que se calcule, previamente, a tensão convencional de flambagem elástica por distorção, $\sigma_{\text {dist. }}$ Portanto, esta tensão será calculada por dois procedimentos: procedimento da NBR 14762:2001 e método das faixas finitas (programa computacional CUFSM).

Devido à utilização do procedimento do anexo D da NBR 14762:2001 resultar em cálculos manuais extensos, e portanto, suscetíveis a erros, foi criada uma planilha de apoio no Microsoft Excel contendo todas as fórmulas do mencionado anexo para que com elas se possam efetuar todos os cálculos, resultando na obtenção da tensão convencional de flambagem elástica por distorção, $\sigma_{\text {dist }}$ e comprimento da meia onda longitudinal associada à tensão convencional de flambagem elástica por distorção, $L_{d}$. Em tal planilha deve-se 
fornecer os valores das dimensões nominais dos elementos da seção transversal do perfil analisado.

Portanto, esta planilha de apoio foi utilizada para se montar a tabela A.1, no que se refere aos valores da norma NBR 14762:2001, e com relação aos valores referentes ao método via faixas finitas, utilizou-se o programa computacional CUFSM, descrito no capítulo 3, item 3.2.

Todos os cálculos efetuados correspondem à utilização de expressões apresentadas ao longo deste capítulo, que não serão novamente explicitadas, mas simplesmente citando-se a numeração das expressões em questão - quando apresentadas no corpo do trabalho.

A tabela A.1 ilustra os valores de $\sigma_{\text {dist }}$ calculados:

Tabela A.1 - valor de $\sigma_{\text {dist }}$ e calculados por meio do procedimento da NBR 14762:2001 e via faixas finitas

\begin{tabular}{|c|c|c|}
\hline \multicolumn{3}{|c|}{ PERFIL Ue 200X100X10X4 } \\
\hline COMPRESSÃO CENTRADA & NBR 14762:2001 & CUFSM \\
\hline$\sigma_{\text {dist }}\left(\mathbf{k N} / \mathbf{c m}^{2}\right)$ & 27,33 & 26,56 \\
\hline & & CUFSM \\
\hline FLEX̃̃O & NBR 14762:2001 & 36,86 \\
\hline
\end{tabular}

A seguir, são então apresentados os exemplos de cálculo da força normal resistente (barras submetidas à compressão centrada) e do momento fletor resistente (barras submetidas à flexão), relativos à flambagem por distorção, com relação ao perfil do tipo $U$ enrijecido com dimensões $200 \times 100 \times 10 \times 4 \mathrm{~mm}$, segundo três procedimentos: norma brasileira NBR 14762:2001 (idêntica à norma australiana AS/NZS 4600:1996), modelo proposto por Hancock em 1997 e Método Direto de Resistência. 


\section{COMPRESSÃO CENTRADA}

NBR 14762:2001

Para o valor de $\sigma_{\text {dist }}$ calculado conforme o anexo D da NBR 14762:2001:

$\sigma_{\text {dist }}=27,33 \mathrm{kN} / \mathrm{cm}^{2}$ (NBR 14762:2001)

$\lambda_{\text {dist }}=\left(f_{y} / \sigma_{\text {dist }}\right)^{0,5}$

$\lambda_{\text {dist }}=0,956<1,414$

$\mathrm{N}_{\text {dist }}=303 \mathrm{kN}$

(expressão 2.69)

$\mathrm{N}_{\mathrm{c}, \mathrm{Rd}}=276 \mathrm{kN}$

(expressão 2.68)

Para o valor de $\sigma_{\text {dist }}$ calculado conforme o método via faixas finitas:

$$
\begin{aligned}
& \sigma_{\text {dist }}=26,56 \mathbf{~ k N} / \mathrm{cm}^{2} \text { (CUFSM) } \\
& \lambda_{\text {dist }}=\left(f_{\mathrm{y}} / \sigma_{\text {dist }}\right)^{0,5} \\
& \lambda_{\text {dist }}=0,970<1,414 \\
& N_{\text {dist }}=301 \mathrm{kN} \\
& N_{c, R d}=274 \mathrm{kN}
\end{aligned}
$$$$
\text { (expressão 2.69) }
$$

Percebe-se que a única diferença entre as duas análises acima foi o modo de obtenção da tensão convencional de flambagem elástica $\sigma_{\text {dist }}$, o qual resultou um valor muito próximo entre o calculado conforme o anexo D da NBR 14762:2001 e conforme o método das faixas finitas. Com isso a força normal resistente resultou praticamente a mesma. 


\section{MÉTODO DIRETO DE RESISTÊNCIA (idem LAU \& HANCOCK 1997)}

Para o valor de $\sigma_{\text {dist }}$ calculado conforme o método via faixas finitas:

$$
\begin{aligned}
& \sigma_{\text {dist }}=26,56 \mathrm{kN} / \mathrm{cm}^{2} \text { (CUFSM) } \\
& \mathrm{N}_{\text {crd }}=\text { (load factor) } \times \mathrm{N}_{\mathrm{y}} \\
& \text { load factor }=1,062 \\
& N_{y}=A_{g} \times f_{y} \\
& A_{g}=15,74 \mathrm{~cm}^{2} \\
& \mathrm{f}_{\mathrm{y}}=25 \mathrm{kN} / \mathrm{cm}^{2} \\
& \mathrm{~N}_{\mathrm{y}}=393,50 \mathrm{kN} \\
& \mathrm{N}_{\text {crd }}=418 \mathrm{kN} \\
& \lambda_{\text {dist }}=\left(\mathrm{N}_{\mathrm{y}} / \mathrm{N}_{\text {crd }}\right)^{0,5} \\
& \lambda_{\text {dist }}=0,970>0,561 \\
& \mathrm{~N}_{\text {dist }}=302 \mathrm{kN}
\end{aligned}
$$

$\mathrm{N}_{\mathrm{c}, \mathrm{Rd}}=274 \mathrm{kN} \quad$ (se utilizado $\gamma=1,1$ - como recomenda a NBR 14762:2001) 


\section{FLEXÃO}

NBR 14762:2001

Para o valor de $\sigma_{\text {dist }}$ calculado conforme o anexo D da NBR 14762:2001:

$$
\begin{aligned}
& \sigma_{\text {dist }}=41,16 \mathrm{kN} / \mathrm{cm}^{2}(\mathrm{NBR} 14762: 2001) \\
& \lambda_{\text {dist }}=\left(\mathrm{f}_{\mathrm{y}} / \sigma_{\text {dist }}\right)^{0,5} \\
& \lambda_{\text {dist }}=0,789<1,414 \\
& M_{\text {dist }}=2125 \mathrm{kN} . \mathrm{cm} \\
& M_{R d}=1932 \mathrm{kN} . \mathrm{cm}
\end{aligned}
$$

Para o valor de $\sigma_{\text {dist }}$ calculado conforme o método via faixas finitas:

$$
\begin{aligned}
& \sigma_{\text {dist }}=36,86 \mathrm{kN} / \mathrm{cm}^{2} \text { (CUFSM) } \\
& \lambda_{\text {dist }}=\left(f_{\mathrm{y}} / \sigma_{\text {dist }}\right)^{0,5} \\
& \lambda_{\text {dist }}=0,824<1,414 \\
& M_{\text {dist }}=2090 \mathrm{kN} \cdot \mathrm{cm} \\
& M_{R d}=1900 \mathrm{kN} \cdot \mathrm{cm}
\end{aligned}
$$$$
\text { (expressão 2.72) }
$$

Percebe-se também nestes dois casos supracitados que a única diferença entre as duas análises foi o modo de obtenção da tensão convencional de flambagem elástica $\sigma_{\text {dist }}$, o qual resultou um valor muito próximo entre o calculado conforme o anexo D da NBR 14762:2001 e conforme o método das faixas finitas. 
Com isso a força normal resistente resultou do mesmo modo praticamente a mesma.

\section{HANCOCK (1997)}

Para o valor de $\sigma_{\text {dist }}$ calculado conforme o anexo D da NBR 14762:2001:

$\sigma_{\text {dist }}=41,16 \mathrm{kN} / \mathrm{cm}^{2}(\mathrm{NBR} 14762: 2001)$

$\lambda_{\text {dist }}=\left(f_{y} / \sigma_{\text {dist }}\right)^{0,5}$

$\lambda_{\text {dist }}=0,789<1,414$

$\mathrm{M}_{\mathrm{Rd}}=1932 \mathrm{kN} \cdot \mathrm{cm}$

(expressão 2.66)

Para o valor de $\sigma_{\text {dist }}$ calculado conforme o método via faixas finitas:

$$
\begin{aligned}
& \sigma_{\text {dist }}=36,86 \mathbf{~ k N} / \mathbf{c m}^{2} \text { (CUFSM) } \\
& \lambda_{\text {dist }}=\left(f_{y} / \sigma_{\text {dist }}\right)^{0,5} \\
& \lambda_{\text {dist }}=0,824<1,414 \\
& M_{R d}=1900 \mathrm{kN} . \mathrm{cm}
\end{aligned}
$$

(expressão 2.66)

OBS:

Neste caso, as resistências de cálculo são idênticas à da NBR 14762, pois $\lambda_{\text {dist }}<1,414$, e a expressão de HANCOCK (1997) só atualizou o trecho elástico da mesma referente à norma australiana (idêntica à NBR 14762:2001). 


\section{MÉTODO DIRETO DE RESISTÊNCIA}

Para o valor de $\sigma_{\text {dist }}$ calculado conforme o método via faixas finitas:

$$
\begin{aligned}
& \sigma_{\text {dist }}=36,86 \mathbf{~ k N} / \mathrm{cm}^{2} \text { (CUFSM) } \\
& M_{\text {crd }}=(\text { load factor }) \times M_{y} \\
& \text { load factor }=1,47 \\
& M_{y}=M_{x x}(\text { valor fornecido pelo programa CUFSM }) \\
& M_{x x}=25607641 \mathrm{kN} \cdot \mathrm{mm}=2561 \mathrm{kN} . \mathrm{cm} \\
& M_{y}=2561 \mathrm{kN} \\
& f_{y}=25 \mathrm{kN} / \mathrm{cm}^{2} \\
& M_{\text {crd }}=3765 \mathrm{kN} \cdot \mathbf{c m} \\
& \lambda_{\text {dist }}=\left(M_{y} / M_{\text {crd }}\right)^{0,5} \\
& \lambda_{\text {dist }}=0,825>0,673 \\
& M_{\text {dist }}=2277 \mathrm{kN} \cdot \mathrm{cm}
\end{aligned}
$$$$
\text { (expressão 2.92) }
$$

$\mathrm{M}_{\mathrm{Rd}}=2070 \mathrm{kN} . \mathrm{cm}$ (se utilizado $\gamma=1,1$ - como recomenda a NBR 14762:2001) 


\section{A.2. COMPARAÇÃO DE RESULTADOS CONFORME DIVERSOS PROCEDIMENTOS: TENSÃO CONVENCIONAL DE FLAMBAGEM ELÁSTICA POR DISTORÇÃO}

Com o intuito de se comparar os valores da tensão convencional de flambagem elástica por distorção resultante de diversos procedimentos, apresentarse-ão as tabelas A.2 a A.6 e as figuras A.1 a A.5.

Obviamente, espera-se que o leitor não assuma que estes resultados configuram comportamentos gerais de relações de resultados entre os procedimentos, mas sim indicativos de comportamento destes perfis analisados.

Com relação às legendas, apresenta-se a nomenclatura do eixo horizontal (eixo das abscissas) nas próprias tabelas, segundo o procedimento analisado para a obtenção do valor da tensão convencional de flambagem elástica.

Tem-se, portanto:

Perfil Ue $200 \times 100 \times 10 \times 4 \mathrm{~mm}$

A tabela A.2 ilustra os resultados apresentados.

Tabela A.2 - Resultados comparativos: perfil Ue $200 \times 100 \times 10 \times 4$

\begin{tabular}{|c|c|c|c|}
\hline & Procedimento & $\begin{array}{c}\text { Compressão centrada } \\
\left(\mathrm{kN} / \mathrm{cm}^{2}\right)\end{array}$ & $\begin{array}{c}\text { Flexão } \\
\left(\mathrm{kN} / \mathrm{cm}^{2}\right)\end{array}$ \\
\hline 1 & CUFSM & 26,56 & 36,86 \\
\hline 2 & NBR 14762:2001 & 27,33 & 41,16 \\
\hline 3 & HIPÓTESE 1 & 27,54 & 48,62 \\
\hline 4 & HIPÓTESE 2 & 27,32 & 36,4 \\
\hline 5 & HIPÓTESE 3 & 28,44 & 38,33 \\
\hline 6 & HIPÓTESE 4 & 21,7 & 17,22 \\
\hline
\end{tabular}


A figura A.1 ilustra os resultados apresentados na tabela A.2.

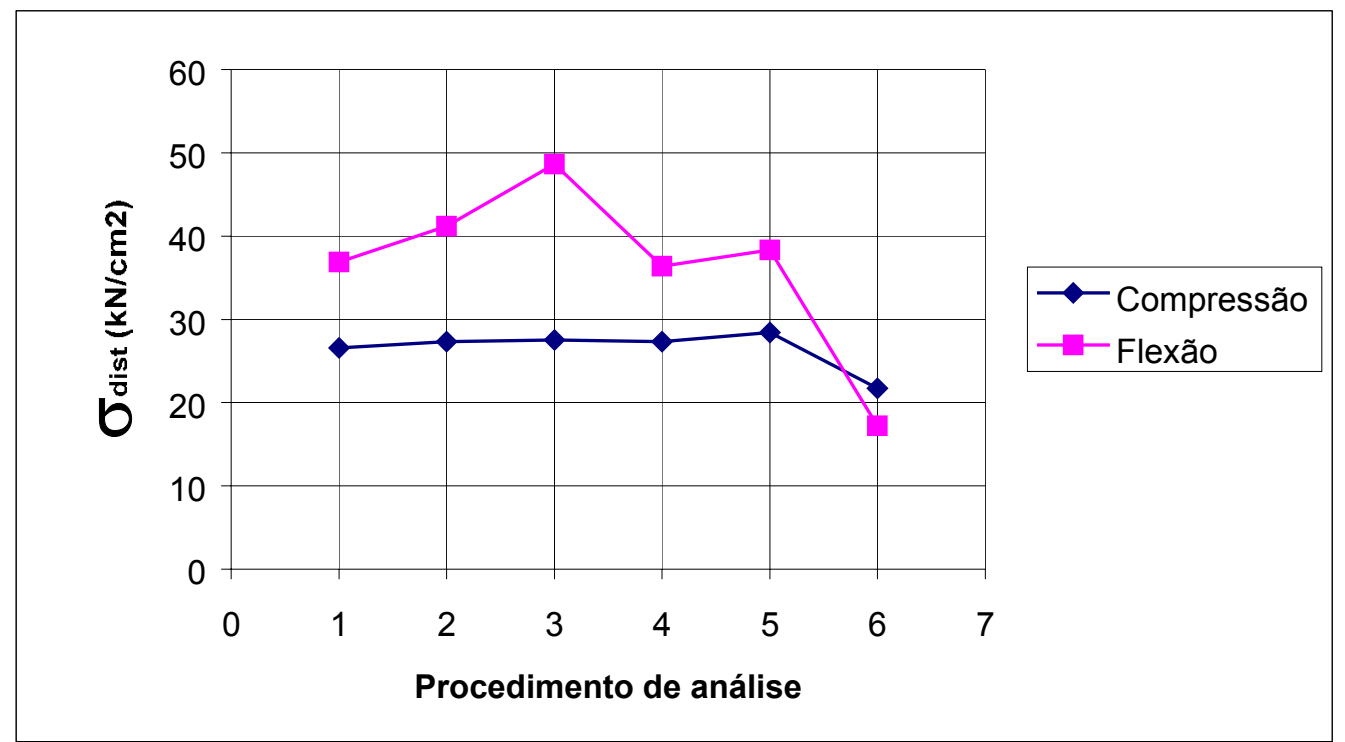

Figura A.1 - Resultados comparativos: Ue 200 × 100 × 10 × 4

Para este caso, não houve mudança significativa quando da análise do perfil submetido à compressão, com exceção da inserção de imperfeições iniciais e nãolinearidade geométrica à análise via elementos finitos, o que reduziu o valor de $\sigma_{\text {dist. }}$.

Com relação à flexão, a condição de contorno (deslocamentos impedidos nas extremidades) não simétrica apresentou valores um pouco discrepantes. A análise assumindo-se não-linearidade geométrica sem imperfeições iniciais, quando comparada à análise de autovalor, não apresentou resultados significativos. Entretanto, a análise via elementos finitos com a adoção de imperfeições iniciais e não-linearidade geométrica também reduziu o valor de $\sigma_{\text {dist. }}$. 
Perfil Ue $200 \times 200 \times 10 \times 2 \mathrm{~mm}$

A tabela A.3 ilustra os resultados apresentados.

Tabela 2.8 - Resultados comparativos: perfil Ue 200 × $200 \times 10 \times 2$

\begin{tabular}{|c|l|c|c|}
\hline \multicolumn{2}{|c|}{ Procedimento } & $\begin{array}{c}\text { Compressão centrada } \\
\left.\text { (kN/cm }{ }^{\mathbf{}}\right)\end{array}$ & $\begin{array}{c}\text { Flexão } \\
\left(\mathbf{k N} / \mathbf{c m}^{\mathbf{2}}\right)\end{array}$ \\
\hline $\mathbf{1}$ & CUFSM & 3,04 & 3,58 \\
\hline $\mathbf{2}$ & NBR 14762:2001 & 3,39 & 4,66 \\
\hline $\mathbf{3}$ & HIPÓTESE 1 & 3,85 & 5,81 \\
\hline $\mathbf{4}$ & HIPÓTESE 2 & 3,35 & 4,10 \\
\hline $\mathbf{5}$ & HIPÓTESE 3 & 3,84 & 4,39 \\
\hline $\mathbf{6}$ & HIPÓTESE 4 & 2,75 & 2,40 \\
\hline
\end{tabular}

A figura A.2 ilustra os resultados apresentados na tabela A.3.

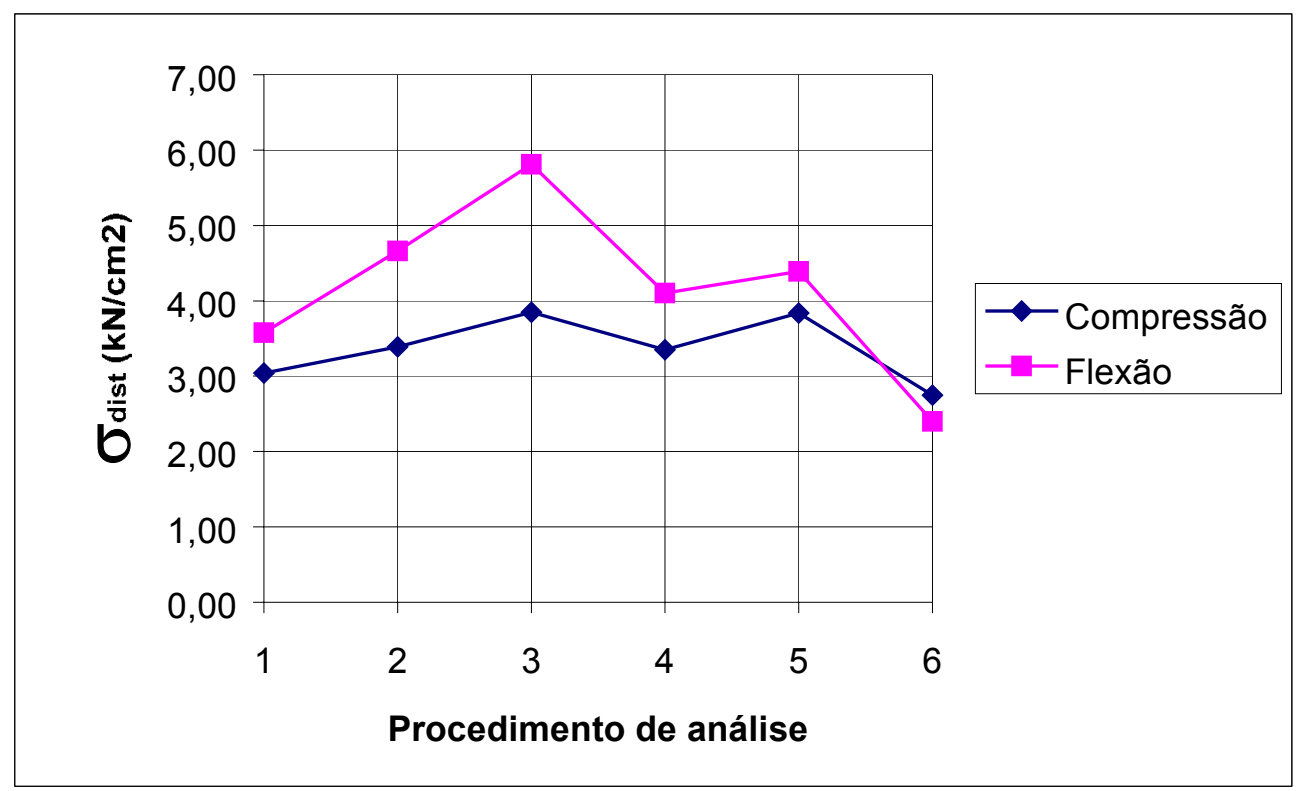

Figura A.2 - Resultados comparativos: Ue $200 \times 200 \times 10 \times 2$ 
Para este caso, também não houve mudança significativa quando da análise do perfil submetido à compressão, com exceção da inserção de imperfeições iniciais e não-linearidade geométrica à análise via elementos finitos, o que novamente reduziu o valor de $\sigma_{\text {dist. }}$

Com relação à flexão, a condição de contorno (deslocamentos impedidos nas extremidades) não simétrica apresentou mais uma vez valores um pouco discrepantes. A análise não-geométrica sem imperfeições iniciais, quando comparada à análise de autovalor, também não apresentou resultados significativos. Entretanto, a análise via elementos finitos com a adoção de imperfeições iniciais e não-linearidade geométrica também reduziu o valor de $\sigma_{\text {dist }}$.

\section{Perfil Ue $200 \times 200 \times 10 \times 4 \mathrm{~mm}$}

A tabela A.4 ilustra os resultados apresentados.

Tabela A.4 - Resultados comparativos: perfil Ue $200 \times 200 \times 10 \times 4$

\begin{tabular}{|c|l|c|c|}
\hline \multicolumn{2}{|c|}{ Procedimento } & $\begin{array}{c}\text { Compressão centrada } \\
\left.\text { (kN/cm }{ }^{\mathbf{}}\right)\end{array}$ & $\begin{array}{c}\text { Flexão } \\
\left.\text { (kN/cm }{ }^{2}\right)\end{array}$ \\
\hline $\mathbf{1}$ & CUFSM & 8,20 & 9,42 \\
\hline $\mathbf{2}$ & NBR 14762:2001 & 9,66 & 12,89 \\
\hline $\mathbf{3}$ & HIPÓTESE 1 & 9,78 & 14,10 \\
\hline $\mathbf{4}$ & HIPÓTESE 2 & 9,15 & 10,12 \\
\hline $\mathbf{5}$ & HIPÓTESE 3 & 10,60 & 11,80 \\
\hline $\mathbf{6}$ & HIPÓTESE 4 & 8,00 & 8,10 \\
\hline
\end{tabular}

A figura A.3 ilustra os resultados apresentados na tabela A.4. 


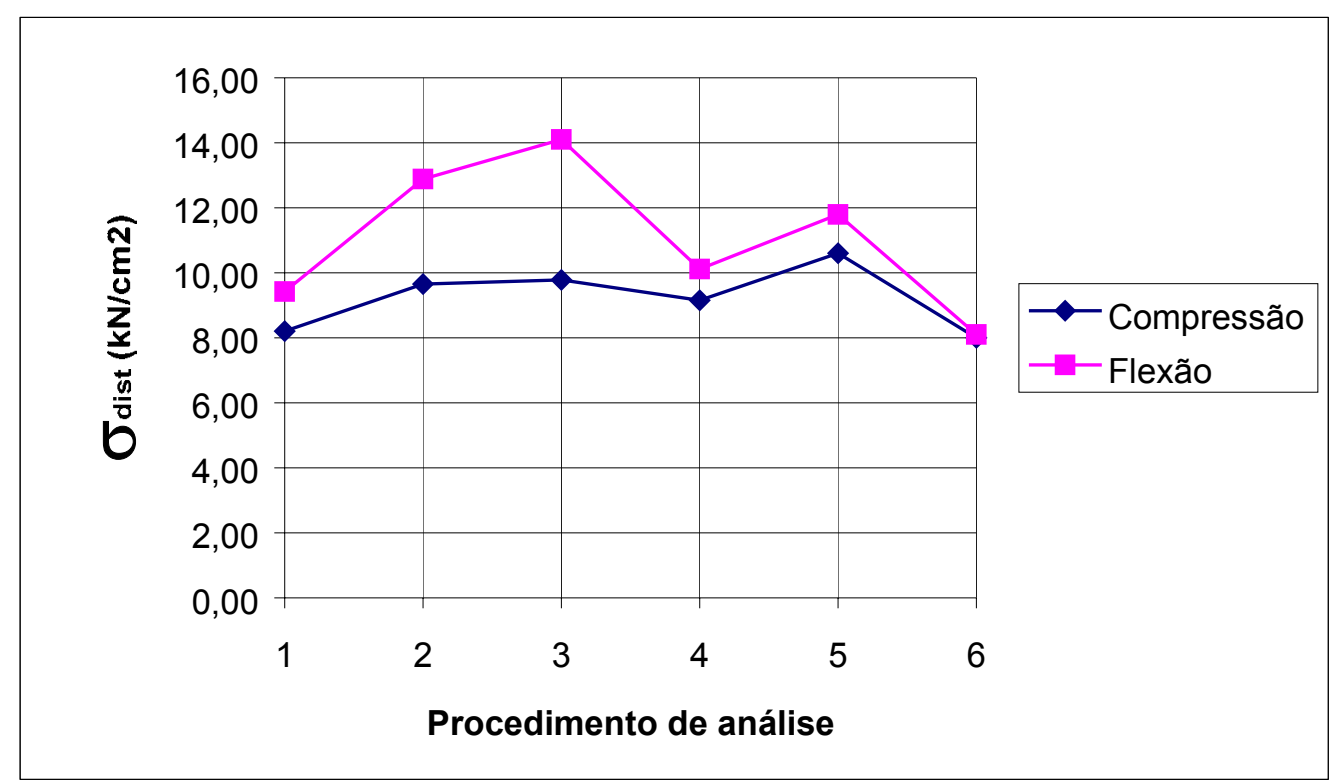

Figura A.3 - Resultados comparativos: Ue 200 × $200 \times 10 \times 4$

Para este terceiro caso, também não houve mudança significativa quando da análise do perfil submetido à compressão, com exceção da análise via elementos finitos com não-linearidade geométrica sem imperfeições iniciais, que elevou o valor de $\sigma_{\text {dist, }}$ e da análise não-linear geométrica com inserção de imperfeições iniciais, o que novamente reduziu o valor de $\sigma_{\text {dist. }}$.

Com relação à flexão, a condição de contorno (deslocamentos impedidos nas extremidades) não simétrica apresentou mais uma vez valores um pouco discrepantes. A análise não-geométrica sem imperfeições iniciais, quando comparada à análise de autovalor, neste caso apresentou diferenças significativas entre os resultados. A análise via elementos finitos com a adoção de imperfeições iniciais e não-linearidade geométrica também reduziu o valor de $\sigma_{\text {dist. }}$ 


\section{Perfil Ue $200 \times 200 \times 30 \times 4 \mathrm{~mm}$}

A tabela A.5 ilustra os resultados apresentados.

Tabela A.5 - Resultados comparativos: perfil Ue $200 \times 200 \times 30 \times 4$

\begin{tabular}{|c|l|c|}
\hline \multicolumn{2}{|c|}{ Procedimento } & $\begin{array}{c}\text { Compressão centrada } \\
\left(\mathbf{k N} / \mathbf{c m}^{\mathbf{2}} \text { ) }\right.\end{array}$ \\
\hline $\mathbf{1}$ & CUFSM & 20,03 \\
\hline $\mathbf{2}$ & NBR 14762:2001 & 20,02 \\
\hline $\mathbf{3}$ & HIPÓTESE 1 & 23,83 \\
\hline $\mathbf{4}$ & HIPÓTESE 2 & 22,14 \\
\hline $\mathbf{5}$ & HIPÓTESE 3 & 24,00 \\
\hline $\mathbf{6}$ & HIPÓTESE 4 & 18,75 \\
\hline
\end{tabular}

A figura A.4 ilustra os resultados apresentados na tabela A.5.

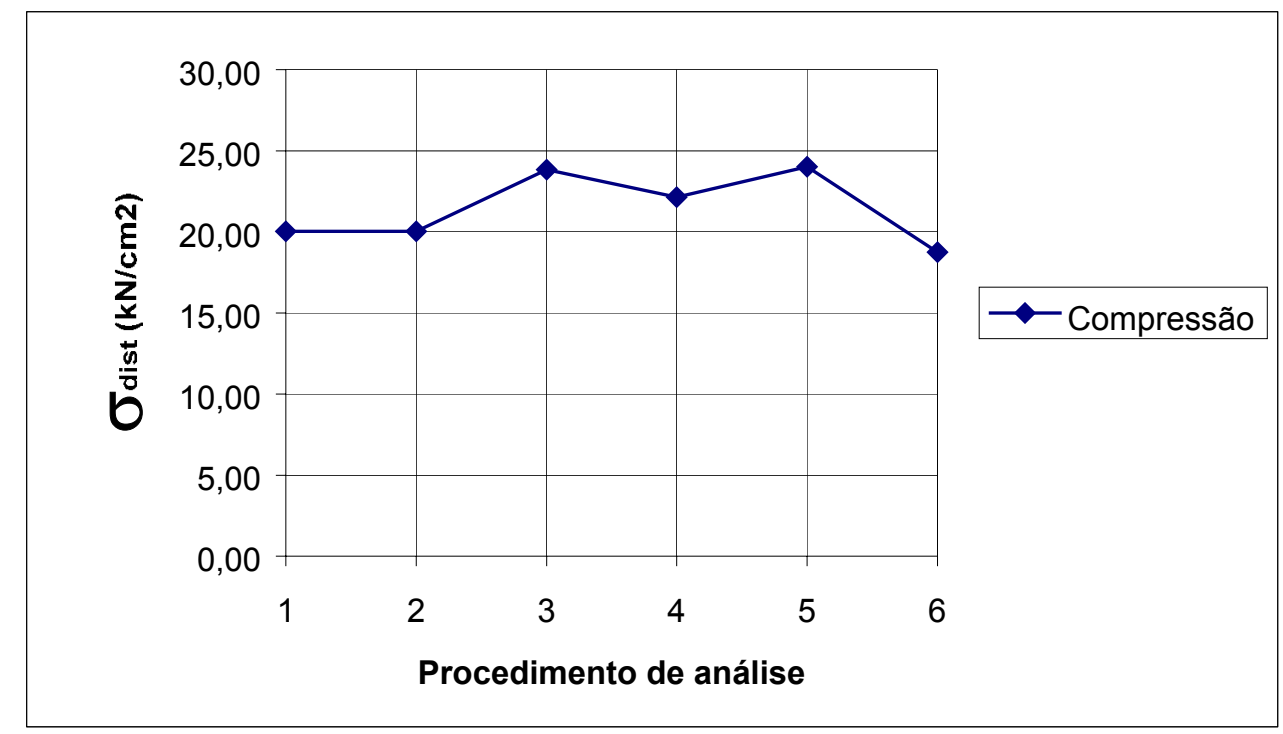

Figura A.4 - Resultados comparativos: Ue $200 \times 200 \times 30 \times 4$ 
Para este caso, os resultados referentes à análise via faixas finitas e via procedimento da NBR 14762:2001 apresentaram-se praticamente idênticos. Também não houve mudança significativa quando da análise do perfil submetido à compressão, com exceção das análises via elementos finitos, que apresentaram maiores valores de $\sigma_{\text {dist }}$ quando comparados com as duas análises iniciais, e da análise não-linear geométrica com inserção de imperfeições iniciais, o que novamente reduziu o valor de $\sigma_{\text {dist. }}$

\section{Perfil Ue $200 \times 200 \times 10 \times 1 \mathrm{~mm}$}

A tabela A.6 ilustra os resultados apresentados.

Tabela A.6 - Resultados comparativos: perfil Ue $200 \times 200 \times 10 \times 1$

\begin{tabular}{|c|l|c|}
\hline \multicolumn{2}{|c|}{ Procedimento } & $\begin{array}{c}\text { Flexão } \\
\left(\mathbf{k N} / \mathbf{c m}^{2}\right)\end{array}$ \\
\hline $\mathbf{1}$ & CUFSM & 1,58 \\
\hline $\mathbf{2}$ & NBR 14762:2001 & 1,96 \\
\hline $\mathbf{3}$ & HIPÓTESE 1 & 2,21 \\
\hline $\mathbf{4}$ & HIPÓTESE 2 & 1,67 \\
\hline $\mathbf{5}$ & HIPÓTESE 3 & 2,16 \\
\hline $\mathbf{6}$ & HIPÓTESE 4 & 1,20 \\
\hline
\end{tabular}

A figura A.5 ilustra os resultados apresentados na tabela A.6. 


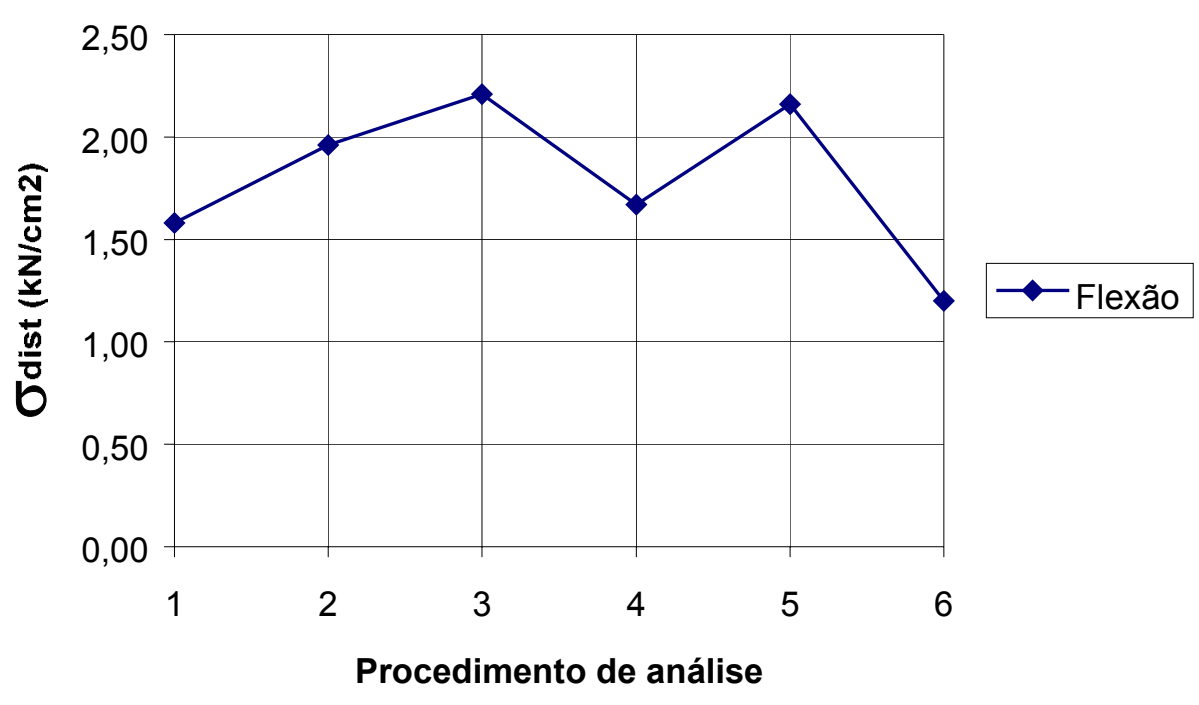

Figura A.5 - Resultados comparativos: Ue $200 \times 200 \times 10 \times 1$

Para este último caso, com relação à flexão, a análise via procedimento da NBR 14762:2001 apresentou valores de $\sigma_{\text {dist }}$ superiores aos valores apresentados conforme a análise via faixas finitas. A condição de contorno (deslocamentos impedidos nas extremidades) não simétrica apresentou mais uma vez valores um pouco discrepantes. A análise não-geométrica sem imperfeições iniciais, quando comparada à análise de autovalor, neste caso apresentou diferenças significativas entre os resultados. A análise via elementos finitos com a adoção de imperfeições iniciais e não-linearidade geométrica também reduziu o valor de $\sigma_{\text {dist. }}$ 


\section{REFERÊNCIAS}

AL-BERMANI, F. G. A.; LUCAS, R. M.; KITIPORNCHAI, S. (1997). Modelling of cold-formed purlin-sheeting systems - part 2: Simplified model. Thin Walled Structures. v.27, n.4, p. 263-286.

AL-BERMANI, F. G. A.; LUCAS, R. M.; KITIPORNCHAI, S. (1997). Modelling of cold-formed purlin-sheeting systems - part 1: Full model. Thin Walled Structures. v. 27, n. 3, p. $223-243$.

AMERICAN IRON AND STEEL INSTITUTE (1996). LRFD cold-formed steel design manual. Washington: AISI.

AMERICAN IRON AND STEEL INSTITUTE (1999). Supplement $n .1$ to the 1996 Specification for the design of cold-formed steel structural members. Washington: AISI.

AMERICAN IRON AND STEEL INSTITUTE (2001). North American Specification for the Design of Cold-Formed Steel Structural Members. Washington: AISI.

ANSYS (1995). Structural nonlinearities: user's guide for revision 5.1. Houston. v.1 
ASSOCIAÇÃO BRASILEIRA DE NORMAS TÉCNICAS (1980). NBR 6355: Perfis estruturais de aço, formados a frio. Rio de Janeiro: ABNT.

ASSOCIAÇÃO BRASILEIRA DE NORMAS TÉCNICAS (2001). NBR 14762: Dimensionamento de estruturas de aço constituídas por perfis formados a frio. Rio de Janeiro: ABNT.

AUSTRALIAN/NEW ZEALAND STANDARD (1996). AS/NZS 4600:1996 : Coldformed steel structures.

AVERY, P.; MAHENDRAN, M.; NASIR, A. (2000). Flexural capacity of hollow flange beams . Journal of Constructional Steel Research, v.53, p.201-223.

BADAWY ABU-SENA, A.B.; CHAPMAN, J.C.; DAVIDSON, P.C. (2001). Interaction between critical torsional flexural and lip buckling in channel sections. Journal of Constructional Steel Research, v.57, p.925-944.

BAMBACH, M. R.; MERRICK, J. T.; HANCOCK, G. H. (1998). Distortional buckling formulae for thin walled channel and Z-sections with return lips. In: INTERNATIONAL SPECIALTY CONFERENCE ON COLD-FORMED STEEL STRUCTURES, $14^{\text {th }}$, University of Missouri-Rolla, Oct. Proceedings.

BATISTA, E. M. et al. (2000). Estudos dos modos de instabilidade local de placa e distorcional em perfis de chapa dobrada de aço. In: JORNADAS SUDAMERICANAS DE INGENIERIA ESTRUCTURAL, 29., Punta Del Este, Uruguay, nov. 2000. Memorias. 14p.

BATISTA, E. M. et al. (2001). Curso paralelo de perfis formados a frio. In: SEMINÁRIO INTERNACIONAL O USO DE ESTRUTURAS METÁLICAS NA CONSTRUÇÃO CIVIL, 4. / CONGRESSO INTERNACIONAL DA CONSTRUÇÃO METÁLICA, 1., nov. 2001, São Paulo.

BATISTA, E. M. et al. (2002). Stability analysis of cold-formed members: finite element and finite strip method results. In: INT. COLLOQUIUM. Budapest, 2002. $8 p$. 
BATISTA, E. M. (2000) Reliability and Progress in design Codes, in Proceedings of the Third Int. Conference on Coupled Instabilities in Metal Structures CIMS'2000, Ed. Camotim, D; Dubina, D. e Rondal, J., Imperial College Press, Lisboa, 661-671.

BATISTA, E. M.; CAMOTIM, D.; PROLA, L. C.; VAZQUEZ, E. (1998). On the stability and strength of steel columns affected by distortional buckling. Journal of Constructional Steel Research, v.46, n.1-3, p.129-131.

BERNARD, E. S.; BRIDGE, R. Q.; COLEMAN, R. (1999). Measurement and assessment of geometric imperfections in thin-walled panels. Thin Walled Structures, v.33, p. 103-126.

BLEICH, F. (1952). Buckling strength of metal structures. New York: McGraw-Hill Book.

BRADFORD, M. A. (1999). Elastic distortional buckling of tee-section cantilevers. Thin Walled Structures, v.33, p. 3-17.

BRADFORD, M. A. (2000). Strength of compact steel beams with partial restraint. Journal of Constructional Steel Research, v.53, p.183-200.

BRADFORD, M. A.; GE, X. P. (1997). Elastic distortional buckling of continuous Ibeams. Journal of Constructional Steel Research, v.41, n.2/3, p.249-266.

CANADIAN STANDARTS ASSOCIATION (1984) CAN3-S136-M84: Cold-formed steel structural members. Toronto: CSA.

CHAJES, A.; FAUG, P. J. ; WINTER, G. (1966). Torsional flexural buckling, elastic and inelastic, of cold formed thin walled columns. Ithaca, NY: School of Civil and Mining Engineering, Cornell University. (Research Bulletin n. 66-1) 
CHODRAUI, G. M. B. et al. (2002). Flambagem por distorção da seção transversal em perfis de aço formados a frio submetidos à compressão centrada e à flexão. In: CONGRESSO INTERNACIONAL DA CONSTRUÇÃO METÁLICA, 2. - II CICOM, São Paulo, Brasil, nov. 2002.

CLARK, J. W.; HILL, H. N. (1960). Lateral buckling of beams. Journal of the Structural Division, ASCE, v.86, n.ST7, p.175-196, July.

DAVIES, J. M. (2000). Recent research advances in cold-formed steel structures. Journal of Constructional Steel Research, v.55, p.267-288.

DAVIES, J. M.; JIANG, C. (1997). Design of thin-walled purlins for distortional buckling. Thin Walled Structures, v.29, n.1-4, p. 189-202.

DAVIES, J. M.; JIANG, C. (1998). Design for distortional buckling. Journal of Constructional Steel Research, v.46, n.1-3, p.174-175.

DAVIES, J. M.; KESTI, J. (1999). Local and distortional buckling of thin-walled short columns. Thin Walled Structures, v.34, p. 115-134.

DAVIES, J. M.; LEACH, P.; TAYLOR, A. (1997). The design of perforated coldformed steel sections subject to axial load and bending. Thin Walled Structures, v. 29 , n. $1-4$, p. $141-157$.

DOUTY, R.T. (1962). A design approach to the strength of laterally unbraced compression flange. Engineering Experiment Station, Cornell University. (Bulletin 37).

DUBINA, D. et al. (1995). Interactive buckling of cold-formed thin-walled member. In: INTERNATIONAL CONFERENCE ICSSD'95 - STRUCTURAL STABILITY AND DESIGN, Sydney, Australia, 1995. Proceedings. Rotterdam: A.A. Balkema. p. 4954.

DUBINA, D. (2001). The ECBL approach for interactive buckling of thin-walled steel members. Steel \& Composite Structures, v.1, n.1, p.75-96. 
DUBINA, D., UNGUREANU, V. (2002) Local-Overall and Distortional-Overall interactive buckling of thin-walled members. In: EUROPEAN CONFERENCE ON STEEL STRUCTURES, 3rd, Coimbra, Portugal, 2002. Proceedings. Guimarães: CMM / Universidade de Coimbra.

ELLIFRITT, D. S.; GLOVER, R. L.; HREN, J. D. (1998). A simplified model for Distorcional buckling of channels and Zees in flexure. In: INTERNATIONAL SPECIALTY CONFERENCE ON COLD-FORMED STEEL STRUCTURES, $14^{\text {th }}$, University of Missouri-Rolla, Oct. Proceedings.

EUROPEAN COMMITTEE FOR STANDARDISATION (1996). Eurocode 3 : Design of steel structures. Part 1.3: General rules. Supplementary rules for cold formed thin gauge members and sheeting. Brussels: CEN. (ENV 1993-1-3:1996)

FRUCHTENGARTEN, J. (1995) Sobre a estabilidade de perfis de seção aberta. Tese (Doutorado) - Escola Politécnica, Universidade de São Paulo, São Paulo.

GALAMBOS, T.V. (1998). Guide to stability design criteria for metal structures. New York: John Wiley \& Sons. 911p.

GODOY, L. A. (1998). Stresses and pressures in thin-walled structures with damage and imperfections. Thin Walled Structures, v.32, p. 181-206.

GONÇALVES, R.M. et al. (1998). Analysis and study of the behavior of purlins on cold-formed $U$ and Z-type shapes: the effect of elastic restriction due to roof tiles [CD-ROM]. In: WORLD CONFERENCE ON STEEL IN CONSTRUCTION, 2., San Sebastian, Spain, May, 1998. Proceedings. Oxford: Elsevier Science. 14p.

GONÇALVES, R.M; MALITE, M.; JAVARONI, C.E. (2000). A theoretical and experimental analysis of cold-formed steel shapes subjected to bending - channel and simple lipped channel. In: INTERNATIONAL SPECIALTY CONFERENCE ON COLD-FORMED STEEL STRUCTURES, $15^{\text {th }}$, St. Louis, USA, October 2000. p.149168. 
HANCOCK, G. J. (1978). Local, distortional, and lateral buckling of I-beams. Journal of the Structural Division, ASCE, v.113, n.5, p.1063-1079, May.

HANCOCK, G.J. (1997). Light gauge construction. Progress in Structural Engineering and Materials, v.1, n.1, p.25-30, Sept.

HANCOCK, G. J. (1997). Design for distortional buckling of flexural members. Thin Walled Structures, v.27, n.1, p. 3-12.

HANCOCK, G. J.; JOHNSTON, N. (1994). Calibration of the AISI R-factor design approach for purlins using Australian test data. Engineering Structures, v.16,n.5, p.342-347.

HANCOCK, G. J.; LAU, S. C. W. (1987). Distortional buckling formulas for channel columns. Journal of Structural Engineering, ASCE, v.125, n.2, p.118-127, February.

HANCOCK, G. J.; MURRAY, T. M.; ELLIFRITT, D. S. (2001). Cold-formed steel structures to the AISI specification. New York: Marcel Dekker.

HANCOCK, G. J.; PAPANGELIS, J. P.; TRAHAIR, N. S. (1998). Computer design of cold-formed C- and Z-section purlins. Journal of Constructional Steel Research, v.46, n.1-3, p.169-171.

HANCOCK, G. J.; ROGERS, C. A. (1998). Design of cold formed steel structures of high strength steel. Journal of Constructional Steel Research, v.46, n.1-3, p.167168.

HANCOCK, G.J.; KWON, Y.B.; BERNARD, E.S. (1994). Strength design curves for thin-walled sections undergoing distortional buckling. Journal of Constructional Steel Research, v.31, n.2-3, p.169-186.

HANCOCK, G.J.; ROGERS, C.A.; SCHUSTER, R.M. (1996). Comparison of the distortional buckling method for flexural members with tests. In: INTERNATIONAL SPECIALTY CONFERENCE ON COLD-FORMED STEEL STRUCTURES, $13^{\text {th }}$, University of Missouri-Rolla, Oct. Proceedings. 
HAUSLLER, R. W. (1964) Strength of elastically stabilized beams. Journal of the Structural Division, ASCE, v.90, n.ST3, p.219-263, June.

JIANG, C.; DAVIES, J. M. (1997). Design of thin-walled purlins for distortional buckling. Thin Walled Structures, v.29, n.1/4, p. 189-202.

JONHSTON, N.; HANCOCK, G. (1994) Calibration of the AISI R-factor design approach for purlins using Australian test data. Engineering Structures, v.16, n.5, p.342-347.

JÖNSSON, J. (1999). Distortional theory of thin-walled beams. Thin Walled Structures, v.33, p. 269-303.

JÖNSSON, J. (1999). Distortional warping functions and shear distributions in thinwalled beams. Thin Walled Structures, v.33, p. 245-268.

KAVANAGH, K. T.; ELLIFRITT, D. S. (1994). Design strengths of cold-formed channels in bending and torsion. Journal of Structural Engineering, ASCE, v.120, n.5, p.1599-1607, May.

KEMP, L. et al. (1995) Structural behavior of cold-formed profiles with emphasis on the Zeta-profile. Journal of Constructional Steel Research, v.34, p.207-224.

KESTI, J.; DAVIES, J. M. (1999). Local and distortional buckling of thin-walled short columns. Thin Walled Structures, v.34, p.115-134.

KESTI, J.; MÄKELÄINEN, P. (1998). Design of Gypsum-sheathed perforated steel wall studs. Journal of Constructional Steel Research, v.46, n.1/3, p.215-216.

KOLAKOWSKI, Z.; KOWAL-MICHALSKA, K.; KROLAK, M. (1999). Modal interactive buckling of thin-walled composite beam-columns regarding distortional deformations. International Journal of Engineering Science, v.37, p.1577-1596.

LaBOUBE, R. A. (1991). Uplift capacity of Z-purlins. Journal of Structural Engineering, ASCE, v.117, n.4, p.1159-1166, April. 
LaBOUBE, R. A. (1992). Estimating uplift capacity of light steel roof system. Journal of Structural Engineering, ASCE, v.118, n.3p.848-852, April.

LaBOUBE, R. A.; YU, W. W. (2000). Recent research and developments in coldformed steel design and construction. In: INTERNATIONAL SPECIALTY CONFERENCE, $15^{\text {th }}$, St. Louis, USA, October 2000.

LU, W. (2000). Neural network model for distortional buckling behaviour of coldformed steel compression members. Thesis for Degree of Licentiate of Science in Technology.

LUCAS, R. M.; AL-BERMANI, F. G. A.; KITIPORNCHAI, S. (1997). Modelling of cold-formed purlin-sheeting systems - Part 2. Simplified model. Thin Walled Structures, v.27, n.4, p. 263-286.

LUCAS, R. M.; AL-BERMANI, F. G. A.; KITIPORNCHAI, S. (1997). Modelling of cold-formed purlin-sheeting systems - Part 1. Full model. Thin Walled Structures, v. 27, n. 3, p. $223-243$.

MACKERLE, J. (1996). Finite element and boundary element analyses of beams and thin-walled structures - A bibliography (1994-1995). Finite Elements in Analysis and Design. v.23, p.77-89.

MACKERLE, J. (1997). Stability problems analysed by finite element and boundary element techniques - A bibliography (1994-1996). Finite Elements in Analysis and Design, v.26, p.337-353.

MALITE, M. (1993) Estruturas de aço constituídas por perfis de chapa dobrada: dimensionamento de ligações. São Carlos: EESC-USP. 49p.

MALITE, M. et al. (1998). Cold-formed shear connectors for composite constructions. In: INTERNATIONAL SPECIALTY CONFERENCE ON COLDFORMED STEEL STRUCTURES, $14^{\text {th }}$, St. Louis, USA, October 1998. p.409-421. 
MALITE, M.; SÁLES, J.J. (1993). Estruturas de aço constituídas por perfis de chapa dobrada: dimensionamento de barras. São Carlos: EESC-USP. 97p.

MALITE, M. et al. (1999). Algumas considerações sobre a nova norma brasileira de dimensionamento de estruturas de aço constituídas por perfis formados a frio [CDROM]. In: SEMINÁRIO INTERNACIONAL O USO DE ESTRUTURAS METÁLICAS NA CONSTRUÇÃO CIVIL, 2., Belo Horizonte, nov. 1999. Belo Horizonte: SME Sociedade Mineira de Engenheiros. 7p.

MALITE, M. et al. (2000). On the structural behavior of composite beams using coldformed shapes. In: INTERNATIONAL SPECIALTY CONFERENCE ON COLDFORMED STEEL STRUCTURES, $15^{\text {th }}$, St. Louis, USA, October 2000. p.307-319.

MURRAY, T. M.; ELHOUAR, S. (1994). North american approach to the design of continuous Z- and C-purlins for gravity loading with experimental verification. Engineering Structures, v.16, n.5, p.337-341.

NETHERCOT, D. A. (1983). Elastic lateral buckling of beams. In: NARAYANAN, R. Beams and beam-columns: stability and strength. Barking, UK: Applied Science. p.1-34.

OUTINEN, J. (2000). Profiled steel sheeting. In: SEMINAR ON STEEL STRUCTURES: DESIGN OF COLD-FORMED STEEL STRUCTURES, Helsinki University of Technology, Laboratory of Steel Structures, Publications 15, Expoo 2000. p.1-13.

PANDEY, M. D.; SHERBOUNE, A. N. (1989). Unified v. integrated approaches in lateral-torsional buckling of beams. The Structural Engineer, v.67, p.245-249, July.

PAPANGELIS, J. P.; HANCOCK, G. J.; TRAHAIR, N. S. (1998). Computer design of cold-formed $\mathrm{C}$ and Zee section purlins. Journal of Constructional Steel Research, v.46, n.1/3, p.169-171. 
PEKÖZ, T. (1983). Diaphragm-braced thin-walled channel and Z-section beams. In: NARAYANAN, R. Beams and beam-columns: stability and strength. Barking, UK: Applied Science. p.161-184.

PEKÖZ, T.; SCHAFER, B. W. (1998). Computational modeling of cold-formed steel: characterizing geometric imperfections and residual stresses. Journal of Constructional Steel Research, v.47, p.193-210.

PERTTOLA, H. (2000). Numerical analysis for thin-walled structures. In: SEMINAR ON STEEL STRUCTURES: DESIGN OF COLD-FORMED STEEL STRUCTURES, Helsinki University of Technology, Laboratory of Steel Structures, Publications 15, Expoo 2000. p.45-64.

POLYZOIS, D. (1987). Sag roads as lateral supports for girts and purlins. Journal of Structural Engineering, ASCE, v.113, n.7, p.1521-1531, July.

POLYZOIS, D.; BIRKEMOE, P. C. (1985). Z-section girts under negative loading. Journal of Structural Engineering, ASCE, v.111, n.3, p.528-544, March,

POLYZOIS, D.; GUILLOTY JR., L. J. (1991). Finite strip method for analysis of cold-formed purlins. Journal of Structural Mechanics, ASCE, v.117, n.1, p.184-203, January,

RASMUSSEN, K.J.R.; YOUNG, B. (2000). Inelastic bifurcation of cold-formed singly symmetric columns. Thin Walled Structures, v.36, p. 213-230.

RHODES, J. (1991). Some interesting phenomena which can occur in light gauge steel members. In: INTERNATIONAL CONFERENCE ON STEEL AND ALUMINIUM STRUCTURES, Singapore, May. Proceedings.

RHODES, J. (1991). Some interesting phenomena which can occur in light gauge steel members. In: INTERNATIONAL CONFERENCE ON STEEL AND ALUMINIUM STRUCTURES, ICSAS 91, Singapore, May. Proceedings. 
RHODES, J. (1997). Research into thin-walled structures at the University of Strathclyde - a brief history. Thin Walled Structures, v.28, n.3/4, p. 201-212.

RODRIGUES, F.C. (1993) Estudo teórico-experimental de perfis de chapa dobrada submetidos à compressão. Tese (Doutorado) - Universidade Federal do Rio de Janeiro, COPPE, Rio de Janeiro.

ROGERS, C. A.; SCHUSTER, R. M. (1997). Flange/Web distortional buckling of cold-formed steel sections in bending. Thin Walled Structures, v.27, n.1, p.13-29.

RONDAL, J. (2000). Cold formed steel members and structures. General report. Journal of Constructional Steel Research, v.55, n.1-3, p.155-158.

RUSCH, A.; LINDNER, J. (2001). Remarks to the direct strength method. Thin Walled Structures, v.39, n. 9, p. 807-820.

SALVADORI, M. G. (1955) Lateral buckling of I beams. Transactions ASCE, v.120, p.1165-1177.

SALVADORI, M. G. (1956) Lateral buckling of eccentrically loaded I columns. Transactions ASCE, v.121, p.1163-1178.

SILVA, J.C.M. (2003). Análise teórica e experimental de perfis formados a frio submetidos à flexão devido à instabilidade por distorção. Monografia de qualificação (Mestrado), Escola de Engenharia de São Carlos, Universidade de São Paulo, São Carlos.

SCHAFER, B. W. (2001). Finite Strip Analysis of Thin-walled Members. In: CUFSM: Cornell University - Finite Strip Method.

SCHAFER, B. W. (2002). Design manual for direct strength method of cold-formed steel design. Draft for American Iron and Steel Institute - Committee on Specifications, January, 2002. 
SCHAFER, B. W.; PEKÖZ, T. (1998). Computational modeling of cold-formed steel: characterizing geometric imperfections and residual stresses. Journal of Constructional Steel Research, v.47, p.193-210, January.

SCHAFER, B. W.; PEKÖZ, T. (1999). Laterally braced cold-formed steel flexural members with edge stiffened flanges. Journal of Structural Engineering, ASCE, v.125, n.2, p.118-127, February.

SHARP, M. L. (1966). Longitudinal stiffeners for compression members. Journal of Structural Division, ASCE, 92 (ST5), p.187-211.

SOOI, T. K. (1993). The behavior of component elements of aluminium members. A thesis presented to the Faculty of the Graduate School of Cornell University, Departament of Structural Engineering, Cornell University, Ithaca, NY, 1993.

TIMOSHENKO, S. P.; GERE, J. M. (1961). Theory of elastic stability. 2.ed. New York: McGraw-Hill. 541p.

TOMÀ, T.; WITTEMANN, K. (1994). Design of cold-formed purlins and rails restrained by sheeting. Journal of Construction and Steel Research, v.31, p.149168.

TRAHAIR, N. S. (1996). Laterally unsupported beams. Engineering Structures, v.18, n.10, p.759-768.

VAZQUEZ, E.G. (1998). Estudo do comportamento pós-crítico de paredes esbeltas de perfis metálicos. Dissertação (Mestrado) - COPPE/UFRJ, Rio de Janeiro.

VAZQUEZ, E. G. (2002). Análise teórica e experimental da instabilidade torcional de perfis formados a frio sob compressão centrada. Tese (Doutorado) - COPPE/UFRJ, Rio de Janeiro.

VLASSOV, B. Z. (1962) Pièces longues en voiles minces. Paris: Eyrolles. 655p. 
WENG, C.C.; PEKÖZ, T. (1990) Residual stresses in cold formed steel members. Journal of Structural Engineering, ASCE, v.116, n.6, p.1230-1246, May.

WILLIS, C. T.; WALLACE, B. (1990). Behavior of cold-formed steel purlins under gravity loading. Journal of the Structural Engineering, ASCE, v.116, n.8, p.848-852, August.

WINTER, G. (1959). Cold-formed, light-gage steel construction. Journal of the Structural Engineering, ASCE, v.85, n.ST9, p.151-173, November.

YOUNG, B.; RASMUSSEN, KIM J. R. (2000). Inelastic bifurcation of cold-formed singly symmetric columns. Thin Walled Structures, v.36, p. 213-230.

YU, W. W. (2000) Cold formed steel design. New York: John Wiley \& Sons. 756p. 